\title{
FUNDAMENTOS TEÓRICOS E ASPECTOS GERAIS PARA PROJETOS DE ESTRUTURAS EM AÇO COM PERFIS CONFORMADOS A FRIO
}

RONISI CAZELI G. SILVA

\begin{abstract}
Dissertação apresentada à Escola de Engenharia de São Carlos, da Universidade de São Paulo, como parte dos requisitos necessários para a obtenção do título de "Mestre em Engenharia de Estruturas".
\end{abstract}

ORIENTADOR: Prof. Dr. ROBERTO MARTINS GONÇALVES 
Silva, Ronisi Cazeli G.

S583f Fundamentos teóricos e aspectos gerais para projetos de estruturas em aço com perfis conformados a frio / Ronisi Cazeli G. Silva. -- São Carlos, 1995.

225 .

Dissertação (Mestrado) -- Escola de Engenharia de São CarlosUniversidade de São Paulo, 1995.

Orientador: Prof.Dr. Roberto Martins Gonçalves

1. Chapa dobrada - Estruturas de aço. I. Título. 
À uma mulher maravilhosa que amo, respeito e admiro muito, minha mãe Olinda Cazeli. Às minhas queridas irmãs Rô e Nely e aos meus queridos sobrinhos Alice e Guilherme. 


\section{AGRADECIMENTOS}

À DEUS pela constante presença.

Ao Prof. Dr. Roberto Martins Gonçalves, pela importante orientação e estímulo para o aprendizado, compreensão e pela amizade.

Aos Prof. Dr. José Jairo de Sáles, Prof. Dr. Roberto Luis A Barbato, Prof. Dr. Maximiliano Malite e Prof. Dr. João Bento de Hanai, pelo inestimável apoio, pela atenção e disponibilidade em atender com seus conhecimentos específicos e amizade.

À todos os funcionários do Departamento de Estruturas pela grande simpatia e atenção, em especial à Rosi Aparecida Jordão Rodrigues, Maria Nadir Minatel, Francisco Carlos G. Brito, Roberto dos Santos Júnior e Fábio Wermersch.

Ao Cesar, pela força, carinho e companheirismo.

À todos meus amigos que sempre me apoiaram, em especial Miriam, Marê, Benedito, Kira, Dany, Bily, Anna, Paula, Cris, Regina, Joice e Ilka pelo estímulo e sólido auxílio prestado durante parte do desenvolvimento desta dissertação.

À todos os colegas do curso de Pós-Graduação pela agradável convivência e amizade.

À minha mãe e minhas irmãs, minha eterna gratidão pelo incentivo e confiança demonstrados sempre.

Ao CNPQ - Concelho Nacional Pesquisa - pela concessão de bolsa que possibilitou a realização deste trabalho.

À todos aqueles que direto ou indiretamente contribuíram para a realização deste trabalho. 


\section{SUMÁRIO}

LISTA DE FIGURAS....................................................................... i

LISTA DE TABELAS....................................................................... v

LISTA DE SÍMBOLOS......................................................................... vi

LISTA DE SIGLAS.........................................................................

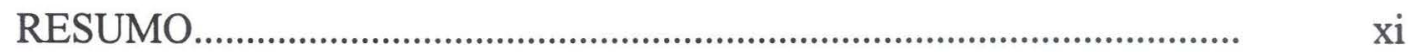

ABSTRACT.................................................................................. xii

\section{INTRODUÇÃO}

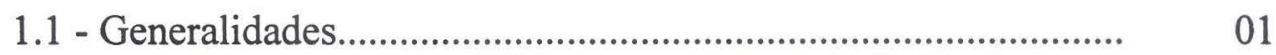

1.2 - Breve Histórico ........................................................................... 02

1.3 - Obras............................................................................. 03

1.4 - Objetivos................................................................................ 07

1.5 - Apresentação do trabalho............................................................... 08

\section{PERFIS ESTRUTURAIS EM CHAPA DOBRADA}

2.1 - Comentário geral dos materiais empregados em perfis de chapa dobrada.

2.2 - Limite de escoamento, resistência a tração e diagrama tensão-

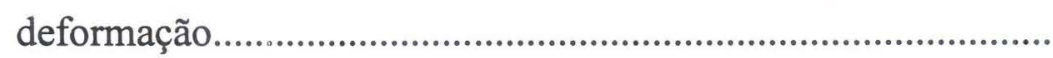

2.3 - Módulo de elasticidade e módulo de elasticidade tangente........................................................................... 17

2.4 - Ductibilidade........................................................................ 18

2.5 - Soldabilidade ..................................................................... 18

2.6 - Influência do trabalho a frio nas propriedades mecânicas do

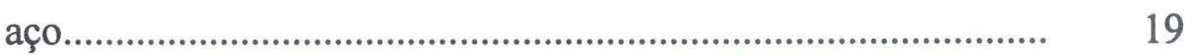

2.7 - Tensões residuais..................................................................... 21

2.8 - Tipos de perfis............................................................................ 23

2.9 - Propriedades geométricas............................................................. 24 


\section{FUNDAMENTOS TEÓRICOS PARA O DIMENSIONAMENTO DE ELEMENTOS ESBELTOS COMPRIMIDOS}

3.1 - Generalidades ....................................................................... 26

3.2 - Definições.......................................................................... 27

3.3 - Tensão básica de projeto......................................................... 28

3.4 - Elementos comprimidos enrijecidos........................................ 29

3.4.1 - Generalidades...................................................... 29

3.4.2 - Tensão crítica de flambagem de chapa em regime elástico

3.4.3 - Tensão crítica de flambagem de chapa em regime inelástico

3.4.4 - Resistência pós-flambagem e largura efetiva............ $\quad 34$

3.5 - Elementos enrijecidos a compressão por meio de enrijecedores de borda............................................................ 38

3.5.1 - Generalidades.......................................................... 38

3.5.2 - Enrijecedores de borda................................................. 39

3.5.3 - Largura efetiva de elemento enrijecido à compressão por meio de enrijecedores de borda........ 41

3.6 - Elemento com enrijecimento múltiplo à compressão................ 43

3.6.1 - Generalidades............................................................. 43

3.6.2 - Enrijecedor intermediário............................................ 45

3.6.3 - Largura efetiva de elemento com enrijecimento múltiplo.à compressão............................................... 46

3.7 - Elemento comprimido não enrijecido......................................... 48

3.7.1 - Generalidades.......................................................... 48

3.7.2 - Tensão crítica de flambagem elástica.......................... 48

3.7.3 - Resistência pós-flambagem e largura efetiva............... 49

3.8 - Elementos comprimidos submetidos a uma distribuição de tensões não uniforme............................................................... 50

3.9 - Relações máximas admissíveis.............................................. 52

4. FUNDAMENTO TEÓRICO PARA O DIMENSIONAMENTO DE BARRAS

4.1 - Conceitos de Segurança................................................................... 53

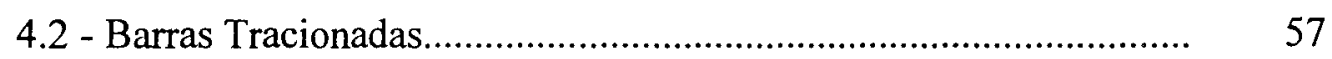

4.2.1 - Generalidades.................................................................. 57

4.3 - Barras Comprimidas .................................................................... 
4.3.1 - Generalidades.

4.3.2 - Perfis comprimidos sujeitos à flambagem por

flexão..

4.3.2.1 - Flambagem elástica................................................ 58

4.3.2.2 - Flambagem inelástica............................................ 59

4.3.3 - Flambagem por flexão e torção............................................... 62

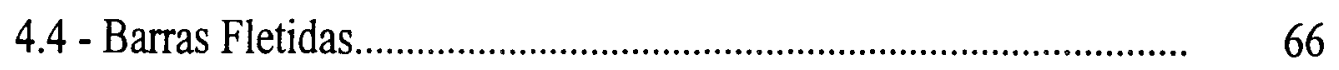

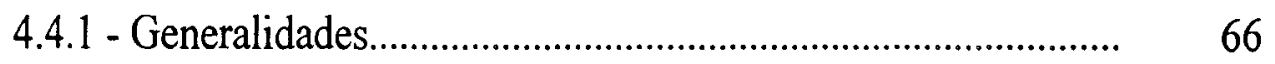

4.4.2 - Resistência ao momento fletor................................................. 67

4.4.2.1 - Flambagem local ..................................................... 67

4.4.2.2 - Flambagem lateral com torção.................................. 68

4.4.2.2.1 - Seção duplamente simétricas..................... 68

4.4.2.2.2 - Outras seções........................................... 72

4.4.2.2.3 - Perfis monossimétricos............................... 73

4.4.2.3 - Reserva de resistência inelástica de vigas devida a plastificação parcial da seção transversal................. $\quad 77$

4.4.3 -Resistência ao cisalhamento.................................................... 80

4.4.4 - Verificação da resistência ao cisalhamento com o momento

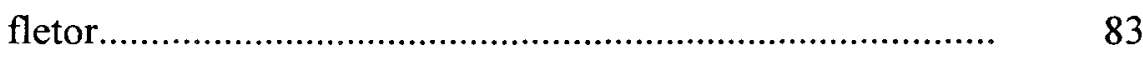

4.4.5 - Enrugamento da alma....................................................... 85

4.4.6 - Combinação entre flexão e enrugamento da alma................... 89

4.4.7 - Enrijecedores transversais..................................................... 90

4.4.8 - Efeito Shear Lag.............................................................. 91

4.4.9 - Ondulação da mesa................................................................ 93

4.5 - Barras Flexo-Comprimidas......................................................... 95

4.5.1 - Considerações preliminares.................................................... 95

4.5.2 - Equações diferenciais que governam o problema de barras

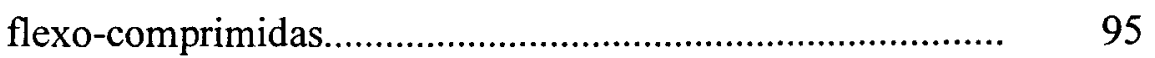

4.5.3 - Resistência no plano de flexão.............................................. 96

4.5.4 - Flambagem lateral com torção................................................ 102

4.6 - Critérios de Dimensionamento....................................................... 103

4.6.1 - Barras Tracionadas............................................................... 104

4.6.1.1 - Estado limite último............................................. 104

4.6.1.2 - Condição de esbeltez............................................... 106

4.6.2 - Barras Comprimidas............................................................. 106

4.6.2.1 - Estado limite último................................................ 106

4.6.2.2 - Resistência de cálculo............................................... 107 
4.6,2.3 - Tensão crítica de flambagem elástica...................... 108

4.6.2.4 - Perfil com elemento não enrijecido......................... 109

4.6.2.5 - Índice de esbeltez................................................. 109

4.6.3 - Barras Fletidas - Resistência ao momento fletor.................... 110

4.6.3.1 - Estado limite último............................................... $\quad 110$

4.6.3.2 - Flambagens locais................................................... 110

4.6.3.3 - Flambagem lateral com torção................................ 112

4.6.3.4 - Estado limite de utilização....................................... 115

4.6.4- Barras Fletidas - Verificações complementares...................... 115

4.6.4.1 - Generalidades......................................................... 115

4.6.4.2 - Resistência de cálculo à força cortante................... 116

4.6.4.3 - Resistência à força cortante com o momento fletor............................................................... 117

4.6.4.4 - Resistência ao enrugamento da alma....................... 117

4.6.4.5 - Flexão e resistência ao enrugamento combinados... 118

4.6.4.6 - Enrijecedores transversais....................................... 118

4.6.4.7 - Efeito shear lag................................................. 119

4.6.4.8 - Ondulação da mesa................................................... 119

4.6.5 - Barras Flexo-Comprimidas.................................................... 119

5. COMPOSIÇÃO ESTRUTURAL

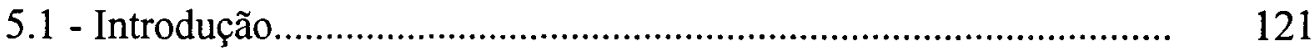

5.2 - Edificação industrial tipo leve........................................................ 121

5.3 - Tipos de elementos estruturais..................................................... 125

5.3 .1 - Terças............................................................................ 125

5.3.2 - Treliças de cobertura.......................................................... 127

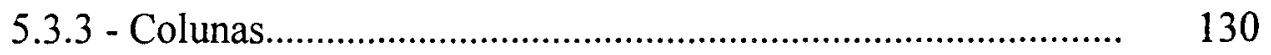

5.3.4 - Contraventamentos.......................................................... 132

6. ANÁLISE PARA O CÁLCULO DE TERÇAS

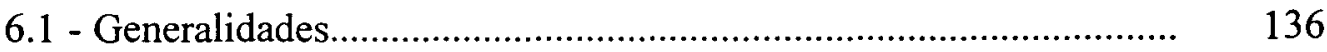

6.2 - Método utilizado para o pré-dimensionamento.............................. 137

6.2.1 - Relações básicas................................................................. 137

6.3 - Exemplo numérico........................................................................ 139

6.3.1 - Escolha do perfil............................................................. 142 
ANEXO - TABELAS E GRÁFICOS.

REFERÊNCIAS BIBLIOGRÁFICAS.................................................... 220 


\section{LISTA DE FIGURAS}

FIGURA 1.1 Estrutura de chapa dobrada em fase de montagem................. 03

FIGURA 1.2 Estruturas especiais constituídas em perfis de chapa dobrada.(YU, 1985)......................................................... 04

FIGURA 1.3 Estrutura de um hangar utilizando perfis de chapa dobrada (YU, 1985).

FIGURA 1.4 Estrutura de um galpão constituído inteiramente por perfis de chapa dobrada (YU, 1985).

FIGURA 1.5 Edificio padronizado com pórtico principal constituído de perfil laminado e fechamentos, cobertura e acessórios de acabamento em chapa dobrada (YU, 1985)........................ 06

FIGURA 1.6 Painéis de cobertura em chapa dobrada (YU, 1985)............ 07

FIGURA 2.1 Tipos de comportamento tensão-deformação de corpos de prova de aços ensaiados à tração

FIGURA 2.2 Limite de escoamento convencional para aços com escoamento gradual.

FIGURA 2.3 Efeito do trabalho a frio nas propriedades mecânicas do aço (YU, 1985)

FIGURA 2.4 Efeito do encruamento e ação da deformação nas características tensão-deformação do aço (MOLITERNO, 1992).

FIGURA 2.5 Tensões residuais em um perfil "U" $(150 \times 60 \times 20 \times 1,90)$ (RODRIGUES \& BATISTA, apud JAVARONI, 1993)...... 22

FIGURA 2.6 Perfil canal tipo "U"......................................................... 23

FIGURA 2.7 Cantoneiras................................................................... 23

FIGURA 2.8 Perfil "Z" "..................................................................... 23

FIGURA 2.9 Perfil cartola..................................................................... 23

FIGURA 2.10 Duplo "U"..................................................................... 23

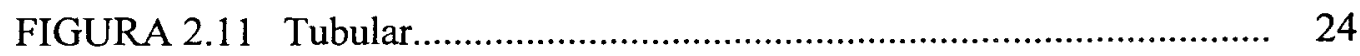

FIGURA 2.12 Coberturas (Telhados)..................................................... 24

FIGURA 2.13 Fechamento ou tapamento (Paredes)................................... 24 
FIGURA 2.14 Pisos (Decks)................................................................... 24

FIGURA 2.15 Telhas portante (coberturas)............................................... 24

FIGURA 2.16 Propriedades geométricas de elementos lineares.................. 25

FIGURA 3.1 Flambagem local de elemento comprimido (YU, 1985)........ 26

FIGURA 3.2 Seções transversais com elementos comprimidos

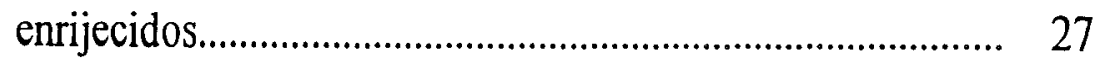

FIGURA 3.3 Seções transversais com elementos comprimidos não enrijecidos..................................................................... 28

FIGURA 3.4 Seções transversais com enrijecimento múltiplo à compressão................................................................. 28

FIGURA 3.5 Chapa quadrada apoiada nas quatro bordas a tensão de compressão uniforme.......................................................... 29

FIGURA 3.6 Chapa retangular sujeita a tensão de compressão

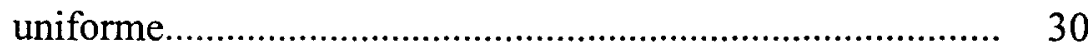

FIGURA 3.7 Coeficiente de flambagem elástica para chapas retangulares uniformemente comprimidas (YU, 1985)............................ 32

FIGURA 3.8 Modelo de grelha para a resistência pós-flambagem de chapas (YU, 1985) ............................................................ 34

FIGURA 3.9 Distribuições de tensões para um elemento comprimido enrijecido.

FIGURA 3.10 Largura efetiva de um elemento enrijecido a compressão (YU, 1985).

FIGURA 3.11 Tipos de enrijecedores de borda........................................... 39

FIGURA 3.12 Modos de flambagem....................................................... 39

FIGURA 3.13 Coeficiente de flambagem para elemento enrijecido por meio de enrijecedor de borda (DESMOND et al, 1981a)..... 40

FIGURA 3.14 Elemento efetivo de um enrijecedor (YU, 1985)................. 43

FIGURA 3.15 Distribuição de tensões normais à mesa comprimida do enrijecedor intermediário (YU,1985)

FIGURA 3.16 Modos de flambagem de elementos com enrijecimentos múltiplos.

FIGURA 3.17 Coeficiente de flambagem para elementos comprimidos não enrijecidos (YU, 1985).

FIGURA 3.18 Largura efetiva de elementos comprimidos não enrijecidos (YU, 1985).

FIGURA 3.19 Elementos submetidos a um gradiente de tensões............... 51

FIGURA 4.1 Tipos de seções transversais para barras comprimidas.......... 58 
FIGURA 4.2 Carregamento e descarregamentos das fibras, teoria do módulo tangente (RACHID \& MORI, 1989).

FIGURA 4.3 Viga com momentos aplicados nas

extremidades.

FIGURA 4.4 Viga simplesmente apoiada com momento fletor constante.

FIGURA 4.5 Dimensões de perfil "I".

FIGURA 4.6 Tensões críticas de flambagem lateral com torção vigas "I"(YU, 1985)

FIGURA 4.7 Viga monossimétrica com momentos aplicados nas extremidades.

FIGURA 4.8 - Fator $\mathrm{C}_{\mathrm{y}}$ para elemento enrijecido à compressão sob momento fletor variável (JAVARONI, 1993)..

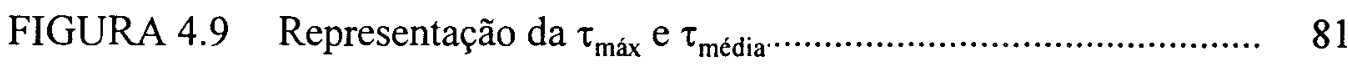

FIGURA 4.10 Limites para as tensões críticas de cisalhamento em almas (JAVARONI, 1993).

FIGURA 4.11 Relação de interação entre " $f_{\mathrm{e}}$ " $\tau$ " (YU, 1985)...

FIGURA 4.12 Distribuição de tensões normais nas mesas de um perfil "I" pelo efeito "shear lag" (YU, 1985)..

FIGURA 4.13 Curvas para a determinação da largura efetiva de mesas de vigas com vão curto (YU, 1985).

FIGURA 4.14 Ondulação da viga para vigas "I" (YU, 1985)...................... 94

FIGURA 4.15 Barras sujeitas à ação de flexo-compressão......................... 96

FIGURA 4.16 Relações trigonométricas.................................................... 98

FIGURA 4.17 Barra prismática sujeita à flexo-compressão......................... 98

FIGURA 4.18 Curvas de interação (JAVARONI, 1993)............................. 102

FIGURA 4.19 Ensaio de tração, diagrama tensão deformação...................... 104

FIGURA 5.1 Estrutura tipo de edificação leve.......................................... 122

FIGURA 5.2 Seção transversal............................................................ 123

FIGURA 5.3 Plano do banzo inferior.................................................... 123

FIGURA 5.4 Plano das terças............................................................. 124

FIGURA 5.5 Elevação lateral.............................................................. 124

FIGURA 5.6 Tipos de seções transversais de terças.................................... 125

FIGURA 5.7 Tipos de treliças............................................................. 126

FIGURA 5.8 Detalhe de ligações parafusadas.......................................... 126

FIGURA 5.9 Exemplos de tesouras...................................................... 127

FIGURA 5.10 Tipos de seções transversais empregadas nas tesouras.......... 128 
FIGURA 5.11 Detalhes de ligações das diagonais com os banzos................ 128

FIGURA 5.12 Detalhe de apoio engastado de treliças com colunas............... 129

FIGURA 5.13 Detalhe de apoio de treliça soldada..................................... 129

FIGURA 5.14 Seções transversais de colunas........................................... 130

FIGURA 5.15 Colunas treliçadas........................................................... 131

FIGURA 5.16 Bases de colunas............................................................ 132

FIGURA 5.17 Sistemas de contraventamento.............................................. 133

FIGURA 6.1 Comprimentos " $L "$ das terças................................................ 136 


\section{LISTA DE TABELAS}

TABELA 2.1 Principais aços estruturais ASTM e sua utilização (MANUAL BRASILEIRO PARA CÁLCULO DE ESTRUTURAS METÁLICAS, 1986)...............................

TABELA 2.2 Propriedades mecânicas dos aços ASTM relacionados pela AISI (SÁLES \& MALITE, 1993)

TABELA 3.1 Valores de $\mathrm{k}$ para determinação da tensão crítica de flambagem elástica (YU, 1985).

TABELA 4.1 Valores dos coeficientes de resistência $(\phi)$ de acordo com as normas CSA (1984) e AISI (1991).

TABELA 4.2 Valores do coeficiente $\mathrm{k}$ de flambagem por flexão (YU, 1985)

TABELA 4.3 Valores de $\mathrm{M}_{\mathrm{cr}}$ para momentos aplicados nas extremidades.

TABELA 4.4 Valores de $\mathrm{M}_{\mathrm{cr}}$ para cargas concentradas e distribuídas.

TABELA 4.5 Seções compostas - seções "I" formadas pela união de dois perfis "U" ligados pela alma ou pela união de duas cantoneiras a um perfis " $U$ "

TABELA 4.6 Seções com alma simples - seções "U" e "Z".

TABELA 4.7 Perfis com almas múltiplas - perfis cartolas, painéis de fechamento e pisos

TABELA 4.8 Máxima relação admissível para largura efetiva pela largura atual (CSA, 1994 e AISI, 1991).............................. 93

TABELA 4.9 Valores de " $\mathrm{C}_{\mathrm{m}}$ " (SÁLES \& MALITE, 1993).................... 101

TABELA 5.1 Perfis de seção simples ou composta................................... 134

TABELA 5.2 Perfis de seção múltipla................................................... 135 


\section{LISTA DE SÍMBOLOS}

\section{Romanos}

a Distância entre enrijecedores

b Largura em geral

$b_{\text {ef }}$ Largura efetiva

$b_{f} \quad$ Largura da mesa

$c_{t}$ Deslocamento da extremidade da mesa em perfil fletido

d Altura da seção; altura do enrijecedor de borda

f Tensão em geral

$\mathrm{f}_{\mathrm{cr}} \quad$ Tensão crítica de flambagem

$\mathrm{f}_{\mathrm{e}} \quad$ Tensão crítica de flambagem elástica

$f_{e x}$ Tensão crítica de flambagem elástica segundo o eixo "x"

$f_{\text {ey }} \quad$ Tensão crítica de flambagem elástica segundo o eixo " $y$ "

$\mathrm{f}_{\mathrm{ez}}$ Tensão crítica de flambagem elástica por torção

$\mathrm{f}_{\mathrm{pr}}$ Tensão correspondente ao limite de proporcionalidade

$\mathrm{f}_{\mathrm{r}}$ Tensão residual

$\mathrm{f}_{\mathrm{u}} \quad$ Limite de resistência à tração do aço

$f_{y} \quad$ Limite de escoamento do aço

$f_{y^{\prime}} \quad$ Limite de escoamento do aço após o dobramento

$f_{y c} \quad$ Limite de escoamento do canto após o dobramento

$\mathrm{f}_{1}, \mathrm{f}_{2}$ Tensões utilizadas no cálculo da largura efetiva de elementos sob tensões não uniformes

h Altura em geral

j Constante da seção transversal, utilizada no dimensionamento à flexo-torção de seções monossimétricas e não simétricas

$\mathrm{k} \quad$ Parâmetro utilizado no cálculo do comprimento de flambagem

$\mathrm{k}_{\mathrm{X}}, \mathrm{k}_{\mathrm{y}}$ Parâmetros utilizados no cálculo dos comprimentos de flambagem segundo os eixos "x" e "y", respectivamente.

$\mathrm{k}_{\mathrm{Z}} \quad$ Parâmetro utilizado no cálculo do comprimento de flambagem com torção

$\mathrm{r}_{0} \quad$ Raio de giração polar em relação ao centro de cisalhamento

$r_{X}, r_{y}$ Raio de giração em relação aos eixos "x" e '"y", respectivamente 
$\mathrm{t}_{\mathrm{W}} \quad$ Espessura da alma

u Deslocamento do centro de cisalhamento segundo o eixo " $x$ "

$v$ Deslocamento de centro de cisalhamento segundo o eixo "y"

$\mathrm{x}_{0}, \mathrm{y}_{0}$ Coordenada do centro de cisalhamento

A Área da seção transversal, coeficiente

$\mathrm{A}_{\mathrm{ef}} \quad$ Área efetiva

$A_{n} \quad$ Área líquida

$\mathrm{A}_{\mathrm{St}} \quad$ Área da seção transversal do enrijecedor

B Coeficiente

$\mathrm{C}_{\mathrm{b}}, \mathrm{C}_{\mathrm{m}}$ Coeficiente utilizado no dimensionamento à flexão simples ou composta

$\mathrm{C}_{\mathrm{mx}} \quad$ Coeficiente $\mathrm{C}_{\mathrm{m}}$ relativo ao eixo " $\mathrm{x}$ "

$C_{m y} \quad$ Coeficiente $C_{m}$ relativo ao eixo " $y$ "

$\mathrm{C}_{\mathrm{W}} \quad$ Constante de empenamento da seção transversal

D Rigidez a flexão da chapa

E Módulo de elasticidade do aço

$\mathrm{E}_{\mathrm{r}} \quad$ Módulo reduzido

$\mathrm{E}_{\mathrm{t}} \quad$ Módulo tangente

G Módulo de elasticidade transversal do aço

H Parâmetro utilizado na flambagem por flexão e torção

I Momento de inércia

$\mathrm{I}_{\mathrm{a}} \quad$ Momento de inércia adequado para enrijecedores de borda e intermediários

Ist Momento de inércia para os enrijecedores transversais

$\mathrm{I}_{\mathrm{t}} \quad$ Momento de inércia à torção

$\mathrm{I}_{\mathrm{x}}, \mathrm{I}_{\mathrm{y}} \quad$ Momento de inércia em relação aos eixos " $\mathrm{x}$ e " $\mathrm{y}$ ", respectivamente

L Comprimento em geral, vão

$\mathrm{l}_{\mathrm{b}} \quad$ Comprimento do trecho sem contenção lateral

$\mathrm{L}_{\mathrm{St}} \quad$ Comprimento do enrijecedor transversal

M Momento fletor

$\mathrm{M}_{\mathrm{cr}} \quad$ Momento crítico

$\mathrm{M}_{\mathrm{d}} \quad$ Momento fletor de cálculo

$\mathrm{M}_{\mathrm{n}} \quad$ Resistência nominal ao momento fletor

$\mathrm{M}_{\mathrm{p}} \quad$ Momento de plastificação

$\mathrm{M}_{\mathrm{S}} \quad$ Momento estático

$\mathrm{M}_{1}, \mathrm{M}_{2}$ Menor e maior momentos fletores nas extremidades do trecho sem contenção lateral

$\mathrm{M}_{\mathrm{y}} \quad$ Momento correspondente ao início de escoamento 


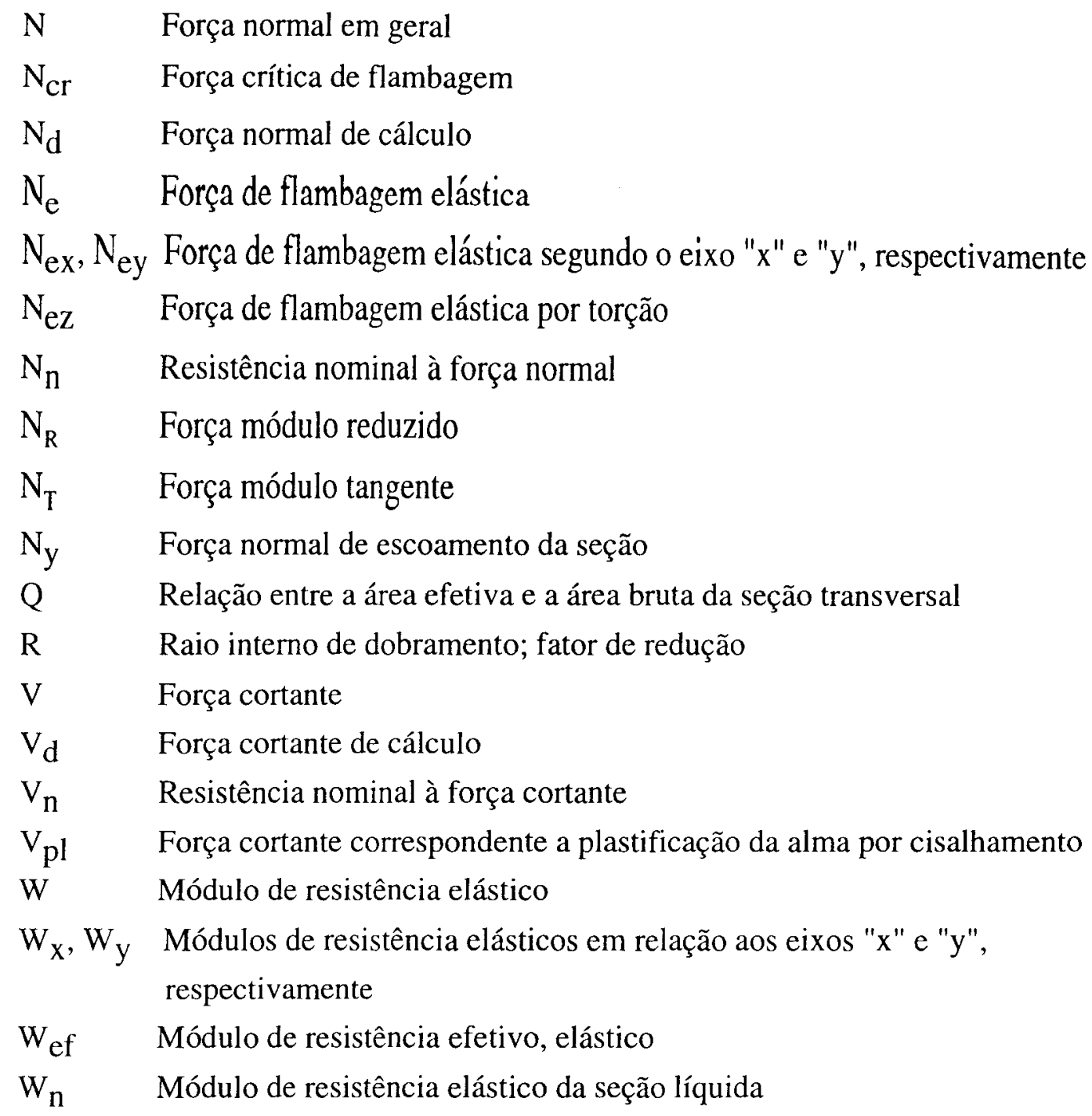

\section{Gregos}

$\alpha \quad$ Ângulo; fator de carga

$\varepsilon_{\mathrm{y}} \quad$ Deformação no escoamento $\left(\mathrm{f}_{\mathrm{y}} / \mathrm{E}\right)$

$\varepsilon_{\mathrm{cu}} \quad$ Máxima deformação a compressão

$\gamma \quad$ Coeficiente de segurança

$\lambda \quad$ Parâmetro de esbeltez

$\lambda_{\mathrm{p}} \quad$ Parâmetro de esbeltez correspondente à plastificação

$\lambda_{R} \quad$ Parâmetro de esbeltez correspondente a fase elástica

$v \quad$ Coeficiente de Poisson

$\sigma \quad$ Tensão normal

$\tau \quad$ Tensão de cisalhamento

$\tau_{y} \quad$ Tensão de escoamento por cisalhamento

$\tau_{\mathrm{cr}} \quad$ Tensão crítica de flambagem por cisalhamento

$\phi \quad$ Coeficiente de resistência em geral; rotação da seção transversal em torno do centro de cisalhamento 
$\phi_{\mathrm{b}} \quad$ Coeficiente de minoração da resistência ao momento fletor

$\phi_{c} \quad$ Coeficiente de resistência à compressão

$\phi_{\mathrm{t}} \quad$ Coeficiente de resistência à tração

$\phi_{v} \quad$ Coeficiente de resistência à força cortante

$\psi \quad$ Fator de combinação

Demais símbolos não listados, serão explicados quando de sua utilização. 


\section{LISTA DE SIGLAS}

AISI Norma Americana de Chapa Dobrada

(American Iron Steel Institute).

CSA Norma Canadense de Chapa Dobrada

(Canadian Standards Associatian CAN3-S136-M84).

NB-143 Norma Brasileira de Chapa Dobrada

(Cálculo de Estruturas de Aço Constituídas por Perfis Leves).

NBR-8800 Norma Brasileira de Perfis Laminados e Soldados

(Projeto e Execução de Estruturas de Aço de Edifícios). 


\section{RESUMO}

SILVA, RONISI CAZELI G. Fundamentos teóricos e aspectos gerais para projeto de estruturas em aço com perfis conformados a frio. São Carlos, 1995. 225p. Dissertação (Mestrado) - Escola de Engenharia de São Carlos, Universidade de São Paulo.

Aborda-se os principais aspectos da fundamentação teórica relativos ao dimensionamento de elementos em aço, constituídos por perfis de chapa dobrada, baseados nas prescrições das normas Americana e Canadense.

A fundamentação teórica destina-se a justificar os procedimentos referentes ao dimensionamento de perfis de aço conformados a frio, em particular os elementos comprimidos e fletidos, além dos aspectos da flambagem local destes perfis.

Aborda-se também uma análise dos métodos de projeto das estruturas metálicas formadas por estes perfis, apresentando-se algumas disposições e alguns aspectos interessantes e essenciais no desenvolvimento de um edifício industrial leve.

Tendo em vista a grande utilização dos perfis conformados a frios em terças, desenvolveu-se uma sistemática de cálculo fornecendo os valores dos momentos admissíveis que poderão ser aplicados para um pré-dimensionamento.

Palavras-chave: Aço; Perfis conformados a frio, Projeto. 


\section{ABSTRACT}

SILVA, RONISI CAZELI G. Theoretical fundamentals and general aspects for the design of cold-formed steel structures. São Carlos, 1995. 225p. Dissertação (Mestrado) - Escola de Engenharia de São Carlos, Universidade de São Paulo.

An analysis of the theoretical basis for the design of cold-formed steel structural members, according to the American and Canadian Standards, is made.

The theoretical background is used to justify the procedure to obtain the required geometry of the cold-formed steel structural members particularly the compression and flexural members, also to explain some aspects of the local buckling.

Furthermore, an analysis of the design method of steel structures with these profiles is made. Some interesting and essential aspects are presented in what concerns to the development of a light industrial building.

Having in mind the intensive use of cold-formed members in purlin structures, a procedure for systematic calculation was developed to determine the allowable bending moment values that can be used on a preliminary design.

Keywords: Steel; Cold-formed steel members; Design. 


\section{CAPÍTULO 1}

\section{INTRODUÇÃO}

\section{1 - GENERALIDADES}

A utilização de estruturas em aço obtidas por perfis de chapa dobrada, também denominados perfis leves, é usual em outros países como na Europa e Estados Unidos, e encontra-se atualmente em fase de rápido crescimento no Brasil.

O sistema de conformação é obtido pelo dobramento a frio de chapas finas de aço, variando a sua espessura entre $0,378 \mathrm{~mm}$ e $6,35 \mathrm{~mm}$. Podem-se obter perfis com espessuras maiores, até $25,4 \mathrm{~mm}$, desde que o equipamento para realizar as dobras (prensa dobradeira) e o tipo de aço especificado sejam apropriados para tal. Com este processo de dobramento podem-se obter seções com diversas formas, sendo as mais usuais perfis do tipo "U", "U" enrijecido, "Z", "Z" enrijecido, cartola, seções fechadas, tubo retangular, etc.

Pela grande variedade de seções obtidas a partir da conformação de chapas finas de aço, associada com as características de resistência, rigidez e leveza, os elementos de chapa dobrada têm sido empregados largamente na construção civil. É comum o uso destes perfis em coberturas, em passarelas, em torres de transmissão, etc. Além disso, pela sua potencialidade tem sido empregados também na indústria automobilística, na indústria aeronáutica, na indústria mecânica, na indústria ferroviária, transportes e também na agroindústria.

Estes perfis estão sendo cada vez mais utilizados devido a sua grande vantagem quando comparados com aos perfis laminados a quente, pois pode-se obter perfis mais leves, mais econômicos, apresentando formas e dimensões adequadas à solicitações, facilidades de produção, baixo custo de estoque, flexibilidade do processo de dobragem a frio e grande liberdade de escolha ao projetista, tanto no formato da seção transversal, como nas dimensões. 
Fazendo-se uma breve comparação com elementos de madeira e de concreto armado, observam-se vantagens tais como leveza, facilidade de produção, alta resistência, instalação fácil e segura, detalhamento preciso, características uniformes, economia, fácil transporte e execução, etc.

A viabilidade econômica da aplicação das estruturas formadas por perfis de chapa dobrada está no baixo peso do aço, proporcionando assim, um custo menor de montagem e diminuição do prazo de execução.

\section{2 - BREVE HISTÓRICO}

Segundo YU (1985), o uso dos elementos de chapa dobrada na construção de edifícios começou por volta de 1850 nos Estados Unidos e Inglaterra.

Em 1939, iniciaram-se pesquisas sobre este material na Universidade Cornell sob a orientação do professor George Winter.

No ano seguinte, houve um avanço nos estudos sobre o comportamento de seções delgadas, com a publicação do livro "Thin-Walled Elastic Beams" de autoria de Vlasov. Neste livro Vlasov expôs sua teoria sobre o efeito do empenamento elástico de vigas com paredes finas, sendo seu método de análise baseado nas propriedades setoriais da seção transversal de vigas e cascas, para as quais a relação largura-espessura das paredes excede 10. Vlasov foi, então, uns dos primeiros a compreender que o princípio de Bernoulli, aplicável aos elementos de paredes espessas, não pode mais ser evocado quando se trata de seções com paredes finas.

Em 1940, iniciou-se o emprego de elementos estruturais em chapa dobrada em maior escala na construção civil e no uso militar, a segunda guerra mundial aumentou de maneira significativa o consumo de elementos de aço.

A partir de 1946, o uso e o desenvolvimento de perfis com paredes finas constituídas em aço, foi incentivado nos Estados Unidos, onde surgiu a primeira norma para projetos e construções de estruturas constituídas de perfis de chapa dobrada publicada pelo AISI ${ }^{1}$ - American Iron and Steel Institute. A especificação foi baseada, em grande parte, nos resultados obtidos da pesquisa efetuada na Universidade Cornell, sob a orientação de George Winter desde 1939.

No Brasil, existe a norma NB-143, "Cálculo de estruturas de aço constituídas por perfis leves", de 1967, baseada nas especificações do AISI de 1962. Devido a sua

${ }^{1}$ Utilizar-se-á a sigla AISI para denominar a normalização americana publicada pelo American Iron and Steel Institute referente aos perfis conformados a frio. 
desatualização, esta norma tem sido substituída por normas estrangeiras mais recentes como CSA2 - Canadian Standards Steel - e o próprio AISI.

A escassez de bibliografia especializada se agrava ainda mais, para os projetos de edificações de pequeno porte (com cargas e vãos relativamente pequenos), justamente o tipo de edificação em que o uso de perfis leves é recomendável e onde se enquadra grande maioria das obras brasileiras.

Para que se tenha uma melhor idéia da importância do emprego de perfis em chapa dobrada, a seguir são apresentadas algumas obras.

\section{3 - OBRAS}

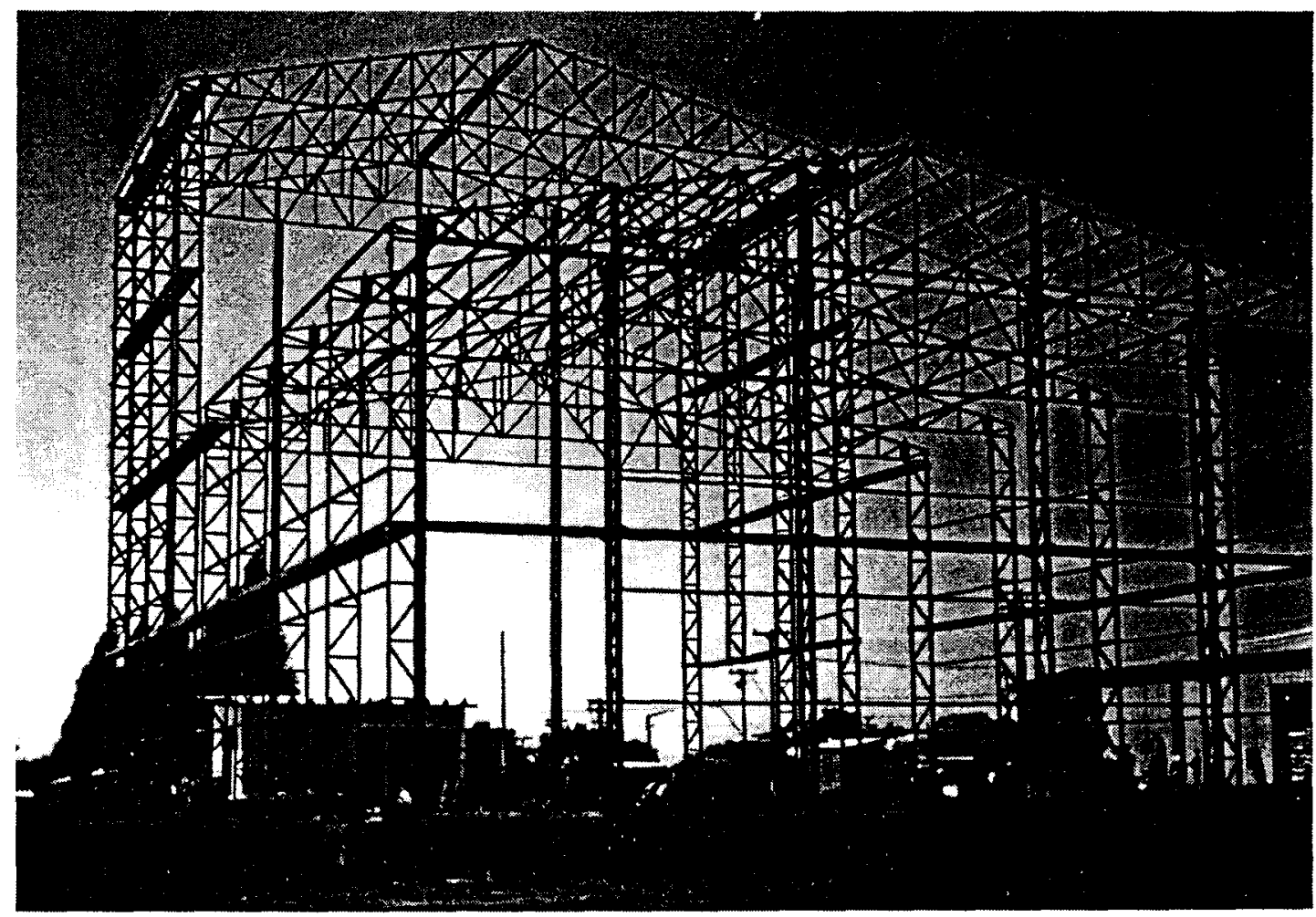

FIGURA 1.1 - Estrutura em chapa dobrada em fase de montagem Descalvado/SP (1990).

${ }^{2}$ Utilizar-se-á a sigla CSA para denominar a normalização canadense publicada pelo Canadian Standards Associatian (CSA) CAN3-S136-M84 referente aos perfis conformados a frio. 

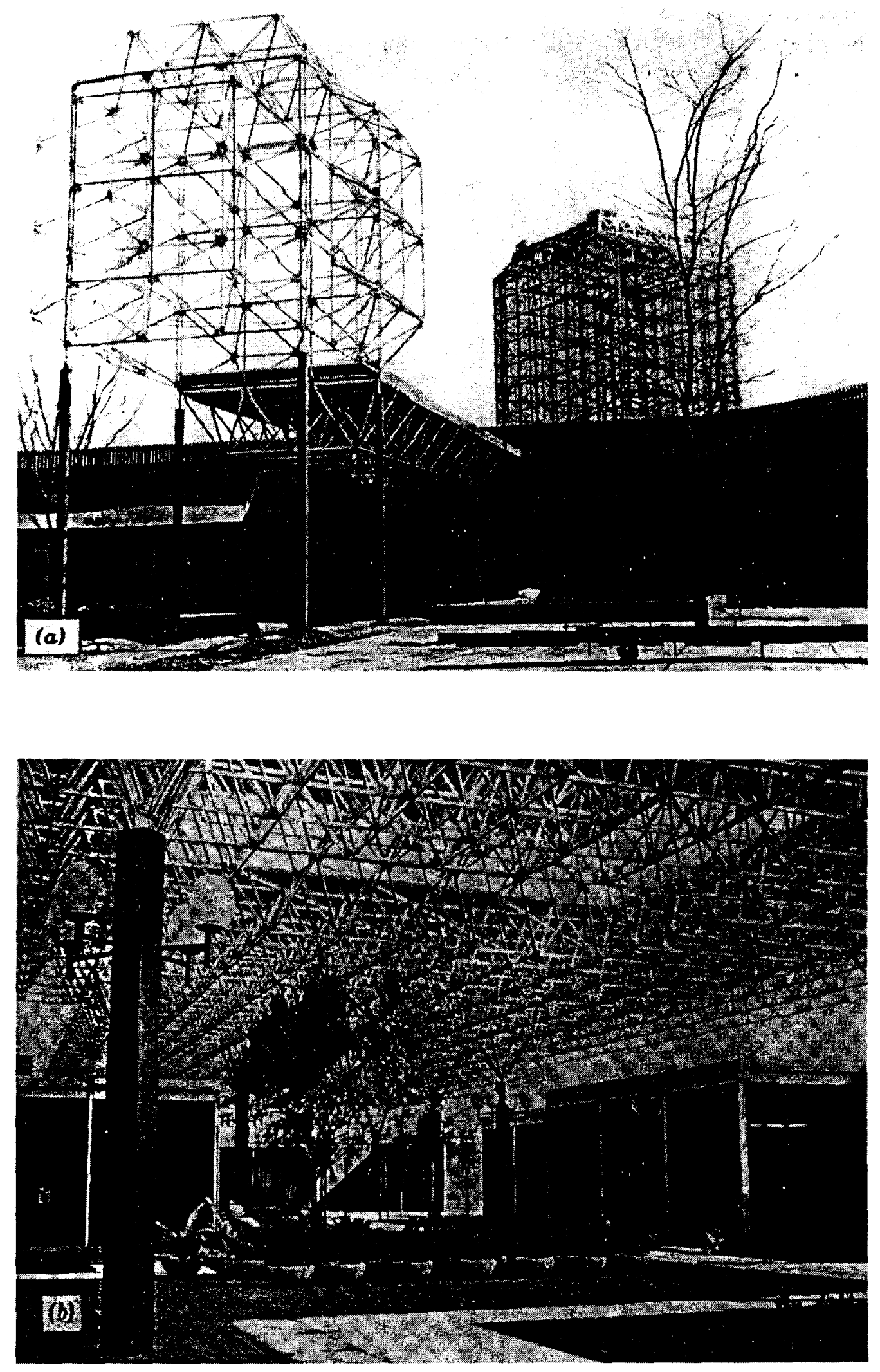

FIGURA 1.2 - Estruturas espaciais constituídas em perfis de chapa dobrada (YU, 1985). 

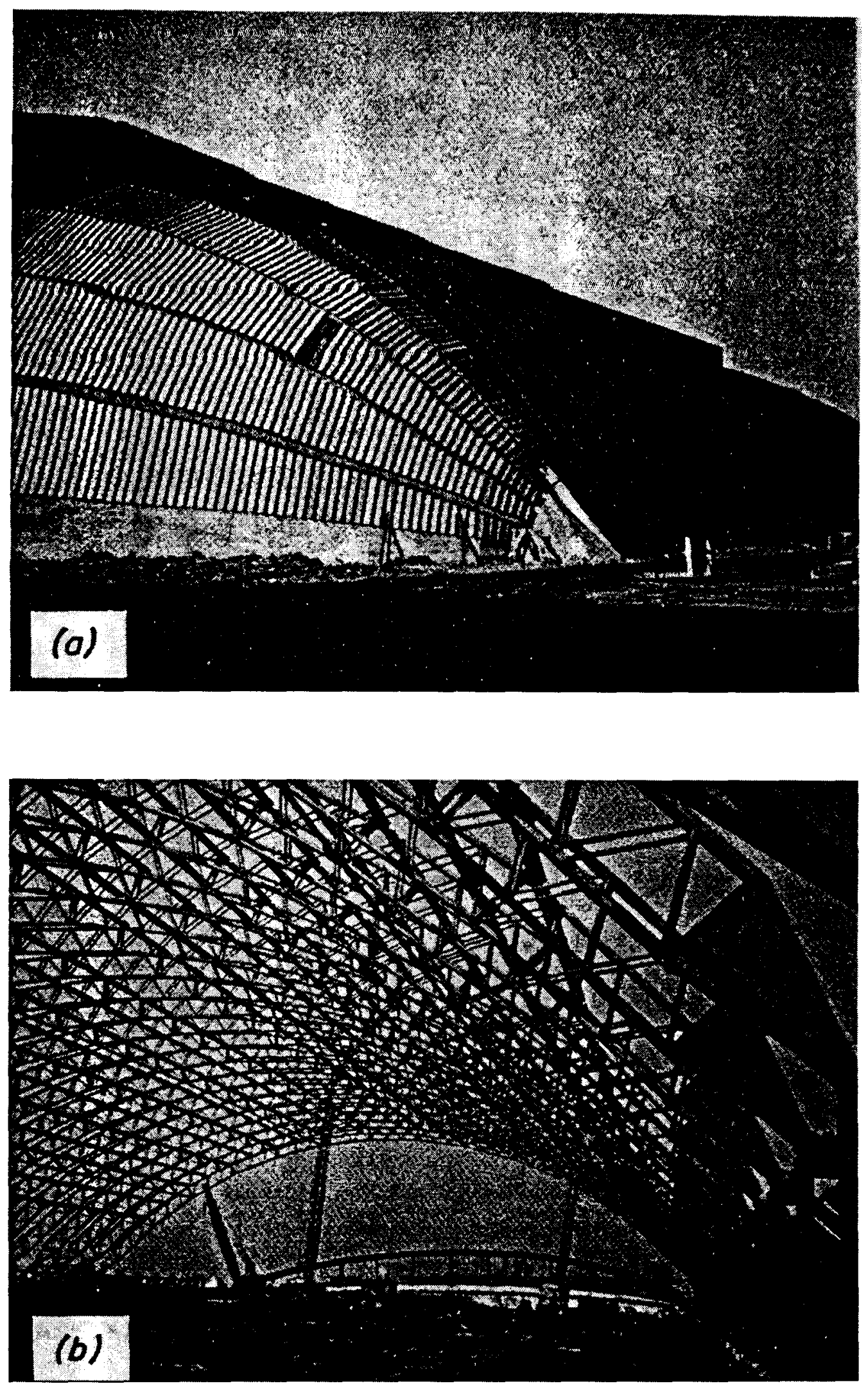

FIGURA 1.3 - Estrutura de um hangar utilizando perfis de chapa dobrada (YU, 1985). 


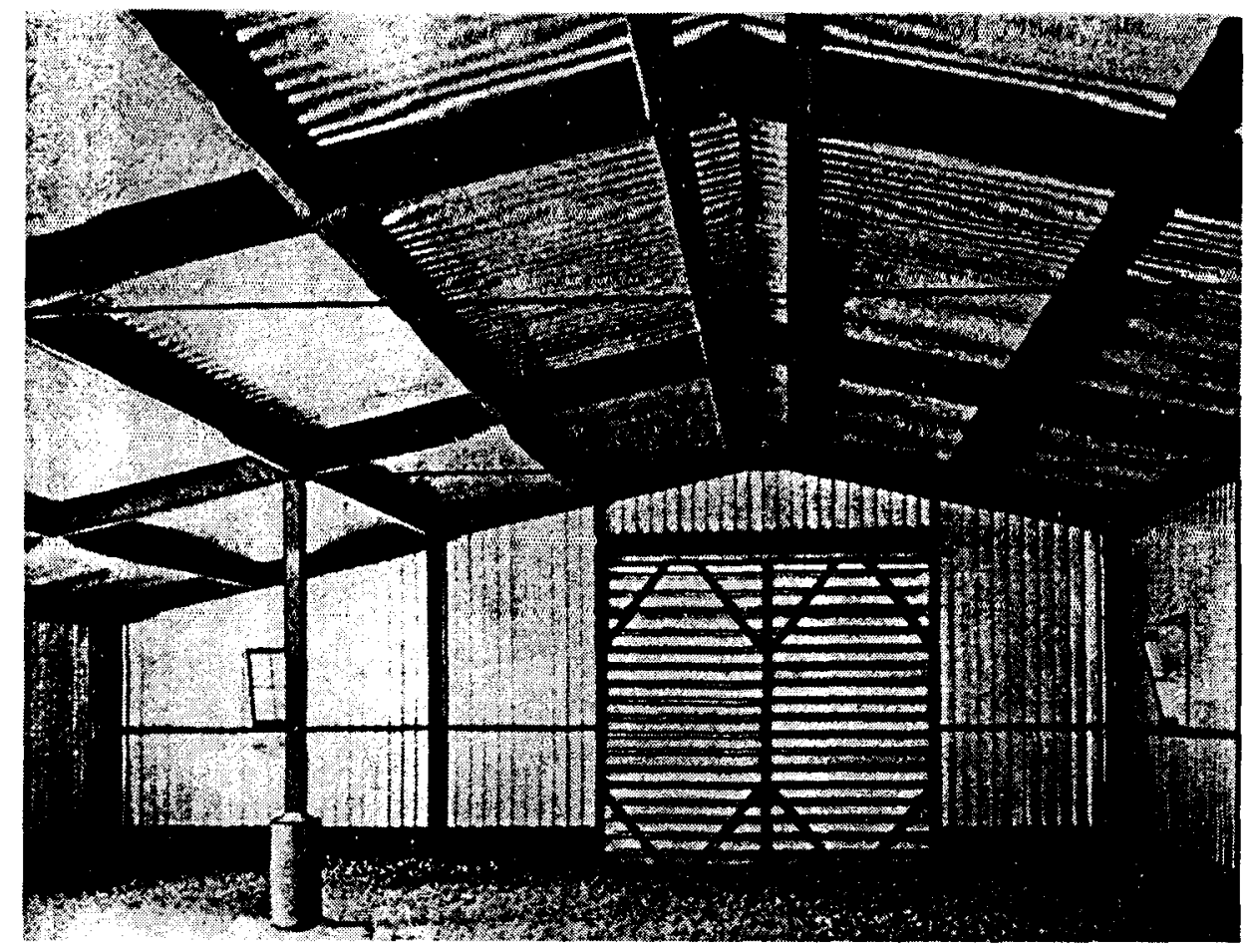

FIGURA 1.4 - Estrutura de um galpão constituído inteiramente por perfis de chapa dobrada (YU, 1985).

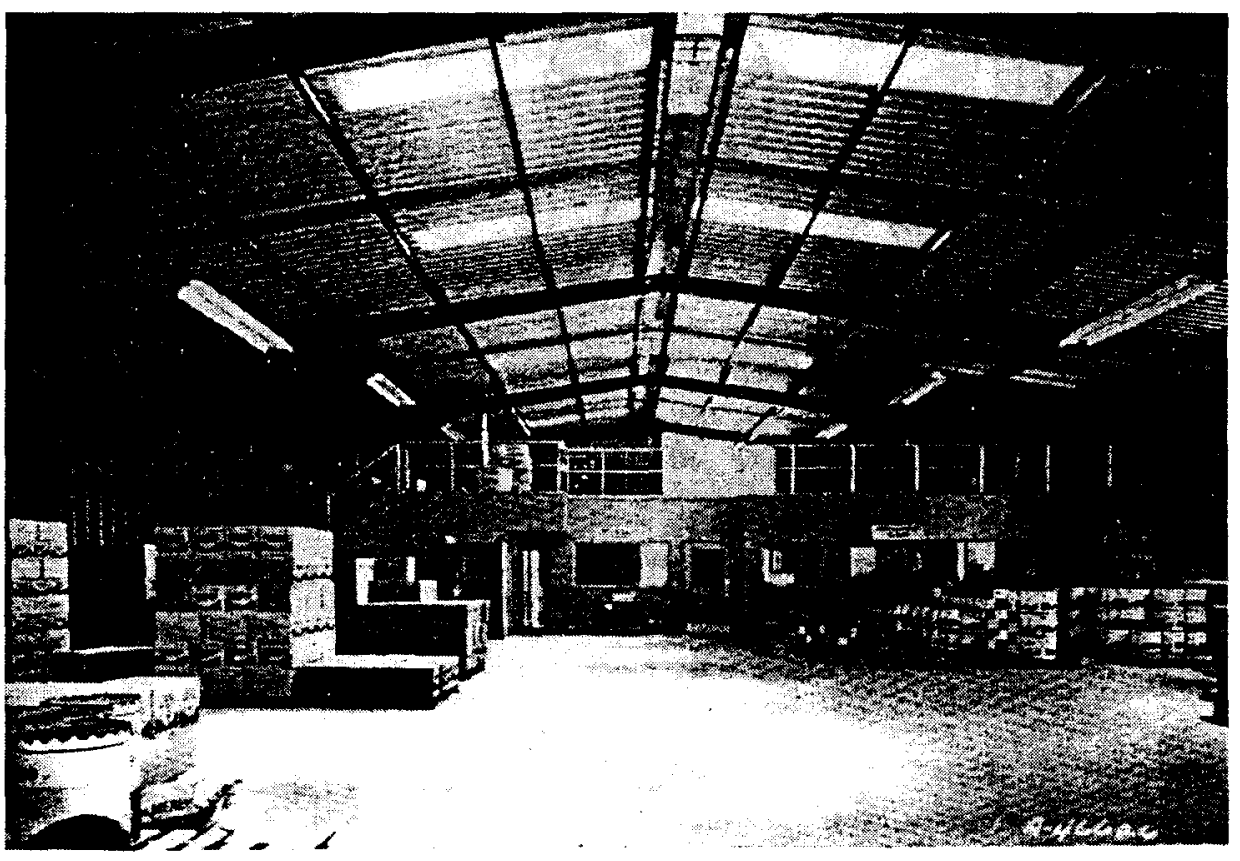

FIGURA 1.5 - Edifício padronizado com pórtico principal constituído de perfil laminado e fechamentos, cobertura e acessórios de acabamento em chapa dobrada (YU, 1985). 


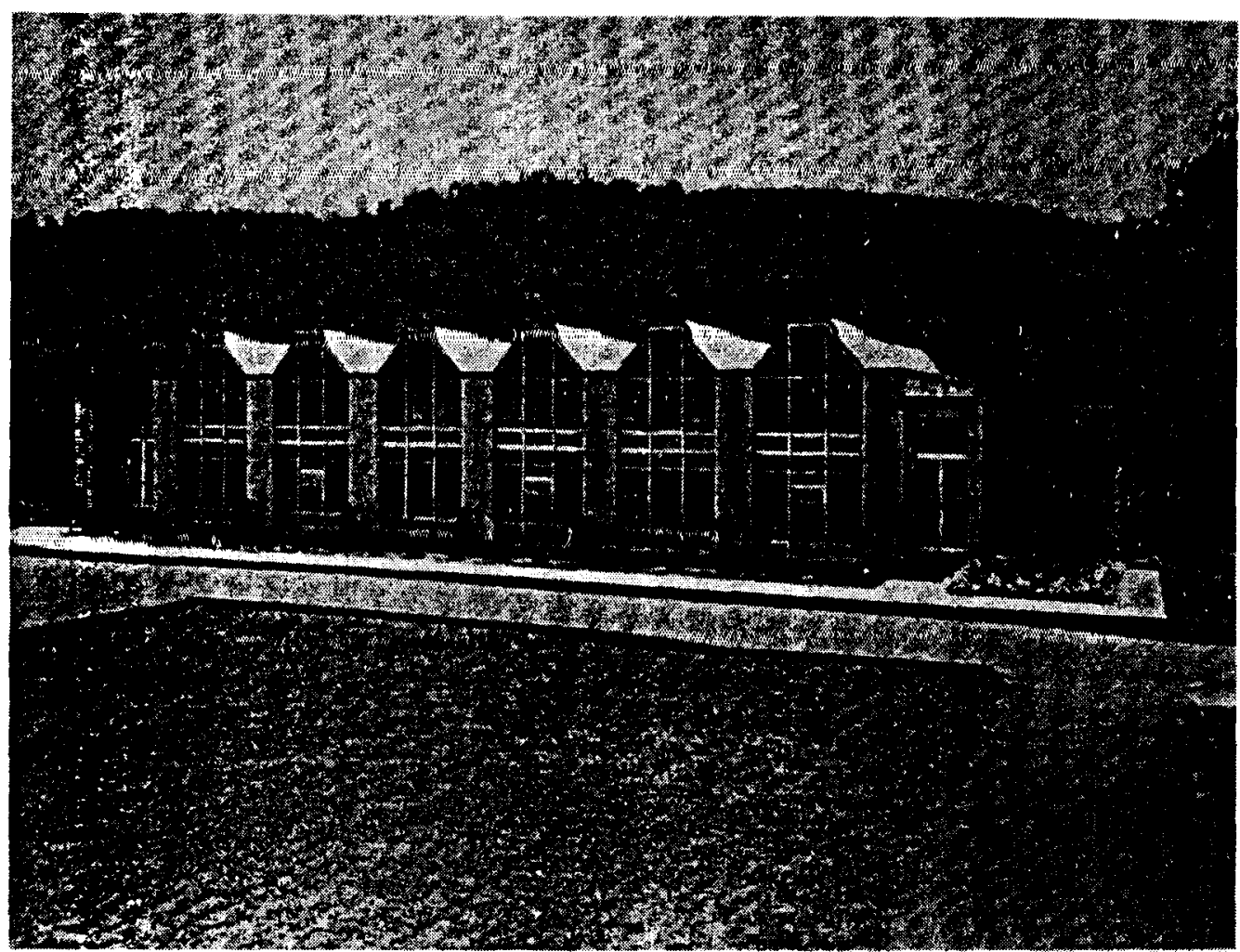

FIGURA 1.6 - Painéis de cobertura em chapa dobrada (YU, 1985).

\section{4 - OBJETIVOS}

Tendo em vista o crescimento da utilização dos perfis de chapa dobrada, como elemento estrutural na construção civil, os objetivos almejados por este trabalho são:

a) apresentar os aspectos gerais destes elementos estruturais;

b) desenvolver vários aspectos da formulação teórica para o dimensionamento deste elementos;

c) apresentar uma composição estrutural com perfis conformados a frio;

d) desenvolver uma sistematização dos cálculos destes elementos estruturais quando aplicados em terças, vigas ou longarinas.

Por serem as terças em chapa dobrada amplamente utilizadas como elementos estruturais de cobertura, tanto em estruturas leves como na composição de estruturas com perfis laminados, torna-se importante a análise destes elementos procurando-se obter uma maior viabilidade técnica para o seu emprego. 
Desta forma, procura-se com este trabalho facilitar os cálculos apresentando, em forma de tabelas e gráficos, os valores dos momentos fletores admissíveis usados no pré-dimensionamento das terças.

\section{5 - APRESENTAÇÃO DO TRABALHO}

Após estas breves considerações sobre o assunto, pode-se descrever, com detalhes, o conteúdo do trabalho. Assim, no segundo capítulo apresentam-se os materiais usados nos perfis de chapa dobrada, contendo uma relação dos aços de qualidade estrutural que devem ser empregados para a conformação a frio. Apresentam-se também as propriedades mecânicas dos principais aços, os tipos de perfis usuais e as características geométricas das seções.

A resistência dos elementos estruturais esbeltos comprimidos em chapa dobrada e critérios de cálculo, estão descritos no terceiro capítulo, analisando-se a tensão crítica de flambagem elástica, de flambagem inelástica e a largura efetiva destes elementos.

No quarto capítulo apresenta-se o procedimento teórico para o dimensionamento dos perfis às solicitações de tração, compressão, flexão, cisalhamento e flexo-compressão. A formulação apresentada baseia-se no método dos estados limites segundo as normas CSA (1984) e AISI (1991) para o projeto de estruturas onde são empregados esses perfis.

No quinto capitulo apresenta-se alguns aspectos para projetos como elementos para terças, treliças de cobertura, colunas e contraventamentos, além dos tipos de elementos e onde são utilizados.

Com a finalidade de facilitar os cálculos para o pré-dimensionamento de terças, no sexto capítulo descreve-se em forma de exemplo numérico o método utilizado, onde foi possível gerar tabelas e gráficos de fácil entendimento e utilização, que encontram-se apresentadas no anexo I.

O capitulo sete trata das considerações finais e conclusões. 


\section{CAPÍTULO 2}

\section{PERFIS ESTRUTURAIS EM CHAPA DOBRADA}

\section{1 - COMENTÁRIO GERAL DOS MATERIAIS EMPREGADOS EM PERFIS DE CHAPA DOBRADA}

Segundo YU (1985), as propriedades do material plano tem um importante papel no desempenho de elementos estruturais, principalmente no tocante às propriedades mecânicas das chapas de aço, tiras, placas ou barras planas normalmente usadas nas construções em chapa dobrada.

São especificados quatorze tipos de aços na edição de 1986 da AISI, sendo eles representados na tabela 2.1 .

TABELA 2.1 - Principais aços estruturais ASTM e sua utilização (MANUAL BRASILEIRO PARA CÁLCULO DE ESTRUTURAS METÁLICAS, 1986)

\begin{tabular}{|c|l|l|}
\hline $\begin{array}{c}\text { ESPECIFICAÇÃO } \\
\text { ASTM }\end{array}$ & \multicolumn{1}{|c|}{$\begin{array}{c}\text { TIPOS DE } \\
\text { PRODUTOS }\end{array}$} & \multicolumn{1}{|c|}{ UTILIZAÇÃO } \\
\hline A36 & $\begin{array}{l}\text { Perfis, chapas e barras de aço- } \\
\text { carbono. }\end{array}$ & $\begin{array}{l}\text { Construção soldada e e } \\
\text { parafusada; pontes, edifícios, } \\
\text { torres e uso estrutural em geral. }\end{array}$ \\
\hline A53 & $\begin{array}{l}\text { Tubos soldados ou sem costura, } \\
\text { pretos ou galvanizados. }\end{array}$ & $\begin{array}{l}\text { Construção soldada e e } \\
\text { parafusada; uso principal em } \\
\text { edifícios, especialmente em } \\
\text { pilares e barras de treliças. }\end{array}$ \\
\hline
\end{tabular}


TABELA 2.1 - Continuação

\begin{tabular}{|c|c|c|}
\hline A242 & $\begin{array}{l}\text { Perfis, chapas e barras de aço de } \\
\text { alta resistência e baixa liga. }\end{array}$ & $\begin{array}{l}\text { Construção soldada } \\
\text { parafusada; pontes edifícios, } \\
\text { torres e uso estrutural em geral. } \\
\text { A resistência a corrosão } \\
\text { atmosférica é cerca de quatro } \\
\text { vezes maior que a do aço- } \\
\text { carbono; aço resistente ao } \\
\text { intemperismo. }\end{array}$ \\
\hline A440 & $\begin{array}{l}\text { Perfis, chapas e barras de aço de } \\
\text { alta resistência. }\end{array}$ & $\begin{array}{l}\text { Construção parafusada; pontes } \\
\text { edifícios, torres e outras } \\
\text { estruturas. A resistência à } \\
\text { corrosão atmosférica é duas } \\
\text { vezes maior que a do aço- } \\
\text { carbono. }\end{array}$ \\
\hline A44 1 & $\begin{array}{l}\text { Perfis, chapas e barras de aço de } \\
\text { alta resistência e baixa liga, } \\
\text { contendo Manganês e Vanádio. }\end{array}$ & $\begin{array}{l}\text { Construção soldada ou } \\
\text { parafusada, porém usado } \\
\text { principalmente em estruturas } \\
\text { soldadas; pontes, edifícios e } \\
\text { outras estruturas. A resistência à } \\
\text { corrosão atmosférica é duas } \\
\text { vezes maior que a do aço- } \\
\text { carbono. }\end{array}$ \\
\hline A446 & $\begin{array}{l}\text { Chapas finas em bobinas ou } \\
\text { cortadas, galvanizadas. }\end{array}$ & $\begin{array}{l}\text { Perfis formados a frio, usados } \\
\text { em edifícios, principalmente do } \\
\text { tipo padronizado, pré-fabricado; } \\
\text { construção soldada, parafusada } \\
\text { com parafusos comuns ou auto- } \\
\text { atarrachantes. }\end{array}$ \\
\hline A 500 & $\begin{array}{l}\text { Perfis tubulares formados a frio, } \\
\text { soldados ou sem costura, redondos, } \\
\text { quadrados, retangulares ou com } \\
\text { formatos especiais. }\end{array}$ & $\begin{array}{l}\text { Construção soldada ou } \\
\text { parafusada; pontes, edifícios e } \\
\text { uso estrutural em geral. }\end{array}$ \\
\hline
\end{tabular}


TABELA 2.1 - Continuação

\begin{tabular}{|c|c|c|}
\hline A501 & $\begin{array}{l}\text { Perfis tubulares formados a quente, } \\
\text { soldados ou sem costura, redondos, } \\
\text { quadrados, retangulares ou com } \\
\text { formatos especiais. }\end{array}$ & $\begin{array}{l}\text { Construção soldada ou } \\
\text { parafusada; pontes, edifícios e } \\
\text { uso estrutural em geral. }\end{array}$ \\
\hline A514 & $\begin{array}{l}\text { Chapas temperadas, aço de elevado } \\
\text { limite de escoamento. }\end{array}$ & $\begin{array}{l}\text { Usado principalmente em pontes } \\
\text { soldadas e outras estruturas. A } \\
\text { técnica de soldagem não deve } \\
\text { afetar as propriedades da chapa, } \\
\text { especialmente na zona afetada } \\
\text { pelo calor. }\end{array}$ \\
\hline A529 & $\begin{array}{l}\text { Chapas e barras de aço-carbono } \\
\text { com espessura até } 13 \mathrm{~mm} \text {. }\end{array}$ & $\begin{array}{l}\text { Edifícios, principalmente do tipo } \\
\text { padronizado, pré-fabricado; } \\
\text { construção soldada ou } \\
\text { parafusada. }\end{array}$ \\
\hline A 570 & $\begin{array}{l}\text { Chapas finas e tiras de aço- } \\
\text { carbono, laminadas a quente, em } \\
\text { bobinas ou cortadas. }\end{array}$ & $\begin{array}{l}\text { Perfis soldados a frio usados em } \\
\text { edifícios, principalmente do tipo } \\
\text { padronizado, pré-fabricado; } \\
\text { construção soldada, parafusada } \\
\text { com parafusos comuns ou auto- } \\
\text { atarrachantes. }\end{array}$ \\
\hline A572 & $\begin{array}{l}\text { Perfis, chapas, estacas pranchas e } \\
\text { barras de aço de alta resistência e } \\
\text { baixa liga, contendo Colúmbio e } \\
\text { Vanádio. }\end{array}$ & $\begin{array}{l}\text { Construção soldada ou } \\
\text { parafusada em edifícios, usando } \\
\text { todos os graus de resistência do } \\
\text { aço; na construção de pontes, } \\
\text { somente nas resistências } 300 \text {, } \\
320 \text { e } 350 \mathrm{MPa} \text {. }\end{array}$ \\
\hline
\end{tabular}


TABELA 2.1 - Continuação

\begin{tabular}{|c|c|c|}
\hline A588 & $\begin{array}{l}\text { Perfis, chapas e barras de alta } \\
\text { resistência e baixa liga. }\end{array}$ & $\begin{array}{l}\text { Usado principalmente em pontes } \\
\text { soldadas e em edifícios. A } \\
\text { resistência à corrosão } \\
\text { atmosférica é cerca de quatro } \\
\text { vezes maior que a do aço- } \\
\text { carbono; aço resistente a0 } \\
\text { intemperismo. }\end{array}$ \\
\hline A606 & $\begin{array}{l}\text { Chapas finas e tiras de aço de alta } \\
\text { resistência e baixa liga, laminadas a } \\
\text { quente e a frio. }\end{array}$ & $\begin{array}{l}\text { Uso em estruturas e em outras } \\
\text { finalidades onde for importante a } \\
\text { economia de peso e maior } \\
\text { durabilidade. }\end{array}$ \\
\hline
\end{tabular}

São apresentadas na tabela 2.2 as propriedades mecânicas dos principais aços citados anteriormente na tabela 2.1.

Na citação dos aços listados na tabela 2.2, outras chapas de aço ou tiras de qualidade não estrutural também podem ser usadas para finalidade estrutural, desde que suas propriedades químicas e mecânicas sejam determinadas através de ensaios adequados. As informações das propriedades do aço podem ser estabelecidas pelos fabricantes.

São especificados pela norma canadense CSA (1984) os aços ASTM citados anteriormente e os aços da especificação CSA Standards, como: CAN3-G40 21, CAN3-G40 21-M, aços de qualidade estrutural.

No Brasil, o material mais usado para fabricação de perfis de chapa dobrada são os aços de qualidade não estrutural. Segundo a norma brasileira NB-143/1967, as chapas ou tiras de aço utilizadas para a fabricação dos perfis estruturais deverão satisfazer às especificações brasileiras (EB), devendo sua espessura estar compreendida entre $1 \mathrm{~mm}$ e $6 \mathrm{~mm}$. Na falta das especificações brasileiras (EB), serão adotadas as especificações ASTM A245, A303, A374, A375 e A446, até o limite máximo de $35 \mathrm{kN} / \mathrm{cm}^{2}$ para limite de escoamento dos vários aços estruturais. 
TABELA 2.2 - Propriedades mecânicas dos aços ASTM relacionados pelo AISI (SÁLES \& MALITE, 1993).

\begin{tabular}{|c|c|c|c|c|c|}
\hline DESCRIÇÃO DO AÇO & $\begin{array}{l}\text { ESPECIFICAÇÃO } \\
\text { ASTM } \\
\end{array}$ & $\mathrm{f}_{\mathrm{v}}(\mathrm{MPa})$ & $\mathrm{f}_{\mathrm{n}}(\mathrm{MPa})$ & $f_{11} / f_{v}$ & $\mathrm{~A}(\%)$ \\
\hline AÇOCARBONO & A 36 & 250 & $\begin{array}{r}400 @ \\
550 \\
\end{array}$ & $\begin{array}{r}1.61^{@} \\
2.22 \\
\end{array}$ & ${ }_{23}(50)$ \\
\hline $\begin{array}{l}\text { AÇO DE BAIXA LIGA E ALTA } \\
\text { RESISTÊNCIA MECÂNICA }\end{array}$ & A 242 & 345 & 480 & 1.39 & $18^{(200)}$ \\
\hline $\begin{array}{l}\text { AÇO DE BAIXA LIGA E ALTA RESIST. } \\
\operatorname{MECÂNICA~}(*) \\
\end{array}$ & A 441 & 345 & 480 & 1.39 & $18^{(200)}$ \\
\hline \multirow{6}{*}{$\begin{array}{l}\text { AÇO ZINCADO DE QUALI- } \\
\text { DADE ESTRUTURAL }\end{array}$} & A $446 / \mathrm{A}$ & 225 & 310 & 1.38 & $20^{(50)}$ \\
\hline & B & 255 & 360 & 1.41 & $18^{(50)}$ \\
\hline & $\mathrm{C}$ & 275 & 380 & 1.38 & $16^{(50)}$ \\
\hline & $\mathrm{D}$ & 345 & 450 & 1.30 & $12^{(50)}$ \\
\hline & $\mathrm{E}$ & 550 & 565 & 1.03 & - \\
\hline & $\mathrm{F}$ & 345 & 480 & 1.39 & $12^{(50)}$ \\
\hline \multirow{3}{*}{ AÇO CARBONO } & A $500 / \mathrm{A}$ & 269 & 310 & 1.15 & \\
\hline & B & 317 & 400 & 1.26 & \\
\hline & $\mathrm{C}$ & 345 & 427 & 1.24 & \\
\hline AÇO CARBONO & A 529 & 290 & $\begin{array}{r}41^{@} \\
585 \\
\end{array}$ & $\begin{array}{r}1.4^{@} \\
2.02 \\
\end{array}$ & $19^{(200)}$ \\
\hline \multirow{5}{*}{ AÇO CARBONO } & A $570 / \mathrm{A}$ & 172 & 310 & 1.80 & $23^{(50)}$ \\
\hline & B & 207 & 338 & 1.63 & $21^{(50)}$ \\
\hline & C & 225 & 359 & 1.60 & $18^{(50)}$ \\
\hline & D & 275 & 379 & 1.38 & $15^{(50)}$ \\
\hline & $E$ & 290 & 400 & 1.38 & $13^{(50)}$ \\
\hline
\end{tabular}


TABELA 2.2 - Continuação.

\begin{tabular}{|c|c|c|c|c|c|}
\hline DESCRIÇÃO DO AÇO & $\begin{array}{c}\text { ESPECIFICAÇÃO } \\
\text { ASTM } \\
\end{array}$ & $\mathrm{f}_{\mathrm{v}}(\mathrm{MPa})$ & $\mathrm{f}_{11}(\mathrm{MPa})$ & $f_{u} / f_{v}$ & $A(\%)$ \\
\hline \multirow{6}{*}{$\begin{array}{l}\text { AÇO DE BAIXA LIGA E } \\
\text { ALTA RESIST. MECÂNICA }\end{array}$} & A $572 / 42$ & 290 & 415 & 1.43 & $24^{(50)}$ \\
\hline & 45 & 310 & 415 & 1.34 & $22^{(50)}$ \\
\hline & 50 & 345 & 448 & 1.30 & $21^{(50)}$ \\
\hline & 55 & 380 & 483 & 1.27 & $20(50)$ \\
\hline & 60 & 415 & 517 & 1.25 & $18^{(50)}$ \\
\hline & 65 & 448 & 552 & 1.23 & $17^{(50)}$ \\
\hline $\begin{array}{c}\text { AÇO DE BAIXA LIGA E } \\
\text { ALTA RESIST. MECÂNICA }\end{array}$ & A 588 & 345 & 483 & 1.40 & $21(50)$ \\
\hline $\begin{array}{l}\text { AÇO DE BAIXA LIGA E ALTA } \\
\text { RESIST MEC. COM RESIST. } \\
\text { À CORROSÃO MELHORADA }\end{array}$ & A 606 & 310 & 448 & 1.44 & $22(50)$ \\
\hline CHAPAS OU TIRAS DE AÇO & A $607 / 45$ & 310 & 414 & 1.33 & $25-22(50)$ \\
\hline DE BAIXA LIGA E ALTA & 50 & 345 & 448 & 1.30 & $22-20^{(50)}$ \\
\hline RESISTÊNCIA MECÂNICA. & 55 & 380 & 483 & 1.27 & $20-18^{(50)}$ \\
\hline (NIÓBIO E / OU VANÁDIO) & 60 & 414 & 517 & 1.25 & $18-16^{(50)}$ \\
\hline LAMINADAS A QUENTE OU & 65 & 448 & 552 & 1.23 & $16-15^{(50)}$ \\
\hline A FRIO. & 70 & 483 & 586 & 1.21 & $14^{(50)}$ \\
\hline \multirow{5}{*}{$\begin{array}{c}\text { AÇO CARBONO LAMINA- } \\
\text { DO A FRIO }\end{array}$} & $\mathrm{A} 611 / \mathrm{A}$ & 172 & 290 & 1.68 & $26^{(50)}$ \\
\hline & B & 207 & 310 & 1.50 & $24^{(50)}$ \\
\hline & C & 228 & 331 & 1.45 & $22^{(50)}$ \\
\hline & D & 276 & 359 & 1.30 & $20^{(50)}$ \\
\hline & E & 552 & 566 & 1.03 & - \\
\hline \multirow{2}{*}{$\begin{array}{l}\text { AÇO DE BAIXA LIGA E AL- } \\
\text { TA RESISTÊNCIA MECÂNICA }\end{array}$} & A $715 / 50$ & 345 & 414 & 1.20 & $24(50)$ \\
\hline & 60 & 414 & 483 & 1.17 & $22^{(50)}$ \\
\hline \multicolumn{6}{|l|}{$\begin{array}{l}\text { NOTAS: } \\
\left({ }^{*}\right) \text { FABRICAÇĀO SUSPENSA EM } 1989 \\
\text { A = ALONGAMENTO MÍNIMO EM P }\end{array}$} \\
\hline
\end{tabular}




\section{2 - LIMITE DE ESCOAMENTO, RESISTÊNCIA À TRAÇÃO E DIAGRAMA TENSÃO-DEFORMAÇÃO}

A resistência dos elementos estruturais depende do limite de escoamento e do limite de resistência à tração, exceto em conexões e nos casos onde a ruptura ocorrerá por flambagem local e global. Como indicado na tabela 2.2, os limites de escoamento dos aços listados pela AISI (1986) varia entre 172 a $483 \mathrm{MPa}$.

Como apresenta a figura 2.1, existem dois tipos gerais para o comportamento curvas tensão-deformação dos aços. A primeira é do tipo escoamento definido (figura 2.1a) e a segunda do tipo escoamento gradual (figura 2.1b). Aços produzidos por laminação a quente têm o comportamento tensão-deformação do tipo escoamento definido. Para estes tipos de aço, o ponto de escoamento é definido pelo valor correspondente ao patamar de escoamento na curva.

Aços trabalhados a frio apresentam escoamento do tipo gradual, onde o limite de escoamento é um valor convencional que pode se adotado por dois métodos: o método "offset" e o método de tensão correspondente a uma deformação arbitrada.

O método "offset" é muito usado para aços inoxidáveis e aços liga, onde o limite de escoamento é definido pela intersecção da curva tensão-deformação e da reta paralela à reta de Hooke (trecho elástico), definida a partir de uma deformação específica. Em geral, esta deformação é de 0,2\% (figura 2.2a).

$\mathrm{O}$ método da tensão correspondente a uma deformação arbitrada é muito usado para chapas e tiras de aço carbono de qualidade estrutural. $O$ valor convencional dado pela tensão correspondente a uma deformação específica é o limite de escoamento. $\mathrm{O}$ alongamento total especificado é usualmente $0,5 \%$ (figura 2.2b). Em muitos casos, os pontos de escoamento determinados por esses dois métodos são similares.

A resistência à tração de tiras ou chapas de aços usadas para seções conformadas a frio tem pouca influência no cálculo destes elementos. A resistência de um elemento comprimido ou fletido é, geralmente, limitada pelo escoamento ou pela estabilidade, principalmente nos elementos comprimidos com elevada relação largura-espessura (flambagem local) e nas barras com grande índice de esbeltez (flambagem global).

Como indicado na tabela 2.2, as resistências mínimas dos aços listados pela especificação do AISI (1986) apresentam uma relação entre o limite de resistência e o limite de escoamento do aço $\left(f_{\mathrm{u}} / \mathrm{f}_{\mathrm{y}}\right)$ de 1,17 a 2,22. Estudos anteriores citados em $\mathrm{YU}$ (1986) indicam que os efeitos do trabalho a frio na conformação de perfis dependem, 
em grande parte, da relação entre a resistência última e o limite de escoamento do aço virgem.

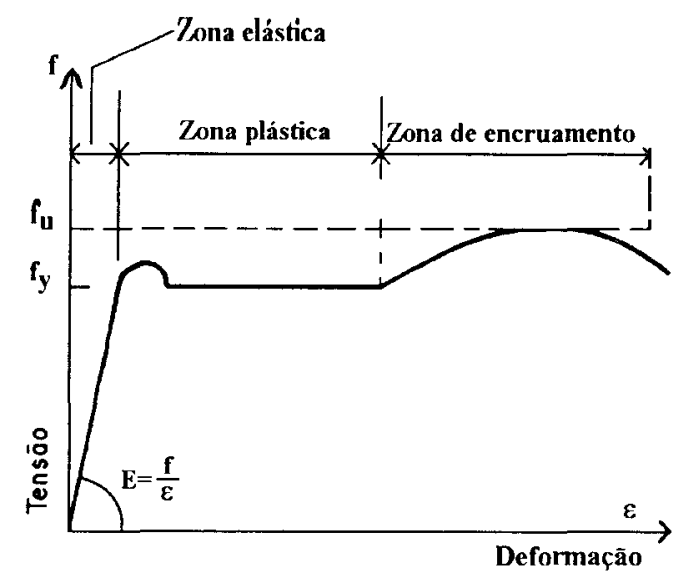

(a) escoamento definido, com patamar de escoamento (correspondem, basicamente, aos aços carbono estruturais, laminados a quente).

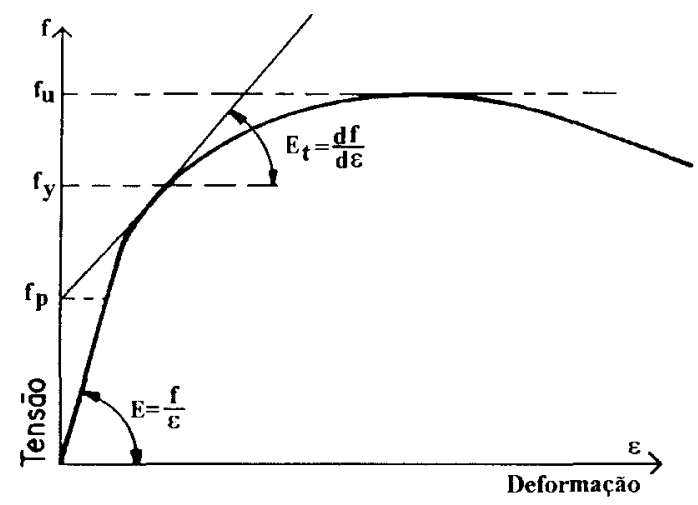

(b) escoamento gradual, sem patamar de escoamento (correspondem, basicamente, aos aços carbono estruturais trabalhados ou laminados a frio)

FIGURA 2.1 - Tipos de comportamento tensão-deformação de corpos de prova de aços ensaiados à tração. 


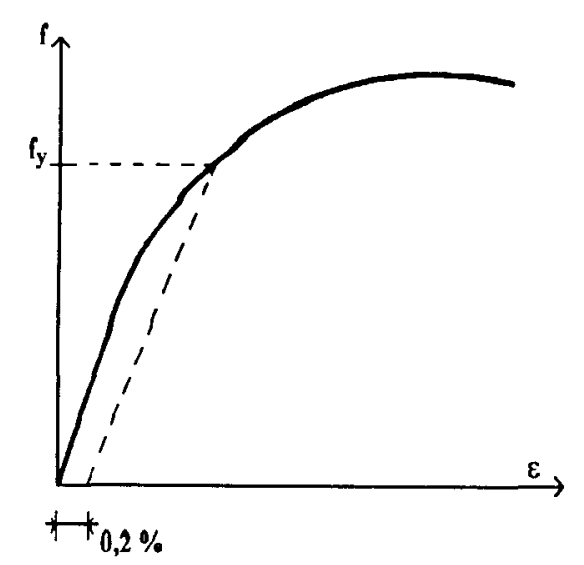

(a) método Offset

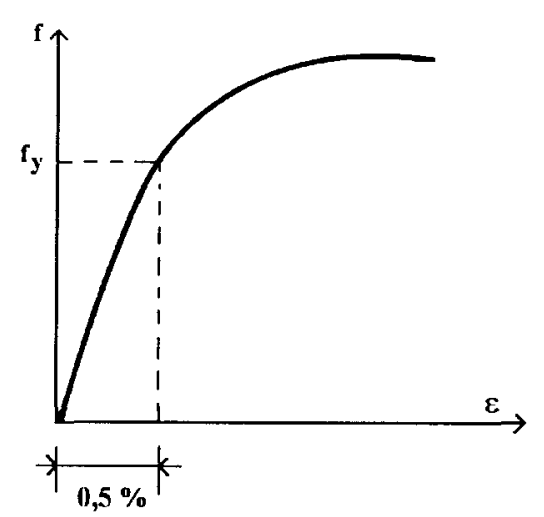

(b) método da deformação arbitrada

FIGURA 2.2 - Limite de escoamento convencional para aços com escoamento gradual.

\section{3 - MÓdULO DE ELASTICIDADE E MÓdULO DE ELASTICIDADE TANGENTE}

Além da tensão de escoamento $f_{y}$, a resistência dos elementos que rompem por flambagem também depende do módulo de elasticidade " $E$ " e do módulo tangente " $E_{t}$ ".

Defini-se como módulo de elasticidade "E" a relação tensão/deformação do trecho linear do diagrama tensão-deformação (reta de Hooke). Os valores de "E" 
geralmente variam de 200.000 a $207.000 \mathrm{MPa}$, sendo o valor recomendado pelas normas AISI (1980) e CSA (1984) para utilização em projetos de 203.000 MPa.

A inclinação da tangente à curva define o módulo tangente " $\mathrm{E}_{\mathrm{t}}$ " do material, sendo variável em função da tensão aplicada. Para os aços com curva tensãodeformação do tipo escoamento definido, o módulo tangente " $E_{\mathrm{t}}$ " é igual ao módulo de alasticidade "E" até o ponto de escoamento. Já para aços com curva tensãodeformação do tipo escoamento gradual, $E_{\mathrm{f}}=\mathrm{E}$ somente até 0 limite de proporcionalidade. Acima deste limite o módulo tangente diminui progressivamente.

Esta análise acima é válida para o estudo de corpos de prova isentos de tensões residuais.

\section{4 - DUCTIBILIDADE}

Define-se ductibilidade como "a capacidade do material em se deformar plasticamente antes da ruptura". Sua importância é fundamental para a conformação a frio e a utilização estrutural de aços, pois conduz a mecanismos de ruptura acompanhados de grandes deformações, possibilitando medidas preventivas antes do colapso da estrutura. Não sendo necessária somente para o processo de conformação a frio de elementos, mas também para a redistribuição plástica, principalmente nas ligações onde podem ocorrer concentrações de tensões.

Geralmente a ductibilidade é medida através do alongamento permanente nos ensaios de tração de materiais metálicos para as diversas categorias de aços. A tabela 2.2 ilustra que, para a faixa usual de espessuras das chapas de aço e tiras usadas em perfis de chapa dobrada, o alongamento mínimo em 2 polegadas $(50,8 \mathrm{~mm})$, varia de 12 a $26 \%$ e em 8 polegadas $(203 \mathrm{~mm})$, varia de 18 a $19 \%$.

\section{5 - SOLDABILIDADE}

Soldabilidade é a capacidade de um aço ser soldado satisfatoriamente, livre de incrustações, permitindo a execução de ligações sem dificuldade na penetração do metal base. Esta propriedade é função básica da composição química do material e varia com o tipo de aço e o processo de soldagem utilizado. 


\section{6 - INFLUÊNCIA DO TRABALHO A FRIO NAS PROPRIEDADES MECÂNICAS DO AÇO}

As propriedades mecânicas dos elementos de chapa dobrada são consideravelmente diferentes das propriedades dos aços planos ("virgens"). Isto ocorre devido à operação de conformação a frio, que aumenta a tensão de escoamento e a resistência à tração na região da dobra, porém diminui a ductibilidade. A porcentagem de aumento no limite de escoamento é maior que no limite de resistência, causando uma sensível redução na diferença entre estes valores.

O material dos cantos de uma seção trabalhada a frio sofre maior influência que o material das partes planas, pois as propriedades mecânicas são diferentes em várias partes da seção transversal. O escoamento, ou flambagem local, sempre se inicia na porção plana da seção devido ao menor limite de escoamento do aço nesta região, ocorrendo uma redistribuição de tensões das partes planas para os cantos da seção. A figura 2.3 apresenta a variação das propriedades mecânicas do aço em vários pontos de uma seção.
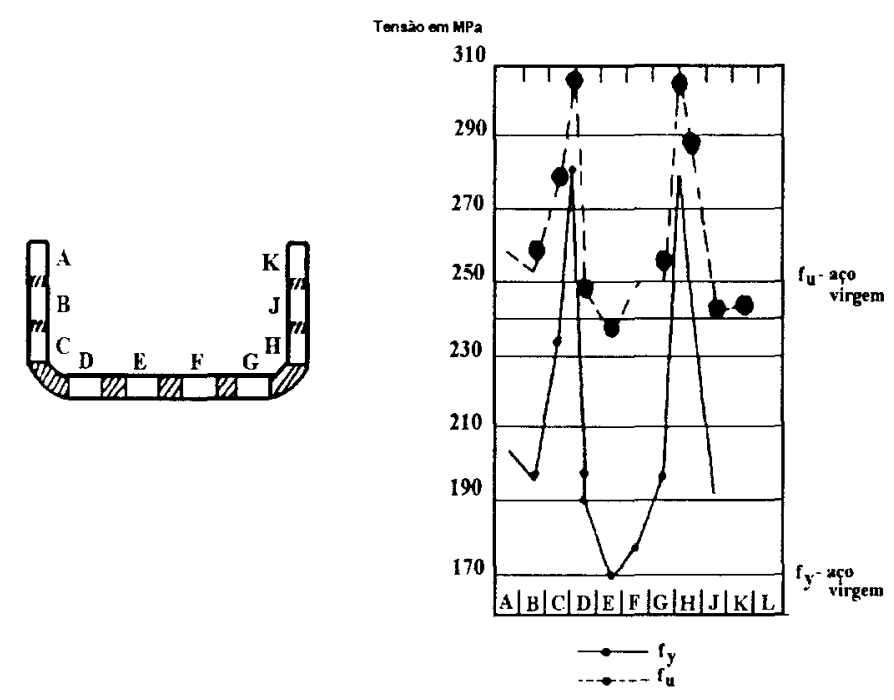

FIGURA 2.3 - Efeito do trabalho à frio nas propriedades mecânicas do aço (YU, 1985).

Basicamente, os efeitos do trabalho a frio nas propriedades mecânicas do aço dependem do tipo de aço, do tipo de solicitação ( tração ou compressão ), da direção da solicitação com relação à direção do trabalho a frio ( transversal ou longitudinal ), 
da proporção $f_{u} / f_{y}$, da relação raio de dobramento com espessura $(R / t)$ e da quantidade do trabalho a frio.

Resultados de pesquisas experimentais citados em YU (1985) indicaram que as mudanças das propriedades mecânicas devido ao dobramento a frio são, principalmente, causadas pelo encruamento, figura 2.4 .

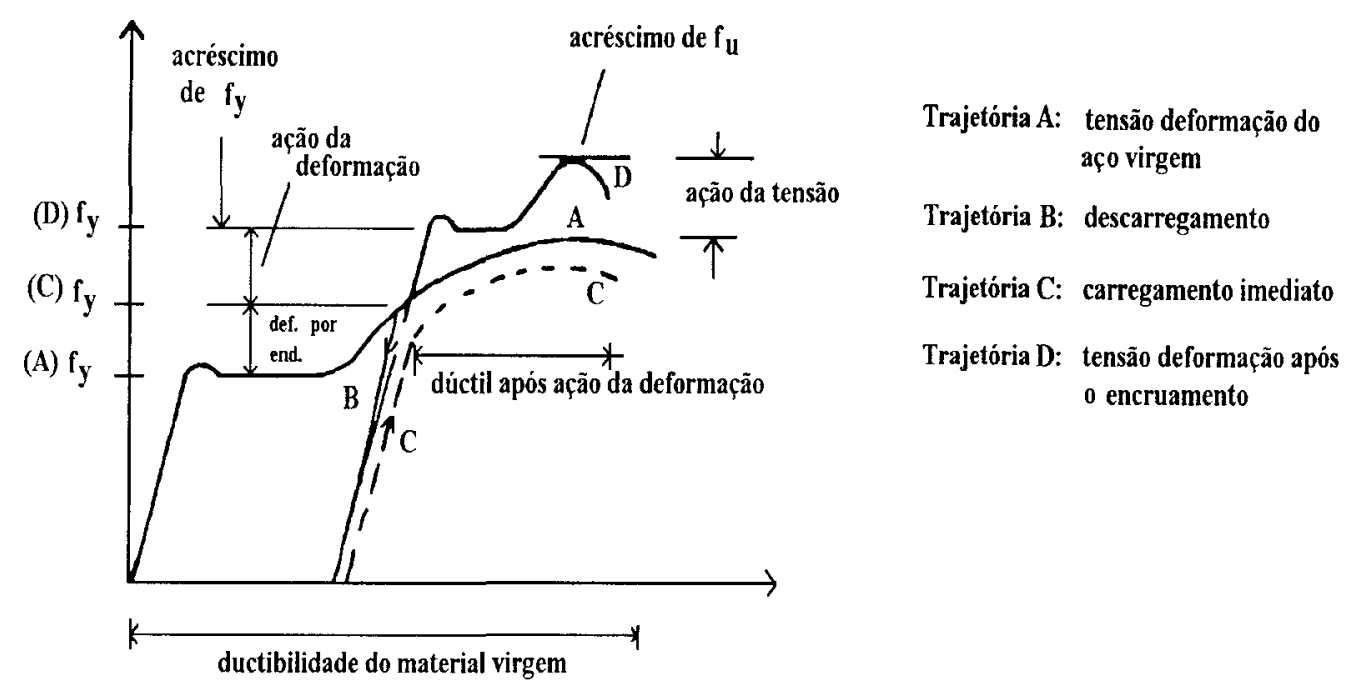

FIGURA 2.4 - Efeito do encruamento e ação da deformação nas características tensão-deformação do aço.

Pode-se notar no diagrama tensão-deformação, que o limite de escoamento das curvas " $\mathrm{C}$ " e "D" são maiores que a do material virgem curva "A", e que a ductibilidade decresce após o encruamento.

A mudança nas propriedades mecânicas produzida pela fabricação da seção a frio e a adição do efeito do encruamento são também causadores do efeito de Bauschinger, direto e inverso.

Neste caso o efeito de Bauschinger direto pode ser compreendido como "a resistência longitudinal à compressão do aço estirado é menor que a resistência longitudinal à tração." Por outro lado, o efeito Bauschinger inverso produz a situação contrária na direção transversal ao estiramento, ou seja, a resistência transversal à compressão é maior que a resistência à tração. 


\section{7 - TENSÕES RESIDUAIS}

A presença de tensões residuais e a distribuição não homogênea das características mecânicas das seções transversais originam um comportamento diferenciado entre as várias partes de um perfil de aço.

As tensões residuais são as tensões que surgem nos elementos metálicos devido ao processo de fabricação, transporte, montagem, sobrecargas ocasionais e cargas pelos serviços de reparação e modificação da estrutura.

Pelo processo de fabricação, as tensões residuais são resultantes dos efeitos térmicos e mecânicos ocorridos durante o processo de laminação dos aços.

Os efeitos térmicos podem ser entendidos como o tratamento sob calor, resfriamento após fundição, soldagem, o corte por maçarico e o resfriamento após laminação a quente. Já os efeitos mecânicos como sendo a laminação a frio, desempenamento de chapas, usinagem, conformação a frio e o corte com serra, guilhotina ou fresa.

Geralmente, as tensões residuais nos perfis de chapa dobrada ocorrem pelo efeito da conformação a frio durante o processo de fabricação. Isto ocorre pelo fato das chapas de aço possuírem um estado de tensão, sendo estas submetidas a uma superposição de tensões por ações externas.

O valor e a distribuição das tensões residuais dependem do tipo de seção transversal, da temperatura de laminação ou soldagem, das condições de resfriamento e do método de retificação das peças.

WENG \& PEKOZ (1990), a partir de resultados experimentais para perfis de chapa dobrada de seção "U", concluíram que o valor e a distribuição das tensões residuais podem ser simplificados e idealizadas como:

- há tensões residuais de tração na superfície externa da seção e tensões residuais de compressão na superfície interna;

- as tensões residuais são supostas como linearmente variáveis através da espessura da chapa;

- o aumento das tensões residuais nas regiões dos cantos pode ser desprezado devido à tensão de escoamento nesta região ser maior;

- os valores das tensões residuais das seções transversais são compreendidos entre $25 \%$ a $75 \%$ do limite de escoamento do material virgem;

- o mesmo padrão da distribuição das tensões residuais pode ser assumido para todas as seções transversais. 
Através do método de seccionamento em tiras, a figura 2.5 apresenta as medições de tensões residuais para um perfil "U".

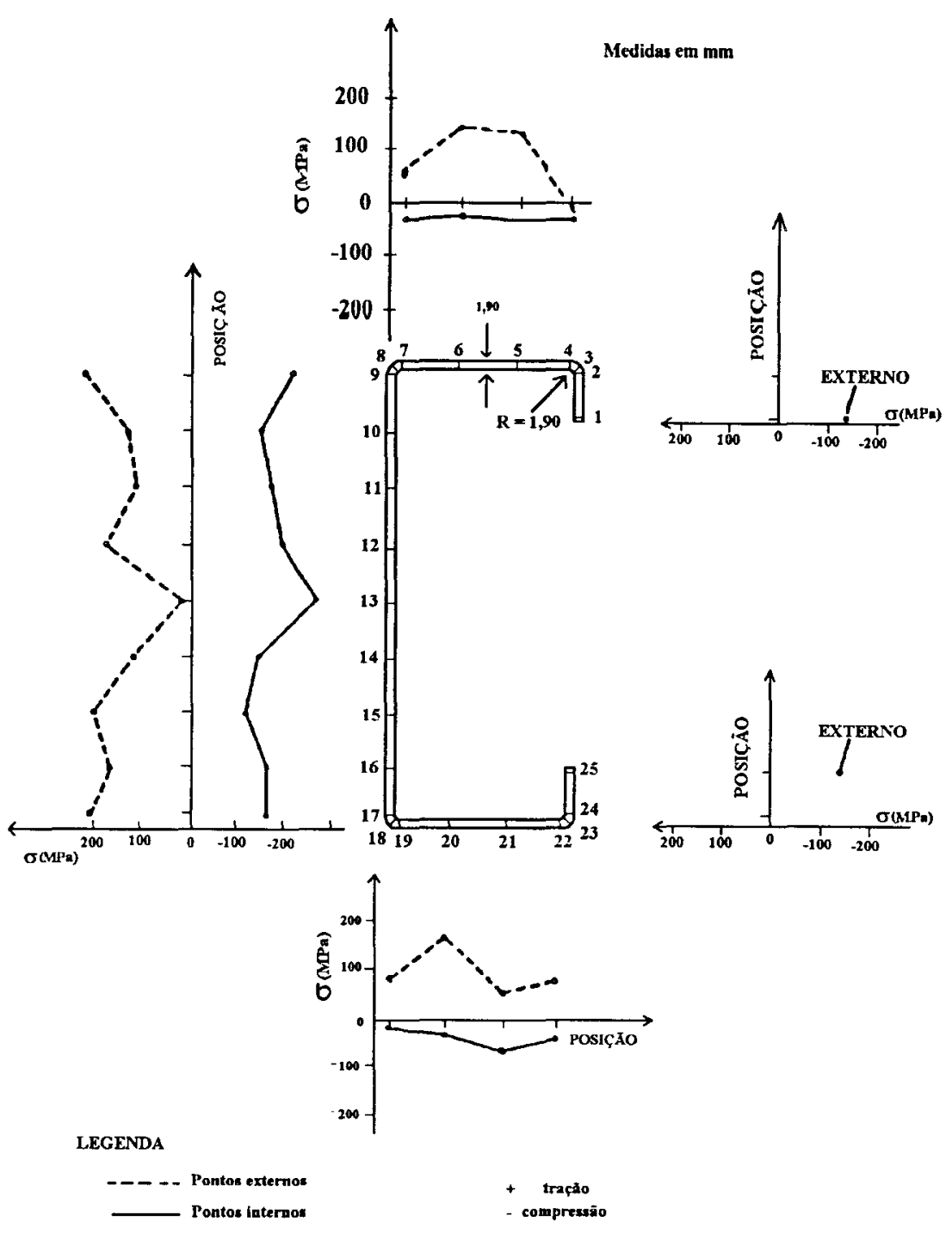

FIGURA 2.5 - Tensões residuais em um perfil U $(150 \times 60 \times 20 \times 1,90)$ (RODRIGUES \& BATISTA apud JAVARONI, 1993, p21) ${ }^{1}$

${ }^{1}$ RODRIGUES, F.C.; BATISTA, E.M. Tensões residuais e imperfeições em perfis industriais conformados a frio por dobramento de chapa fina da aço. Rio de Janeiro: COPPE - URFJ, s. d. 18p apud JAVARONI, C. E. (1993). "Perfis de aço conformados a frio por dobramento de chapas finas, fundamentos teóricos para o dimensionamento de barras"; dissertação (Mestrado) EESC-USP. 


\section{8 - TIPOS DE PERFIS}

Existe uma variedade de seções que podem ser obtidas pela composição de perfis ou por dobramento para aplicações específicas. As peças estruturais de perfis de chapa dobrada podem ser utilizadas como elementos individuais, elementos múltiplos, painéis para coberturas, fechamentos e pisos, conforme a descrição das seguintes figuras:

a) Elementos individuais e múltiplos

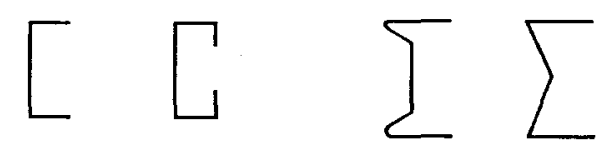

Figura 2.6 - Perfil canal tipo "U"

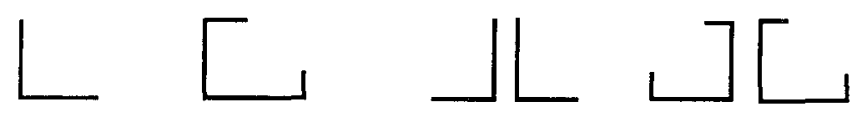

Figura 2.7 - Cantoneiras

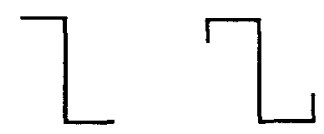

Figura 2.8 - Perfil "Z"

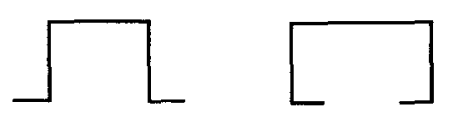

Figura 2.9 - Perfil cartola

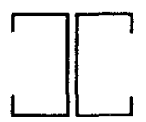

Figura 2.10 - Duplo U 


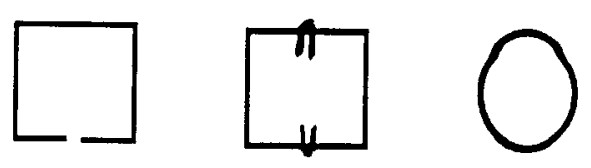

Figura 2.11 - Tubular

b) Painéis para coberturas, fechamentos e pisos

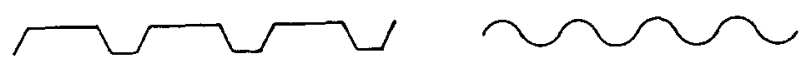

figura 2.12 - Coberturas (Telhados)
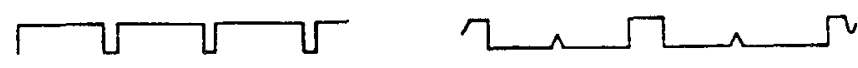

figura 2.13 - Fechamento ou tapamento (Paredes)
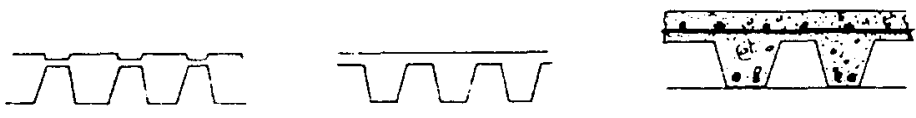

figura 2.14 - Pisos (Decks)

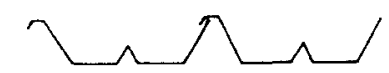

Figura 2.15 - Telhas portantes (coberturas)

\section{9 - PROPRIEDADES GEOMÉTRICAS}

Como geralmente as espessuras (t) dos elementos que compõem os perfis de chapa dobrada são constantes, as propriedades geométricas das linhas e curvas destes perfis podem ser simplificadas pelo uso do método linear. Neste método, o material da seção transversal é admitido como sendo concentrado ao longo da linha média da seção e os elementos planos e os cantos são tratados como linha. 
Após o cálculo linear ter sido completado, é introduzido a espessura (t). Deste modo, a área total será $\mathrm{A}=\mathrm{L} \times \mathrm{t}$, e o momento de inércia $\mathrm{I}=\mathrm{I}^{\prime} \mathrm{x} \mathrm{t}$, sendo "L" 0 comprimento total dos elementos planos e em curva e I' é o momento de inércia tratado como uma linha.

São apresentadas a seguir, figura 2.16, as propriedades de elementos de linha para algumas seções transversais típicas:
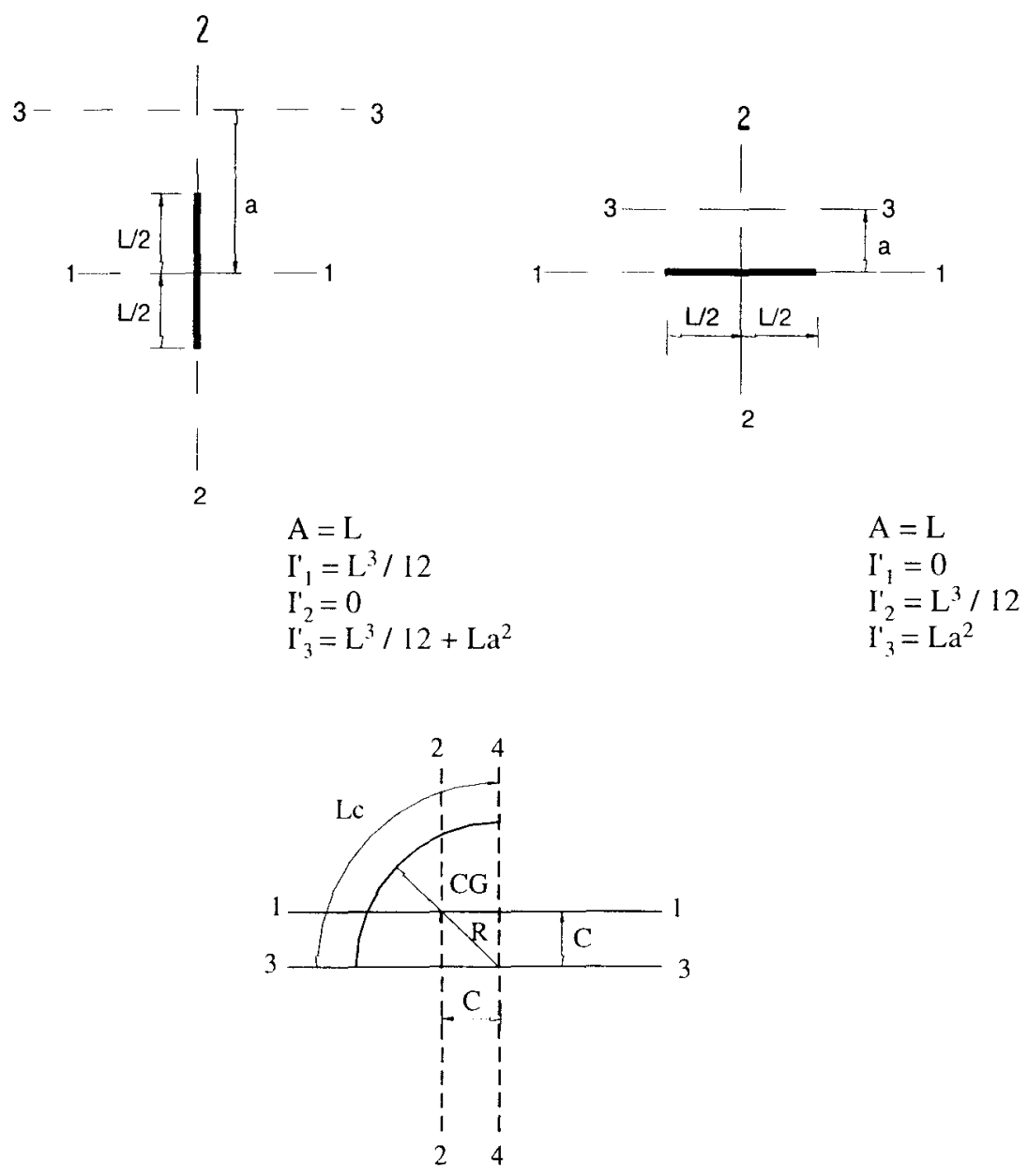

$$
\begin{aligned}
& \mathrm{L}_{\mathrm{C}}=1,5 \mathrm{R} \\
& \mathrm{A}=\mathrm{L} \\
& \mathrm{C}=0,637 \mathrm{R} \\
& \mathrm{I}_{1}=\mathrm{I}_{2}=0,149 \mathrm{R}^{3} \\
& \mathrm{I}_{12}=-0,137 \mathrm{R}^{3} \\
& \mathrm{I}^{\prime}=\mathrm{I}_{4}=0,785 \mathrm{R}^{3} \\
& \mathrm{I}_{34}=0,5 \mathrm{R}^{3}
\end{aligned}
$$

Figura 2.16 - Propriedades geométricas de elementos lineares. 


\section{CAPÍTULO 3}

\section{FUNDAMENTOS TEÓRICOS PARA ELEMENTOS ESBELTOS COMPRIMIDOS}

\section{1 - GENERALIDADES}

Em geral, os elementos de chapa dobrada são de espessura pequena com relação largura/espessura elevada. Portanto, torna-se indispensável a verificação e o controle da flambagem local dos elementos, pois quando submetidos à compressão axial, compressão na flexão, cisalhamento, etc, tendem a flambar localmente com tensões bem menores que as de escoamento. A figura 3.1 apresenta a flambagem local de alguns perfis fletidos e comprimidos.
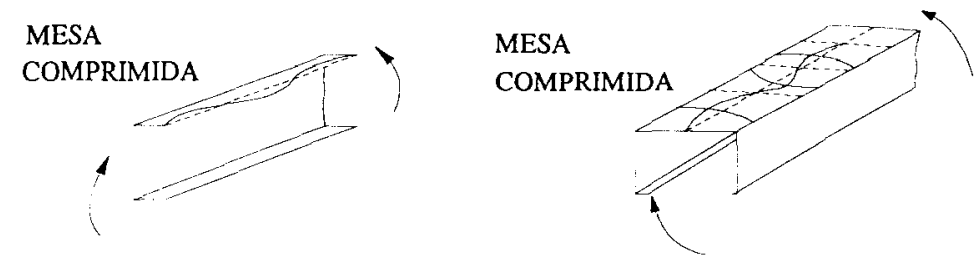

(a)

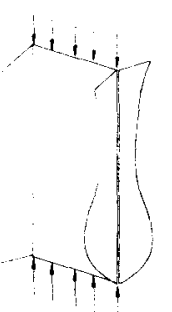

A

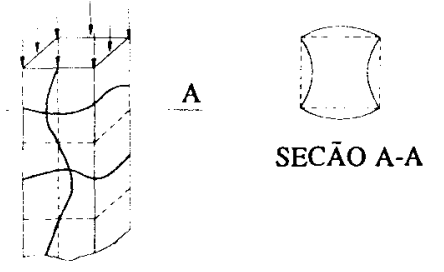

(b)

FIGURA 3.1 - Flambagem local de elementos comprimidos
(a) vigas
(b) colunas 
Nas estruturas de chapa dobrada, os elementos planos da seção transversal do perfil podem flambar localmente (flambagem de chapa) sob uma tensão menor que a tensão que provoca o escoamento inicial da sua seção transversal ou mesmo daquela que provoca a flambagem global do perfil. Entretanto, a resistência destes elementos é tal que são capazes de apresentar uma "redistribuição de tensões" uma vez atingida a tensão crítica de flambagem. Este fenômeno é conhecido como "resistência pósflambagem" dos elementos. No dimensionamento dos elementos de aço, esta resistência pós-flambagem é considerada por torná-los mais econômicos.

\section{2 - DEFINIÇÕES}

Elemento comprimido enrijecido $\rightarrow$ trata-se de um elemento plano uniformemente comprimido com duas bordas paralelas à direção da tensão normal de compressão, apoiadas lateralmente por enrijecedores adequados, figura 3.2.

Elemento comprimido não enrijecido $\rightarrow$ trata-se de um elemento plano comprimido que apresenta uma borda livre, paralela à direção da tensão normal de compressão, figura 3.3 .

Elementos com enrijecedores múltiplos à compressãa $\rightarrow$ trata-se de um elemento adequadamente enrijecido nas duas bordas paralelas à direção da tensão e também por meio de enrijecedor intermediário, figura 3.4.

Largura plana (b) $\rightarrow$ trata-se da largura da parte plana de um elemento entre enrijecedores, viradas de borda ou outros elementos, não incluindo a parte curva.

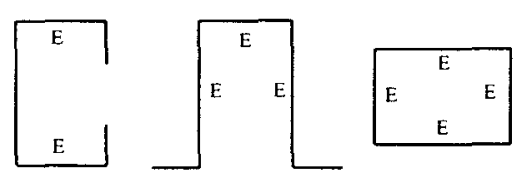

FIGURA 3.2 - Seções transversais com elementos comprimidos enrijecidos. 


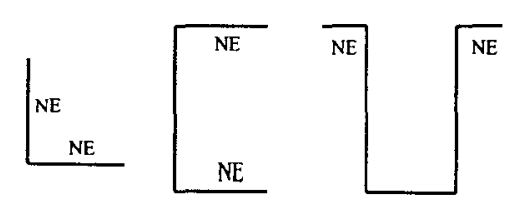

FIGURA 3.3 - Seções transversais com elementos comprimidos não enrijecidos.
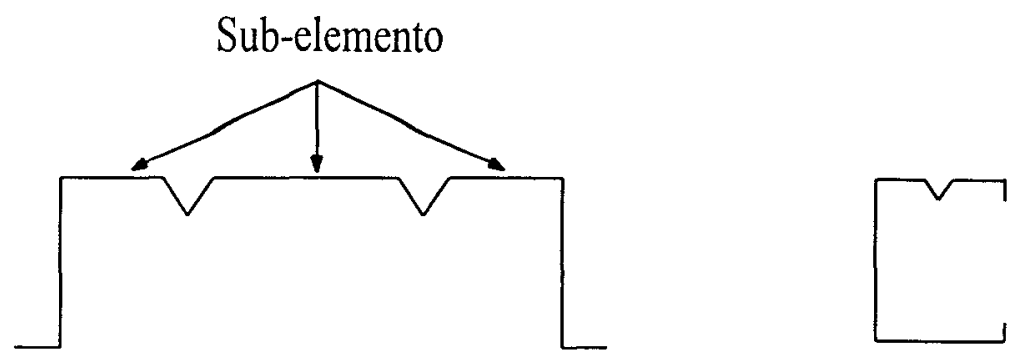

FIGURA 3.4 - Seções transversais com enrijecimento múltiplo à compressão.

\section{3 - TENSÃo BÁSICA DE PROJETO (f)}

Pode-se definir a tensão básica de projeto para as ações devidas às cargas permanentes e às cargas acidentais.

Para o caso de tração, compressão (sem flambagem) e flexão, utiliza-se um coeficiente de segurança igual a $5 / 3(1,67)$ :

$$
f=0,6 f_{y}
$$

Esta tensão é aplicada quando a ruptura ocorre por escoamento. No caso de flambagem, para os elementos enrijecidos emprega-se uma largura efetiva, com uma redução da seção e, para os elementos não enrijecidos, adota-se uma tensão admissível à flambagem, sendo esta menor ou igual à tensão básica de projeto "f".

Para o caso de cisalhamento, a tensão básica de projeto é dada pelo critério de resistência de von Mises com um coeficiente de segurança igual a 1,44.

$$
f_{r}=\frac{f_{y}}{\sqrt{3}} \frac{1}{1,44}=0,4 f_{y}
$$


Estas condições e conceitos de segurança são as adotadas quando utiliza-se o método das tensões admissiveis, em particular estes são os valores recomendados pela AISI (1986).

\section{4 - ELEMENTOS COMPRIMIDOS ENRIJECIDOS}

\subsection{1 - GENERALIDADES}

Um elemento enrijecido de uma seção transversal qualquer, quando sujeito à tensão de compressão, pode flambar tal como uma chapa, sem que ocorra a flambagem global da barra. $O$ elemento atinge o colapso por escoamento se a relação (b/t) for relativamente pequena.

\subsection{2 - TENSÃO CRÍTICA DE FLAMBAGEM DE CHAPA EM REGIME ELÁSTICO}

Analisando-se uma chapa quadrada, simplesmente apoiada nas quatro bordas e uniformemente comprimida na direção $\mathrm{x}$, a flambagem da chapa ocorrerá com uma curvatura simples nas duas direções, figura 3.5. Entretanto, para uma chapa retangular, com o comprimento (a) bem maior que a largura (b), sujeita à tensão uniforme de compressão na direção x e simplesmente apoiada em todas suas bordas, a configuração deformada da chapa na flambagem apresenta uma série de ondas, com a largura (h) aproximadamente igual a largura (b) da mesma figura 3.6.

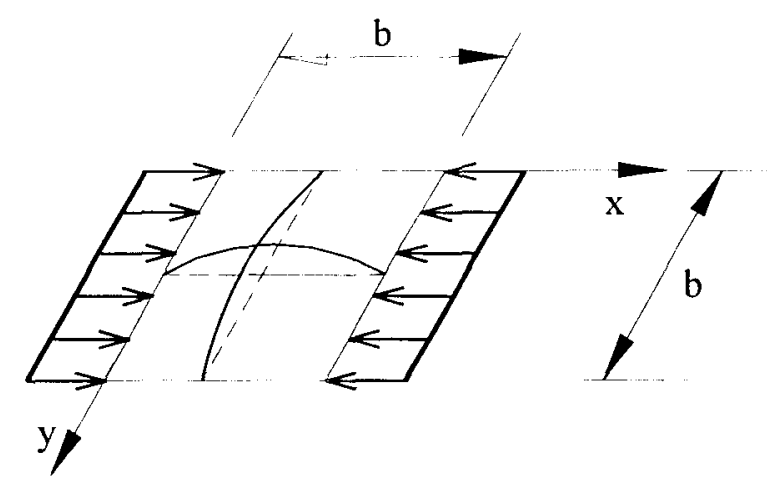

FIGURA 3.5 - Chapa quadrada apoiada nas quatro bordas sujeita a tensão de compressão uniforme. 


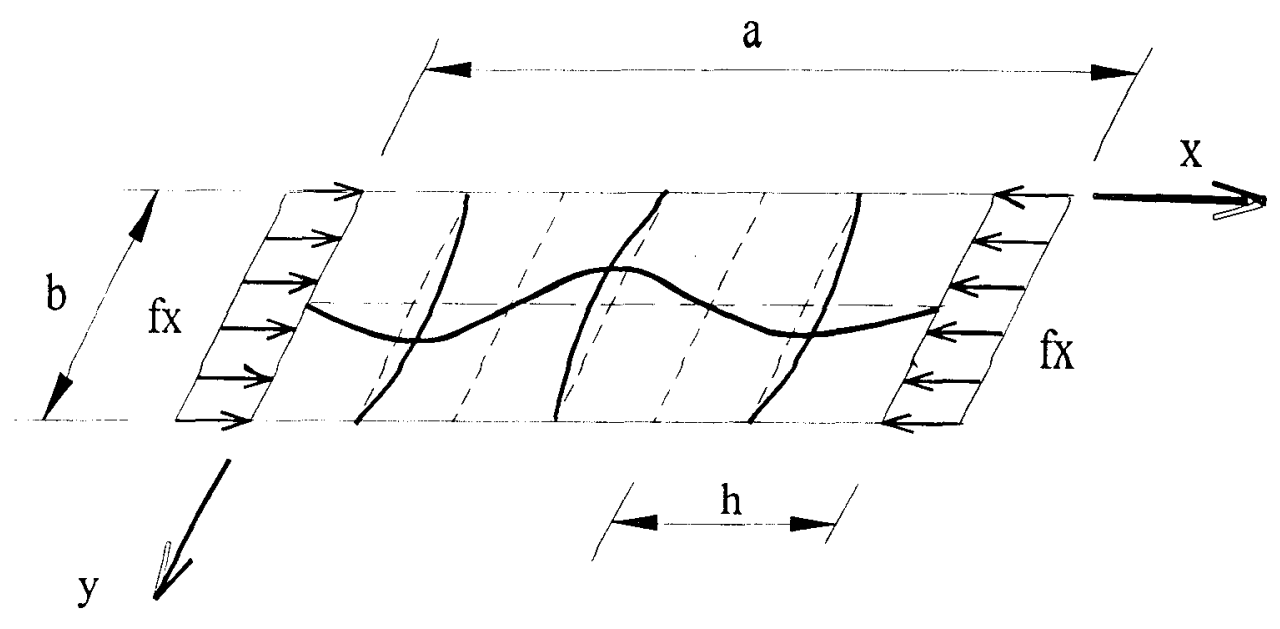

FIGURA 3.6 - Chapa retangular sujeita a tensão de compressão uniforme.

Pode-se determinar a tensão crítica de flambagem elástica a partir da equação diferencial baseada na hipótese de pequenos deslocamentos, dado por:

$$
\frac{\partial^{4} \omega}{\partial x^{4}}+2 \frac{\partial^{4} \omega}{\partial x^{2} \partial y^{2}}+\frac{\partial^{4} \omega}{\partial y^{4}}+\frac{f_{x} t}{D} \frac{\partial^{2} \omega}{\partial x^{2}}=0
$$

onde:

$\mathrm{D}=\frac{\mathrm{Et}^{3}}{12\left(1-\mathrm{v}^{2}\right)}=$ rigidez à flexão da chapa

$v=$ coeficiente de Poisson (adotado 0,3 para aço em regime elástico)

$\omega=$ deslocamento da chapa perpendicular à superfície

$\mathrm{f}_{\mathrm{X}}=$ tensão de compressão na direção

$\mathrm{t}=$ espessura da chapa

Se $\mathrm{m}$ e $\mathrm{n}$ são os números de meia onda senoidal nas direções $\mathrm{x}$ e $\mathrm{y}$, respectivamente, o deslocamento $(\omega)$ de uma chapa retangular com as bordas simplesmente apoiadas, pode ser representado por uma série dupla:

$$
\omega=\sum_{m=1}^{\infty} \sum_{n=1}^{\infty} A_{m n} \operatorname{sen} \frac{m \pi x}{a} \operatorname{sen} \frac{n \pi y}{b}
$$

A equação anterior satisfaz as condições de contorno para uma chapa simplesmente apoiada em todas as bordas.

A tensão crítica de flambagem elástica para uma chapa pode ser determinada resolvendo-se a equação (3.3) empregando o deslocamento da equação (3.4), sendo: 


$$
f_{c r}=\frac{D \pi^{2}}{t b^{2}}\left[m\left(\frac{b}{a}\right)+\frac{n^{2}}{m}\left(\frac{a}{b}\right)\right]^{2}
$$

Através da equação (3.5), considerando-se $\mathrm{n}=1$, uma meia onda senoidal na direção y, obtém-se o menor valor para a tensão crítica, por:

$$
f_{c r}=\frac{k D \pi^{2}}{t b^{2}}
$$

onde:

$$
k=\left[m\left(\frac{b}{a}\right)+\frac{1}{m}\left(\frac{a}{b}\right)\right]^{2}
$$

Obtém-se a equação geral para a tensão crítica de flambagem elástica, para uma chapa retangular comprimida em uma direção, substituindo-se o valor de $\mathrm{D}$ na equação (3.6):

$$
f_{c r}=\frac{k \pi^{2} E}{12\left(1-v^{2}\right)(b / t)^{2}}
$$

O valor do coeficiente de flambagem de chapa $\mathrm{k}$, usado na equação (3.8), encontra-se na figura 3.7 para diferentes relações $a / b$, das condições de contorno e distribuição de tensões na chapa. Nota-se que o valor $\mathrm{k}$ é igual a 4 para valores inteiros da relação $a / b$. Também é válido este valor de $k=4$, para valores relativamente grandes da relação a/b.

A figura 3.7 apresenta, de uma forma gráfica, o valor de $\mathrm{k}$ em função da relação a/b. Quando a relação a/b for maior que 4 , o valor mínimo de $k$ é igual a $4 \mathrm{e}$ pode ser usado para a determinação da tensão crítica de flambagem elástica para uma chapa retangular simplesmente apoiada ao longo das suas quatro bordas e sujeita a tensão de compressão uniforme em uma direção, sendo:

$$
f_{c r}=\frac{\pi^{2} E}{3\left(1-v^{2}\right)(b / t)^{2}}
$$

A tabela 3.1 apresenta os valores de $\mathrm{k}$ para uma chapa retangular longa $(\mathrm{a} / \mathrm{b} \geq 4)$, sujeita a diferentes distribuições de tensões e com diferentes condições de contorno. 


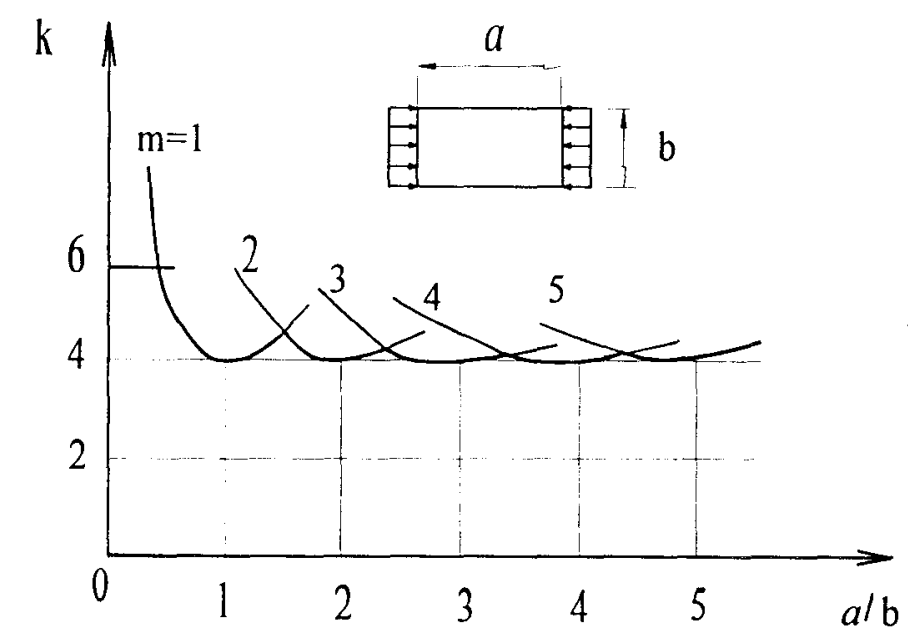

FIGURA 3.7 - Coeficiente de flambagem elástica para chapas retangulares uniformemente comprimidas (YU, 1985).

\subsection{3 - TENSÃO CRÍTICA DE FLAMBAGEM DE CHAPA EM REGIME INELÁSTICO}

Quando a tensão de compressão na chapa ultrapassa a tensão limite de proporcionalidade do aço, a chapa comporta-se como uma chapa anisotrópica, ou seja, apresenta propriedades diferentes em todas as direções.

BLEICH (1924), propôs a seguinte equação diferencial para flambagem de chapa no regime inelástico:

$$
\tau \frac{\partial^{4} \omega}{\partial x^{4}}+2 \sqrt{\tau} \frac{\partial^{4} \omega}{\partial x^{2} \partial y^{2}}+\frac{\partial^{4} \omega}{\partial y^{+}}+\frac{f_{x} t}{D} \frac{\partial^{2} \omega}{\partial x^{2}}=0
$$

onde:

$$
\begin{aligned}
& \tau=E_{\mathrm{t}} / \mathrm{E} \\
& \mathrm{E}_{\mathrm{t}}=\text { módulo de elasticidade tangente do aço. }
\end{aligned}
$$

Portanto, a expressão para o cálculo da tensão crítica de flambagem de chapa no regime inelástico pode ser representada por:

$$
f_{c r}=\frac{k \pi^{2} E \sqrt{\tau}}{I 2\left(I-v^{2}\right)(b / t)^{2}}
$$


O termo " $\sqrt{\tau}$ " é o fator de redução plástica de uma chapa sujeita a tensão de compressão uniforme em uma direção, sendo este fator variável com o tipo de solicitação e as condições de contorno da chapa.

TABELA 3.1 - Valores de K para determinação da tensão crítica de flambagem elástica (YU, 1985).

\begin{tabular}{|c|c|c|c|}
\hline Caso & Vínculação das bordas & Solicitação & Valor de $\mathrm{k}$ \\
\hline 1 & $\begin{array}{r}\mathrm{A} \\
\mathrm{A} \\
\end{array}$ & compressão & 4,0 \\
\hline 2 & \begin{tabular}{|ll} 
& $E$ \\
7 & $E$ \\
\end{tabular} & compressão & 6,97 \\
\hline 3 & $\begin{array}{c}\mathrm{A} \\
\mathrm{L} \\
\end{array}$ & compressão & 0,425 \\
\hline 4 & $\begin{array}{l}E \\
L \\
\end{array}$ & compressão & 1,277 \\
\hline 5 & $\begin{array}{r}\mathrm{E} \\
\mathrm{A} \\
\end{array}$ & compressão & 5,42 \\
\hline 6 & $\begin{array}{l}\mathrm{A} \\
\mathrm{A} \\
\end{array}$ & cisalhamento & 5,34 \\
\hline 7 & $\begin{array}{r}\mathrm{E} \\
\mathrm{E} \\
\end{array}$ & cisalhamento & 8,98 \\
\hline 8 & $\begin{array}{l}\mathrm{A} \\
\mathrm{A}\end{array}$ & flexão & 23,9 \\
\hline 9 & $\notin$ & flexão & 41,8 \\
\hline E : engaste & A : apoio simples & ivre & \\
\hline
\end{tabular}




\subsection{4 - RESISTÊNCIA PÓS-FLAMBAGEM E LARGURA EFETIVA}

O comportamento de uma chapa é diferente do comportamento de um elemento considerado unidimensional como uma barra, quando esta atinge a tensão de flambagem. Devido às suas características consideradas bidimensionais, após atingir a tensão de flambagem, a chapa suporta um acréscimo de tensão ocorrendo uma redistribuição de tensões para as partes enrijecidas, ao contrário da barra que, ao atingir a tensão crítica de flambagem, praticamente não há condições de suportar acréscimos de tensões. Este fenômeno da chapa é denominado de "comportamento pós-flambagem" e é muito pronunciado para chapas com relação largura espessura elevadas.

O mecanismo pós-flambagem pode ser ilustrado por meio do modelo de grelha na figura 3.8. As "colunas longitudinais" tendem a flambarem mas são impedidas pelas "vigas transversais".

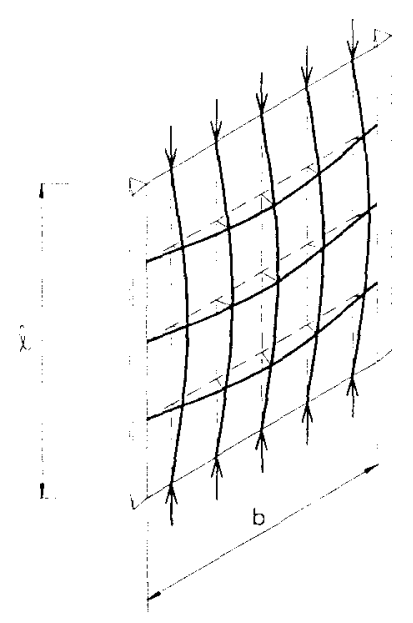

FIGURA 3.8 - Modelo de grelha para a resistência pós-flambagem de chapas (YU, 1985).

Na chapa, a distribuição de tensão na seção transversal é uniforme até a iminência da flambagem, figura 3.9a. Após flambar, uma pequena parte da tensão do centro da chapa é transferida para as bordas. Com isto obtém-se uma distribuição não uniforme de tensões, figura 3.9b. A redistribuição de tensões continua ocorrendo até que a tensão na borda atinge a tensão limite de escoamento, figura 3.9c, verificase portanto o colapso da chapa. 
$\mathrm{fl}<\mathrm{fcr}$
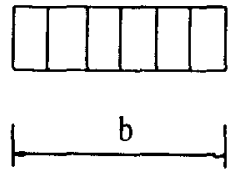

(a)
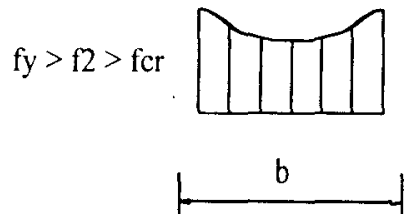

(b)

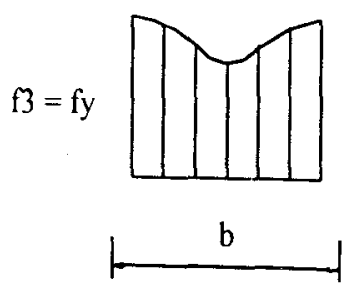

(c)

FIGURA 3.9 - Distribuições da tensão para um elemento comprimido enrijecido.

O comportamento pós-flambagem de uma chapa isolada pode ser analisado através da teoria dos grandes deslocamentos. YU (1985) apresenta a equação diferencial para o estudo do comportamento para grandes deslocamentos que foi introduzida por von Karman em 1910, sendo:

$$
\frac{\partial^{+} \omega}{\partial x^{+}}+2 \frac{\partial^{+} \omega}{\partial x^{2} \partial y^{2}}+\frac{\partial^{+} \omega}{\partial y^{+}}=\frac{t}{D}\left(\frac{\partial^{2} F}{\partial y^{2}} \frac{\partial^{2} \omega}{\partial x^{2}}-2 \frac{\partial^{2} F}{\partial x \partial y} \frac{\partial^{2} \omega}{\partial x \partial y}+\frac{\partial^{2} F}{\partial x^{2}} \frac{\partial^{2} \omega}{\partial y^{2}}\right)
$$

onde F é uma função de tensão definida como a tensão para fibra média da chapa, e:

$$
f_{x}=\frac{\partial^{2} F}{\partial y^{2}} \quad f_{y}=\frac{\partial^{2} F}{\partial x^{2}} \quad \tau_{x y}=-\frac{\partial^{2} F}{\partial x \partial y}
$$

Devido sua complexidade para fins práticos, esta teoria para grandes deslocamentos é pouco aplicada. Visando simplificar o tratamento das chapas esbeltas em regime pós-flambagem, von Karman et al (1932)1 apud YU (1985), propôs o método da largura efetiva.

Neste método, ao invés de se considerar a distribuição não uniforme de tensões sobre toda a largura " $b$ " da chapa, considera-se que a força total é suportada por uma largura efetiva fictícia "bef", que fica sujeita esteja sujeita a uma distribuição uniforme de tensões " $f_{\text {máx }}$ ", conforme figura 3.10. A largura efetiva pode ser obtida de modo que a área sob a curva da distribuição não uniforme de tensões seja igual a soma de duas partes da área retangular equivalente de largura total e com uma intensidade de tensão igual a " $f_{\operatorname{máx}}$ ", como:

\footnotetext{
${ }^{1}$ Von Karman, T., E. E. Sechler, and L. H. Donnel (1932). "The Strength of Thin Plates in Compression," Transactions ASME, vol.54, APM 54-5 apud YU, W. W. (1985). "Cold-Formed Steel Design," New York, John Wiley \& Sons.
} 


$$
\int_{0}^{b} f d x=b_{e f} f_{m a ́ x}
$$

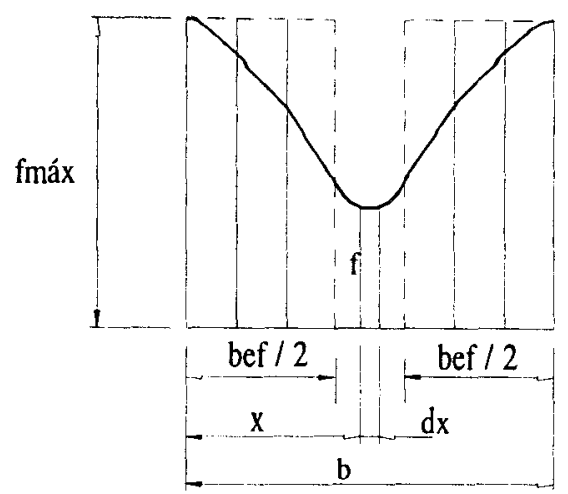

FIGURA 3.10 - Largura efetiva de um elemento enrijecido à compressão (YU, 1985).

A largura efetiva também pode ser considerada como uma largura particular da chapa em que a flambagem ocorre quando a tensão de compressão atinge a tensão de escoamento do aço. O valor teórico de "bef", para uma chapa longa apoiada nas quatro bordas e sujeita a tensão uniforme de compressão, pode ser determinado pela equação (3.14) assumindo "bef" com a tensão "f" e $f_{c r}=f_{y}$.

$$
f_{c r}=f_{y}=\frac{\pi^{2} E}{3\left(1-v^{2}\right)\left(b_{e f} / t\right)^{2}}
$$

ou, isolando bef:

$$
b_{e f}=c t \sqrt{\frac{E}{f_{y}}}=1,9 t \sqrt{\frac{E}{f_{y}}}
$$

onde:

$$
\begin{array}{ll}
v & =0,3 \\
c & =\frac{\pi}{\sqrt{3\left(1-v^{2}\right)}}=1,9
\end{array}
$$

WINTER (1959), com base em intensas pesquisas, mostrou que a equação (3.15) aplica-se também para elementos em que a tensão máxima " $f_{\text {máx" é inferior à }}$ tensão limite de escoamento do aço. Desta forma, a equação (3.15) pode ser reescrita como: 


$$
b_{e f}=c t \sqrt{\frac{E}{f_{\text {max }}}}
$$

onde $\mathrm{f}_{\text {máx }}$ é a máxima tensão atuante na borda da chapa, que pode ser menor que o limite de escoamento do aço $\mathrm{f}_{\mathrm{y}}$.

Com bases em resultados experimentais adicionais, WINTER ${ }^{2}$ apud YU (1985) desenvolveu a equação (3.17) para o cálculo do termo "c" da equação (3.16) que depende, principalmente, do parâmetro adimensional $\sqrt{E / f_{\text {máx }}}(t / b)$, sendo:

$$
c=1,9\left(1-0,475\left(\frac{t}{b}\right) \sqrt{\frac{E}{f_{\text {mix }}}}\right)
$$

No entanto, WINTER (1946) ${ }^{3}$ apud YU (1985) apresentou a expressão modificada para o cálculo da largura efetiva "bef" de uma chapa longa apoiada nas quatro bordas sujeita à compressão uniforme:

$$
b_{e f}=1,9 t \sqrt{\frac{E}{f_{\text {mix }}}}\left[1-0,475\left(\frac{t}{b}\right) \sqrt{\frac{E}{f_{\text {max }}}}\right]
$$

Segundo YU (1985), após várias pesquisas realizadas com perfis leves dobrados a frio, o AISI chegou a uma equação mais realista que é empregada atualmente para a determinação da largura efetiva " $\mathrm{eff}_{\mathrm{ef}}$, sendo:

$$
b_{e f}=1,9 t \sqrt{E / f_{\text {mix }}}\left(1-0,415(t / b) \sqrt{E / f_{\text {mix }}}\right)
$$

A equação anterior pode ser utilizada para a determinação da largura efetiva de elementos enrijecidos à compressão para diferentes condições de contorno, sendo reescrita por:

$$
b_{e f}=0,95 t \sqrt{k E / f_{\text {max }}}\left(1-0,208(t / b) \sqrt{k E / f_{\text {mix }}}\right)
$$

${ }^{2}$ WINTER, G.; (1947). "Strength of Thin Steel Compression Flanges,"(With Appendix), bulletin 35/3, Cornell University Engineering Experiment Station, ithaca, NY apud YU, W. W. (1985). ColdFormed Steel Desing, "New York, John Wiley \& Sons.

${ }^{3}$ WINTER, G.: (1970). "Commentary on the 1968 Edition of the Specification for the Design of ColdFormed Steel Structural Members," American Iron and Steel Institute ed apud YU,W. W. (1985). "Cold-Formed Steel Desing," New York: John Wiley \& Sons. 
onde "k" é o coeficiente de flambagem de chapa.

Pela equação (3.20), pode ser determinado o valor para o qual o elemento enrijecido à compressão é totalmente efetivo, $b_{\mathrm{ef}}=\mathrm{b}$ quando $\mathrm{b} / \mathrm{t} \mathrm{t}$ é menor que:

$$
\left(\frac{b}{t}\right)_{\text {lim }}=\lambda_{\text {lim }}=\frac{1}{1,5574} \sqrt{\mathrm{kE} / f_{\text {max }}}
$$

ou

$$
\begin{gathered}
\lambda_{\text {lim }}=\frac{581}{\sqrt{f_{\text {max }}}} \\
\left(\mathrm{K}=4 \text { e } \mathrm{f}_{\text {máx }} \text { em MPa }\right)
\end{gathered}
$$

Para a fase de utilização, como exemplo na determinação de deslocamentos, o conceito da largura efetiva é baseado na tensão de utilização "f", resultante das ações nominais e devidamente combinadas, como:

$$
b_{e f}=\frac{581}{\sqrt{f}} t, \mathrm{f} \text { em } \mathrm{MPa}
$$

\section{5 - ELEMENTOS ENRIJECIDOS Ȧ COMPRESSÃO POR MEIO DE ENRIJECEDORES DE BORDA}

\subsection{1 - GENERALIDADES}

Como apresentado no item 3.2, os elementos de chapa dobrada podem ser enrijecidos ou não enrijecidos. Como os elementos não enrijecidos à compressão apresentam uma borda livre, podem atingir a tensão crítica de flambagem com valores menores que os elementos enrijecidos de mesma dimensão e material.

O emprego de enrijecedores longitudinais nos componentes planos da seção transversal dos perfis é uma forma econômica de aumentar a resistência à flambagem local destes elementos. A borda enrijecida serve para manter um apoio contínuo ao elemento comprimido, paralelamente ao esforço solicitante. A figura 3.11 apresenta alguns tipos de enrijecedores de borda. 


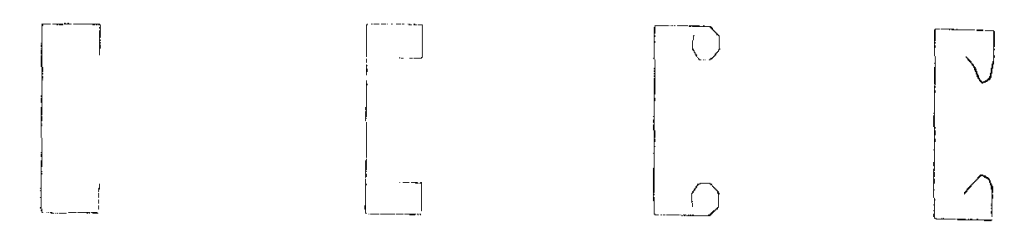

FIGURA 3.11 - Tipos de enrijecedores de borda.

\subsection{2 - ENRIJECEDORES DE BORDA}

Segundo DESMOND et al. (1981a), o comportamento de flambagem dos elementos planos enrijecidos por meio de enrijecedores de borda é caracterizado por dois modos de flambagem.

O primeiro é o modo de flambagem do enrijecedor, onde a instabilidade se inicia pela flambagem do enrijecedor na direção perpendicular ao plano da chapa a qual suporta. Para este modo, a instabilidade do enrijecedor induz simultaneamente a flambagem local do elemento, figura 3.12a. O segundo modo é a flambagem local da chapa, onde a instabilidade inicia-se pela flambagem da chapa, figura $3.12 b$.

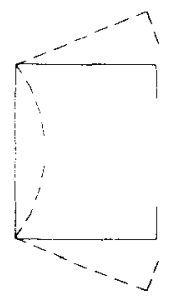

(a)

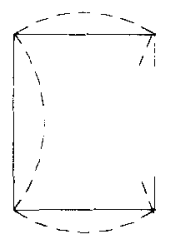

(b)

FIGURA 3.12 - Modos de flambagem

(a) flambagem do enrijecedor

(b) flambagem do elemento enrijecido

O coeficiente de flambagem $\mathrm{K}$ para os dois modos de flambagem está apresentado na figura 3.13 para várias combinações da altura " $\mathrm{d}$ " do enrijecedor e largura " $b$ " do elemento plano. Com base nesta figura, a influência do enrijecedor na flambagem do elemento plano pode ser classificado como:

a) Para relações $d / b$ menores que aproximadamente 0,12 , a rigidez do enrijecedor é suficiente para caracterizar um apoio contínuo ao elemento plano. 
Consequentemente, a flambagem do conjunto se inicia pela flambagem do enrijecedor.

b) Para $0,12<\mathrm{d} / \mathrm{b}<0,4$, a flambagem se inicia simultaneamente no elemento plano e no enrijecedor. 0 coeficiente de flambagem de chapa, $\mathrm{K}$, se aproxima assintoticamente de 4,0 .

c) Para $\mathrm{d} / \mathrm{b}>0,4$, a flambagem se inicia pela flambagem local do elemento plano enrijecido. Neste caso, a estabilidade local do enrijecedor de borda interage com a do elemento enrijecido e se inicia uma flambagem prematura desse elemento.

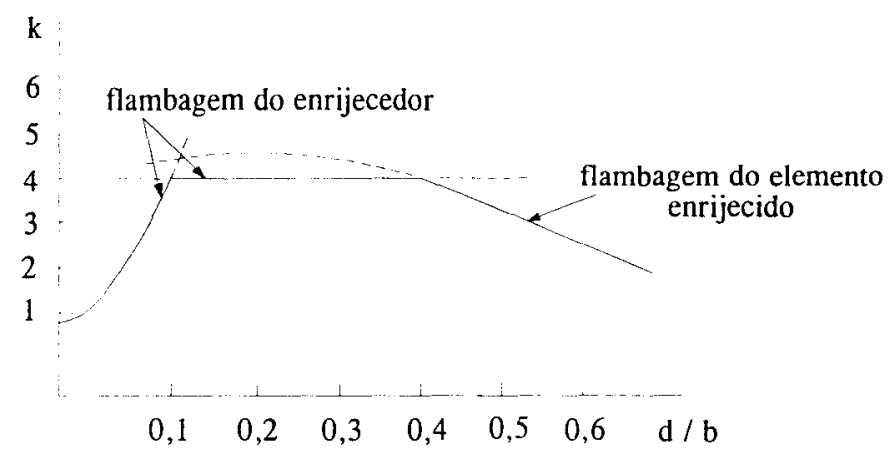

FIGURA 3.13 - Coeficiente de flambagem para elemento enrijecido por meio de enrijecedor de borda (DESMOND et al, 1981a).

De acordo com as especificações do AISI (1986) o momento de inércia adequado do enrijecedor pode ser obtido conforme três casos específicos:

Caso I

$$
\frac{b}{t} \leq \frac{1,28}{3} \sqrt{\frac{E}{f}}
$$

onde:

$\mathrm{b}=$ largura plana do elemento a ser enrijecido

$t=$ espessura do elemento

$\mathrm{f}=$ tensão normal do elemento

É dispensável o uso do enrijecedor de borda neste caso, pois a largura efetiva do elemento não enrijecido à compressão é igual a sua largura bruta. 
Caso II

$$
\begin{aligned}
& \frac{1,28}{3} \sqrt{\frac{E}{f}}<\frac{b}{t} \leq 1,28 \sqrt{\frac{E}{f}} \\
& I_{a}=399\{[(b / t) /(1,28 \sqrt{E / f})]-0,33\}^{3} t^{4}
\end{aligned}
$$

Caso III

$$
\begin{aligned}
& \frac{b}{t}>1,28 \sqrt{\frac{E}{f}} \\
& I_{a}=\{[115(b / t) /(1,28 \sqrt{E / t})]+5\}^{3} t^{t}
\end{aligned}
$$

A altura total da aba, "d", para enrijecedores formados de uma simples virada de borda tendo ângulo reto com o elemento a ser enrijecido, deve ser no mínimo:

$$
d=\left(24 \frac{b}{t}-156\right)^{1 / 3} t \geq 4,8 t
$$

NOTA: Para a relação "b/t" maior que 60 , não deve ser usado este tipo de enrijecedor.

\subsection{3 - LARGURA EFETIVA DE ELEMENTO ENRIJECIDO À COMPRESSÃO POR MEIO DE ENRIJECEDORES DE BORDA}

Para determinar as propriedades geométricas da seção efetiva de um elemento enrijecido à compressão por meio de enrijecedores de borda, emprega-se a equação (3.20) para o cálculo da largura efetiva de um elemento de chapa.

Segundo DESMOND et al (1981a), o coeficiente de flambagem (K) é determinado de forma a considerar a interação entre o elemento a ser enrijecido e o enrijecedor, figura 3.13, e as expressões de "b'ef", equação (3.32) e "A' $\mathrm{ef}^{\prime}$ ", equação (3.33) permitem avaliar também um elemento parcialmente enrijecido $\left(\mathrm{I}_{\mathrm{st}}<\mathrm{I}_{\mathrm{a}}\right)$ : 
a) Para $0,25<(d / b) \leq 0,80$ :

$$
k=\left[4,82-5\left(\frac{d}{b}\right)\right]\left(\frac{I_{s t}}{I_{a}}\right)^{n}+0,43 \leq 5,25-5\left(\frac{d}{b}\right)
$$

b) Para $(d / b) \leq 0,25$

$$
\begin{aligned}
& k=3,57\left(\frac{I_{s t}}{I_{a}}\right)^{n}+0,43 \leq 4,0 \\
& b_{e f}^{\prime}=b_{e f}\left(\frac{I_{s t}}{I_{a}}\right) \leq b_{e f} \\
& A_{e f}^{\prime}=A_{e f}\left(\frac{I_{s t}}{I_{a}}\right) \leq A_{e f}
\end{aligned}
$$

onde:

$\mathrm{A}_{\mathrm{ef}}=$ área efetiva do elemento enrijecido

$A_{\text {ef }}^{\prime}=$ área efetiva reduzida para o caso de se ter enrijecimento parcial $\left(\mathrm{I}_{\mathrm{st}}<\mathrm{I}_{\mathrm{a}}\right)$

b = largura plana do elemento a ser enrijecido.

$b_{\text {ef }}=$ largura efetiva do elemento enrijecido.

$b_{\text {ef }}^{\prime}=$ largura efetiva reduzida para o caso de se ter enrijecimento parcial $\left(\mathrm{I}_{\mathrm{St}}<\mathrm{I}_{\mathrm{a}}\right)$

$\mathrm{d}=$ dimensão definida na figura 3.14.

$\mathrm{d}^{\prime} \quad=$ largura plana da borda enrijecida definida na figura 3.14.

$\mathrm{I}_{\mathrm{a}}=$ momento do inércia adequado do enrijecedor.

$\mathrm{I}_{\mathrm{St}}=$ momento de inércia total do enrijecedor em relação ao seu eixo central paralelo ao elemento a ser enrijecido.

$$
\begin{aligned}
& \mathrm{n}=1 / 2 \text { para } \frac{1,28}{3} \sqrt{\mathrm{E} / \mathrm{f}}<\frac{\mathrm{b}}{\mathrm{t}} \leq 1,28 \sqrt{\mathrm{E} / \mathrm{f}} \\
& \mathrm{n}=1 / 3 \text { para } \frac{\mathrm{b}}{\mathrm{t}}>1,28 \sqrt{\mathrm{E} / \mathrm{f}}
\end{aligned}
$$

Como um enrijecedor de borda é um elemento não enrijecido à compressão, deverá ter suas propriedades geométricas efetivas determinadas como tal. 

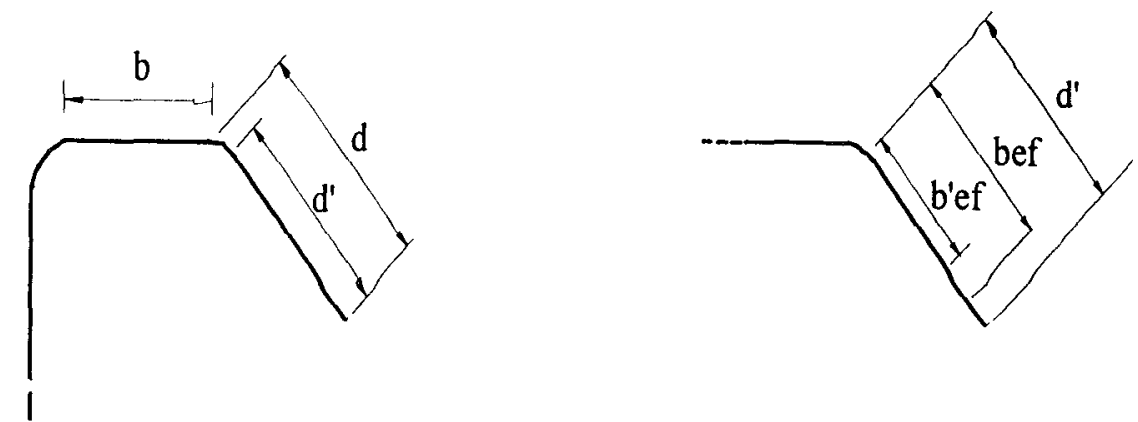

FIGURA 3.14 - Elemento efetivo de um enrijecedor (YU,1985).

\section{6 - ELEMENTO COM ENRIJECIMENTO MÚLTIPLO À COMPRESSÃO}

\subsection{1 - GENERALIDADES}

WINTER (1970) ${ }^{4}$ apud YU (1985), através de ensaios com perfis de chapa dobrada contendo enrijecimentos intermediários, demonstrou que a largura efetiva de cálculo de um sub-elemento de um elemento com enrijecimento múltiplo é menor que a de um elemento enrijecido com a mesma relação largura espessura (b/t). Esta afirmação é válida para relações (b/t) maiores que 60 .

Este fenômeno ocorre devido ao fato que, nas seções das vigas, à tensão normal da mesa superpõe à tensão de cisalhamento entre almas e mesas. A alma produz tensões normais na mesa por meio das tensões de cisalhamento transferidas a ela.

O enrijecedor intermediário não é um elemento resistente às tensões de cisalhamento. Qualquer tensão normal ao enrijecedor intermediário é transferida a ele a partir da alma ou almas através dos sub-elementos da mesa. Como o subelemento entre alma e enrijecedor é plano, esta transferência de tensão ocorre de maneira a não afetá-lo.

Neste caso, a tensão no enrijecedor é igual à tensão da alma e o sub-elemento comporta-se individualmente como um elemento enrijecido com a mesma relação $(\mathrm{b} / \mathrm{t})$.

Para sub-elemento com relação (b/t) elevada, pequenas ondas de flambagem no sub-elemento interferem com a completa transferência de tensões de

\footnotetext{
4 WINTER, G. (1974). "Commentary on the 1968 Edition of the especification for the Design of cold-formed steel strutural members" apud YU, W. W.; Cold-formed steel design, New York:, John Wiley \& Sons, 1985.
} 
cisalhamento e produzem o efeito "shear lag", no qual resulta em uma distribuição de tensões, conforme ilustrado na figura 3.15 .

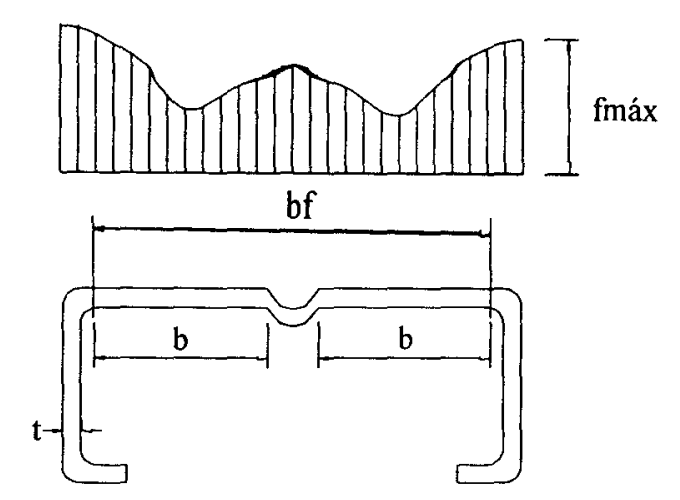

FIGURA 3.15 - Distribuição de tensões normais a mesa comprimida com enrijecedor intermediário (YU, 1985).

DESMOND et al (1981b), concluíram que, como para os elementos planos com enrijecedores de borda, dois modos distintos de flambagem caracterizam o comportamento a flambagem dos elementos com enrijecedores intermediários. $\mathrm{O}$ primeiro modo é a flambagem do conjunto na direção perpendicular ao plano do elemento. O segundo modo é a flambagem local do elemento. A figura 3.16 apresenta estes dois modos de flambagem.

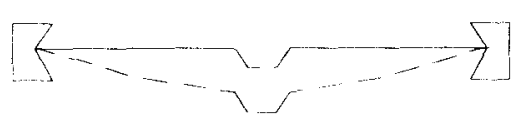

(a)

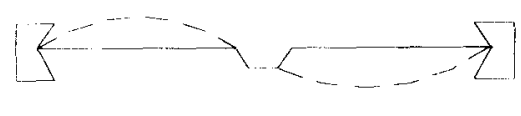

(b)

FIGURA 3.16 - Modos de flambagem de elementos com enrijecimentos múltiplos.

(a) flambagem do enrijecedor.

(b) flambagem do elemento multi enrijecidos. 


\subsection{2 - ENRIJECEDOR INTERMEDIÁRIO}

Para um elemento enrijecido à compressão, com a relação (b/t) relativamente elevada, uma maneira econômica de se aumentar a resistência última destes elementos é adicionar enrijecedores intermediários adequadamente dispostos.

Ao contrário de um enrijecedor de borda, um enrijecedor intermediário deve prover "apoio" a dois elementos comprimidos adjacentes.

DESMOND et al (1981b), estudando o emprego de um único enrijecedor intermediário em um elemento esbelto comprimido, concluíram que o momento de inércia que um enrijecedor intermediário deve possuir é determinado conforme os três casos a seguir:

Caso I

$$
\frac{b_{f}}{t} \leq 1,28 \sqrt{\frac{E}{f}}
$$

" $\mathrm{b}_{\mathrm{f}}$ "é a largura plana total do elemento de chapa, figura 3.15. A largura efetiva do elemento enrijecido à compressão é igual à sua largura plana bruta e não há necessidade de enrijecedor intermediário.

Caso II

$$
\begin{aligned}
& I, 28 \sqrt{\frac{E}{f}}<\frac{b_{f}}{t}<3,84 \sqrt{\frac{E}{f}} \\
& I_{a}=\left\{\left[50\left(\frac{b_{f}}{t}\right) /\left(1,28 \sqrt{\frac{E}{f}}\right)\right]-50\right\} t^{\prime}
\end{aligned}
$$

Caso III

$$
\begin{aligned}
& \frac{b_{f}}{t} \geq 3,84 \sqrt{\frac{E}{f}} \\
& I_{a}=\left\{\left[128\left(\frac{b_{f}}{t}\right) /\left(1,28 \sqrt{\frac{E}{f}}\right)\right]-285\right\} t^{+}
\end{aligned}
$$


Em elementos multi-enrijecidos com mais de um enrijecedor intermediário, cada enrijecedor deverá apresentar um momento de inércia mínimo dado por:

$$
I_{m i n}=3,66\left[\left(\frac{b}{t}\right)^{2}-0,136\left(\frac{E}{f}\right)\right]^{1 / 2} t^{4} \geq 18,4 t^{4}
$$

onde:

$$
\begin{aligned}
\mathrm{I}_{\text {mín }}= & \text { momento de inércia mínimo do enrijecedor em relação ao seu } \\
& \text { próprio eixo central paralelo ao elemento a ser enrijecido. } \\
\mathrm{b} / \mathrm{t}= & \text { relação largura espessura do maior sub-elemento a ser enrijecido. }
\end{aligned}
$$

Para o emprego de dois ou mais enrijecedores intermediários, devem-se observar que:

a) somente enrijecedores intermediários adjacentes a elemento de alma devem ser efetivamente considerados;

b) se os enrijecedores intermediários estiverem próximos um ao outro $\left(b_{\mathrm{ef}}=\mathrm{b}\right)$, o conjunto comporta-se como um elemento simples à compressão cuja rigidez é dada pelo momento de inércia do elemento multi-enrijecido, incluindo os enrijecedores.

Para o cálculo da relação largura-espessura de um elemento, deve ser considerado um elemento equivalente de largura " $b_{0}$ " igual à distância total entre almas ou entre alma e enrijecedor de borda, e uma espessura equivalente " $t_{0}$ " deve ser determinada como:

$$
t_{0}=\sqrt[3]{12 I / b_{0}}
$$

sendo:

I = momento de inércia da área total do elemento com enrijecimento múltiplo, incluindo os enrijecedores.

\subsection{3 - LARGURA EFETIVA DE ELEMENTO COM ENRIJECIMENTO MÚLTIPLO}


A largura efetiva para sub-elementos de um elemento com enrijecimento múltiplo à compressão normalmente é menor que a de um elemento enrijecido.

Para um elemento com enrijecimento múltiplo, dado por apenas um enrijecedor intermediário, a largura efetiva do sub-elemento é obtida através da equação (3.20) com o coeficiente de flambagem "k" dado por:

$$
k=3\left(\frac{I_{s t}}{I_{a}}\right)^{n}+1 \leq 4,0
$$

onde:

$$
\begin{aligned}
& \mathrm{n}=1 / 2 \rightarrow \text { para } \quad 1,28 \sqrt{E / f}<\frac{b_{f}}{t}<3,84 \sqrt{E / f} \\
& \mathrm{n}=1 / 3 \rightarrow \text { para } \quad \frac{b_{f}}{t} \geq 3,84 \sqrt{E / f} \\
& \mathrm{I}_{\mathrm{a}}=\text { momento de inércia adequado do enrijecedor. } \\
& \mathrm{I}_{\mathrm{St}}=\text { momento de inércia do enrijecedor. }
\end{aligned}
$$

Para $\left(\mathrm{I}_{\mathrm{St}}<\mathrm{I}_{\mathrm{a}}\right)$, a área efetiva do enrijecedor intermediário deve ser calculada conforme a equação (3.33) se a sua relação largura-espessura é menor que 60 .

Segundo YU (1985), quando a tensão nos enrijecedores intermediários for menor que a tensão ao longo da alma longitudinal, figura 3.15 , a capacidade dos enrijecedores é reduzida para sub-elementos com grande relação (b/t). Portanto, quando se calculam as propriedades geométricas efetivas para uma seção transversal com enrijecedores intermediários na qual a relação exceda 60 , a área efetiva do enrijecedor deve ser determinada como:

a) para $60<\mathrm{b} / \mathrm{t}<90$

$$
A_{e f}=\alpha A_{S t}
$$

onde:

$$
\alpha=\left(3-\frac{b_{e f}}{b}\right)-\frac{1}{30}\left(1-\frac{b_{e f}^{\prime}}{b}\right)\left(\frac{b}{t}\right)
$$


b) para $b / t \geq 90$

$$
\begin{aligned}
& A_{e f}=\frac{b_{e f}^{\prime}}{b} A_{s t} \\
& b_{e f}^{\prime}=b_{e f}-0,1 t(b / t-60)
\end{aligned}
$$

onde:

$\mathrm{A}_{\mathrm{st}}, \mathrm{A}_{\mathrm{ef}} \rightarrow \mathrm{a}$ área total e a área efetiva do enrijecedor intermediário.

b'ef $\rightarrow$ a largura efetiva reduzida do sub-elemento.

\section{7 - ELEMENTOS COMPRIMIDOS NÃO ENRIJECIDOS}

\subsection{1 - GENERALIDADES}

Um elemento comprimido não enrijecido, tal como uma mesa de uma coluna de seção "I", pode atingir o colapso convencional por escoamento se a coluna for curta $e$ as relações (b/t) dos elementos que a compõem forem menores que determinados valores. Portanto, pode ocorrer a flambagem local dos elementos com uma tensão menor que a tensão limite de escoamento, ou com uma tensão menor que a tensão crítica de flambagem global da coluna, quando as relações (b/t) excederem aquele limite.

\subsection{2- TENSÃO CRÍTICA DE FLAMBAGEM ELÁSTICA}

A tensão crítica de flambagem elástica para um elemento uniformemente comprimido pode também ser determinada pela equação (3.8).

Segundo YU (1985), para uma chapa retangular longa $(a / b \geq 4)$, simplesmente apoiada nas três bordas e uma borda livre (figura 3.17), o valor teórico do coeficiente de flambagem de chapa $\mathrm{K}$ é 0,425 . Entretanto, $\mathrm{k}$ pode ser considerado para o cálculo como sendo igual a 0,5 devido ao efeito de restrição ao giro dos elementos adjacentes. 


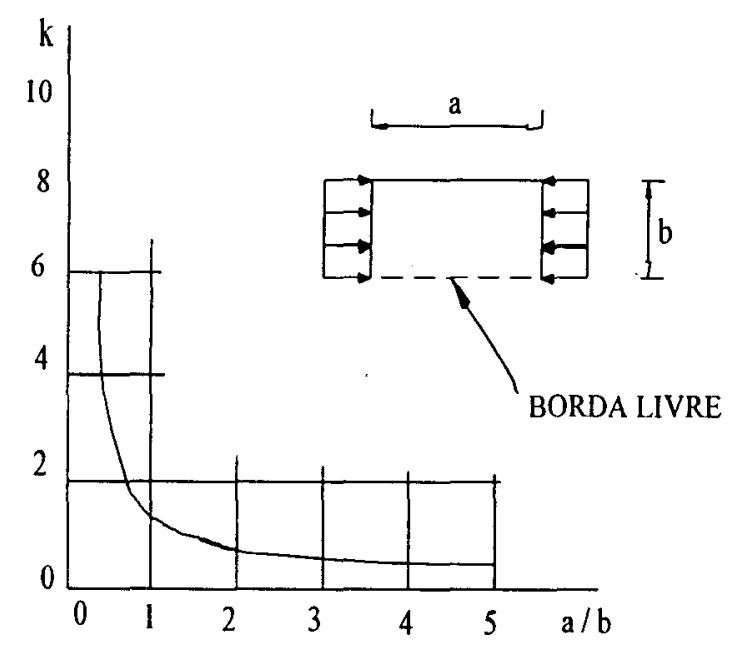

FIGURA 3.17 - Coeficiente de flambagem para elementos comprimidos não enrijecidos (YU, 1985).

\subsection{3 - RESISTÊNCIA PÓS-FLAMBAGEM E LARGURA EFETIVA}

Como nos elementos enrijecidos, os elementos não enrijecidos também apresentam a resistência pós-flambagem podendo, do mesmo modo, aplicar o conceito de largura efetiva, figura 3.18.

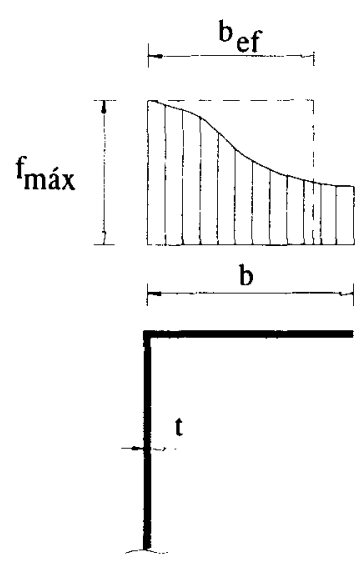

FIGURA 3.18 - Largura efetiva de elementos comprimidos não enrijecidos (SÁLES \& MALITE, 1993).

Baseado em resultados de pesquisas experimentais, WINTER (1947) 4 apud YU (1985) obteve a equação para o cálculo de largura efetiva dos elementos não

${ }^{5}$ WINTER, G. (1947). Strength of thin steel compression flanges, (with Appendix, bulletin 35/3, Cornel University Engineering Experiment Station, Ithaca, New York apud YU, W. W.; (1985). Coldformed steel design, New York: John Wiley \& Sons. 
enrijecidos à compressão, equação 3.46 , onde, $\mathrm{f}_{\text {máx }}$ é a tensão máxima no elemento, figura 3.18 .

$$
b_{e f}=0,8 t \sqrt{\frac{E}{f_{\text {máx }}}}\left[1-0,202\left(\frac{t}{b}\right) \sqrt{\frac{E}{f_{\text {máx }}}}\right]
$$

Assumindo-se um coeficiente de flambagem de chapa $\mathrm{k}=0,5$, a equação anterior pode ser generalizada por:

$$
b_{e f}=1,13 t \sqrt{\frac{k E}{f_{\max }}}\left[1-0,286\left(\frac{t}{b}\right) \sqrt{\frac{k E}{f_{\max }}}\right]
$$

\section{8 - ELEMENTOS COMPRIMIDOS SUBMETIDOS A UMA DISTRIBUIÇÃO DE TENSÕES NÃO UNIFORME}

Barras comprimidas axialmente ou barras fletidas, onde o elemento comprimido é paralelo à linha neutra, a distribuição de tensão é uniforme até o início da flambagem. No entanto, em muitos casos, tais como as abas e alma das seções transversais ilustradas na figura 3.19 , as quais são perpendiculares a linha neutra, a tensão de compressão deixa de ser uniforme variando linearmente com a distância à linha neutra. A área hachureada na figura representa a largura efetiva do elemento.

Para o cálculo da largura efetiva emprega-se a equação 3.20 , admitindo-se uma distribuição uniforme de tensões com valor " $f_{1}$ ", figura 3.19a, e o coeficiente de flambagem de chapa "k" igual 0,43.

Assume-se que um elemento enrijecido, sujeito a um gradiente de tensão, pode ser totalmente efetivo até o valor limite de:

$$
\left(\frac{b}{t}\right)_{l i m}=\lambda_{l i m}=\frac{1}{1,5574} \sqrt{k E / f_{l}}
$$

Para elementos enrijecidos com relações $(b / t)$ maiores que $\lambda_{\lim }$, a largura efetiva do elemento é tomada como $\left(b_{1}+b_{2}\right)$, conforme apresenta a figura 3.19a. As larguras $b_{1}$ e $b_{2}$ devem ser determinadas como se segue: 


$$
\begin{aligned}
& b_{1}=\frac{b_{e f}}{3-\psi} \\
& b_{2}=\frac{b_{e f}}{2} \quad \text { para } \quad \psi \leq-0,236 \\
& b_{2}=b_{e f}-b_{1} \quad \text { para } \quad \psi>-0,236 \\
& b_{e f}=0,95 t \sqrt{k E / f_{l}}\left[1-\frac{0,208}{(b / t)} \sqrt{k E / f_{l}}\right]
\end{aligned}
$$

onde:

$\mathrm{f}_{1}$ e $\mathrm{f}_{2}=$ tensões, conforme figura 3.19. $\mathrm{f}_{1}$ é a tensão de compressão( +$)$ e $\mathrm{f}_{2}$ pode ser de tração (-) ou de compressão (+). Se ambas forem de compressão, $\mathrm{f}_{1}>\mathrm{f}_{2}$.

$$
\begin{array}{ll}
k & =4+2(1-\psi)^{3}+2(1-\psi) \\
\psi & =f_{2} / f_{1}
\end{array}
$$

A largura efetiva do elemento $\left(b_{\mathrm{ef}}=b_{1}+b_{2}\right)$, não deve exceder a parte comprimida da alma.
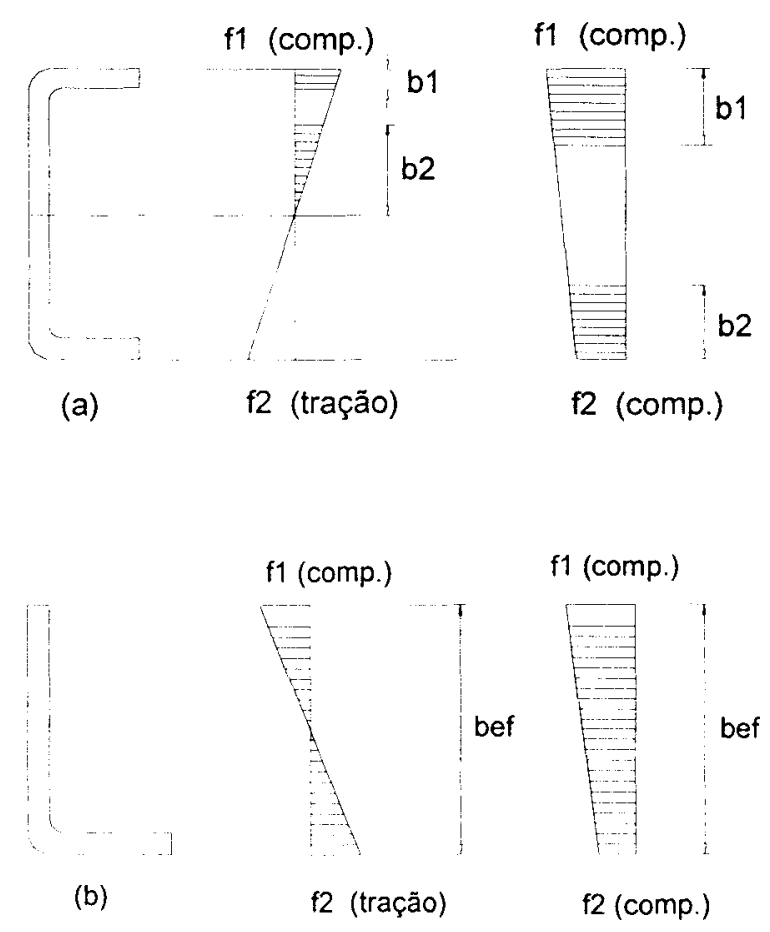

FIGURA 3.19 - Elementos submetidos a um gradiente de tensões. 


\section{9 - RELAÇÕES MÁXIMAS ADMISSÍVEIS}

As relações a seguir apresentadas, são de acordo com a AISI (1986) para o cálculo dos elementos de chapa dobrada.

\section{Caso I}

Considerações máximas sobre a relação largura / espessura de mesas:

a) Elementos comprimidos enrijecidos:

$\rightarrow$ por virada simples de borda ou ângulo reto, a relação b/t deverá ser $\leq 60$;

$\rightarrow$ conectada por outros tipos de enrijecedores, $b / t \leq 90$;

$\rightarrow$ quando as duas bordas longitudinais forem conectadas a outros elementos enrijecidos $\leq 500$.

b) Elementos comprimidos não enrijecidos

$\rightarrow$ a relação $b / t$ deverá ser $\leq 60$.

Nota: Elementos comprimidos não enrijecidos cujas relações $b / t$ excedam aproximadamente 30 e elementos comprimidos enrijecidos cuja a relação b/t excedam aproximadamente 250 , podem apresentar deformações significativas sob a carga total admissível, sem que seja efetivada a capacidade dos mesmos para suportar as cargas de projeto. Elementos enrijecidos com relação b/t maiores que 50 poderão ser utilizados com segurança para suportar cargas, embora deformações substanciais possam ocorrer e tornar-se inaplicáveis as fórmulas apresentadas segundo esta especificação do AISI.

\section{Caso II}

Considerações máximas sobre a relação altura plana/espessura de almas:

$\rightarrow$ almas não enrijecidas, a relação $h / t$ deverá ser $\leq 200$;

$\rightarrow$ almas com enrijecedores transversais de apoio, $\mathrm{h} / \mathrm{t} \leq 260$;

$\rightarrow$ almas com enrijecedores transversais intermediários e nos apoios $h / t \leq 300$. 


\section{CAPÍTULO 4}

\section{FUNDAMENTOS TEÓRICOS PARA O DIMENSIONAMENTO DE BARRAS}

\section{1 - CONCEITOS DE SEGURANÇA}

Para garantir a eficiência de uma estrutura deve-se projetá-la de modo que se obtenha uma edificação que seja resistente, estável e duradoura.

As estruturas devem ser dimensionadas de maneira que possam resistir aos esforços que surgem devido às ações a que será submetida. As tensões em seus elementos não devem ultrapassar valores que possam comprometer o seu uso ou a sua durabilidade. Para ser segura, ela tem que suportar as combinações das ações mais críticas previstas para toda a sua vida útil, com uma certa reserva em relação a qualquer tipo de estado limite.

Existem dois métodos para a verificação da segurança das estruturas. $O$ primeiro é o método das "Tensões Admissíveis", que é o utilizado pela norma AISI (1980) e (1986), e pela norma brasileira de chapa dobrada NB-143 (1967). O segundo é o método dos "Estados Limites", que é adotado pela norma CSA (1984) e pela norma AISI (1991).

No método das tensões admissíveis, considera-se que a estrutura está submetida às ações de serviço. A segurança é introduzida impondo-se que as máximas tensões atuantes nos elementos da estrutura não ultrapassem a tensão admissível do material. A tensão admissivel do material é definida como sendo uma fração da tensão de escoamento ou da tensão de ruptura.

Resumidamente, pode-se dizer que no método dos estados limites a estrutura é projetada considerando-se ações majoradas e as resistências minoradas.

Os coeficientes de ponderação utilizados, bem como as ações atuantes, são estabelecidos por critérios que contemplam a aleatoriedade do fenômeno. 
Considera-se que uma estrutura atinja um estado limite quando, de modo efetivo ou convencional, deixa de cumprir as finalidades para as quais foi projetada. Estabelece-se para esta verificação a probabilidade de ocorrer o estado limite último ou o estado limite de utilização.

Os estados limites últimos são referidos ao colapso da estrutura ou de parte dela. São caracterizados pelos fenômenos da perda da estabilidade, de equilíbrio, de uma parte ou do conjunto da estrutura (tombamento, deslizamento), do colapso da estrutura por plastificação tornando-a hipostática total ou parcialmente, da perda de estabilidade por deformação, de uma parte ou do conjunto da estrutura, da deformação plástica excessiva, deformação lenta e fissuração, da perda da capacidade de sustentação por parte dos seus elementos, da propagação de um colapso que se inicia em um ponto ou região da estrutura e de grandes deformações transformando-a em um mecanismo.

Os estados limites de utilização correspondem a interrupção do uso normal da estrutura, de acordo com as condições de danos e/ou deterioração da mesma. São caracterizados por deformações excessivas para uma utilização normal da estrutura, por deslocamentos excessivos sem perda do equilíbrio, por danos locais excessivos afetando a aparência, a utilização ou sua durabilidade, vibrações que afetem o conforto dos ocupantes ou a operação de equipamentos.

A título de comentário, a norma NBR-8800/86 especifica a aplicação do método dos estados limites para estruturas de edifícios executados em aço com espessura dos elementos igual ou superior a $3,00 \mathrm{~mm}$.

Como exemplo das diferença entre os dois métodos, apresentam-se a seguir as considerações feitas para peças tracionadas segundo as normas do AISI (1986) e CSA (1984).

1 - AISI(1986) $\rightarrow$ para barras solicitadas axialmente a tração, a força de tração aplicada não poderá exceder $\mathrm{T}_{\mathbf{a}}$ na área bruta, determinada como:

$$
T_{a} \leq T_{n} / \gamma=0,6 T_{n}
$$

onde:

$$
\begin{array}{ll}
\mathrm{T}_{\mathrm{a}} & =\text { resistência admissível. } \\
\mathrm{T}_{\mathrm{n}} & =\text { resistência das barras tracionadas }=\mathrm{A}_{\mathrm{g}} \mathrm{f}_{\mathrm{y}} \\
\mathrm{A}_{\mathrm{g}} & =\text { área bruta da seção transversal da barra. } \\
\mathrm{f}_{\mathrm{y}} & =\text { tensão limite de escoamento da aço. } \\
\gamma & =\text { fator de segurança para a tração }=1,67
\end{array}
$$


2 - CSA (1984) $\rightarrow$ a tensão de resistência $T_{\mathrm{r}}$, de um elemento tracionado, deverá ser menor que:

$$
T_{r}=\phi A_{g} f_{y}=0,9 T_{n}
$$

onde:

$\mathrm{T}_{\mathrm{r}} \quad=$ resistência de cálculo à tração $=\alpha_{L} T$

$\mathrm{A}_{\mathrm{g}} \quad$ área total da seção transversal da barra.

$\phi \quad=$ coeficiente de resistência à tração $=0,9$

Comparando as expressões:

$$
\begin{aligned}
& T_{a} \leq T_{n} / \gamma=0,6 T_{n} \quad \leftrightarrow \quad T_{r}=\phi A_{g} f_{y}=0,9 T_{n} \\
& 1,5 T=0,9 T_{n} \quad \therefore T=0,6 T_{n}
\end{aligned}
$$

Pode-se notar que os dois métodos são similares.

As combinações das ações que devem ser consideradas para a utilização do método dos estados limites estão apresentadas, a seguir, de acordo com a norma CSA:

a) Para os fatores de carga $(\alpha)$, os seguintes valores deverão ser levados em conta para os coeficientes de ponderação:

$\alpha_{\mathrm{D}} \quad=1,25$ (carga permanente)

$\alpha_{\mathrm{L}} \quad=1,50$ (sobrecarga de equipamentos)

$\alpha_{\mathrm{Q}} \quad=1,50$ (sobrecarga devido ao vento e terremoto)

$\alpha_{\mathrm{T}} \quad=1,25$ (temperatura)

b) Para os fatores de combinação $(\psi)$, deverá ser considerado:

$\psi \quad=1,00$ (quando ocorrer somente uma ação de sobrecarga, ação do vento, efeitos sísmicos ou temperatura).

$\psi \quad=0,70$ (quando tiverem duas combinações entre as ações: sobrecargas, ação do vento, efeitos sísmicos ou temperatura).

$\psi=0,60$ (quando ocorrerem todas ações combinadas: sobrecarga, ação do vento, efeitos sísmicos e a temperatura). 
$\mathrm{Na}$ tabela 4.1 apresentam-se os valores dos coeficientes de resistência $(\phi)$ segundo a CSA (1984) e AISI (1991) para a determinação da resistência de cálculo para cada tipo de solicitação.

TABELA 4.1 - Valores dos coeficientes de resistência ( $\phi)$, de acordo com as normas CSA (1984) e AISI (1991).

\begin{tabular}{|c|c|c|}
\hline TIPOS DE RESISTÊNCIAS & $\begin{array}{c}\text { COEFICIENTE DE } \\
\text { RESISTÊNCIA } \\
\text { CSA } \\
\end{array}$ & $\begin{array}{c}\text { COEFICIENTE DE } \\
\text { RESISTÊNCIA } \\
\text { AISI } \\
\end{array}$ \\
\hline enrijecedores transversais & 0,85 & 0,85 \\
\hline enrijecedores de cisalhamento & 0.90 & 0.90 \\
\hline barras tracionadas & 0,90 & 0,95 \\
\hline barras comprimidas & 0,90 & 0,85 \\
\hline $\begin{array}{l}\text { barras fletidas: } \\
\text { resistência à flexão: } \\
\text { - seções com elementos enrijecidos à compressão } \\
\text { - seções com elementos não enrijecidos à } \\
\text { compressão } \\
\text { - flambagem lateral }\end{array}$ & $\begin{array}{l}0,95 \\
0.90 \\
0,90\end{array}$ & $\begin{array}{l}0,95 \\
0.90 \\
0,90\end{array}$ \\
\hline $\begin{array}{l}\text { resistência da alma: } \\
\text { - resistência ao cisalhamento } \\
\text { - resistência ao enrugamento: } \\
\text { - almas simples, não reforçadas } \\
\text { - almas de seção I }\end{array}$ & $\begin{array}{l}0,75 \\
0,80\end{array}$ & $\begin{array}{l}0,90 \\
0,75 \\
0,80\end{array}$ \\
\hline $\begin{array}{l}\text { barras flexo-comprimidas: } \\
\text { - resistência à compressão } \\
\text { - resistência à flexão }\end{array}$ & $\begin{array}{l}0,90 \\
0,90\end{array}$ & $\begin{array}{l}0,85 \\
0,95\end{array}$ \\
\hline $\begin{array}{l}\text { barras tubulares cilindricas: } \\
\text { - resistência à flexão } \\
\text { - resistência à compressão }\end{array}$ & $\begin{array}{l}0,90 \\
0,90\end{array}$ & $\begin{array}{l}0,90 \\
0,90\end{array}$ \\
\hline ligações & 0,67 & 0,67 \\
\hline $\begin{array}{l}\text { para estado limite último determinado pela resistência } \\
\text { à tração do material }\left(f_{\mathrm{u}}\right)\end{array}$ & 0,75 & 0,75 \\
\hline
\end{tabular}




\section{2- BARRAS TRACIONADAS}

\subsection{1 - GENERALIDADES}

As barras tracionadas são elementos solicitados por força normal de tração e geralmente são empregados em construções como tirantes, elementos do sistema de contraventamentos e elementos de treliças. 0 dimensionamento destas barras consiste basicamente em fornecer uma área suficientemente segura para sua seção transversal, pois em barras tracionadas não ocorre o fenômeno da instabilidade.

Os estados limites últimos considerados para peças tracionadas são: o escoamento da seção bruta e a ruptura da seção líquida, não levando em consideração a redistribuição de tensões nas proximidades das seções enfraquecidas.

\section{3 - BARRAS COMPRIMIDAS}

\subsection{1 - GENERALIDADES}

Barras comprimidas são elementos estruturais solicitados apenas à força axial de compressão. Ao contrário das barras tracionadas, que entram em colapso somente quando o limite de resistência é ultrapassado, as barras esbeltas comprimidas podem sofrer colapso com tensões bem menores que a de escoamento, devido ao problema de instabilidade.

As barras solicitadas por uma força axial de compressão estarão sujeitas ao colapso por escoamento da seção transversal e pelos estados limites relacionados com a instabilidade de barra. A tensão de compressão para peças solicitadas axialmente não deve ultrapassar a tensão crítica associada à instabilidade global que será função do índice de esbeltez do elemento, ou à instabilidade local das partes que compõem o perfil.

O colapso por escoamento nas barras poderá ocorrer com baixos valores do índice de esbeltez global $(\lambda)$ e baixos valores do índice de esbeltez local (relações $b / t$ ), ocorrendo em barras curtas e com espessuras elevadas das chapas que compõem o perfil.

Alguns tipos de seções transversais para barras comprimidas encontram-se apresentadas na figura 4.1. Perfis com seções fechadas (figuras 4.1a, b), perfis com elementos não enrijecidos (figuras $4.1 \mathrm{c}, \mathrm{f}, \mathrm{i}$ ), perfis com elementos enrijecidos (figura 4.1e, g) e combinação de ambos (figura $4.1 \mathrm{~d}, \mathrm{~h}, \mathrm{j}$ ). 


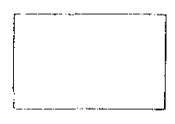

(a)

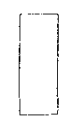

(b)

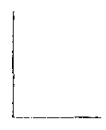

(c)

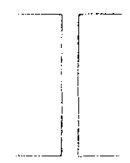

(h)

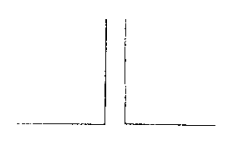

(d)

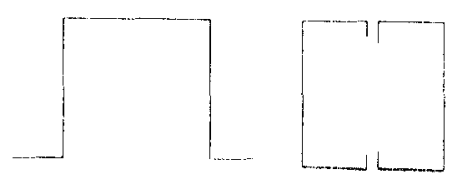

(i)

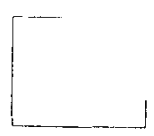

(e)

(j)

Figura 4.1 - Tipos de seções transversais para barras comprimidas.

\subsection{2 - PERFIS COMPRIMIDOS SUJEITOS 'A FLAMBAGEM POR FLEXÃO}

\subsubsection{1 - FLAMBAGEM ELÁSTICA}

Um elemento que está sujeito a uma força normal de compressão pode apresentar o fenômeno da flambagem por flexão. A força crítica de flambagem é a deduzida por Euler:

$$
N_{e}=\frac{\pi^{2} E I}{(k l)^{2}}
$$

onde:

$\mathrm{E} \quad=$ módulo de elasticidade.

I = momento de inércia mínimo da seção transversal.

$\mathrm{N}_{\mathrm{e}} \quad=$ força crítica de flambagem de Euler.

$\mathrm{kl}=$ comprimento efetivo de flambagem da barra.

$\mathrm{f}_{\mathrm{e}} \quad=$ tensão crítica de flambagem.

$\mathrm{r} \quad=$ raio de giração da seção trnaversal.

A tensão crítica de flambagem elástica de Euler pode ser obtida substituindose $I=A_{g} r^{2}$ :

$$
f_{e}=\frac{\pi^{2} E}{(k l / r)^{2}}
$$


Aplica-se esta equação às colunas de aço, desde que estes apresentem patamar de escoamento definido e sem a ocorrência de tensões residuais ou dos efeitos de trabalho a frio.

Considerando que os processos de conformação a frio diminuem o limite de proporcionalidade, a equação (4.4) não se aplica acima desse limite. Isto ocorre porque, quando a tensão atuante é maior que a tensão limite de proporcionalidade do material, a flambagem da coluna não ocorre no regime elástico, ocorrendo no regime inelástico.

\subsubsection{2 - FLAMBAGEM INELÁSTICA}

O regime inelástico é definido como a perda de linearidade do diagrama tensão-deformação no intervalo entre a tensão de proporcionalidade e a tensão de escoamento do material, decorrentes das tensões residuais do elemento e imperfeições iniciais existentes no aço.

$O$ fenômeno da flambagem de barras axialmente comprimidas no regime inelástico pode ser definido através do conceito do módulo tangente e do conceito do módulo reduzido.

ENGESSER (1889) propôs o método do módulo tangente onde a força normal que corresponde à flambagem de barras é idêntica a apresentada por Euler, porém o módulo de elasticidade passa a ser pontual e variável, adotando-se a tangente em cada ponto da curva tensão-deformação. A força normal de flambagem pelo módulo tangente pode ser obtida por:

$$
N_{T}=\frac{\pi^{2} E_{t} I}{(k l)^{2}}
$$

e substituindo-se o valor de "I ", a tensão crítica de flambagem inelástica pode ser dada por:

$$
f_{T}=\frac{\pi^{2} E_{l}}{(k l / r)^{2}}
$$

Portanto, pode-se definir o módulo tangente $\left(E_{t}\right)$ como a inclinação da curva tensão-deformação no ponto correspondente à tensão considerada. Este módulo tangente varia de ponto a ponto, sendo função da tensão solicitante. 
Considerando-se que o efeito do descarregamento é elástico e que, a partir do regime plástico, ocorre 0 aparecimento de deformações residuais que não foram consideradas no conceito da teoria do módulo tangente, ENGESSER corrigiu sua teoria apresentando o conceito de módulo reduzido ou duplo modo, mantendo os mesmos conceitos fundamentais adotados para o módulo tangente, porém considerando a não reversibilidade do diagrama tensão-deformação, no qual:

$$
N_{R}=\frac{\pi^{2} E_{r} I}{(k l)^{2}} \quad \text { ou } \quad f_{R}=\frac{\pi^{2} E_{r}}{(k l / r)^{2}}
$$

onde:

$\mathrm{E}_{\mathrm{r}} \quad=$ módulo reduzido $=\mathrm{E}_{\mathrm{t}}\left(\mathrm{I}_{\mathrm{l}} / \mathrm{I}\right)+\mathrm{E}_{\mathrm{t}}\left(\mathrm{I}_{2} / \mathrm{I}\right)$.

$\mathrm{I}_{\mathrm{I}} \quad=$ momento de inércia com relação à linha neutra da área do lado descarregado após a flambagem (ou seja, região tracionada devido à flexão).

$\mathrm{I}_{2}=$ momento de inércia com relação à linha neutra da área ao lado carregado após a flambagem (ou seja, região comprimida devido à flexão).

Desta forma, na fase inelástica os acréscimos das tensões de compressão devido ao efeito de flexão são governados pelo módulo tangente $\mathrm{E}_{\mathrm{t}} \mathrm{e}$ os decréscimos, tensões de tração, governados pelo módulo elástico E, conforme a figura 4.2.

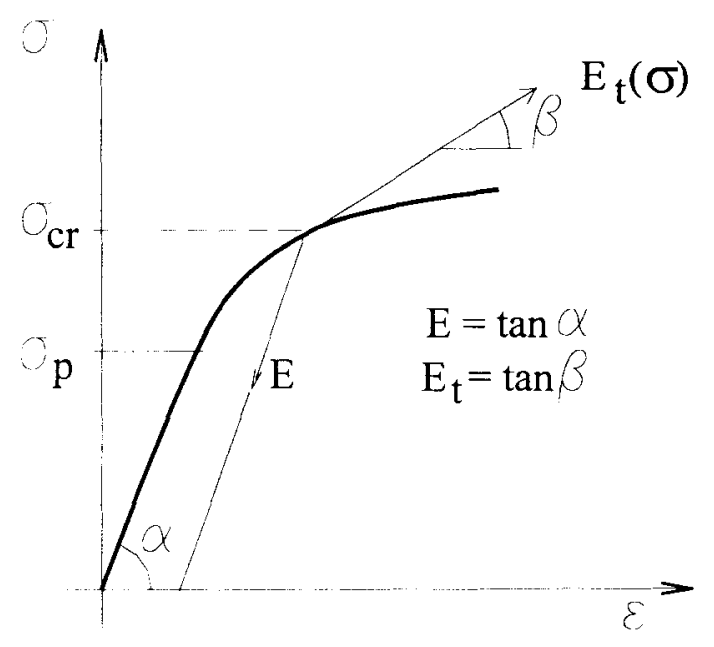

FIGURA 4.2 - Carregamento e descarregamento das fibras, teoria do módulo reduzido (RACHID \& MORI, 1989). 
Em 1947, SHANLEY1 apud RACHID \& MORI (1989), após ensaios teóricos e experimentais, apresentou as seguintes conclusões para 0 cálculo da flambagem no regime plástico:

a) O conceito do módulo tangente fornece a carga máxima na qual, ainda, a barra permanece reta;

b) A carga máxima real excede a carga do módulo tangente $\mathrm{N}_{\mathrm{T}}$, mas não pode ser maior que a do módulo reduzido $\mathrm{N}_{\mathrm{R}}$;

c) As forças $\mathrm{N}>\mathrm{N}_{\mathrm{T}}$ provocam deflexões laterais na barra;

d) Na prática, como não se conhece exatamente as condições reais, é prudente optar pela carga do módulo tangente $\mathrm{N}_{\mathrm{T}}$.

BLEICH (1952) propôs uma equação parabólica (4.8) com uma aproximação para a tensão crítica pelo módulo tangente (4.6), pois a variação do módulo tangente com o nivel de tensão depende do processo de conformação da seção e das propriedades do material virgem, tornando-se difícil prever, com exatidão, o comportamento tensão-deformação para perfis de chapa dobrada .

$$
f_{T}=f_{y}-\frac{f_{p r}\left(f_{y}-f_{p r}\right)}{\pi^{2} E}
$$

Considerando-se que a tensão limite de proporcionalidade seja igual à metade da tensão limite de escoamento, a equação (4.8) pode ser reescrita como:

$$
f_{T}=f_{y}\left(1-\frac{f_{y}}{4 f_{e}}\right)
$$

A equação anterior só é aplicável para barras cujo índice de esbeltez seja menor que $\sqrt{2 \pi^{2} \mathrm{E} / \mathrm{f}_{\mathrm{y}}}$. Para valores de $(\mathrm{Kl} / \mathrm{r})$ maiores, utiliza-se a equação de Euler, caracterizando a ocorrência da flambagem em regime elástico.

1 SHANLEY, F. R. (1947). Inelastic colum theory. Journal of Aeronautical Sciences, 14 (5): 261-268, May, apud RACHID \& MORI (1989). Instabilidade, conceitos, aplicação na flambagem por flexão, São Carlos: EESC-USP. 


\subsection{3- FLAMBAGEM POR FLEXÃO E TORÇÃO}

Geralmente as barras com seções transversais abertas de paredes finas estão sujeitas à flambagem por flexão, por torção ou por um efeito combinado de flexão e torção, sob a ação de forças de compressão axial.

Segundo RACHID (1992), as equações diferenciais gerais que governam o equilíbrio, as quais representam o problema da flambagem por flexão e torção de uma barra com seção transversal qualquer, aberta e de parede fina, comprimida axialmente por uma força "N", são as seguintes:

$$
\begin{aligned}
& E I_{x} v^{i v}+N v^{\prime \prime}-N x_{0} \phi^{\prime \prime}=0 \\
& E I_{y} u^{i v}+N u^{\prime \prime}+N y_{0} \phi^{\prime \prime}=0 \\
& E C_{w} \phi^{i v}-\left(G I_{1}-N r_{0}^{2}\right) \phi^{\prime \prime}+N y_{0} u^{\prime \prime}-N x_{0} v^{\prime \prime}=0
\end{aligned}
$$

onde:

$$
\begin{array}{ll}
\mathrm{C}_{\mathrm{W}} & =\text { constante de empenamento da seção. } \\
\mathrm{E} & =\text { módulo de elasticidade. } \\
\mathrm{G} & =\text { módulo de elasticidade transversal }(0,385 \mathrm{E}) \\
\mathrm{I}_{\mathrm{X}} & =\text { momento de inércia em relação ao eixo } \mathrm{x} . \\
\mathrm{I}_{\mathrm{y}} & =\text { momento de inércia em relação ao eixo } \mathrm{y} . \\
\mathrm{I}_{\mathrm{t}} & =\text { momento de inércia à torção. } \\
\mathrm{r}_{\mathrm{O}} & =\text { raio de giração polar em relação ao centro de cisalhamento } \\
\mathrm{r}_{\mathrm{x}} & =\sqrt{\mathrm{r}_{\mathrm{x}}^{2}+\mathrm{r}_{\mathrm{y}}^{2}+\mathrm{x}_{0}^{2}+\mathrm{y}_{0}^{2}} \\
\mathrm{r}_{\mathrm{y}} & =\text { raio de giração da seção transversal em relação ao eixo } \mathrm{x} . \\
\mathrm{u} & =\text { deslocamento lateral na direção do eixo } \mathrm{x} . \\
\mathrm{v} & =\text { deslocamento lateral na direção do eixo y. } \\
\mathrm{x}_{\mathrm{O}} & =\text { coordenada } \mathrm{x} \text { do eixo de cisalhamento. } \\
\mathrm{y}_{\mathrm{O}} & =\text { coordenada y do eixo de cisalhamento. } \\
\mathrm{x}, \mathrm{y} & =\text { eixos principais de inércia. } \\
\phi & =\text { ângulo de giro. }
\end{array}
$$

Todas as derivadas referem-se ao eixo longitudinal $\mathrm{z}$, o qual contém os centros de gravidade das seções transversais.

Analisando-se uma barra com vínculo de garfo nas extremidades, torção impedida e empenamento livre, figura 4.3 , têm-se as seguintes condições de contorno: 


$$
\begin{aligned}
& u=v=\phi=0 \\
& u^{\prime \prime}=v^{\prime \prime}=\phi^{\prime \prime}=0
\end{aligned}
$$

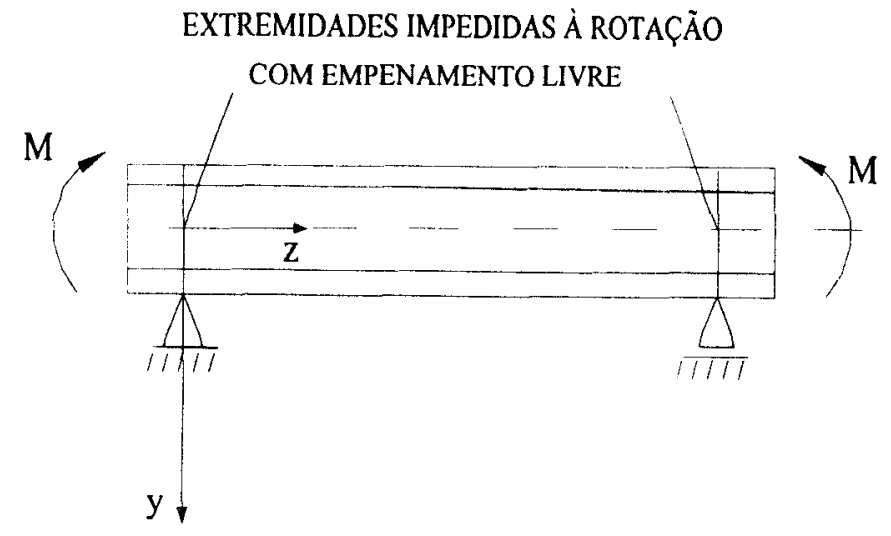

FIGURA 4.3 - Viga com momentos aplicados nas extremidades.

Substituindo-se estas condições de contorno nas equações (4.10) a (4.12), pode-se obter a equação característica dada por:

$$
\begin{aligned}
& r_{0}^{2}\left(N_{c r}-N_{e x}\right)\left(N_{c r}-N_{e y}\right)\left(N_{c r}-N_{e z}\right)-\left(N_{c r}\right)^{2}\left(y_{0}\right)^{2}\left(N_{c r}-N_{e x}\right) \\
& -\left(N_{c r}\right)^{2}\left(x_{0}\right)^{2}\left(N_{c r}-N_{e y}\right)=0
\end{aligned}
$$

onde:

$\mathrm{N}_{\text {ex }}$ = força normal de flambagem elástica de Euler em relação ao eixo $\mathrm{x}$ $=\pi^{2} \mathrm{EI}_{\mathrm{x}} /\left(\mathrm{k}_{\mathrm{x}} \mathrm{L}_{\mathrm{x}}\right)^{2}$

$\mathrm{N}_{\text {ey }}$ = força normal de flambagem elástica de Euler em relação ao eixo y $=\pi^{2} \mathrm{EI}_{\mathrm{y}} /\left(\mathrm{k}_{\mathrm{y}} \mathrm{L}_{\mathrm{y}}\right)^{2}$

$\mathrm{N}_{\mathrm{ez}}$ = força normal de flambagem elástica por torção em relação ao eixo $\mathrm{z}$ $=\frac{1}{\mathrm{r}_{0}^{2}}\left[\frac{\pi^{2} \mathrm{EC}_{\mathrm{w}}}{\left(\mathrm{k}_{\mathrm{z}} \mathrm{L}_{\mathrm{z}}\right)^{2}}+\mathrm{GI}_{\mathrm{t}}\right]$

Portanto, o modo de flambagem da barra pode ser determinado pela equação (4.14). A força crítica de flambagem $\left(\mathrm{N}_{\mathrm{cr}}\right)$ é o menor valor entre as três raízes $\left(\mathrm{N}_{\mathrm{ex}}\right.$, $\left.\mathrm{N}_{\text {ey }}, \mathrm{N}_{\mathrm{ez}}\right)$ que compõem a mesma $\left(\mathrm{N}_{\mathrm{cr}}\right)$.

Para diferentes condições de contorno, admite-se o coeficiente " $k$ " para o cálculo do comprimento efetivo de flambagem, conforme tabela 4.2 . 
TABELA 4.2 - Valores do coeficiente $k$ de flambagem por flexão (YU, 1985).

\begin{tabular}{|c|c|c|c|c|c|c|}
\hline $\begin{array}{c}\text { A linha tracejada indica a linha } \\
\text { de flambagem elástica }\end{array}$ & (a) & (b) & $\begin{array}{l}\text { (c) } \\
\vdots \\
\vdots \\
\vdots \\
\vdots \\
\vdots \\
\vdots \\
\vdots \\
1\end{array}$ & (d) & $\mid \begin{array}{l}\text { (e) } \\
1 \\
\vdots \\
\vdots \\
1 \\
1 \\
1 \\
1 \\
1\end{array}$ & $\begin{array}{c}\text { (f) } \\
\vdots \\
\vdots \\
\vdots \\
\vdots \\
\vdots\end{array}$ \\
\hline Valores teóricos de $\mathrm{k}$ & 0,5 & 0,7 & 1,0 & 1,0 & 2,0 & 2,0 \\
\hline $\begin{array}{c}\text { Valores recomendados para o } \\
\text { dimensionamento }\end{array}$ & 0,65 & 0,80 & 1,2 & 1,0 & 2,1 & 2,0 \\
\hline Condições de vinculação & 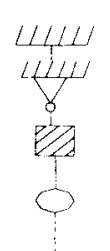 & \multicolumn{5}{|c|}{$\begin{array}{l}\text { Rotação e translação impedidas } \\
\text { Rotação livre, translação impedida } \\
\text { Rotação impedida, translação livre } \\
\text { Rotação e translação livres }\end{array}$} \\
\hline
\end{tabular}

A equação 4.14 pode ser empregada em função da forma da seção transversal da barra comprimida, como:

\section{a) para seções duplamente simétricas}

Para seções transversais duplamente simétricas, como perfis "I" e em cruz, o centro de cisalhamento coincide com o centro de gravidade da seção, isto é, $\mathrm{x}_{\mathrm{O}}=\mathrm{y}_{\mathrm{O}}=0$. A força crítica de flambagem da equação (4.14) será o menor valor entre $\mathrm{N}_{\mathrm{ex}}, \mathrm{N}_{\mathrm{ey}}$ e $\mathrm{N}_{\mathrm{ez}}$.

\section{b) para seções com um eixo de simetria}

Tratam-se de perfis amplamente utilizados em chapa dobrada como cantoneiras, "U", cartola, dupla cantoneira, etc. O centro de torção não coincide com 
o centro de gravidade da seção, portanto, uma das coordenadas $\mathrm{x}_{0}$ ou $\mathrm{y}_{0}$ deixa de ser nula.

Adotando-se o eixo " $\mathrm{x}$ " como sendo o eixo de simetria, a coordenada $y_{0}$ permanece nula $\left(\mathrm{y}_{0}=0\right)$. A flambagem por flexão ocorrerá em torno do eixo "y" (eixo de não simetria), e ocorrerá a flambagem por flexão e torção em torno do plano "xz", respectivamente. A força crítica de flambagem elástica será determinada pelo menor valor encontrado com base nas raizes da equação (4.14):

$$
\begin{aligned}
& \left(N_{c r}\right)_{1}=N_{e y}=\frac{\pi^{2} E I_{y}}{\left(k_{y} L_{y}\right)^{2}} \\
& \left(N_{c r}\right)_{2}=\frac{1}{2 H}\left[\left(N_{e x}+N_{e z}\right)+\sqrt{\left(N_{e x}+N_{e z}\right)^{2}-4 H N_{e x} N_{e z}}\right] \\
& \left(N_{c r}\right)_{3}=\frac{1}{2 H}\left[\left(N_{e x}+N_{e z}\right)-\sqrt{\left(N_{e x}+N_{e z}\right)^{2}-4 H N_{e x} N_{e z}}\right]
\end{aligned}
$$

onde:

$$
H=I-\left(x_{0} / r_{0}\right)^{2}
$$

Sendo $\left(\mathrm{N}_{\mathrm{cr}}\right)_{3}$ menor que $\left(\mathrm{N}_{\mathrm{cr}}\right)_{2}$, a força crítica de flambagem da barra $\left(\mathrm{N}_{\mathrm{cr}}\right)$ será o menor valor entre $\left(\mathrm{N}_{\mathrm{cr}}\right)_{1}$ e $\left(\mathrm{N}_{\mathrm{cr}}\right)_{3}$.

A tensão de flambagem elástica por flexão e torção $\left(f_{\text {exz }}\right)$ pode ser obtida dividindo-se a equação (4.17) pela área total da seção transversal $\left(A_{g}\right)$, sendo:

$$
f_{e x z}=\frac{1}{2 H}\left[\left(f_{e x}+f_{e z}\right)-\sqrt{\left(f_{e x}+f_{e z}\right)^{2}-4 H f_{e x} f_{e z}}\right]
$$

onde:

$$
\begin{aligned}
& f_{e x}=\frac{N_{x}}{A} \rightarrow f_{e x}=\frac{\pi^{2} E}{\left(k_{x} l_{x} / r_{x}\right)^{2}} \\
& f_{e z}=\frac{N_{z}}{A} \rightarrow f_{e z}=\frac{1}{A_{g} r_{0}^{2}}\left[\frac{\pi^{2} E C_{w}}{\left(k_{z} l_{z}\right)^{2}}+G I_{t}\right]
\end{aligned}
$$


Conclui-se que as seções com um eixo de simetria podem flambar tanto por flexão em torno dos eixos "x" ou "y", quanto por flexão e torção simultaneamente, dependendo das características geométricas da seção transversal e dos comprimentos efetivos de flambagem da barra.

\section{c) para seções assimétricas}

Para peças assimétricas, o centro de torção não coincide com o centro de gravidade da seção e as coordenadas $\mathrm{x}_{\mathrm{O}}$ e $\mathrm{y}_{\mathrm{O}}$ são diferentes de zero.

Para seções assimétricas em relação a um eixo ou a um ponto, a tensão crítica de flambagem elástica $\left(\mathrm{f}_{\mathrm{e}}\right)$ por flexão e torção será o menor valor entre as três raízes da equação (4.20).

$$
r_{0}^{2}\left(f_{e}-f_{e x}\right)\left(f_{e}-f_{e y}\right)\left(f_{e}-f_{e z}\right)-f_{e}^{2} y_{0}^{2}\left(f_{e}-f_{e x}\right)-f_{e}^{2} x_{0}^{2}\left(f_{e}-f_{e y}\right)=0
$$

Como no caso da flambagem por flexão, a tensão crítica de flambagem inelástica por flexão e torção pode ser obtida pela expressão (4.9), onde a tensão " $f_{\mathrm{e}}$ " será a tensão crítica de flambagem elástica por flexão e torção.

\section{4 - BARRAS FLETIDAS}

\subsection{1 - GENERALIDADES}

O cálculo de elementos fletidos em chapa dobrada consiste, basicamente, em verificar a resistência ao momento fletor. Esta resistência deve ser determinada para um dos seguintes estados limites: escoamento de uma fibra extrema da seção transversal, flambagens locais (mesas e almas) e flambagem lateral com torção.

Após ser verificada a resistência ao momento fletor, verifica-se a resistência à força cortante, combinação da força cortante com o momento fletor, a resistência ao enrugamento da alma e combinação desta resistência com o momento fletor.

O cálculo da resistência ao momento fletor para vigas contidas lateralmente, pode ser determinado pela reserva da resistência inelástica devida a plastificação da seção transversal. 
Pela pequena espessura dos perfis de chapa dobrada, para as vigas de vão curto e mesa larga $\left(L / b_{f}<30\right)$, consideram-se para o cálculo de barras fletidas problemas decorrentes dos efeitos localizados, como o efeito "Shear Lag" e a ondulação da mesa. 0 aumento de resistencia nas propriedades mecânicas do aço, devido ao trabalho de dobramento a frio, é um fator importante para o cálculo deste elementos que também deve ser considerado.

\subsection{2 - RESISTÊNCIA AO MOMENTO FLETOR}

\subsubsection{1 - FLAMBAGEM LOCAL}

Em vigas contidas lateralmente, onde o fenômeno da flambagem lateral com torção não ocorre, estando sujeitas somente a tensões de flexão, a resistência a flexão pode ser determinada pelo escoamento de uma fibra extrema da seção transversal.

A tensão máxima pode ocorrer tanto na mesa comprimida como na mesa tracionada, isto é, depende da posição da linha neutra. Se a linha neutra estiver próxima da mesa tracionada, a máxima tensão ocorrerá na mesa comprimida, $f_{c}=f_{y}>f_{t}$, e se a linha neutra estiver próxima a mesa comprimida, a máxima tensão ocorrerá na mesa tracionada, $f_{t}=f_{y}>f_{c}$. A resistência nominal à flexão da barra é obtida pelo menor valor entre esses dois valores:

$$
\begin{aligned}
& M_{n}=W_{e f} f_{c} \\
& M_{n}=W_{t} f_{y}
\end{aligned}
$$

onde:

$\mathrm{W}_{\mathrm{ef}}, \mathrm{W}_{\mathrm{t}}=$ módulos de resistência elásticos das regiões comprimida e tracionada.

A flambagem local dos elementos não enrijecidos à compressão também pode ser uma outra limitação na resistência nominal à flexão da barra. A tensão de flambagem elástica de um elemento não enrijecido à compressão, equação (3.8), é utilizada para esta limitação, $(k=0,5)$, resultando em:

$$
M_{n}=W \frac{\pi^{2} E}{24\left(1-v^{2}\right)(b / t)^{2}}
$$


onde:

$\mathrm{W}=$ módulo de resistência elástico da seção transversal bruta da parte comprimida.

$(\mathrm{b} / \mathrm{t})=$ relação entre largura plana e espessura do elemento não comprimido

\subsubsection{2 - FLAMBAGEM LATERAL COM TORÇÃO}

\subsubsection{1 - SEÇÕES DUPLAMENTE SIMÉTRICAS}

O sistema de três equações diferenciais regentes do problema da instabilidade por flexão e torção, no caso de uma viga simplesmente apoiada, com seções transversais duplamente simétricas, sujeita à flexão simples com momento fletor constante, figura 4.4, fica reduzido a:

$$
\begin{aligned}
& E I_{x} v^{i v}=0 \\
& E I_{y} u^{i v}+M \phi^{\prime \prime}=0 \\
& E C_{w} \phi^{i v}-G I_{t} \phi^{\prime \prime}+M u^{\prime \prime}=0
\end{aligned}
$$

onde:

$\mathrm{C}_{\mathrm{W}} \quad$ = constante de empenamento da seção.

$\mathrm{G} \quad=$ módulo de elasticidade transversal $=0,385 \mathrm{E}$

$\mathrm{M} \quad=$ momento de flexão pura.

$\mathrm{I}_{\mathrm{t}} \quad=$ momento de inércia à torção.

$\mathrm{I}_{\mathrm{X}} \quad=$ momento de inércia em torno do eixo $\mathrm{x}$.

$\mathrm{I}_{\mathrm{y}} \quad=$ momento de inércia em torno do eixo $\mathrm{y}$.

$\mathrm{u} \quad=$ deslocamento do centro de cisalhamento na direção $\mathrm{x}$.

$\mathrm{v} \quad=$ deslocamento do centro de cisalhamento na direção $\mathrm{y}$.

$\phi \quad=$ ângulo de giro da seção. 


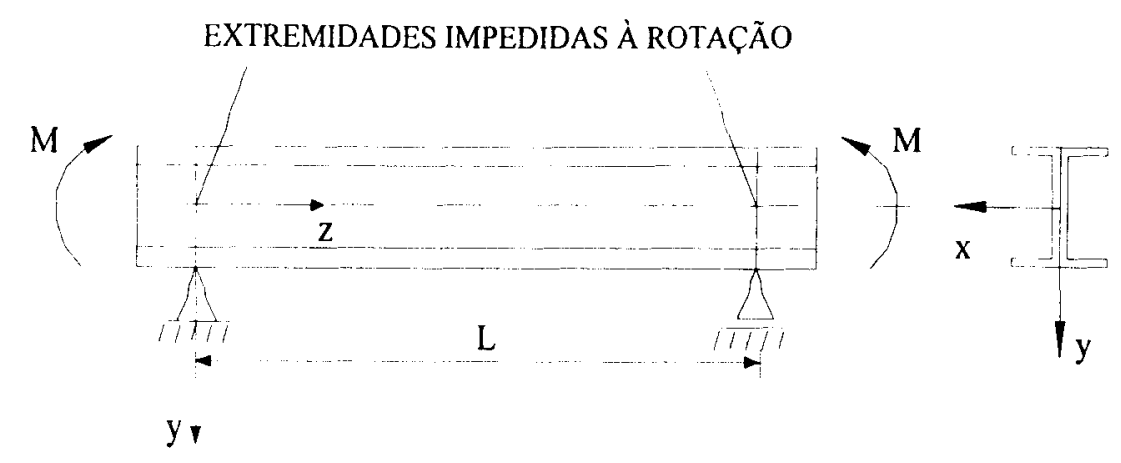

FIGURA 4.4 - Viga simplesmente apoiada com momento fletor constante.

Considerando-se vínculo de garfo nas extremidades, torção impedida e empenamento livre, têm-se as seguintes condições de contorno:

$$
\begin{aligned}
& v(0)=v(L)=u(0)=u(L)=\phi(0)=\phi(L)=0 \\
& u^{\prime \prime}(0)=u^{\prime \prime}(L)=\phi^{\prime \prime}(0)=\phi^{\prime \prime}(L)=0 \\
& v^{\prime \prime}(0)=v^{\prime \prime}(L)=-\frac{M}{E I_{x}}
\end{aligned}
$$

Resolvendo-se a equação 4.23 pode-se obter a posição deslocada da viga no plano yz, como:

$$
v=\frac{M L^{2}}{2 E I_{x}}\left[(z / L)-(z / L)^{2}\right]
$$

Pela solução do sistema constituído das equações (4.24) e (4.25), que representam a instabilidade por flexão (elástica "u") e por torção (elástica " $\phi ")$, obtém-se o momento crítico de flambagem lateral :

$$
M_{c r}=\frac{\pi}{L} \sqrt{E I_{y} G I_{t}\left(1+\frac{\pi^{2} E C_{w}}{G I_{t} L^{2}}\right)}
$$

$\mathrm{O}$ primeiro termo sob raiz quadrada, $\left(\mathrm{EI}_{\mathrm{y}} \mathrm{GI}_{\mathrm{t}}\right.$ ), apresentado na equação anterior, refere-se a rigidez torcional de St. Venant (torção livre) e o segundo termo, $\left(\pi^{2} \mathrm{EC}_{\mathrm{W}} \mathrm{I}_{\mathrm{y}} / \mathrm{L}^{2}\right)$, refere-se a rigidez à flexo-torção.

A equação (4.30), foi obtida a partir de um momento fletor constante aplicado nas extremidades da viga. Havendo outras combinações de momentos fletores, esta equação é modificada utilizando-se um coeficiente de flexão, $\mathrm{C}_{\mathrm{b}}$, que multiplica o 
valor de $\mathrm{M}_{\mathrm{cr}}$. Pode-se obter uma outra expressão de $\mathrm{M}_{\mathrm{cr}}$ representada pela equação (4.31), onde $\mathrm{L}_{\mathrm{b}}$ é o comprimento do trecho sem contenção lateral.

$$
\begin{aligned}
& M_{c r}=C_{b} \frac{\pi}{L_{b}} \sqrt{E I_{y} G I_{1}\left(1+\frac{\pi^{2} E C_{w}}{G I_{1} L_{b}^{2}}\right)} \\
& C_{b}=1,75+1,05\left(M_{1} / M_{2}\right)+0,3\left(M_{1} / M_{2}\right)^{2} \leq 2,30
\end{aligned}
$$

onde:

$\mathrm{M}_{1}$ = menor momento fletor de extremidade do trecho não contido lateralmente.

$\mathrm{M}_{2}$ = maior momento fletor de extremidade do trecho não contido lateralmente.

A relação $M_{1} / M_{2}$ é positiva quando estes momentos provocam curvatura reversa e negativa quando provocam curvatura simples.

Havendo uma distribuição não linear de momentos e em trechos onde o momento fletor intermediário for maior que os momentos de extremidades, a expressão de $C_{b}$, equação (4.32), não se aplica. Pode-se adotar, conservativamente, o valor de $\mathrm{C}_{\mathrm{b}}=1,0$.

Para perfis "I" duplamente simétricos, desprezando a contribuição da alma, figura 4.5, podem-se considerar as seguintes aproximações:

$$
C_{w} \cong \frac{b^{3} t d^{2}}{24} \quad I_{y} \cong \frac{b^{3} t}{6}
$$

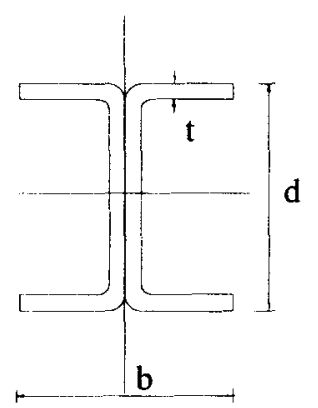

FIGURA 4.5 - Dimensões de perfil "I"

Com os valores de $\mathrm{C}_{\mathrm{w}}$ e $\mathrm{I}_{\mathrm{y}}$ aproximados e desprezando-se a rigidez de St. Venant, a equação (4.31) pode ser reescrita como: 


$$
M_{c r}=C_{b} \frac{\pi^{2} E d I_{y}}{2 L_{b}^{2}}
$$

Consequentemente, a tensão crítica de flambagem elástica, para um perfil "I" sujeito à flexão pura pode ser dada por:

$$
f_{e}=\frac{M_{c r}}{W_{x}}=\frac{M_{c r} d}{2 I_{x}}=C_{b} \frac{\pi^{2} E d^{2} I_{y}}{4 L_{b}^{2} I_{x}}
$$

No entanto, em se tratando de um perfil "I" enrijecido, o momento crítico é determinado por:

$$
M_{c r}=C_{b} \frac{\pi^{2} E}{L_{b}^{2}} \sqrt{C_{w} I_{y}}
$$

As equações (4.34) e (4.36) são aplicadas para o regime elástico, onde a tensão de flambagem é menor ou igual ao limite de proporcionalidade $\mathrm{f}_{\mathrm{pr}}$, caso contrário, para tensões acima deste limite, o comportamento da viga será dado pela flambagem inelástica.

Para vigas com pequena esbeltez lateral $\left(\lambda_{b}\right)$ e sem flambagens locais, $o$ momento de plastificação total da seção " $\mathrm{M}_{\mathrm{p}}$ " pode ser atingido.

Segundo GALAMBOS (1963), o momento de plastificação total da seção pode ser dado por:

$$
M_{p}=1,11 M_{y}
$$

onde:

$$
\begin{aligned}
& \mathrm{M}_{\mathrm{p}}=\text { momento de plastificação da seção. } \\
& \mathrm{M}_{\mathrm{y}} \quad=\text { momento de início de escoamento }=\mathrm{Wf}
\end{aligned}
$$

Assume-se que a tensão limite de proporcionalidade para perfis "I" em chapa dobrada seja igual a metade da tensão máxima resistente dada por:

$$
f_{p r}=\frac{1}{2}\left(1,11 f_{y}\right)=0,56 f_{y}
$$


O comportamento inelástico pode ser obtido quando a tensão crítica excede 0 limite de proporcionalidade sendo que, neste caso, é utilizada uma equação parabólica para representar tal comportamento:

$$
f=f_{y}\left(1,11-\frac{1}{3,24}\left[f_{y} \frac{\lambda_{b}^{2}}{C_{b} \pi^{2} E}\right]\right)
$$

A figura 4.6 apresenta graficamente as tensões críticas de flambagem lateral com torção, em regime elástico e inelástico, para vigas de seção "I" duplamente simétricas.
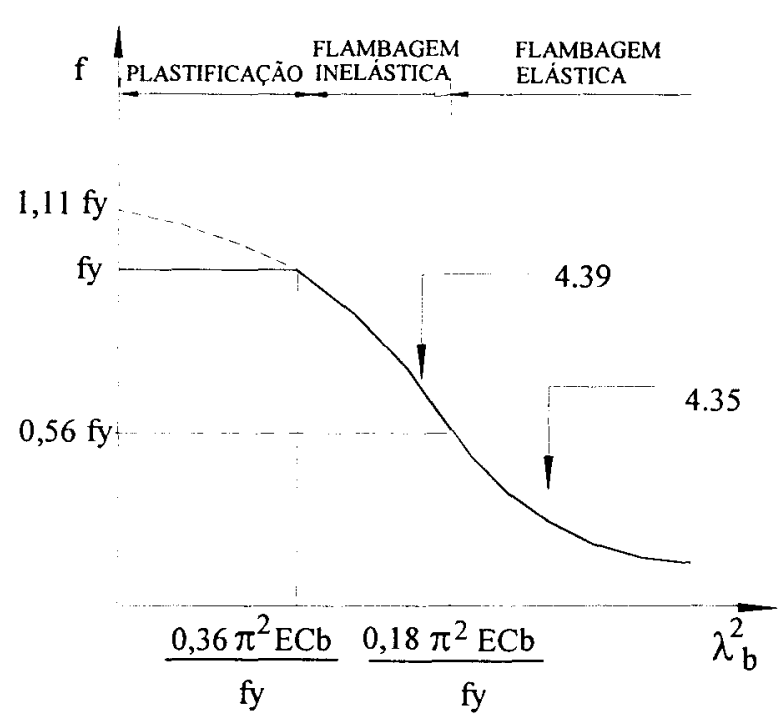

FIGURA 4.6 - Tensões críticas de flambagem lateral com torção de vigas "I" (YU, 1985).

\subsubsection{2 - OUTRAS SEÇÕES}

Para vigas com seção " $Z$ " utiliza-se o mesmo procedimento utilizado para perfis com dupla simetria no problema da flambagem lateral com torção.

De maneira conservadora prescrita pelo AISI (1980), o momento crítico, neste caso, deverá ser a metade do valor encontrado pela equação (4.34). A curva da tensão crítica de flambagem lateral para este perfil esta representado na figura 4.6, com uma tensão crítica calculada para um momento crítico igual a metade do valor obtido pela equação (4.34), ou seja: 


$$
M_{c r}=C_{b} \frac{\pi^{2} E d I_{y}}{4 L_{b}^{2}}
$$

As vigas com seção caixão têm uma rigidez maior à torção que os perfis "I", "U" e "Z", tornando-as mais econômicas se a flambagem lateral do perfil for determinante.

O momento crítico de flambagem lateral com torção, considerando constante de empenamento desta seção seja nula, $\mathrm{C}_{\mathrm{W}}=0$, ou seja, desprezando o efeito da flexo-torção, pode ser dado por:

$$
M_{c r}=C_{b} \frac{\pi}{L_{b}} \sqrt{E I_{y} G I_{t}}
$$

onde:

$$
\mathrm{I}_{\mathrm{y}}<\mathrm{I}_{\mathrm{X}}
$$

Se $I_{y} \geq I_{X}$, a viga se encontra na posição mais estável, consequentemente, não ocorrerá a flambagem lateral com torção.

\subsubsection{3 - SEÇÕES MONOSSIMÉTRICAS}

Perfis com simetria única, a simetria pode estar ou no eixo " $x$ " ou no eixo " $y$ ". A flexão ocorre em relação ao eixo de não simetria, que depende da seção transversal utilizada. O cálculo do momento crítico pode ser dado pela equação (4.31) e a flexão em relação ao eixo perpendicular ao eixo de simetria. $O$ centro de gravidade não coincide com o centro de torção, modificando o comportamento do perfil.

A flambagem lateral elástica destas seções, para uma viga simplesmente apoiada, com momentos fletores iguais e opostos aplicados nas extremidades, figura 4.7, pode ser representada pelas seguintes equações diferenciais:

$$
\begin{aligned}
& E I_{x} v^{i v}=0 \\
& E I_{y} u^{i v}+M \phi^{\prime \prime}=0 \\
& E C_{w} \phi^{i v}-\left[G I_{\imath}+2 M\left(k_{y}-y_{\nu}\right)\right] \phi^{\prime \prime}+M u^{\prime \prime}=0
\end{aligned}
$$




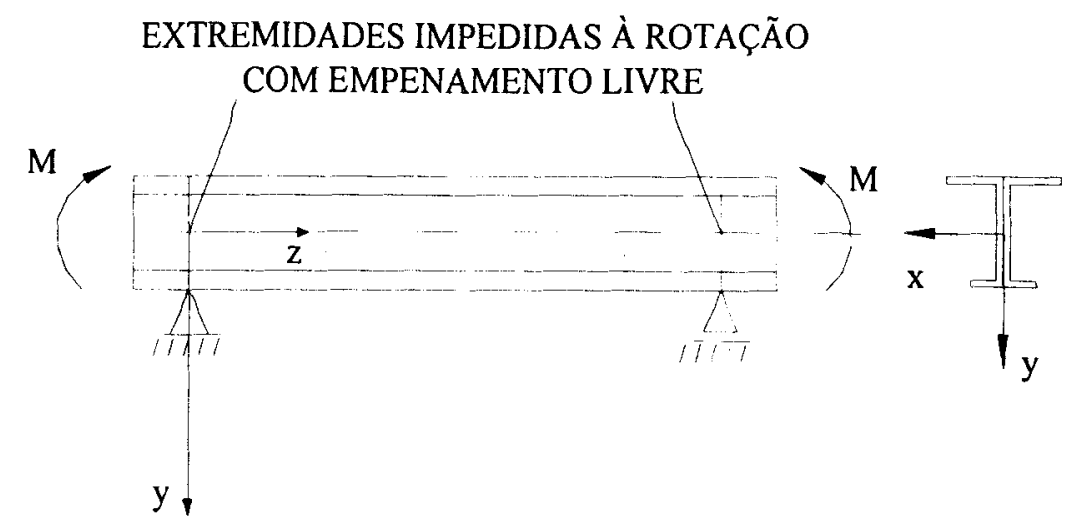

FIGURA 4.7 - Viga monossimétrica com momentos aplicados nas extremidades.

O valor do momento crítico elástico de flambagem lateral com torção pode ser obtido através das equações (4.43) e (4.44), nas variáveis "u" e " $\phi$ ", e com as respectivas condições de contorno das equações (4.26) e (4.27), como:

$$
M_{c r}=\frac{\pi E I_{y}}{L}\left[\frac{\pi}{L} j \pm \sqrt{\left(\frac{\pi j}{L}\right)^{2}+\frac{G I_{1}}{E I_{y}}+\left(\frac{\pi}{L}\right)^{2} \frac{C_{w}}{I_{y}}}\right]
$$

onde:

$$
\begin{aligned}
\mathrm{j} & =\text { característica geométrica da seção transversal }=\mathrm{k}_{\mathrm{y}}-\mathrm{y}_{0} \\
\mathrm{k}_{\mathrm{y}} & =\text { coordenada do centro do círculo de instabilidade segundo o eixo } \mathrm{y} \\
& =\mathrm{k}_{\mathrm{y}}=\frac{1}{2 \mathrm{I}_{\mathrm{x}}} \int_{\mathrm{A}} \mathrm{y}\left(\mathrm{x}^{2}+\mathrm{y}^{2}\right) \mathrm{dA}
\end{aligned}
$$

O sinal ( + ) se aplica para momentos fletores que causem tensões de compressão no lado do centro de cisalhamento em relação ao centro de gravidade e o sinal (-) se aplica para momentos fletores que causem tensões de tração no lado do centro de gravidade em relação ao centro de cisalhamento.

No caso particular de uma seção monossimétrica, sendo a constante de empenamento nula, $\mathrm{C}_{\mathrm{W}}=0$, como exemplo para um perfil " $\mathrm{T}$ ", a equação (4.45) pode ser reescrita por:

$$
M_{c r}=\frac{\pi E I_{y}}{L}\left[\frac{\pi}{L} j \pm \sqrt{\left(\frac{\pi j}{L}\right)^{2}+\frac{G I_{1}}{E I_{y}}}\right]
$$


Os perfis monossimétricos podem ter as soluções abordadas de maneira semelhante aos perfis de dupla simetria, dependendo da variação das condições de contorno e de carregamentos. De maneira aproximada, o coeficiente de momento uniforme equivalente " $\mathrm{C}_{b}$ " dado pela equação (4.32), levando em conta estas várias combinações de momentos nas extremidades da viga.

Portanto, pode-se determinar o valor do momento crítico dos perfis de simetria única em relação ao eixo "y", por:

$$
M_{c r}=C_{b} A_{g} f_{e y}\left[j \pm \sqrt{j^{2}+r_{0}^{2}\left(f_{e z} / f_{e y}\right)}\right]
$$

onde:

$$
\begin{aligned}
f_{e y} & =\frac{\pi^{2} E}{\left(k_{y} L_{y} / r_{y}\right)^{2}} \\
f_{e z} & =\frac{1}{A_{g} r_{0}^{2}}\left[\frac{\pi^{2} E C_{w}}{\left(k_{z} L_{z}\right)^{2}}+G I_{t}\right] \\
r_{0}^{2} & =r_{x}^{2}+r_{y}^{2}+y_{0}^{2} \\
A_{g} & =\text { área bruta da seção transversal. } \\
k L & =\text { comprimento efetivo de flambagem em relação ao eixo. }
\end{aligned}
$$

Para a análise do comportamento de uma viga em regime inelástico, admitese como tensão de proporcionalidade a metade da tensão limite de escoamento, sendo:

$$
\begin{array}{cc}
\text { para } \quad f_{e}>f_{y} / 2 & f=f_{y}\left(1-\frac{f_{y}}{4 f_{e}}\right) \\
\text { para } \quad f_{e} \leq f_{y} / 2 & f=f_{e}
\end{array}
$$

No regime elástico os valores de $M_{\mathrm{cr}}$ estão apresentados na tabela 4.3. Neste mesmo regime, para os casos de vigas submetidas a uma carga concentrada ou uniformemente distribuída, os valores de $\mathrm{P}_{\mathrm{cr}}$ estão na tabela 4.4. O regime elástico é admitido para valores abaixo da tensão de escoamento dividido por dois. 
TABELA 4.3 - Valores de $M_{\mathrm{cr}}$ para momentos aplicados nas extremidades.

\begin{tabular}{|c|c|c|}
\hline CARREGAMENTO & $\begin{array}{c}\text { SEÇÃO } \\
\text { TRANSVERSAL }\end{array}$ & $M_{c r}$ \\
\hline \multirow{4}{*}{ (Amो $\quad L^{\frac{\lambda}{n m m}}$} & & $\frac{\pi E I_{y}}{L}\left[\frac{\pi}{L} j \pm \sqrt{\left(\frac{\pi j}{L}\right)^{2}+\frac{G I_{t}}{E I_{y}}+\left(\frac{\pi}{L}\right)^{2} \frac{C_{w}}{I_{y}}}\right.$ \\
\hline & & $\frac{\pi E I_{y}}{L}\left[\frac{\pi}{L} j \pm \sqrt{\left(\frac{\pi j}{L}\right)^{2}}+\frac{G I_{t}}{E I_{y}}\right]$ \\
\hline & & $\frac{\pi}{L} \sqrt{E I_{y} G I_{t}\left(1+\frac{\pi^{2} E C_{w}}{G I_{t} L^{2}}\right)}$ \\
\hline & & $\frac{\pi}{L} \sqrt{E I_{y} G I_{\imath}}$ \\
\hline 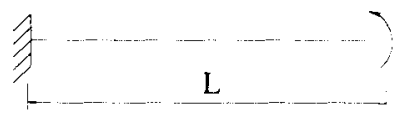 & 1 & $\frac{\pi}{2 L} \sqrt{E I_{y} G I_{t}}$ \\
\hline
\end{tabular}

TABELA 4.4 - Valores de $\mathrm{P}_{\text {cr }}$ para cargas concentradas e distribuídas.

\begin{tabular}{|c|c|c|}
\hline CARREGAMENTO & $\begin{array}{c}\text { SEÇÃO } \\
\text { TRANSVERSAL }\end{array}$ & $\mathrm{P}_{\mathrm{cr}}$ \\
\hline (Aीगे। & & $\frac{16,94}{L^{2}} \sqrt{E I_{y} G I_{c}}$ \\
\hline 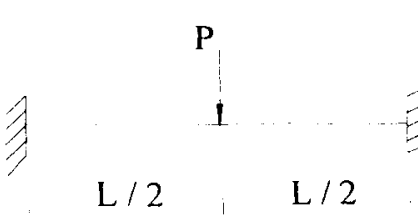 & 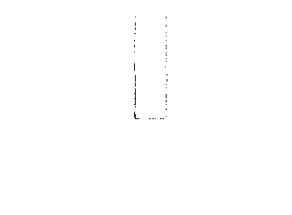 & $\frac{26,60}{L^{2}} \sqrt{E I_{y} G I_{t}}$ \\
\hline
\end{tabular}


TABELA 4.4 - Continuação.

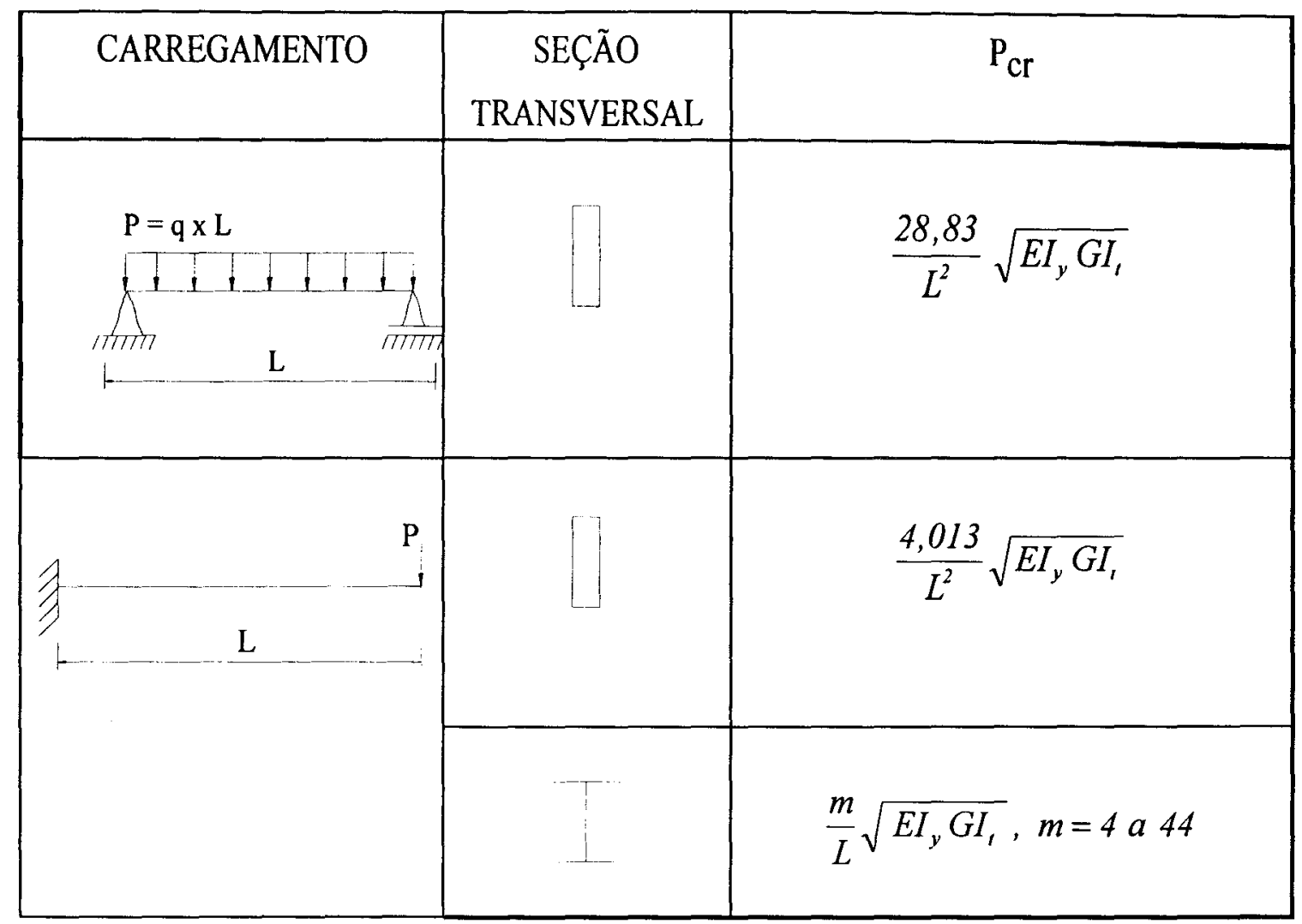

onde:

$$
\begin{aligned}
\mathrm{m} & =\frac{4,013}{\left(1-\sqrt{E C_{w} / l^{2} G J_{t}}\right)^{2}} \\
\mathrm{GJ}_{\mathrm{t}} & =\text { rigidez à torção. } \\
\mathrm{EC}_{\mathrm{W}} & =\text { rigidez ao empenamento. }
\end{aligned}
$$

\subsubsection{3 - RESERVA DE RESISTÊNCIA INELÁSTICA DE VIGAS DEVIDA A PLASTIFICAÇÃO PARCIAL DA SEÇÃO TRANSVERSAL}

Para o dimensionamento de elementos fletidos no regime inelástico, o limite último pode ser caracterizado pelo início de escoamento de uma fibra extrema da seção transversal. Quando o momento fletor máximo excede o valor limite que causa o seu escoamento inicial, ocorre a plastificação da seção transversal.

Segundo YU (1985), estudos conduzidos por RECK et al. na Universidade Cornell verificaram a reserva de resistência inelástica devida a plastificação parcial da seção transversal para os elementos de chapa dobrada. 
Esta reserva de resistência inelástica pode ser definida como a relação entre o momento último " $\mathrm{M}_{\mathrm{u}}$ " e o momento que causa o início de escoamento de uma fibra extrema da seção transversal da viga " $\mathrm{M}_{\mathrm{y}}$ ".

$\mathrm{O}$ momento último " $\mathrm{M}_{\mathrm{u}}$ " representa a máxima resistência à flexão da viga considerando-se a reserva de resistência inelástica através de plastificação parcial da seção transversal. A distribuição de tensão na seção transversal depende da máxima deformação à compressão do elemento enrijecido " $\varepsilon_{c u}$ ".

A partir de ensaios realizados na Universidade Cornell em vigas com seção transversal em cartola, sob a ação de flexão pura, a especificação do AISI estabeleceu limites para máxima deformação à compressão como sendo $\mathrm{C}_{\mathrm{y}} \varepsilon_{\mathrm{y}}$, como:

$$
\varepsilon_{c u}=C_{y} \varepsilon_{y}
$$

onde:

$\varepsilon_{\mathrm{y}} \quad=$ deformação no escoamento $=\mathrm{f}_{\mathrm{y}} / \mathrm{E}$.

$\mathrm{E} \quad=$ módulo de elasticidade $(\mathrm{em} \mathrm{MPa})$.

$\mathrm{f}_{\mathrm{y}} \quad=$ tensão de escoamento do aço (em $\left.\mathrm{MPa}\right)$.

$\mathrm{C}_{\mathrm{y}} \quad=$ fator de deformação à compressão determinado a seguir:

1) Elementos comprimidos enrijecidos, sem enrijecedores intermediários:

a) Para $b / t \leq 500 / \sqrt{f_{y}}$

$$
C_{y}=3
$$

b) Para $500 / \sqrt{f_{y}}<b / t<580 \sqrt{f_{y}}$

$$
C_{y}=3-\frac{(b-t) \sqrt{f_{y}}-500}{40}
$$

c) Para $b / t>580 \sqrt{f_{y}}$

$$
C_{y}=1,0
$$


A relação entre $C_{y}$ e a proporção b/t do elemento comprimido está representada na figura 48.

\section{2) Elementos comprimidos não enrijecidos}

$$
C_{y}=1,0
$$

3) Elementos multi-enrijecidos à compressão e elementos à compressão com enrijecedores de borda:

$$
C_{y}=1,0
$$

Os valores de $\mathrm{C}_{\mathrm{y}}$ foram adotados como um limite inferior para os resultados experimentais. A especificação do AISI (1980) não impôs nenhum limite à deformação por tração.

Com base na máxima deformação de compressão " $\varepsilon_{\mathrm{cu}}$ " admissível, equação (4.53), localiza-se a linha neutra utilizando-se a equação (4.59), e o momento fletor último " $\mathrm{M}_{\mathrm{u}}$ ", determina-se de acordo com a equação (4.60), como:

$$
\begin{aligned}
& \int_{A} \sigma d A=0 \\
& \int_{A} \sigma y d A=M_{u}
\end{aligned}
$$

onde " $\sigma$ " é a máxima tensão normal do elemento de área correspondente da seção transversal. Utilizando-se a reserva de resistência inelástica dos elementos fletidos, a especificação do AISI adota o procedimento de cálculo acima, sendo que, devem ser respeitados os seguintes itens:

I) A viga não deve estar sujeita à torção ou à flambagem lateral.

II) $\mathrm{O}$ efeito do trabalho a frio não está incluído na determinação da tensão limite de escoamento.

III) A relação da altura da parte comprimida da alma pela sua espessura não deve exceder $500 / \sqrt{f_{y}}, f_{y}$ em MPa.

IV) A força de cisalhamento não deve exceder $0,35 f_{y} \times h t$, onde h $\times$ t é a área da alma.

V) $\mathrm{O}$ ângulo entre qualquer alma e a vertical não deve exceder $30^{\circ}$. 


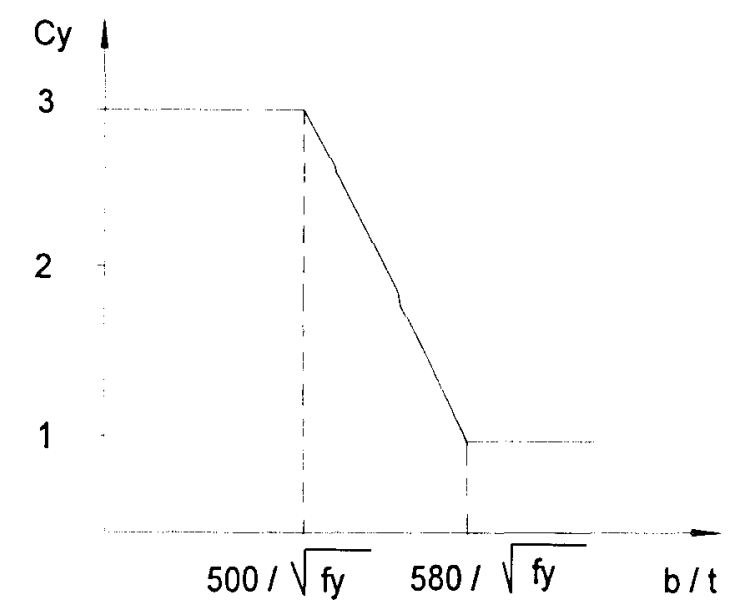

FIGURA 4.8 - Fator $C_{y}$ para elemento enrijecido à compressão sob momento fletor variável (f $f_{y}$ em MPa) [JAVARONI, 1993).

\subsection{3 - RESISTÊNCIA À FORÇA CORTANTE}

Considerando-se os conceitos da resistência dos materiais, a máxima tensão de cisalhamento na seção transversal de vigas é representada por:

$$
\tau_{\text {máx }}=\frac{V M_{s}}{I t}
$$

onde:

I = momento de inércia da seção transversal em relação ao eixo de

$$
\text { flexão }=\frac{t h^{3}}{12}
$$

$\mathrm{M}_{\mathrm{S}} \quad$ = momento estático da parte da seção acima da fibra na qual a tensão de cisalhamento é determinada em relação aos eixos principais de inércia $=\frac{h}{2} t \frac{h}{4}$

$\mathrm{t} \quad=$ espessura ou largura da seção transversal na fibra em estudo.

$\mathrm{V}=$ força cortante na seção transversal.

Nos perfis metálicos, a maior parte das tensões de cisalhamento nas seções encontra-se na alma. Para os perfis de seções delgadas, considera-se o uso de uma tensão média de cisalhamento sobre a área bruta da alma, não considerando as tensões de cisalhamento na mesa, equação (4.62). 


$$
\tau_{\text {max }}=\frac{V M_{s}}{I t}=\frac{V l, 5}{h t} \therefore \quad \tau_{\text {média }}=\frac{V}{h t_{w}}
$$

onde:

h = = distância livre entre mesas.

$\mathrm{t}_{\mathrm{W}} \quad=$ espessura da alma.
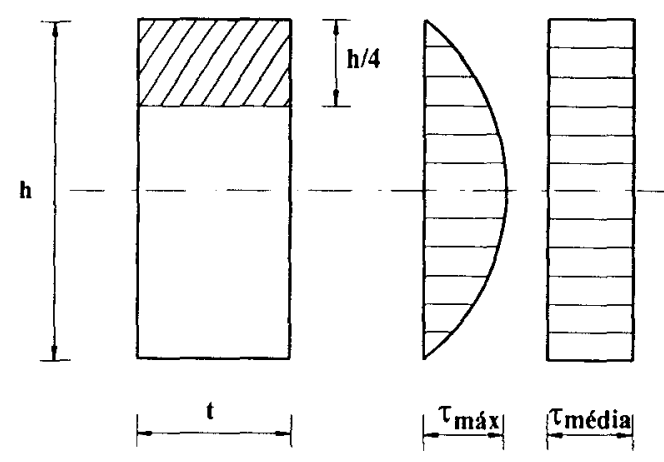

FIGURA 4.9 - Representação da $\tau_{\text {máx }}$ e $\tau_{\text {média. }}$

Para almas com relação $\mathrm{h} / \mathrm{t}_{\mathrm{w}}$ relativamente pequena, $\left(h / t_{w} \leq 1,08 \sqrt{k E / f_{y}}\right)$, as quais estando sujeitas a tensão de cisalhamento, a ruptura se dará pelo seu escoamento.

Devido ao estado de cisalhamento simples têm-se, pelo critério de energia de distorção, a tensão de escoamento representada por:

$$
\tau_{y}=\frac{f_{y}}{\sqrt{3}}=0,577 f_{y}
$$

Em almas esbeltas $\left(h / t_{w}>140 \sqrt{k E / f_{y}}\right)$, devido às tensões atuantes de cisalhamento, obtém-se a resistência ao cisalhamento pela flambagem elástica. Pode ser determinada a tensão crítica de flambagem elástica por cisalhamento como:

$$
\tau_{c r}=\frac{k \pi^{2} E}{12\left(1-v^{2}\right)\left(h / t_{w}\right)^{2}}
$$

onde: 
a = distância entre enrijecedores transversais.

h = altura da alma.

$\mathrm{k}=$ coeficiente de flambagem por cisalhamento [para diferentes relações de (a/h), equações (4.176), (4.177) e (4.178)].

$\mathrm{t}_{\mathrm{W}} \quad=$ espessura da alma.

$v \quad=$ coeficiente de Poisson.

O valor teórico da tensão crítica de flambagem inelástica para almas medianamente esbeltas é maior que a tensão limite de proporcionalidade no cisalhamento $\left(0,8 \tau_{\mathrm{y}}\right)$. BASLER (1961), a partir de análises experimentais, apresentou a equação (4.65) para o cálculo da tensão crítica de flambagem inelástica por cisalhamento, isto é, quando " $\tau_{\mathrm{cr}}$ " for maior que o limite de proporcionalidade em cisalhamento.

$$
\tau_{c r}=\sqrt{\tau_{p r} \tau_{c r e}}
$$

onde:

$\tau_{\mathrm{pr}} \quad=$ tensão limite de proporcionalidade em cisalhamento $=\left(0,8 \tau_{\mathrm{y}}\right)$

$\tau_{\text {cre }}=$ tensão crítica de flambagem elástica, equação (4.64).

Substituindo os valores de $\tau_{\mathrm{pr}}$ e $\tau_{\mathrm{cr}}$ obtém-se a equação da tensão crítica por cisalhamento, como:

$$
\tau_{c r}=0,21 \pi \frac{\sqrt{k E f_{y}}}{h / t_{w}}=0,577 f_{y}
$$

Igualando-se as equações (4.63) e (4.66) obtém-se o valor limite de $\lambda_{p}$ para o qual aplica-se a equação (4.63), ou seja:

$$
\lambda_{p}=1,08 \sqrt{k E / f_{y}}
$$

Para valores da equação $(\mathrm{h} / \mathrm{t})$ maiores que este valor de $\lambda_{\mathrm{p}}$, aplica-se a equação (4.66) até o limite em que a tensão crítica $\left(\tau_{c r}\right)$, representada pela equação(4.64), for igual à tensão limite de proporcionalidade no cisalhamento, sendo: 


$$
\lambda_{r}=1,40 \sqrt{k E / f_{y}}
$$

Para valores da relação $(\mathrm{h} / \mathrm{t})$ maiores que $\lambda_{\mathrm{r}}$, a flambagem da alma ocorrerá no regime elástico, aplicando-se assim a equação (4.64).

As equações para o cálculo da tensão crítica de flambagem por cisalhamento podem ser representadas pela figura 4.10 .

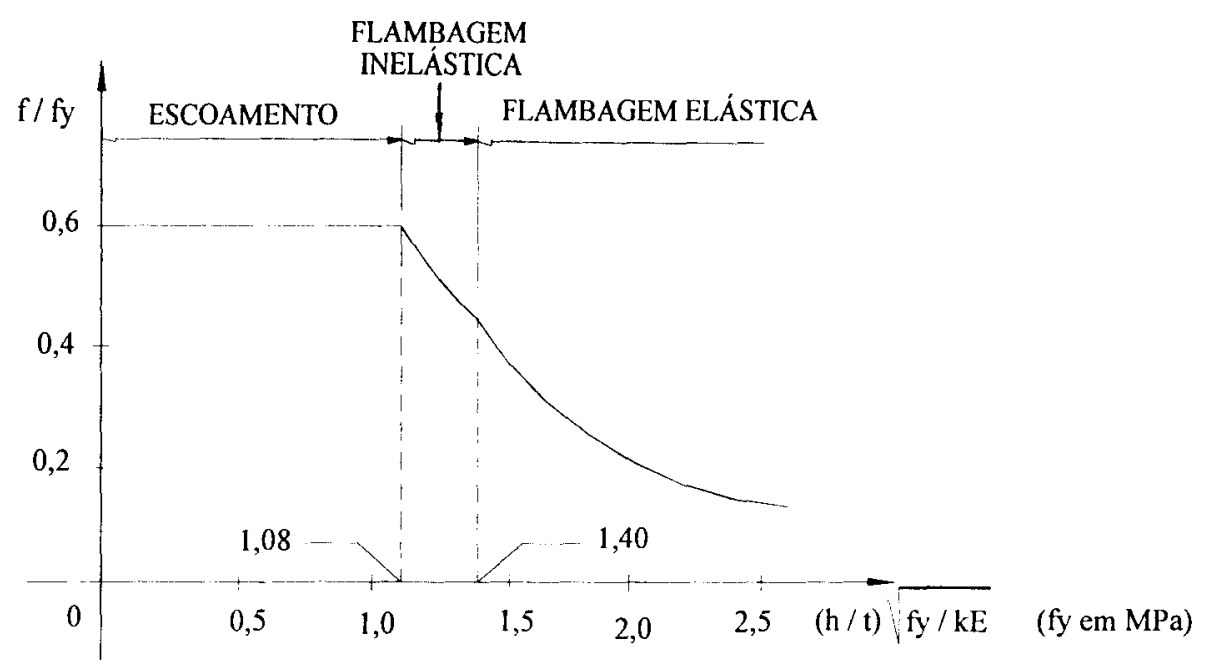

FIGURA 4.10 - Limites para as tensões críticas de cisalhamento em almas (JAVARONI, 1993).

A partir da equação (4.62) e dos parâmetros de esbeltez $\lambda_{p} \mathrm{e} \lambda_{\mathrm{r}}$, as equações (4.63), (4.64) e (4.66) podem ser escritas em termos de força cortante $\mathrm{V}$, como se segue:
a) para $\lambda \leq \lambda_{p}$
$\rightarrow \quad V=V_{p l}$
b) para $\lambda_{\mathrm{p}}<\lambda \leq \lambda_{\mathrm{r}} \quad \rightarrow \quad V=\frac{\lambda_{p}}{\lambda} V_{p l}$
c) para $\lambda>\lambda_{r}$
$\rightarrow \quad V=1,28\left(\frac{\lambda_{p}}{\lambda}\right)^{2} V_{p l}$

onde:

$\lambda \quad=$ parâmetro de esbeltez $=\mathrm{h} / \mathrm{t}_{\mathrm{W}}$

$\lambda_{\mathrm{p}} \quad=$ parâmetro de esbeltez correspondente à plastificação.

$\lambda_{\mathrm{r}} \quad=$ parâmetro de esbeltez correspondente ao comportamento elástico.

$\mathrm{V}_{\mathrm{pl}}=$ força cortante correspondente à plastificação da alma $=0,6 \mathrm{~A}_{\mathrm{w}} \mathrm{f}_{\mathrm{y}}$

$\mathrm{A}_{\mathrm{W}} \quad=$ área bruta da alma $=\mathrm{ht}_{\mathrm{W}}$. 


\subsection{4 - VERIFICAÇÃO DA FORÇA CORTANTE COM O MOMENTO FLETOR}

As vigas em balanço $e$ as vigas contínuas estão sujeitas às tensões normais elevadas devidas a flexão, que podem estarem, ou não combinadas com tensões elevadas de cisalhamento.

TIMOSHENKO \& GERE (1961) estudaram as combinações mais críticas destas tensões e obtiveram os seguintes resultados:

- Para valores da relação $\tau / \tau_{c r} \leq 0,4$, o efeito das tensões de cisalhamento no valor da tensão crítica devido à flexão é pequeno.

- Para valores da relação $f / f_{c r} \leq 0,4$, o efeito das tensões normais de flexão no valor da tensão crítica de cisalhamento é pequeno.

Para chapas isoladas com valores da relação $(\mathrm{a} / \mathrm{h})$ variando entre 0,5 e 1,0 , a curva de interação entre $\mathrm{f} / \mathrm{f}_{\mathrm{cr}}$ e $\tau / \tau_{\mathrm{cr}}$ aproxima-se de um segmento de círculo, figura 4.11, e pode ser expresso pela equação (4.72).

$$
\left(\frac{f}{f_{c r}}\right)^{2}+\left(\frac{\tau}{\tau_{c r}}\right)^{2}=1
$$

onde:

$\mathrm{f} \quad=$ tensão devida a flexão.

$\mathrm{f}_{\mathrm{Cr}} \quad=$ tensão crítica de flambagem elástica na flexão pura.

$\tau \quad=$ tensão de cisalhamento.

$\tau_{\mathrm{cr}}=$ tensão crítica de flambagem elástica por cisalhamento puro.

LABOUBE \& YU (1991), baseados em resultados experimentais, desenvolveram a seguinte interação para almas de vigas com enrijecedores transversais:

$$
0,6\left(\frac{f}{f_{c r}}\right)+\left(\frac{\tau}{\tau_{c r}}\right)=1,3
$$

A equação anterior aplica-se somente quando a relação $\left(\mathrm{f} / \mathrm{f}_{\mathrm{cr}}\right)>0,5$ e $\left(\tau / \tau_{c r}\right)>0,7$. Para outras condições, o projeto da alma é governado ou pela resistência à flexão ou pela resistência ao cisalhamento. 


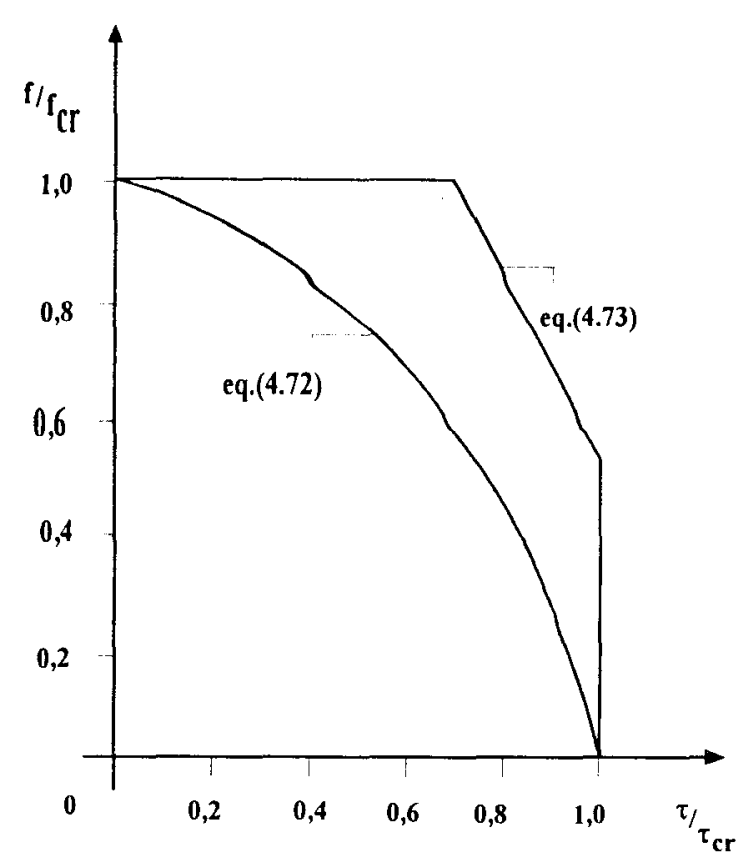

FIGURA 4.11 - Relação de interação entre "f" e " $\tau "$ (YU, 1985).

\subsection{5 - ENRUGAMENTO DA ALMA}

O enrugamento de almas das barras à flexão ocorre com a flambagem da alma onde há forças concentradas de alta intensidade ou reações de apoio atuando perpendicularmente ao eixo longitudinal da barra e no plano da alma considerada, causando tensão de compressão elevada na alma.

Para evitar o enrugamento da alma, as equações seguintes são válidas somente para almas planas não enrijecidas, com relação altura-espessura $(\mathrm{h} / \mathrm{t})$ menor ou igual que 200. Valores maiores que este limite exigem o uso de enrijecedores transversais. Devem-se levar em conta os seguintes limites:

- vigas de almas simples: $\mathrm{R} / \mathrm{t} \leq 4, l / \mathrm{t} \leq 200 \mathrm{e} l / \mathrm{h} \leq 1$

- vigas de alma múltipla: $\mathrm{R} / \mathrm{t} \leq 10, l / \mathrm{t} \leq 200$ e $l / \mathrm{h} \leq 2$

sendo, "R" o raio interno de dobramento, "t" a espessura, "h" a altura da alma e "l" o comprimento de atuação da força.

Devem-se fazer as considerações dos casos a seguir, para o emprego das equações das tabelas (4.5), (4.6) e (4.7): 


\section{Caso I}

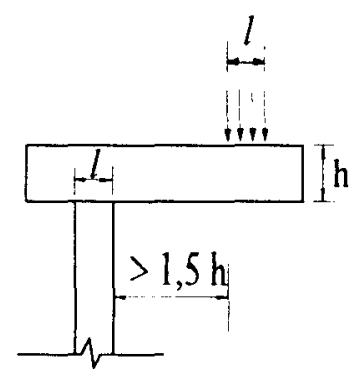

Carregamento ou reação em uma mesa: quando a distância entre a borda do apoio e a da força ou reação for $>1,5 \mathrm{~h}$.

Caso II

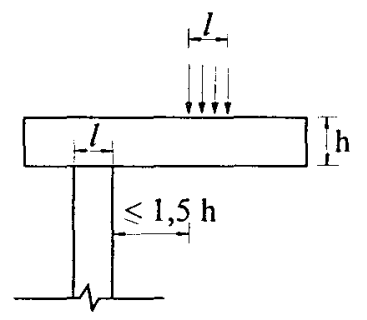

Carregamento ou reação em duas mesas: quando a distância entre a borda do apoio e a da força ou reações for $\leq 1,5 \mathrm{~h}$.

Caso III

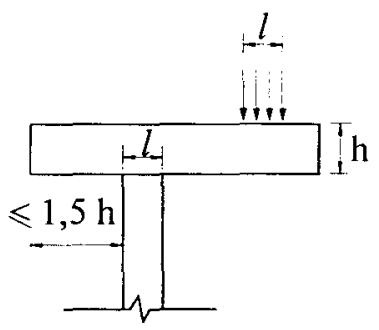

Carregamento ou reação extremo: quando a distância da borda do apoio à extremidade da mesma for $\leq 1,5 \mathrm{~h}$.

\section{Caso IV}

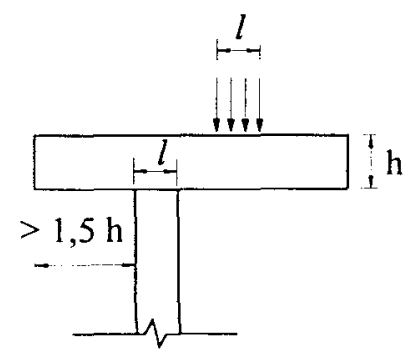

Carregamento ou reação interno: quando a distância da borda do apoio à extremidade da mesma for $>1,5 \mathrm{~h}$. 
TABELA 4.5 - Seções compostas $\rightarrow$ seções "I" formadas pela união de dois perfis "U" ligados pela alma ou pela união de duas cantoneiras a um perfil "U" (CSA, 1984).

\begin{tabular}{|l|l|}
\hline \multirow{2}{*}{$\begin{array}{l}\text { Carregamento em uma mesa } \\
\text { interno: } \\
\end{array}$} & $\begin{array}{l}\text { extremo: } N_{n}=t^{2} f_{y} C_{2}(10+1,25 \sqrt{1 / t}) \\
N^{2} f_{y} C_{1}(0,88+0,063 t)(15+3,25 \sqrt{1 / t})\end{array}$ \\
\hline $\begin{array}{l}\text { Carregamento em duas } \\
\text { mesas }\end{array}$ & $\begin{array}{l}\text { extremo: } \\
N_{n}=t^{2} f_{y} C_{f}(0,64+0,16 t)(10+1,25 \sqrt{1 / t}) \\
\text { interno: } \\
N_{n}=t^{2} f_{y} C_{3}(0,82+0,079 t)(15+3,25 \sqrt{1 / t})\end{array}$ \\
&
\end{tabular}

TABELA 4.6 - Seções com alma simples $\rightarrow$ seções "U" e "Z", (CSA, 1984).

\begin{tabular}{|c|c|}
\hline Carregamento em uma mesa & $\begin{array}{l}\text { extremo: } \\
\text { para seções com mesas enrijecidas } \\
\begin{aligned} N_{n}= & 10 t^{2} f_{y}(1,33-0,33 \mathrm{k})(1,15-0,15 R / t) \\
$\[ \]$ & (1+0,1 \mathrm{ll} t \mathrm{t})(1-0,018 \mathrm{~h} / \mathrm{t})\end{aligned} \\
\text { para seções com mesas não enrijecidas } \\
N_{n}=6,6 t^{2} f_{y}(1,33-0,33 \mathrm{k})(1,15-0,15 \mathrm{R} / \mathrm{t}) \\
\qquad(1+0,01 \mathrm{l} / \mathrm{t})(1-0,0013 \mathrm{~h} / \mathrm{t}) \\
\text { interno: } \\
N_{n}=16 t^{2} f_{y}(1,22-0,22 \mathrm{k})(1,06-0,06 \mathrm{R} / \mathrm{t}) \\
\quad(1,0,007 \mathrm{l} / \mathrm{t})(1-0,0014 \mathrm{~h} / \mathrm{t})\end{array}$ \\
\hline Carregamento em duas mesas & $\begin{array}{l}\text { extremo: } \\
\begin{aligned} N_{n}=7,4 t^{2} f_{y}(1,33-0,33 k)(1,15-0,15 R / t) \\
$\[ \]$ \\
\quad(1+0,01 l / t)(1-0,0023 h / t)\end{aligned} \\
\text { interno } \\
\begin{aligned} N_{n}= & 16 t^{2} f_{y}(1,22-0,22 k)(1,06-0,06 R / t) \\
& (1+0,01 l / t)(1-0,0029 h / t)\end{aligned}\end{array}$ \\
\hline
\end{tabular}


TABELA 4.7 - Perfis com almas múltiplas $\rightarrow$ perfis cartolas, painéis de fechamento e pisos, (CSA, 1984).

\begin{tabular}{|c|c|}
\hline Carregamento em uma mesa & $\begin{array}{l}\text { extremo; } \\
\begin{array}{l}N_{n}=10 t^{2} f_{y}(\operatorname{sen} \alpha)(1-0,1 k)(1-0,1 \sqrt{R / t}) \\
\qquad(1+0,005 l / t)(1-0,002 h / t) \\
\text { interno } \\
N_{n}=18 t^{2} f_{y}(\operatorname{sen} \alpha)(1-0,1 k)(1-0,075 \sqrt{R / t}) \\
\qquad(1+0,005 l / t)(1-0,001 h / t)\end{array}\end{array}$ \\
\hline Carregamento em duas mesas & $\begin{array}{l}\text { extremo: } \\
\begin{aligned} N_{n}= & 19 t^{2} f_{y}(\operatorname{sen} \alpha)(1-0,1 k)(1-0,1 \sqrt{R / t}) \\
& (1-0,001 l / t)(1-0,002 h / t) \\
\text { interno } & \\
N_{n}= & 10 t^{2} f_{y}(\operatorname{sen} \alpha)(1-0,2 k)(1-0,03 \sqrt{R / t}) \\
& (1+0,01 l / t)(1-0,015 h / t)\end{aligned}\end{array}$ \\
\hline
\end{tabular}

onde:

$$
\begin{array}{ll}
\mathrm{C}_{1} & =(1,49-0,53 \mathrm{k}) \geq 0,6 \\
\mathrm{C}_{2} & =1+\mathrm{h} /(750 \mathrm{t}) \leq 1,2 \\
\mathrm{C}_{3} & =1 / \mathrm{k} \quad \text { para } \mathrm{h} / \mathrm{t} \leq 66,5 \\
\mathrm{C}_{3} & =[1,1-\mathrm{h} /(665 \mathrm{t})] / \mathrm{k} \rightarrow \quad \text { para } \mathrm{h} / \mathrm{t}>66,5 \\
\mathrm{C}_{4} & =[0,98-\mathrm{h} /(865 \mathrm{t})] / \mathrm{k} \\
\mathrm{h} & =\text { altura da alma. } \\
\mathrm{k} & =\mathrm{f}_{\mathrm{y}} / 230 \quad\left(\mathrm{f}_{\mathrm{y}}\right. \text { em MPa) } \\
\mathrm{l} & =\text { comprimento, na direção longitudinal da viga, de atuação }
\end{array}
$$$$
\text { da força ou reação. }
$$

$\mathrm{N}_{\mathrm{n}} \quad$ = resistência nominal ao enrugamento da alma.

$\mathrm{R} \quad=$ raio interno de dobramento.

$\alpha \quad$ = ângulo entre o plano da alma e o plano da superfície de apoio $\left(45^{\circ}<\alpha<90^{\circ}\right)$. 


\subsection{6 - COMBINAÇÃO ENTRE FLEXÃO E ENRUGAMENTO DA ALMA}

Devido aos efeitos do momento fletor, a resistência ao enrugamento da alma pode ser reduzida significativamente. YU (1985), baseado em resultados experimentais de vigas ensaiadas com a combinação do enrugamento com a flexão, concluiu que:

a) Vigas com almas simples:

a.1) Quando a relação $M_{\exp } / M_{\mathfrak{u}}$ exceder 0,35, a presença de momento fletor reduz a resistência ao enrugamento da alma. A equação seguinte apresenta uma correlação de resultados experimentais:

$$
1,07 \frac{\mathrm{N}_{\exp }}{N_{u}}+\frac{M_{\exp }}{M_{u}}=1,42
$$

onde:

$$
\begin{aligned}
\mathrm{N}_{\exp }= & \text { máxima força concentrada ou reação na presença de momento fletor. } \\
\mathrm{N}_{\mathrm{U}}= & \text { máxima força concentrada ou reação na ausência de momento } \\
& \text { fletor, tabela } 4.6 . \\
\mathrm{M}_{\mathrm{exp}}= & \text { máximo momento fletor na região do ponto de aplicação da força } \\
& \text { concentrada de reação. } \\
\mathrm{M}_{\mathrm{U}} \quad & \text { máximo momento fletor determinado somente pela resistência à } \\
& \text { flexão, excluindo-se o caso da flambagem lateral com torção. }
\end{aligned}
$$

a.2) Quando uma força cortante "V" em uma viga for menor ou igual a $40 \%$ da resistência ao cisalhamento, a presença da força de cisalhamento não reduz significativamente a resistência ao enrugamento da alma.

b) Vigas "I"

b.1) Vigas "I" com relação $(h / t) \leq\left(2,33 / \sqrt{f_{y} / E}\right)$ e $(b / t) \leq(b / t)_{\lim }$, o momento fletor causa pouca influência ao enrugamento da alma. Resultados experimentais em vigas "I", apresentaram boa correlação com relações de esbeltez da alma e da mesa para os limites acima, obtidos através da equação (4.93). 


$$
0,82 \frac{N_{\text {exp }}}{N_{u}}+\frac{M_{\text {exp }}}{M_{u}}=1,32
$$

onde: $N_{\text {exp }}, N_{u}, M_{\text {exp }}$ e $M_{u}$ conforme item a).

b.2) A combinação da força cortante, cujo valor não seja maior que $80 \%$ da resistência ao cisalhamento, com o enrugamento da alma não afeta consideravelmente a resistência ao enrugamento da alma.

Pode-se assumir a equação (4.94) para almas simples ou vigas "I", sendo:

$$
\frac{N_{e x p}}{N_{u}}+\frac{M_{e x p}}{M_{u}} \leq 1,32
$$

\subsection{7 - ENRIJECEDORES TRANSVERSAIS}

A utilização de enrijecedores transversais, ou enrijecedores de cisalhamento, proporciona um aumento na resistência da alma aumentando, portanto, a resistência da viga. São utilizados para almas cujo índice de esbeltez, $\left(\mathrm{h} / \mathrm{t}_{\mathrm{W}}\right)$, for maior que $200 \mathrm{e}$ em vigas onde as condições dos iténs anteriores para almas não são satisfeitos.

A resistência nominal do enrijecedor pode ser determinada pelo menor valor entre:

$$
\begin{aligned}
& N_{n}=A_{c} f_{w y} \\
& N_{n}=A_{b} f
\end{aligned}
$$

onde:

$\mathrm{A}_{\mathrm{b}}=b_{1} t_{w}+A_{s t}$ para enrijecedores nos apoios internos sob força concentrada.

$\mathrm{A}_{\mathrm{b}}=b_{2} t_{w}+A_{s t}$ para enrijecedores nas extremidades das vigas.

$\mathrm{A}_{\mathrm{C}}=18 t_{w}^{2}+A_{s t}$ para enrijecedores nos apoios internos sob forças concentradas. 
$\mathrm{A}_{\mathrm{c}} \quad=10 t_{w}^{2}+A_{\mathrm{st}}$ para enrijecedores nas extremidades das vigas.

$\mathrm{b}_{1}=25 t_{w}\left[0,0024\left(L_{s t} / t_{w}\right)+0,72\right] \leq 25 t_{w}$

$\mathrm{b}_{2}=25 t_{w}\left[0,0024\left(L_{s t} / t_{w}\right)+0,83\right] \leq 12 t_{w}$

$\mathrm{f}=$ tensão crítica de flambagem.

$\mathrm{f}_{\mathrm{y}}=$ menor valor da tensão limite de escoamento da alma ou do enrijecedor transversal.

$\mathrm{L}_{\mathrm{St}} \quad=$ comprimento do enrijecedor transversal.

$\mathrm{t}_{\mathrm{W}} \quad=$ espessura da alma.

$\mathrm{A}_{\mathrm{St}} \quad=$ área bruta da seção transversal do enrijecedor não deverá ser menor que:

$$
A_{s t}=\frac{1-V_{n} / V_{p l}}{2}\left[1-\frac{a / h}{a / h+\sqrt{1+(a / h)^{2}}}\right] Y D a t_{w}
$$

onde:

a = espaçamento entre enrijecedores transversais.

$\mathrm{D} \quad=1,0 \rightarrow$ para enrijecedores colocados aos pares.

$\mathrm{D} \quad=1,8 \rightarrow$ para enrijecedores constituídos de uma cantoneira.

D $\quad=2,4 \rightarrow$ para enrijecedores constituídos de uma chapa.

$\mathrm{V}_{\mathrm{n}} \quad=$ resistência nominal à força cortante.

y = relação entre os limites de escoamento dos aços da alma e do enrijecedor.

\subsection{8 - EFEITO SHEAR LAG}

O fenômeno conhecido como "Shear lag" ocorre em vigas cujas mesas têm grande largura relativamente ao vão $\left(b_{f} \geq L / 30\right)$. Nesses casos, a distribuição de tensões normais de flexão nas mesas das vigas não é uniforme, decrescendo com o aumento da distância a partir da alma, como apresentado na figura 4.12. 


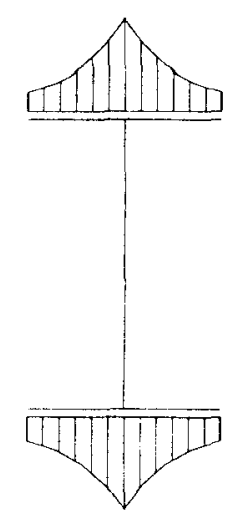

FIGURA 4.12 - Distribuição de tensões normais nas mesas de um perfil "I", pelo efeito "Shear Lag" (YU, 1985).

WINTER ${ }^{1}$ apud YU (1985), baseado na teoria da tensão plana, analisou o problema "shear lag" e dispôs dados em forma de tabelas e gráficos para os quais a largura efetiva pode ser obtida diretamente. Foi verificada a importância do efeito "shear lag" em vigas com pequenos vãos sujeitas a cargas concentradas, isto é, quanto menor a relação vão pela largura, maior o efeito. Em vigas sujeitas a cargas uniformemente distribuídas, o efeito shear lag é desprezivel exceto quando a relação $\mathrm{L} / \mathrm{b}_{\mathrm{f}}$ for menor que 5 , figura 4.13 . Winter também concluiu que para dadas relações $\mathrm{L} / \mathrm{b}_{\mathrm{f}}$ o efeito shear lag é praticamente o mesmo para diferentes tipos de perfis.

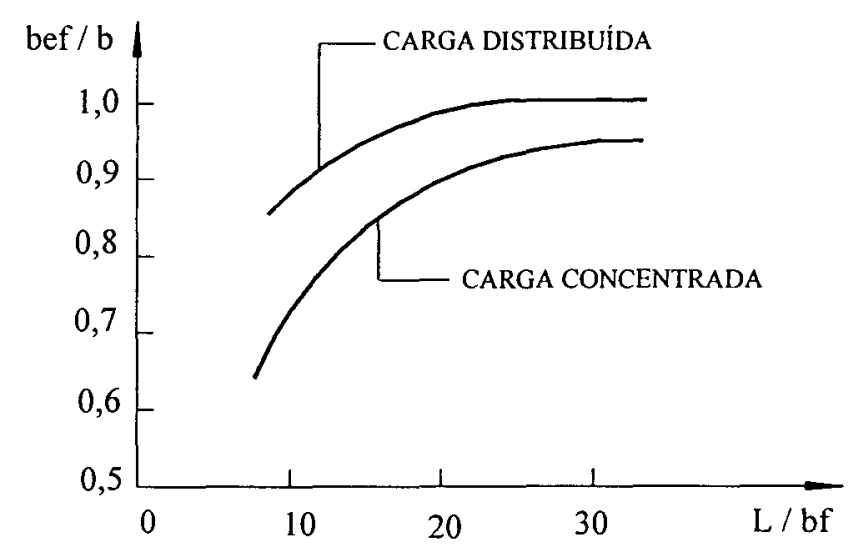

FIGURA 4.13 - Curvas para a determinação da largura efetiva de mesas de vigas com vão curto (YU, 1985).

${ }^{1}$ WINTER, G. (1940). Stress distribution in and euivalent width of flanges of wide, thin-wall steel beams, NACA technical note 784 apud YU, W. W. (1985) Cold-formed steel design, New York, Wiley \& Sons. 
As normas AISI e CSA estabelecem que, quando o vão da viga " $L$ " for menor que $\left(30 b_{f}\right)$ e quando suporta uma força concentrada ou várias forças distantes entre si de pelo menos ( $\left.2 \mathrm{~b}_{\mathrm{f}}\right)$, a relação largura efetiva e a largura plana em mesas tracionada ou comprimida deve ser limitada pelos valores das relações dadas na tabela 4.8.

TABELA 4.8 - Máxima relação admissível para largura efetiva pela largura atual.

\begin{tabular}{|c|c|c|c|c|c|c|c|c|c|c|}
\hline $\mathrm{L} / \mathrm{b}_{\mathrm{f}}$ & 30 & 25 & 20 & 18 & 16 & 14 & 12 & 10 & 8 & 6 \\
\hline Relação $\mathrm{b}_{\mathrm{ef}} / \mathrm{b}$ & 1,00 & 0,96 & 0,91 & 0,89 & 0,86 & 0,82 & 0,78 & 0,73 & 0,67 & 0,55 \\
\hline
\end{tabular}

onde:

L $\rightarrow$ vão teórico total para a viga simplesmente apoiada, ou a distância entre pontos de inflexão para viga contínua, ou duas vezes o comprimento de viga em balanço.

$\mathrm{b}_{\mathrm{f}} \quad \rightarrow$ largura da projeção da mesa além da alma para vigas "I" e/ou seções similares, ou a metade da distância entre almas de seção caixão ou cartola. Para mesas enrijecidas por meio de enrijecedores de borda," $b_{f}$ " deve ser tomado como a soma da projeção da mesa além da alma mais a altura do enrijecedor de borda.

\subsection{9 - ONDULAÇÃO DA MESA}

Em 1940, estudos conduzidos por WINTER ${ }^{2}$ apud YU (1985) obtiveram que, independentemente do vão de uma viga, a região de sua mesa afastada da alma tende a deslocar-se em direção à linha neutra. Este fato deve-se ao efeito da curvatura longitudinal da viga e às deflexões causadas pela flexão da mesa.

Conforme apresenta a figura 4.14, considerando uma viga "I" sujeita à flexão pura, a componente transversal "q" pode ser determinada por:

$$
q=\frac{2 f^{2} t}{E d}
$$

2 WINTER, G. (1940). Stress distribution in and equivalent width of flanges of wide, thin-wall steel beams, NACA technical note 784 apud YU, W. W. (1985). Cold-formed steel design, New York, Wiley \& Sons. 
onde:

$$
\begin{array}{ll}
\mathrm{d} & =\text { altura da viga. } \\
\mathrm{f} & =\text { tensão média na mesa. } \\
\mathrm{t} & =\text { espessura na mesa. }
\end{array}
$$

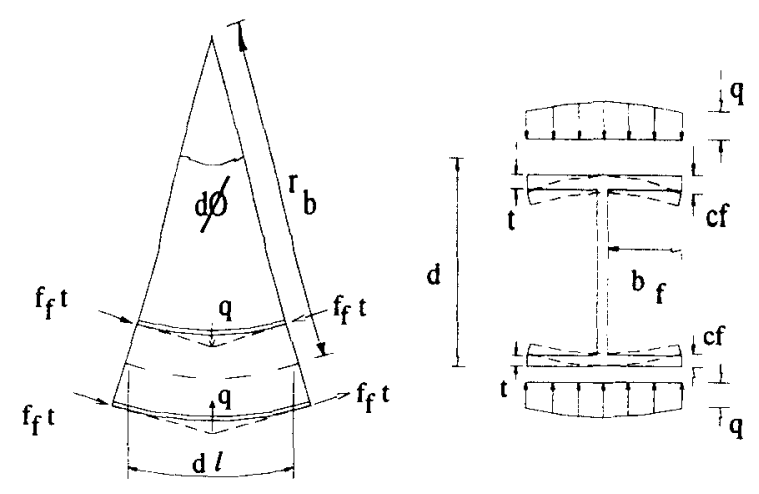

FIGURA 4.14 - Ondulação da viga para vigas "I" (YU, 1985).

Se a componente transversal " $q$ " for considerada como uma carga uniformemente distribuída ao longo da mesa, a deformação ou ondulação na sua extremidade pode ser determinada como para uma placa em balanço de largura unitária, sendo:

$$
c_{f}=\frac{q b_{f}^{+}}{8 D}=3\left(\frac{t}{E}\right)^{2}\left(\frac{b_{f}^{+}}{t^{2} d}\right)\left(1-v^{2}\right)
$$

onde:

$\mathrm{c}_{\mathrm{f}} \quad=$ deslocamento da extremidade da mesa.

$\mathrm{b}_{\mathrm{f}} \quad=$ projeção da mesa além da alma.

$\mathrm{D}=$ rigidez à flexão da placa $=E t^{3} /\left[12\left(1-v^{2}\right)\right]$

A máxima largura da mesa em função do deslocamento da sua extremidade pode ser obtida através da equação (4.100), sendo ela enrijecida ou não, comprimida ou tracionada, como:

$$
b_{f}=\sqrt{0,061 t d E / f}+\sqrt{100 c_{f} / d}
$$

A equação (4.100) também pode ser utilizada na determinação de perfis caixão e cartola, sendo que estes perfis têm suas mesas apoiadas nas almas e bf é assumida como a metade da distância entre as almas. 
O projetista deve limitar a ondulação da mesa ou seu deslocamento na extremidade. Normalmente é aceitável assumir um deslocamento de $5 \%$ da altura da seção. Portanto, assumindo-se que $\left(c_{f} / d=0,05\right)$, a equação anterior fica sendo:

$$
b_{f}=0,37 \sqrt{t d E / f}
$$

\section{5 - BARRAS FLEXO-COMPRIMIDAS}

\subsection{1 - CONSIDERAÇÕES PRELIMINARES}

Elementos estruturais flexo-comprimidos, definidos como vigas-colunas, são elementos sujeitos à combinação dos esforços de compressão e flexão. O esforço de flexão pode ser resultado das cargas de compressão aplicadas excentricamente, das cargas transversais à barra ou dos momentos fletores aplicados.

Basicamente, vigas-colunas são todas as peças estruturais pois quando sujeitas somente à tração, à compressão ou à flexão são casos particulares de vigascolunas.

O comportamento de barras flexo-comprimidas será estudado como elemento isolado, tanto para estabilidade no plano de flexão, quanto para estabilidade por flexo-torção.

\subsection{2 - EQUAÇÕES DIFERENCIAIS QUE GOVERNAM O EQUILÍBRIO DAS BARRAS FLEXO-COMPRIMIDAS}

Barras com seções transversais simétricas e não simétricas podem estar sujeitas à flambagem por flexão e torção sob os efeitos combinados de flexão e compressão. As equações diferenciais que governam o equilíbrio do comportamento elástico destes elementos, sob o esforço de compressão "N" e dos momentos fletores " $\mathrm{M}_{\mathrm{X}}$ "e " $\mathrm{M}_{\mathrm{y}}$ ", aplicados nas extremidades, figura 4.15, são:

$$
\begin{aligned}
& E I_{x} v^{i v}+N v^{\prime \prime} \phi^{\prime \prime}-N x_{0} \phi^{\prime \prime}+M_{y} \phi^{\prime \prime}=0 \\
& \begin{aligned}
E I_{y} u^{i v}+N u^{\prime \prime}+N y_{0} \phi^{\prime \prime}+M_{x} \phi^{\prime \prime}=0 \\
E C_{w} \phi^{i v}-G I_{1} \phi^{\prime \prime}++\left(N_{r_{0}^{2}}+2 M_{x}\left(k_{y}-y_{0}\right)+2 M_{y}\left(k_{x}-x_{0}\right)\right) \phi^{\prime \prime} \\
\quad+N x_{0} v^{\prime \prime}-N y_{0} u^{\prime \prime}-M x u^{\prime \prime}+M y v^{\prime \prime}=0
\end{aligned}
\end{aligned}
$$


Admitindo-se que $\mathrm{M}_{\mathrm{x}}$ e $\mathrm{M}_{\mathrm{y}}$ sejam iguais a zero, ocorrendo portanto somente a compressão, as equações (4.102) à (4.104) ficam limitadas pelas equações (4.10) a (4.12) que governam o equilíbrio de barras axialmente comprimidas sob a ação de uma força "N".

Visto que as equações diferenciais (4.102) a (4.104) são acopladas e complexas para fins práticos, pode se considerar uma análise simplificada supondose que a flexão ocorra no plano "yz", $\left(M_{y}=0\right.$ e $\left.M_{X}=M\right)$, e que a seção transversal da barra apresenta um eixo de simetria, sendo y este eixo, $x_{0}=0$, as equações (4.102) a (4.104) são reescritas nas seguintes equações:

$$
\begin{aligned}
& E I_{x} v^{i v}+N v^{\prime \prime}=0 \\
& E I_{y} u^{i v}+N u^{\prime \prime}+\left(N y_{0}+M\right) \phi^{\prime \prime}=0 \\
& E C_{w} \phi^{i v}-\left[G I_{t}-N r_{0}^{2}+2 M_{x}\left(k_{y}-y_{0}\right)\right] \phi^{\prime \prime}+\left(N y_{0}+M\right) u^{\prime \prime}=0
\end{aligned}
$$

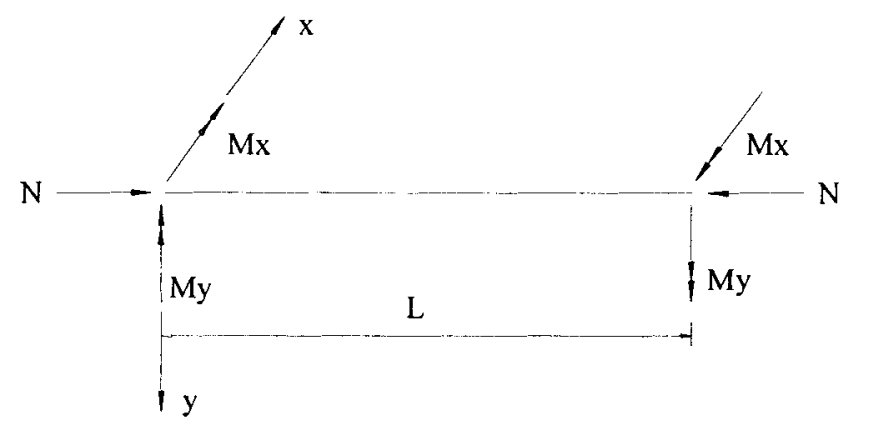

FIGURA 4.15 - Barras sujeitas à ação de flexo-compressão.

Se o esforço de compressão for igual a zero, ocorrerá somente a flexão. As equações (4.105) a (4.107) ficam limitadas às equações (4.42) a (4.44), que representam as equações de equilibrio que governam a seção transversal de uma barra monossimétrica sob a ação de momentos fletores uniformes.

\subsection{3 - RESISTÊNCIA NO PLANO DE FLEXÃO}

A equação (4.105) é desacoplada e representa a elástica da barra no plano de flexão sob a ação de compressão e flexão. As condições de contorno para uma barra simplesmente apoiada são: 


$$
\begin{aligned}
& v(0)=v(L)=0 \\
& v^{\prime \prime}(0)=v^{\prime \prime}(L)=-\frac{M}{E I_{x}}
\end{aligned}
$$

Através destas condições de contorno, pode-se determinar as constantes de integração da equação (4.105) sendo o deslocamento final representado por:

$$
v=\frac{M}{N}\left[\left(\frac{1-\cos k L}{\operatorname{sen} k L}\right) \operatorname{sen} k z+\cos k z-1\right]
$$

onde:

$$
\begin{array}{ll}
\mathrm{k} & =\sqrt{N /\left(E I_{x}\right)} \\
\mathrm{L} & =\text { comprimento da barra }
\end{array}
$$

O momento fletor em qualquer ponto " $\mathrm{z}$ " pode ser obtido por:

$$
M(z)=-E I_{x} v^{\prime \prime}=M\left[\left(\frac{1-\cos k L}{\operatorname{sen} k L}\right) \operatorname{sen} k z+\cos k z\right]
$$

O máximo valor de $\mathrm{M}(\mathrm{z})$ encontra-se em um ponto " $\bar{z}$ " que pode ser obtido por:

$$
\frac{d M}{d z}=0=M k\left[\left(\frac{1-\cos k L}{\operatorname{sen} k L}\right) \cos k \bar{z}-\operatorname{sen} k \bar{z}\right]
$$

sendo:

$$
\tan k \bar{z}=\frac{1-\cos k L}{\operatorname{sen} k L}
$$

Substituindo-se a expressão (4.113) na equação (4.111) obtém-se:

$$
M_{\text {max }}=\frac{M}{\cos k \bar{z}}
$$

Através da equação (4.113) obtém-se as relações trigonométricas apresentadas pela figura 4.16 , dadas por: 


$$
\alpha=\frac{1}{\cos k z}=\frac{\sqrt{2-2 \cos k L}}{\operatorname{sen} k L}
$$

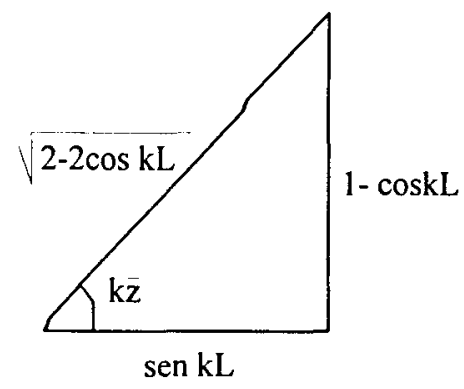

FIGURA 4.16 - Relações trigonométricas para a equação (4.116)

$O$ fator " $\alpha$ " pode ser entendido como um fator que amplia os momentos fletores ao longo da barra devido à presença do esforço de compressão.

De acordo com a figura 4.17, para diferentes valores de momentos fletores aplicados nas extremidades, $M_{1}$ e $M_{2}$, o valor do fator " $\alpha$ " pode ser dado por:

$$
\alpha_{r}=\frac{1}{\cos k \bar{z}}=\frac{\sqrt{1+r^{2}-2 r \cos k L}}{\operatorname{sen} k L}
$$

sendo:

$$
\begin{aligned}
& \mathrm{r}=\mathrm{M}_{2} / \mathrm{M}_{1} \\
& \left|M_{1}\right| \geq\left|M_{2}\right| \\
& \tan k \bar{z}=\frac{r-\cos k L}{\operatorname{sen} k L}
\end{aligned}
$$

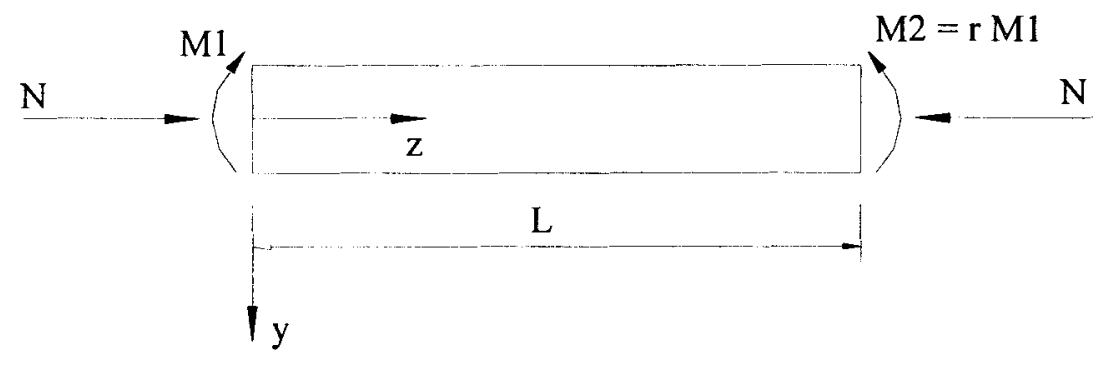

FIGURA 4.17 - Barra prismática sujeita à flexo-compressão. 
No regime elástico, a máxima tensão na barra limita-se ao ponto no qual atinge a tensão de escoamento " $\mathrm{f}_{\mathrm{y}}$ " ou a tensão limite de proporcionalidade do material. Adotando-se " $f_{y}$ " como este limite, tem-se:

$$
f_{\max }=f_{y}=\frac{N}{A_{g}}+\frac{M_{\text {max }}}{W_{x}}
$$

Admitindo-se as seguintes relações adimensionais:

$$
\begin{aligned}
& \frac{N}{N_{y}}=\frac{N}{f_{y} A_{g}} \\
& \frac{M}{M_{y}}=\frac{M}{f_{y} W_{x}}
\end{aligned}
$$

a equação de interação pode ser obtida, multiplicada pelo fator de ampliação dos momentos " $\alpha_{r}$ ", por:

$$
\frac{N}{N_{y}}+\frac{M}{M_{y}} \alpha_{r}=1,0
$$

A equação anterior de integração não diz respeito à flambagem lateral com torção, mas para valores de $(0 \leq \mathrm{kL} \leq \pi)$, ou seja, para valores de $\mathrm{N} \leq \mathrm{N}_{\mathrm{ex}}$, sendo:

$$
N_{e x}=\frac{\pi^{2} E I_{x}}{L^{2}}
$$

Aplica-se a equação (4.120) para uma barra sujeita à compressão axial e a momentos aplicados nas extremidades, ou seja, momento fletor constante ao longo da barra. Esta mesma equação pode ser usada para outras condições de carregamento utilizando-se um coeficiente de momento uniforme equivalente " $\mathrm{C}_{\mathrm{m}}$ ":

$$
C_{m}=\frac{\alpha_{r}}{\alpha}=\sqrt{\frac{1+r^{2}-2 r \cos k L}{2(1-\cos k L)}}
$$

A partir desta equação, pode-se reescrever a equação (4.120) como: 


$$
\frac{N}{N_{y}}+\frac{C_{m} M}{M_{y}} \alpha=1,0
$$

Pela equação (4.102), pode-se escrever:

$$
E I_{x} v^{\prime \prime}+N v=-M
$$

Não havendo força de compressão, a equação anterior fica reduzida a:

$$
v_{1}^{\prime \prime}=-\frac{M}{E I_{x}}
$$

onde o índice "1" equivale à solicitação da barra somente por momentos fletores. Substituindo-se "M" da equação (4.124) obtém-se:

$$
E I_{x} v^{\prime \prime}+N v=E I_{x} v_{1}^{\prime \prime}
$$

Considerando-se que, havendo cargas longitudinais ou não, a forma da linha elástica da barra aproxima-se de uma curva senoidal, e assumindo " $\mathrm{C}$ " e " $\mathrm{C}_{1}$ " como os deslocamentos máximos no meio do vão, $v=C \operatorname{sen}(\pi z / L)$ e $v_{1}=C \operatorname{sen}(\pi z / L)$, a equação (4.125) pode ser reescrita como:

$$
E I_{x} C \pi^{2} / L^{2}-N C=E I_{x} C_{1} \pi^{2} / L^{2}
$$

onde pode-se obter:

$$
C=\frac{C_{l}}{I-N / N_{e x}}
$$

Admitindo-se que os momentos fletores são proporcionais aos deslocamentos (flechas), obtém-se: 


$$
M_{\max }=\frac{M}{1-N / N_{e x}}
$$

O fator " $\alpha$ ", comparando-se as expressões (4.128) com (4.114), é dado por:

$$
\alpha=\frac{1}{\left(1-N / N_{e x}\right)}
$$

Substituindo-se o valor de $\alpha$ da equação (4.129) na equação (4.123), pode-se ter a seguinte equação de integração:

$$
\frac{N}{N_{y}}+\frac{C_{m} M}{\left(1-N / N_{e x}\right) M_{y}}=1,0
$$

Os valores do coeficiente de momento uniforme equivalente " $\mathrm{C}_{\mathrm{m}}$ " são dados

\begin{tabular}{|c|c|}
\hline & Valores de " $C_{m}$ " \\
\hline $\begin{array}{l}\text { Barras com momentos máximos nas } \\
\text { extremidades (sem carregamento transversal) e } \\
\text { translações não impedidas }\end{array}$ & 0.85 \\
\hline $\begin{array}{l}\text { Barras com momentos máximos nas } \\
\text { extremidades (sem carregamento transversal) e } \\
\text { translação impedida }\end{array}$ & $0,6-0,4 \frac{M_{1}}{M_{2}} \geq 0,4$ \\
\hline $\begin{array}{l}\text { Barras com carregamento transversal e } \\
\text { translação impedida }\end{array}$ & 0,85 \\
\hline $\begin{array}{l}\text { Barras com carregamento transversal e } \\
\text { translação não impedida }\end{array}$ & 1,0 \\
\hline
\end{tabular}
na tabela 4.9 .

TABELA 4.9 - Valores de "C $\mathrm{m}_{\mathrm{m}}$ (SÁlES \& MALITE, 1993).

Apresentam-se na figura 4.18 as curvas de interação obtidas com $C_{m}$, equação (4.131), em comparação com os valores teóricos dados pela equação (4.122). 


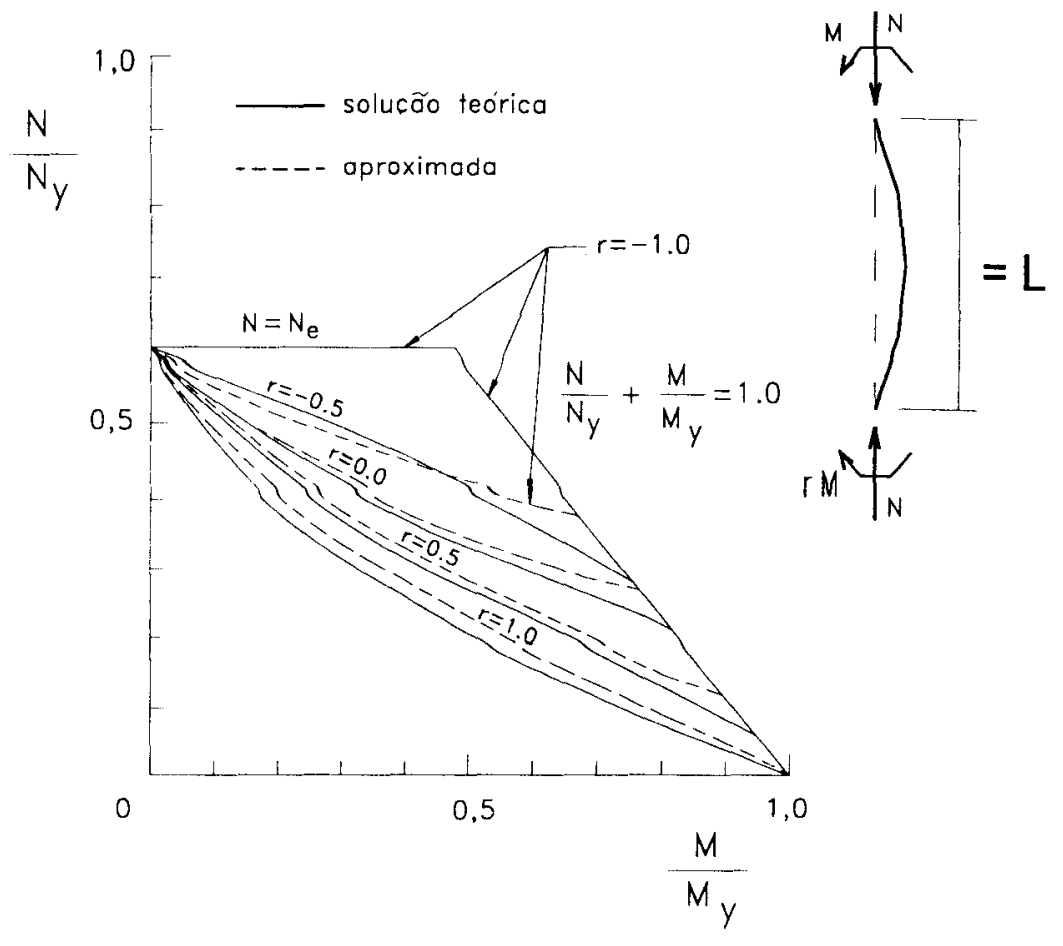

FIGURA 4.18 - Curvas de interação exatas e aproximadas no limite elástico para elementos flexo-comprimidos.

\subsection{4 - FLAMBAGEM LATERAL COM TORÇÃO}

Quando uma viga-coluna flete em torno do seu eixo de maior inércia, sem restrições laterais, ela pode flambar fora do plano de flexão por deslocamento lateral e rotação.

Este fenômeno pode ser representado pelas equações (4.106) e (4.107) para uma seção transversal com um eixo de simetria, sob cargas de compressão "N" e momentos fletores uniformes $\mathrm{M}_{\mathrm{X}}=\mathrm{M}$. Os deslocamentos laterais (u) são seguidos por rotações $(\phi)$ da seção transversal em relação ao centro de cisalhamento.

A solução daquelas equações diferenciais, para condições de contorno de uma viga simplesmente apoiada cujas extremidades estão impedidas de girar, pode ser obtida por:

$$
u=C_{1} \operatorname{sen} \frac{\pi z}{L} \quad \text { e } \quad \phi=C_{2} \operatorname{sen} \frac{\pi z}{L}
$$

Assumindo-se que o determinante dos coeficientes de $\mathrm{C}_{1}$ e $\mathrm{C}_{2}$ seja igual a zero e substituindo-se a equação (4.132) nas equações (4.106) e (4.107) pode-se obter uma solução não trivial para o sistema, dado por: 


$$
\left|\begin{array}{cc}
\left(N_{e y}-N\right) & -\left(M+N y_{0}\right) \\
-\left(M+N y_{0}\right) & \left(r_{0}^{2} N_{e z}-N r_{0}^{2}+2 M j\right.
\end{array}\right|=0
$$

A partir deste sistema, pode-se obter:

$$
\left(N e_{y}-N\right)\left(r_{0}^{2} N e_{z}-N r_{0}^{2}+2 M j\right)=\left(M+N y_{0}\right)^{2}
$$

sendo:

$$
\begin{array}{ll}
\mathrm{N}_{\text {ey }} \text { e } \mathrm{N}_{\mathrm{ez}} & =\text { carga crítica de flambagem por flexão e torção } \\
\mathrm{j} & =\left(\mathrm{k}_{\mathrm{y}}-\mathrm{y}_{0}\right)
\end{array}
$$

Desde que se conheçam as propriedades geométricas de uma seção, pode-se aplicar a expressão (4.133) para uma combinação crítica de "N" e "M".

Para uma seção transversal duplamente simétrica, $y_{0}=j=0$, obtém-se a equação (4.133) reescrita por:

$$
M=r_{o} \sqrt{\left(N_{e y}-N\right)\left(N_{e z}-N\right)}
$$

onde, conhecido o valor de "N", determina-se o valor crítico do momento fletor " $\mathrm{M}$ ".

Considerando-se a flambagem lateral com torção, a equação de interação que apresenta a máxima resistência pode ser definida por:

$$
\frac{N}{N_{c r}}+\frac{C m M}{\left(1-N / N_{e x}\right) M_{c r}}=1
$$

\section{6 - CRITÉRIO DE DIMENSIONAMENTO}

Descrevem-se neste item os critérios de dimensionamento segundo as normas CSA (1984) e AISI (1991) empregando-se o método dos estados limites. Os valores dos coeficientes de resistência $(\phi)$ para cada tipo de barra estão apresentados na tabela 4.1 , sendo valores recomendados por estas normas. 


\subsection{1 - BARRAS TRACIONADAS}

\subsubsection{1 - ESTADO LIMITE ÚLTIMO}

A resistência de cálculo " $\mathrm{R}_{\mathrm{d}}=\phi_{\mathrm{t}} \mathrm{N}_{\mathrm{n}}$ " a ser utilizada no dimensionamento das peças tracionadas é o menor dos valores obtidos de acordo com os estados limites de escoamento da seção bruta e ruptura da seção líquida.

a) Escoamento da seção bruta $\rightarrow$ estado limite último caracterizado pelo escoamento da seção transversal de uma barra tracionada, ou seja, para uma determinada barra aplica-se ação externa $P$ de tração até que a tensão produzida numa dada seção atinja a tensão de escoamento do material, figura 4.19. Atingido este escoamento, há grandes deformações na barra caracterizando a perda da função estrutural.
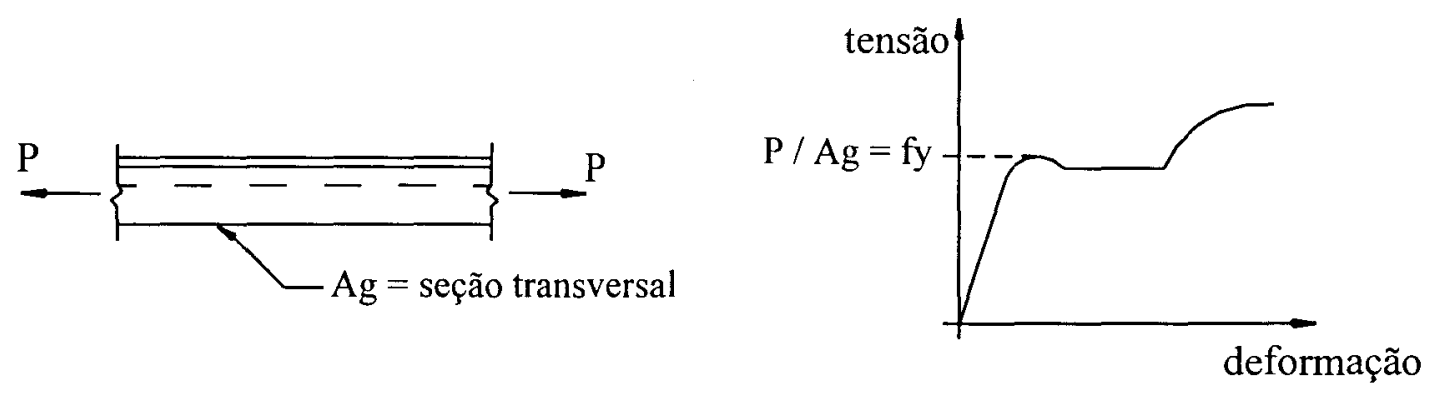

FIGURA 4.19 - Ensaio de tração, diagrama tensão-deformação.

A resistência de cálculo neste estado limite pode ser obtida por:

$$
N_{n}=A_{g} f_{y}
$$

onde:

$\mathrm{A}_{\mathrm{g}} \quad$ = área bruta da seção transversal da barra.

$\mathrm{f}_{\mathrm{y}} \quad=$ limite de escoamento do aço.

$\phi_{\mathrm{t}} \quad=$ coeficiente de resistência à tração.

b) Ruptura da seção líquida $\rightarrow$ a utilização de parafusos nas barras solicitadas à tração faz com que as seções transversais fiquem enfraquecidas, ou seja, com área 
inferior à seção bruta da barra. Este estado limite caracteriza-se pela ruptura da seção enfraquecida, portanto, a resistência de cálculo neste estado limite é:

$$
N_{n}=A_{n} f_{u}
$$

onde:

$$
\begin{aligned}
& \mathrm{A}_{\mathrm{n}} \quad=\text { área líquida da seção transversal da barra } \\
& \mathrm{f}_{\mathrm{u}} \quad=\text { limite de resistência à tração do aço. }
\end{aligned}
$$

Para determinar a área efetiva de barras tracionadas, " $\mathrm{A}_{\mathrm{n}}$ " será dada por:

a) Para cantoneiras com abas não enrijecidas ligadas por parafusos ao longo de uma aba:

$$
A_{n}=\left[A_{g} \cdot(0,7 b+m d) t\right]
$$

b) Para seções "U" com mesas não enrijecidas ligadas por parafusos ao longo da alma:

$$
A_{n}=\left[A_{g}-(b+m d) t\right]
$$

onde:

b = largura da aba para cantoneira ou da mesa para seção "U".

d = largura do furo, perpendicular à direção da força de tração.

$\mathrm{m}=$ número de furos perpendiculares à força de tração.

$\mathrm{t}=$ espessura do elemento.

Para barras tracionadas com excentricidade inicial da força de tração em relação ao centro de gravidade, a resistência de cálculo $" \mathrm{R}_{\mathrm{d}}=\phi_{t} \mathrm{~N}_{\mathrm{n}}$ " será o menor dos valores obtidos entre:

a) Estado limite de escoamento da seção bruta:

$$
N_{n}=\frac{f_{y}}{\left(\frac{1}{A_{g}}+\frac{e}{W}\right)}
$$


b) Estado limite de ruptura da seção líquida:

$$
N_{n}=\frac{f_{u}}{\left(\frac{1}{A_{n}}+\frac{e}{W_{n}}\right)}
$$

onde:

$$
\begin{array}{ll}
\mathrm{e} & =\text { excentricidade da força de tração. } \\
\mathrm{W} & =\text { módulo de resistência elástico na seção bruta. } \\
\mathrm{W}_{\mathrm{n}} & =\text { módulo de resistência elástico da seção líquida. }
\end{array}
$$

\subsubsection{2 - CONDIÇÃO DE ESBELTEZ}

Apesar das normas AISI e CSA não apresentarem nenhuma limitação para o índice de esbeltez " $l / \mathrm{r}^{\prime}$ em barras tracionadas é comum limitar este valor. A limitação deste índice nas barras tracionadas está relacionada com uma possível vibração destas barras, o que acarretaria acréscimos significativos nas tensões e que não foram considerados no cálculo.

A norma NBR-8800 (1986) fixa para os perfis laminados e soldados os seguintes valores:

a) $\lambda \leq 240 \rightarrow$ para barras principais;

b) $\lambda \leq 300 \rightarrow$ para barras secundárias.

\subsection{2 - BARRAS COMPRIMIDAS}

\subsubsection{1 - ESTADO LIMITE ÚLTIMO}

Para os perfis comprimidos de chapa dobrada, verificam-se os problemas da flambagem global, local e os efeitos da flambagem inelástica. $\mathrm{Na}$ verificação da tensão crítica de flambagem elástica global " $\mathrm{f}$ " adota-se a equação básica (4.14). Havendo flambagem inelástica, utiliza-se a equação (4.9) para o cálculo da tensão de flambagem " $\mathrm{f}$ ". De acordo com o conceito de largura efetiva, calcula-se a área efetiva da seção transversal para esta tensão " $\mathrm{f}$ ". 
Após a determinação das tensões, verifica-se a resistência de cálculo da barra solicitada, como a seguir.

\subsubsection{2 - RESISTÊNCIA DE CÁLCULO}

Para barras axialmente comprimidas, sujeitas à flambagem por flexão, a resistência de cálculo é dada por $R_{d}=\phi_{c} N_{n}$, onde $N_{n}$ é expressa por :

$$
N_{n}=A_{e f} f
$$

A tensão crítica de flambagem "f" (AISI/1986) é dada por, :

$$
\begin{aligned}
& \text { para } f_{e}>f_{y} / 2 \quad \rightarrow \quad f=f_{y}\left(1-f_{y} / 4 f_{e}\right) \\
& \text { para } f_{e} \leq f_{y} / 2 \quad \rightarrow \quad f=f_{e}
\end{aligned}
$$

onde:

$\mathrm{A}_{\mathrm{ef}} \rightarrow$ área da seção efetiva calculada com as larguras efetivas dos elementos de chapa submetidos à tensão "f", determinada no capítulo 3 .

$f_{e} \rightarrow$ tensão crítica de flambagem elástica por flexão, torção ou flexão e torção, determinada a seguir.

\subsubsection{3 - TENSÃO CRÍTICA DE FLAMBAGEM ELÁSTICA}

a) Perfis duplamente simétricos

Para perfis com dupla simetria ou simétricos em relação a um ponto, a tensão crítica de flambagem elástica " $\mathrm{f}_{\mathrm{e}}$ " é o menor valor entre:

a.1) Flambagem elástica por flexão em relação ao eixo x:

$$
f_{e x}=\frac{\pi^{2} E}{\left(k_{x} l_{x} / r_{x}\right)^{2}}
$$

a.2) Flambagem elástica por flexão em relação ao eixo y: 


$$
f_{e y}=\frac{\pi^{2} E}{\left(k_{y} l_{y} / r_{y}\right)^{2}}
$$

a.3) Flambagem elástica flexo-torção:

$$
f_{e z}=\frac{1}{A_{g} r_{0}^{2}}\left[\frac{\pi^{2} E C_{w}}{\left(k_{z} l_{z}\right)^{2}}+G I_{1}\right]
$$

onde:

$$
\begin{aligned}
\mathrm{A} & =\text { área bruta da seção transversal da barra. } \\
\mathrm{kl} & =\text { comprimento efetivo de flambagem. } \\
\mathrm{r}_{\mathrm{O}} & =\text { raio de giração polar em relação ao centro de cisalhamento } \\
& =\sqrt{\mathrm{r}_{\mathrm{x}}^{2}+\mathrm{r}_{\mathrm{y}}^{2}+\mathrm{x}_{0}^{2}+\mathrm{y}_{0}^{2}} \\
\mathrm{r}_{\mathrm{X}} & =\text { raio de giração da seção transversal em relação ao eixo } \mathrm{x} . \\
\mathrm{r}_{\mathrm{y}} & =\text { raio de giração da seção transversal em relação ao eixo y. } \\
\mathrm{x}_{\mathrm{O}} & =\text { coordenada } \mathrm{x} \text { do centro de cisalhamento. } \\
\mathrm{y}_{\mathrm{O}} & =\text { coordenada y do centro de cisalhamento. }
\end{aligned}
$$

b) perfis monossimétricos

Para perfis de simetria única, adotando o eixo " $\mathrm{x}$ " como de simetria, a tensão crítica de flambagem elástica " $\mathrm{f}_{\mathrm{e}}$ " será o menor valor entre:

b.1) $f_{\text {ey }}$ conforme item a

b.2) Flambagem elástica por flexão em torno de $\mathrm{x}$ e torção simultaneamente:

$$
f_{e x z}=\frac{1}{2 H}\left[\left(f_{e x}+f_{e z}\right)-\sqrt{\left(f_{e x}+f_{e z}\right)^{2}-4 H f_{e x} f_{e z}}\right]
$$

onde:

$$
\begin{aligned}
& H=1-\left(x_{0}+r_{0}\right)^{2} \\
& x_{0}, r_{0}, f_{e y}, f_{e z}, \text { já citados no item a). }
\end{aligned}
$$

c) perfis assimétricos 
Para perfis assimétricos, obtém-se a tensão crítica de flambagem " $\mathrm{f}_{\mathrm{e}}$ " pelo menor valor das três raizes da equação:

$$
r_{0}^{2}\left(f_{e}-f_{e x}\right)\left(f_{e}-f_{e y}\right)\left(f_{e}-f_{e z}\right)-f_{e}^{2} y_{0}^{2}\left(f_{e}-f_{e x}\right)-f_{e}^{2} x_{0}^{2}\left(f_{e}-f_{e y}\right)=0
$$

onde:

$\mathrm{x}_{0}, \mathrm{y}_{0}, \mathrm{r}_{0}, \mathrm{f}_{\mathrm{ex}}, \mathrm{f}_{\mathrm{ey}}, \mathrm{f}_{\mathrm{ez}}$, conforme item $\left.\mathrm{a}\right)$.

\subsubsection{4 - PERFIL COM ELEMENTO NÃO ENRIJECIDO}

A resistência nominal à compressão para seções tipo "U", "L" e "Z", cuja seções são compostas de elementos não enrijecidos, deverá ser calculada por:

$$
N_{n}=\frac{\pi^{2} E A_{g}}{24\left(1-v^{2}\right)(b / t)^{2}}
$$

onde:

$\mathrm{A}_{\mathrm{g}} \quad$ = área bruta da seção transversal.

$\mathrm{b} / \mathrm{t}=$ relação largura-espessura do elemento não enrijecido.

\subsubsection{5 - ÍNDICE DE ESBELTEZ}

O limite de índice de esbeltez para perfis comprimidos fica em 200 . Um índice maior que este valor resulta num projeto anti-econômico, já que estes perfis têm uma resistência à flambagem muito pequena e também estas barras podem apresentar aumentos significativos nas tensões atuantes devido a problemas associados à vibração.

\subsection{3 - BARRAS FLETIDAS - RESISTÊNCIA AO MOMENTO FLETOR}

\subsubsection{1 - ESTADO LIMITE ÚLTIMO}

Verifica-se o estado limite último, a resistência ao momento fletor para flambagens locais (mesas e almas) e flambagem lateral com torção.

Para verificar as flambagens locais de uma seção, determina-se a resistência à flexão pelas propriedades geométricas com base no escoamento da seção efetiva, ou na reserva de resistência inelástica. 
$\mathrm{Na}$ flambagem lateral com torção, inicialmente determina-se o momento crítico elástico da viga, obtendo-se a tensão crítica de flambagem elástica " $\mathrm{f}_{\mathrm{e}}$ ". Pelas equações (4.39), (4.51) e (4.52) tem-se a tensão crítica " $\mathrm{f}$ " a que for aplicável e a área efetiva pode ser determinada pelo conceito de largura efetiva.

\subsubsection{2 - FLAMBAGENS LOCAIS}

Em barras estruturais submetidas à flexão, a resistência ao momento fletor " $\phi_{b} M_{n}$ " da seção deverá ser calculada com base no início do escoamento da seção efetiva (procedimento "a") ou com base na reserva de resistência inelástica (procedimento "b"). $\mathrm{M}_{\mathrm{n}}$ é a resistência nominal.

a) baseado no início de escoamento da seção transversal:

$$
M_{n}=W_{e f} f_{y}
$$

onde:

$\mathrm{f}_{\mathrm{y}} \quad=$ tensão limite de escoamento do aço.

$\mathrm{W}_{\text {ef }}$ = módulo de resistência efetivo, elástico, calculado para as fibras extremas comprimidas ou tracionadas submetidas à tensão $\mathrm{f}_{\mathrm{y}}$.

b) baseado na reserva de resistência inelástica à flexão, as seguintes condições devem ser seguidas:

- A barra não pode estar submetida à torção ou à flambagem lateral, torcional ou flexo-torção.

- Na determinação do limite de escoamento $f_{y} o$ efeito da conformação a frio não está incluido .

- A relação da altura da parte comprimida da alma pela sua espessura não deve exceder $\lambda_{1}$.

- A força de cisalhamento não deve exceder $0,35 f_{y} h t$, onde a área da alma é $h \times t$.

- Um ângulo qualquer entre alma e a vertical não deve exceder $30^{\circ}$.

A resistência nominal ao momento fletor $M_{n}$ não deverá exceder 1,25 vezes ao determinado no procedimento "a" nem aquele que causar uma deformação 
máxima de compressão de " $\mathrm{C}_{\mathrm{y}} \varepsilon_{\mathrm{y}}$ " (nenhum limite é solicitado para a deformação máxima de tração), onde:

$$
\begin{aligned}
& \varepsilon_{y}=\text { deformação no escoamento }=\mathrm{f}_{\mathrm{y}} / \mathrm{E} . \\
& \mathrm{C}_{\mathrm{y}}=\text { fator de deformação à compressão determinado como: }
\end{aligned}
$$

i) Elemento enrijecido à compressão sem enrijecedores intermediários:

$$
\begin{aligned}
& \text { para } b / t \leq \lambda_{I} \quad \rightarrow \quad C_{y}=3 \\
& \text { para } \lambda_{1} \leq b / t \leq \lambda_{2} \rightarrow \quad C_{y}=3-\frac{(b / t) \sqrt{f_{y}}-500}{40} \\
& \text { para } b / t \geq \lambda_{2} \quad \rightarrow \quad C_{y}=1
\end{aligned}
$$

onde:

$$
\begin{aligned}
& \lambda_{1}=\frac{1,11}{\sqrt{f_{y} / E}} \\
& \lambda_{2}=\frac{1,28}{\sqrt{f_{y} / E}}
\end{aligned}
$$

ii) Elemento não enrijecido à compressão:

$$
C_{y}=1
$$

iii) Elementos multi-enrijecidos à compressão e elementos à compressão com enrijecedores de borda:

$$
C_{y}=1
$$

Quando aplicáveis, as larguras efetivas definidas no capítulo 3 deverão ser utilizadas no cálculo das propriedades geométricas da seção transversal. A resistência nominal ao momento fletor " $\mathrm{M}_{\mathrm{n}}$ " deverá ser calculado considerando-se o equilíbrio das tensões, assumindo-se um diagrama tensão-deformação idealmente elástoplástico, que seja o mesmo tanto à tração quanto à compressão. 
c) Para seções "U" e "Z", elementos não enrijecidos à compressão, o valor de $M_{n}$ não deverá ser maior que:

$$
M_{n}=W \frac{\pi^{2} E}{24\left(1-v^{2}\right)(b / t)^{2}}
$$

onde:

$\mathrm{W}=$ módulo de resistência elástico da seção reduzida.

$\mathrm{b} / \mathrm{t}=$ relação largura espessura do elemento não enrijecido.

\subsubsection{3 - FLAMBAGEM LATERAL COM TORÇÃO}

A resistência de cálculo ao momento fletor para seções transversais fletidas em relação ao eixo de maior inércia é dado por " $\phi_{b} M_{n}$ ", sendo:

$$
M_{n}=W_{e f} f
$$

onde:

$$
\begin{aligned}
\mathrm{W}_{\mathrm{ef}}= & \text { módulo de resistência efetivo elástico, calculado para a tensão "f" na } \\
& \text { fibra extrema comprimida. } \\
\mathrm{f} \quad & \text { tensão crítica de flambagem lateral com torção, calculada como a } \\
& \text { seguir: }
\end{aligned}
$$

a) Perfis "I", "Z" ou caixão fletidos em torno do eixo perpendicular a alma:

$$
\begin{array}{ll}
\text { para } f_{e}>0,56 f_{y} & f=f_{y}\left(1,11-\frac{1}{3,24}\left[f_{y} \frac{\lambda_{b}^{2}}{C_{b} \pi^{2} E}\right]\right) \\
\text { para } f_{e} \leq 0,56 f_{y} & f=f_{e}
\end{array}
$$

onde:

$$
f_{e}=\frac{M_{c r}}{W}
$$

$\mathrm{W}=$ módulo de resistência elástico da seção transversal bruta não reduzida.

$\mathrm{M}_{\mathrm{cr}}$ = momento crítico calculado como se segue: 
i) Seções "I" duplamente simétricas:

$$
M_{c r}=C_{b} \frac{\pi^{2} E}{L_{b}^{2}} \sqrt{C_{w} I_{y}}
$$

\section{ii) Seções "Z"}

$$
M_{c r}=C_{b} \frac{\pi^{2} E}{2 L_{b}^{2}} \sqrt{C_{w} I_{y}}
$$

iii) Seções caixão fechado

$$
M_{c r}=C_{b} \frac{\pi}{L_{b}} \sqrt{E I_{y} G I_{r}}
$$

onde:

E, $\mathrm{G}, \mathrm{C}_{\mathrm{W}}, \mathrm{I}_{\mathrm{y}}, \mathrm{I}_{\mathrm{t}}$, definidos anteriormente.

$\mathrm{C}_{\mathrm{b}}=1,75+1,05\left(\mathrm{M}_{1} / \mathrm{M}_{2}\right)+0,3\left(\mathrm{M}_{1} / \mathrm{M}_{2}\right)^{2} \leq 2,30$

Sendo, na expressão de $\mathrm{C}_{\mathrm{b}}, \mathrm{M}_{1}$ o menor e $\mathrm{M}_{2}$ o maior dos momentos fletores nas extremidades do trecho não contido lateralmente.

A relação $M_{1} / M_{2}$ é positiva quando estes momentos provocam curvatura reversa e negativa quando provocam curvatura simples. Se no interior do trecho o momento fletor for maior que nas extremidades adota-se o valor de $C_{b}=1,0$.

b) Perfis monossimétricos, onde y é o eixo de simetria:

$$
\begin{array}{ll}
\text { para } f_{e}>0,50 f_{y} & \rightarrow \quad f=f_{y}\left(1-\frac{f_{y}}{4 f_{e}}\right) \\
\text { para } f_{e} \leq 0,50 f_{y} & \rightarrow \quad f=f_{e}
\end{array}
$$

sendo $f_{\mathrm{e}}$ dado pela equação (4.163) e $\mathrm{M}_{\mathrm{cr}}$ determinado como:

i) Para flexão em relação ao eixo de simetria:

$$
M_{c r}=C_{b} r_{0} A_{g} \sqrt{f_{e x} f_{e z}}
$$


ii) Para flexão em relação ao eixo perpendicular ao eixo de simetria:

$$
M_{c r}=C_{b} A_{g} f_{e y}\left[j \pm \sqrt{j+r_{0}^{2}\left(f_{e z} / f_{e y}\right)}\right]
$$

onde, o sinal $(+)$, se aplica para momentos fletores que causem tensões de compressão no lado do centro de cisalhamento em relação ao centro de gravidade. E o sinal (-), se aplica para momentos fletores que causem tensões de tração no centro de gravidade em relação ao centro de cisalhamento.

$$
\begin{aligned}
f_{e x} & =\frac{\pi^{2} E}{\left(k_{x} L_{x} / r_{x}\right)^{2}} \\
f_{e y} & =\frac{\pi^{2} E}{\left(k_{y} L_{y} / r_{y}\right)^{2}} \\
f_{e z} & =\frac{1}{A_{g} r_{0}^{2}}\left[\frac{\pi^{2} E C_{w}}{\left(k_{z} L_{z}\right)^{2}}+G I_{t}\right] \\
r_{0} & =\sqrt{r_{x}^{2}+r_{y}^{2}+y_{0}^{2}} \\
j & =\frac{1}{2 I_{x}} \int_{A} y\left(x^{2}+y^{2}\right) d A-y_{0} \\
A_{g} & =\text { área bruta da seção transversal. }
\end{aligned}
$$

$\mathrm{kL}=$ comprimento efetivo de flambagem em relação ao eixo correspondente.

$r_{X}=$ raio de giração em relação ao eixo $x$.

$r_{y}=$ raio de giração em relação ao eixo y.

$\mathrm{y}_{0}=$ coordenada y do centro de cisalhamento, tomada como negativa.

E, G, $C_{W}, I_{y}, I_{t}, C_{b}$ conforme item a)

Para o estado limite último de flambagem lateral com torção, os valores da resistência nominal ao momento fletor foram feitos para aplicação de forças externas no centro de cisalhamento da seção transversal. Para forças externas aplicadas excentricamente em relação ao centro de cisalhamento, referir-se ao item 4.4.2.2. 


\subsubsection{4 - ESTADO LIMITE DE UTILIZAÇÃO - CÁLCULO DE DESLOCAMENTOS}

Para o estado limite de utilização, calculam-se os deslocamentos pelo tipo de elemento comprimido utilizado na seção transversal da viga. As larguras efetivas são baseadas na tensão correspondente ao carregamento sob a qual os deslocamentos são determinados.

O momento de inércia poderá variar ao longo do comprimento da viga. Se, no caso, for utilizada uma aproximação, os deslocamentos em vigas simplesmente apoiadas podem ser determinados para o máximo valor do momento fletor solicitante. Para vigas contínuas, podem ser utilizadas as fórmulas convencionais, onde o valor médio dos momentos de inércia para as regiões de momentos fletores positivo e negativo será utilizado como o momento de inércia da seção.

\subsection{4 - BARRAS FLETIDAS - VERIFICAÇÕES COMPLEMENTARES}

\subsubsection{1 - GENERALIDADES}

Após a verificação da resistência nominal ao momento fletor, deve-se considerar as verificações adicionais seguintes. Determina-se a resistência à força cortante de uma viga, em função da relação dos parâmetros de esbeltez da alma $\left(\mathrm{h} / \mathrm{t}_{\mathrm{W}}\right)$.

Pode-se obter a resistência ao enrugamento da alma sob a ação de cargas concentradas, através de resultados experimentais. Esta resistência é restrita às condições obedecidas na realização dos ensaios.

As equações de interação podem ser empregadas para a verificação do momento fletor com força cortante e o momento fletor com o enrugamento da alma.

Apesar de não ser um fator determinante, o efeito "Shear Lag" e a ondulação da mesa podem ser determinados para alguns casos específicos.

\subsubsection{2 - RESISTÊNCIA DE CÁLCULO À FORÇA CORTANTE}

A resistência de cálculo de almas à força cortante, em relação ao eixo perpendicular à alma, pode ser obtido por " $\phi_{\mathrm{V}} \mathrm{V}_{\mathrm{n}}$ ", onde a resistência nominal " $\mathrm{V}_{\mathrm{n}}$ " é determinada como a seguir, como as CSA, 1984 e AISI, 1991: 

a) para $\lambda \leq \lambda_{p} \quad \rightarrow \quad V=V_{p l}$
b) $\operatorname{para} \lambda_{\mathrm{p}}<\lambda \leq \lambda_{\mathrm{r}} \rightarrow \quad V=\frac{\lambda_{p}}{\lambda} V_{p l}$
c) para $\lambda>\lambda_{r} \quad \rightarrow \quad V=1,28\left(\frac{\lambda_{p}}{\lambda}\right)^{2} V_{p l}$

onde:

$$
\begin{aligned}
\mathrm{A}_{\mathrm{W}} & =\mathrm{h} / \mathrm{t}_{\mathrm{W}} \\
\mathrm{a} & =\text { distância entre enrijecedores transversais } \\
\mathrm{h} & =\text { altura da alma. } \\
\mathrm{k}_{\mathrm{V}} & =4+\frac{5,34}{(a / h)^{2}} \quad \text { para } \quad \mathrm{a} / \mathrm{h}<1 \\
\mathrm{k}_{\mathrm{V}} & =5,34+\frac{4}{(a / h)^{2}} \quad \text { para } \quad 1 \leq \mathrm{a} / \mathrm{h}<3 \\
\mathrm{k}_{\mathrm{V}} & =5,34 \\
\mathrm{t}_{\mathrm{W}} & =\text { espessura da alma. } \\
\mathrm{V}_{\mathrm{pl}} & =0,6 \mathrm{~A}_{\mathrm{W}} \mathrm{f}_{\mathrm{y}} \\
\lambda & =h / t_{w} \\
\lambda_{P} & =1,08 \sqrt{k_{v} E / F_{y}} \\
\lambda_{r} & =1,40 \sqrt{k_{v} E / f_{y}}
\end{aligned}
$$

\subsubsection{3 - INTERAÇÃO ENTRE A RESISTÊNCIA DE CÁLCULO À FORÇA CORTANTE COM O MOMENTO FLETOR}

Para vigas com almas não enrijecidas, o momento de cálculo " $\mathrm{M}_{\mathrm{d}}$ " e o esforço cortante de cálculo " $\mathrm{V}_{\mathrm{d}}$ " deverão satisfazer a seguinte equação de interação:

$$
\left(\frac{M_{d}}{\phi_{b} M_{n}}\right)^{2}+\left(\frac{V_{d}}{\phi_{v} V_{n}}\right)^{2} \leq 1
$$

Para vigas com enrijecedores de alma transversais, e quando $M_{d} /\left(\phi_{b} M_{n}\right)>0,5$ e $V_{d} /\left(\phi_{v} V_{n}\right)>0,7$, então $\mathrm{M}_{\mathrm{d}}$ e $\mathrm{V}_{\mathrm{d}}$ deverão satisfazer a seguinte equação de interação:

$$
0,6\left(\frac{M_{d}}{\phi_{b} M_{n}}\right)^{2}+\left(\frac{V_{d}}{\phi_{v} V_{n}}\right) \leq 1,3
$$


onde:

$\mathrm{M}_{\mathrm{d}}=$ momento fletor de cálculo.

$\mathrm{V}_{\mathrm{d}}$ = carga concentrada ou reação de apoio, de cálculo.

$\phi \mathrm{M}_{\mathrm{n}}$ = resistência de cálculo ao momento fletor, conforme item 4.4.2.

$\phi_{\mathrm{V}} \mathrm{V}_{\mathrm{n}}=$ resistência de cálculo à força cortante, conforme item 4.4.3.

sendo:

$$
\begin{aligned}
& M_{d} \leq \phi_{b} M_{n} \\
& V_{d} \leq \phi_{v} V_{n}
\end{aligned}
$$

\subsubsection{4 - RESISTÊNCIA AO ENRUGAMENTO DA ALMA}

Para não ocorrer enrugamento em almas planas não enrijecidas de barras fletidas cuja relação de esbeltez $\left(\mathrm{h} / \mathrm{t}_{\mathrm{W}}\right)$ seja menor ou igual a 200 , as cargas concentradas e reações não deverão exceder os valores de " $\phi \mathrm{N}_{\mathrm{n}}$ ", sendo $\mathrm{N}_{\mathrm{n}}$ dados nas tabelas (4.5), (4.6) e (4.7), $\phi=0,75$ para almas simples não reforçadas e $\phi=0,80$ para outras almas.

Para almas de barras fletidas cuja a relação de esbeltez seja maior que 200, deverão ser fornecidos meios adequados para a aplicação de cargas concentradas e/ou reações diretamente nas almas.

Almas que consistem da formação de duas ou mais chapas, $N_{n}$ deverá ser calculado para cada chapa individualmente e os resultados somados para a obtenção da resistência nominal ao enrugamento.

\subsubsection{5 - FLEXÃO E RESISTÊNCIA AO ENRUGAMENTOS COMBINADOS}

Para almas planas não enrijecidas nas quais, estando sujeitas à combinação de flexão e carga concentrada ou reação de apoio, devem satisfazer as seguintes exigências:

$$
\frac{N_{d}}{\phi N_{n}}+\frac{M_{d}}{\phi_{b} M_{n}} \leq 1,3
$$

onde: 
$\mathrm{N}_{\mathrm{d}} \quad$ = carga concentrada ou reação de apoio, de cálculo, na presença de momento fletor.

$\mathrm{M}_{\mathrm{d}} \quad$ = momento fletor de cálculo.

$\phi_{\mathrm{c}} \mathrm{N}_{\mathrm{n}}=$ resistência de cálculo à força cortante.

$\phi_{\mathrm{b}} \mathrm{M}_{\mathrm{n}}=$ resistência de cálculo ao momento fletor.

\subsubsection{6 - ENRIJECEDORES TRANSVERSAIS}

Devem-se dimensionar os enrijecedores transversais para carga concentrada na mesa, causando compressão nos enrijecedores, como barras comprimidas sujeitas à flambagem em relação a um eixo no plano médio da alma ou sujeitas ao escoamento da seção transversal, pelo menor valor entre:

$$
\begin{aligned}
& N_{n}=A_{c} f_{y} \\
& N_{n}=A_{b} f
\end{aligned}
$$

sendo $A_{c}, A_{b}, f_{y}$ e f conforme item 4.5.6.

\subsubsection{7 - EFEITO SHEAR LAG}

Quando o vão de uma viga for menor que $\left(30 b_{f}\right)$ e suportando uma carga concentrada ou cargas distantes entre si de no mínimo $\left(2 b_{f}\right)$, a relação largura efetiva e largura plana em mesas tracionadas e comprimidas deverá ser limitada pelos valores fornecidos pela tabela (4.9).

\subsubsection{8 - ONDULAÇÃO DA MESA}

Para limitar os movimentos da mesa em direção à linha neutra, tanto para mesas tracionadas ou comprimidas, sendo enrijecidas ou não, utiliza-se a seguinte equação:

$$
b_{f}=\sqrt{0,061 t d E / f} \sqrt[4]{100 c_{f} / d}
$$


onde:

$\mathrm{b}_{\mathrm{f}} \quad$ = projeção da mesa além da alma.

$\mathrm{c}_{\mathrm{f}} \quad=$ deslocamento da mesa em direção à linha neutra.

d = altura da seção.

$\mathrm{f}=$ = tensão média da mesa.

$\mathrm{t}=$ espessura da mesa.

\subsection{5 - BARRAS FLEXO-COMPRIMIDAS}

Para dimensionar um perfil flexo-comprimido, onde há combinação do esforço de compressão com o momento fletor, as seguintes equações de interação devem ser respeitadas:

a) cálculo para a verificação da resistência

$$
\frac{N_{d}}{\phi_{c} N_{n}}+\frac{M_{d x}}{\phi_{b} M_{n x}}+\frac{M_{d y}}{\phi_{b} M_{n y}} \leq 1,0
$$

onde:

$\mathrm{Nd} \quad=$ força normal de cálculo.

$\mathrm{Md}=$ momento fletor, em relação ao plano analisado.

$\phi_{\mathrm{C}} \mathrm{N}_{\mathrm{n}}=$ resistência de cálculo à compressão.

$\phi_{\mathrm{b}} \mathrm{M}_{\mathrm{n}}=$ resistência da cálculo ao momento fletor (excluindo os efeitos da flambagem lateral com torção).

b) verificação da estabilidade

$$
\frac{N_{d}}{\phi_{c} N_{n}}+\frac{C_{m x} M_{d x}}{\left(1-N_{d} / N_{e x}\right) \phi_{b} M_{n x}}+\frac{C_{m y} M_{d y}}{\left(1-N_{d} / N_{e y}\right) \phi_{b} M_{n y}} \leq 1,0
$$

onde:

$$
\begin{aligned}
& N_{e x}=\frac{\pi^{2} E I_{x}}{(k L)_{x}^{2}} \\
& N_{e y}=\frac{\pi^{2} E I_{y}}{(k L)_{y}^{2}}
\end{aligned}
$$


$\mathrm{C}_{\mathrm{m}} \quad$ = coeficiente de momento uniforme equivalente, correspondente à flexão em torno do eixo analisado, que pode ser determinado de acordo com a tabela 4.9 .

$\mathrm{I}_{\mathrm{X}} \quad=$ momento de inércia da seção transversal bruta, em relação ao eixo "x".

Iy = momento de inércia da seção transversal bruta, em relação ao eixo "y".

$\mathrm{kL}$ = comprimento efetivo de flambagem em relação ao plano de flexão analisado. 


\section{CAPÍTULO 5}

\section{COMPOSIÇÃO ESTRUTURAL}

\section{1 - INTRODUÇão}

O presente capítulo tem por finalidade apresentar alguns aspectos para projeto de edificação industrial leve em aço, constituído por perfis de chapa dobrada. Como já citado no capítulo I, o emprego dos perfis de chapa dobrada está sendo ampliado na construção civil devido a grande variedade de seções transversais que podem ser obtidas a partir da conformação de chapas finas de aço.

Estas seções são estudadas para as mais diferentes estruturas e as mais variadas condições de construção, buscando-se encontrar as mais econômicas e convenientes para satisfazer a todos os pré-requisitos do projeto, bem como assegurando a devida segurança.

As estruturas de aço surgem da junção destes elementos estruturais montados na obra, compondo estruturas como coberturas, galpões, construções residenciais, torres de transmissão, pontes, etc. Estas estruturas são formadas por elementos como vigas, colunas, treliças, terças e contraventamentos.

\section{2 - EDIFICAÇÃO INDUSTRIAL TIPO LEVE}

As edificações industriais leves podem ser agrupadas em pórticos simples e múltiplos com contraventamentos longitudinais, sendo submetidas as solicitações do peso próprio, vento e sobrecargas.

Por ser uma estrutura que pode ser decomposta em uma série de substruturas planas, sua estabilidade global é assegurada por uma série de ligações e de contraventamentos racionalmente dispostos. 
O esquema geral para uma edificação leve é , basicamente, constituído de terças, treliças ou vigas de cobertura, colunas e contraventamentos. As terças servem de apoio para os elementos de vedação, as treliças ou vigas de cobertura são barras que suportam ações devidas ao peso próprio, ação do vento, etc, as colunas transmitem os esforços de toda a estrutura até as fundações e os contraventamento asseguram a estabilidade local dos elementos estruturais e global da estrutura como um todo.

A figura 5.1 apresenta a constituição de uma edificação industrial do tipo leve.

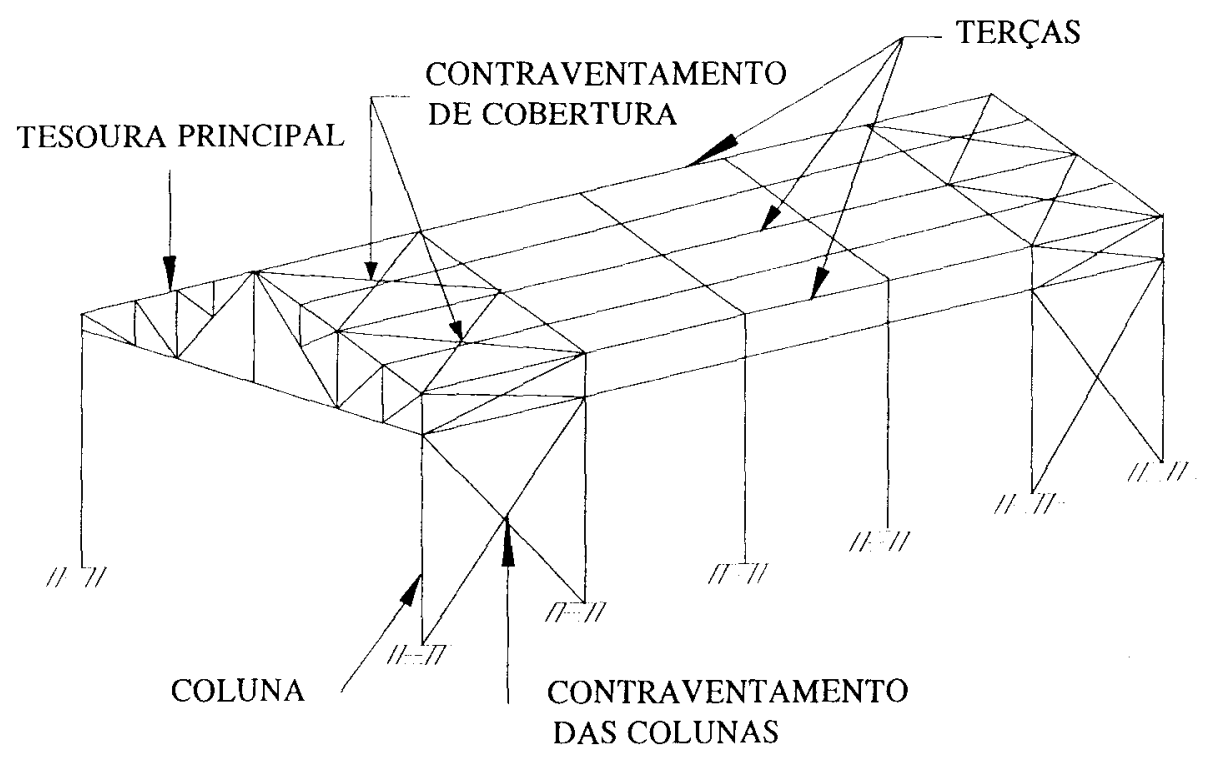

FIGURA 5.1 - Estrutura tipo de edificação leve. 


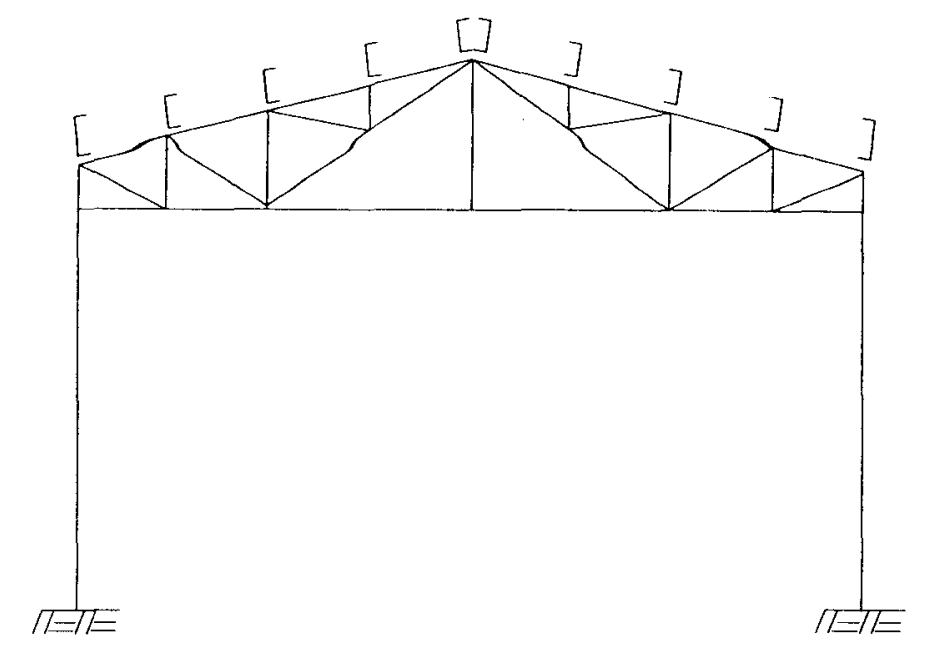

FIGURA 5.2 - Seção transversal

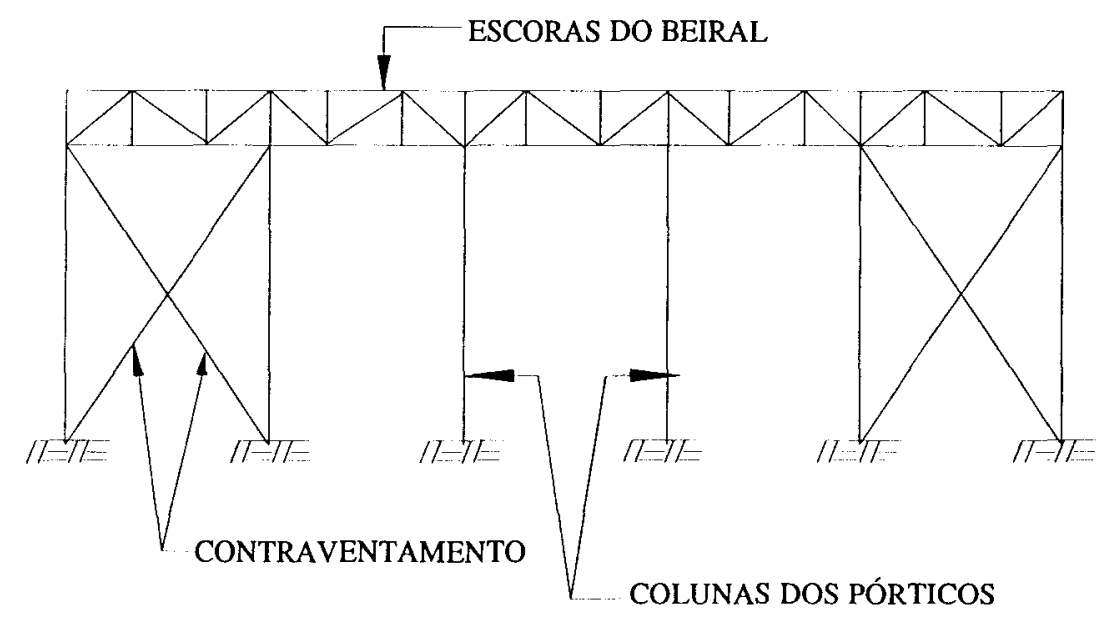

FIGURA 5.3 - Elevação lateral 


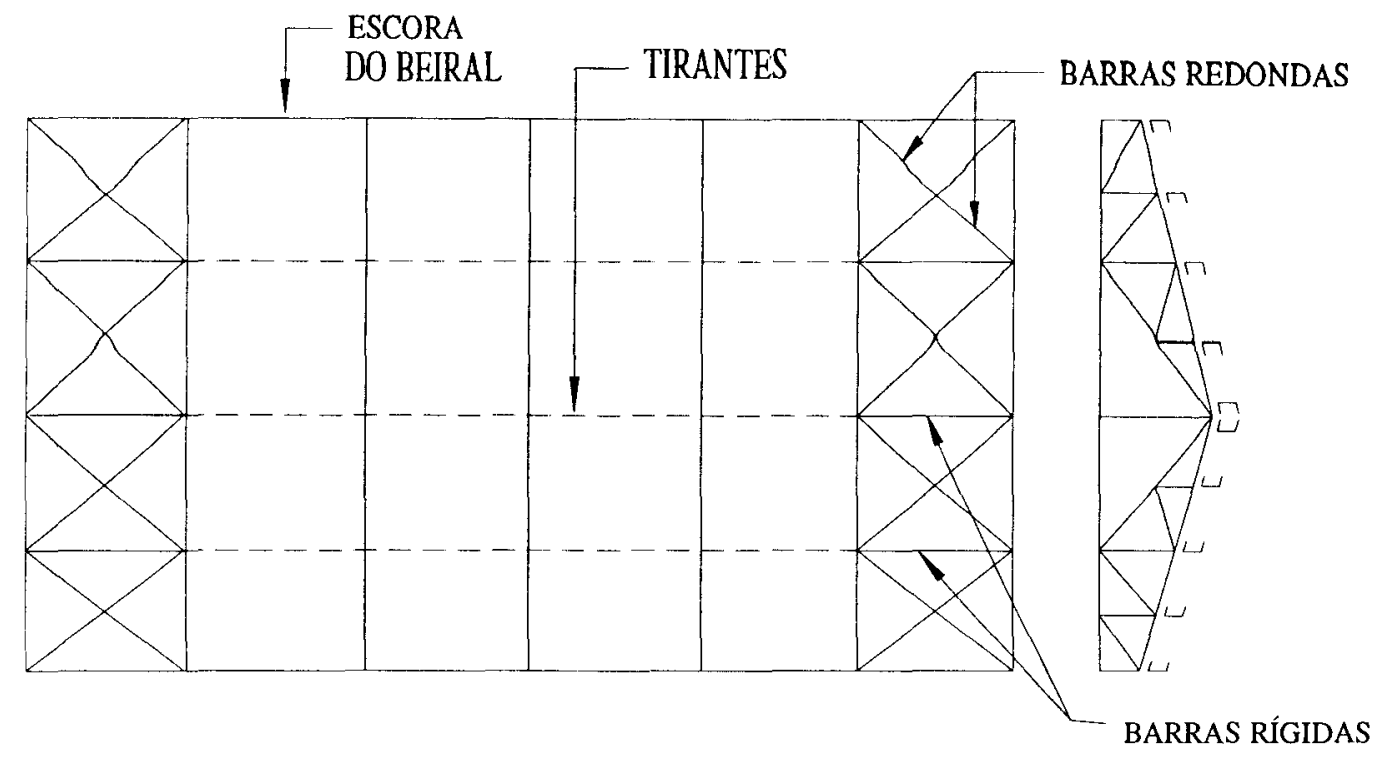

FIGURA 5.4 - Plano do banzo inferior

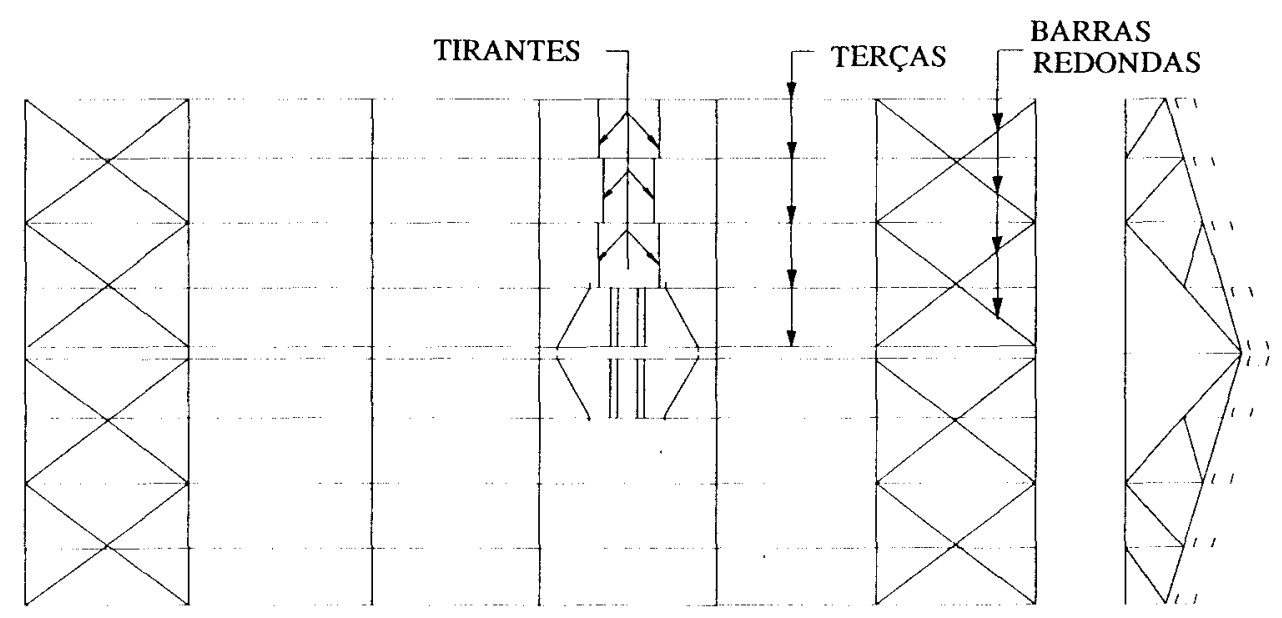

TÍPICO PARA TODOS OS VÃOS

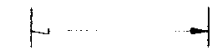

FIGURA 5.5 - Plano das terças 


\section{3 - TIPOS DE ELEMENTOS ESTRUTURAIS}

\subsection{1 - TERÇAS}

As terças são vigas colocadas na cobertura, situadas entre vigas principais ou secundárias de pórticos ou tesouras, destinadas a servir de apoio às telhas da cobertura.

Podem ser dimensionadas como vigas contínuas ou biapoiadas. Para diminuir o vão das terças no sentido da menor inércia, é comum o emprego de tirantes intermediários aos apoios. Os tirantes, por trabalharem só a tração, auxiliam no alinhamento das terças antes da fixação das telhas por ocasião da montagem e posicionados mais próximos da aba comprimida das terças, ajudam a combater a perda de estabilidade lateral que esta aba apresenta. Usualmente, emprega-se um tirante para vão de terças até $5 \mathrm{~m}$. Para vãos maiores que este valor, empregam-se dois tirantes.

As ações que atuam sobre as terças geradas pelo vento (pressão e sucção) e por outras cargas permanentes e sobrecargas fazem com que elas fiquem sujeitas às solicitações de flexão oblíqua.

A escolha dos tipos de perfis a serem empregados é feita, naturalmente, em função da intensidade das ações atuantes e do vão a vencer.

Os perfis de chapa dobrada empregados nas terças, para vãos menores que $7 \mathrm{~m}$, usualmente são seções em "U", "U" enrijecidos, "Z" e "Z" enrijecidos. No caso de vãos maiores, onde a flexão composta é preponderante, a seção mais empregada para as terças é a cartola. A figura 5.6 ilustra estas seções.

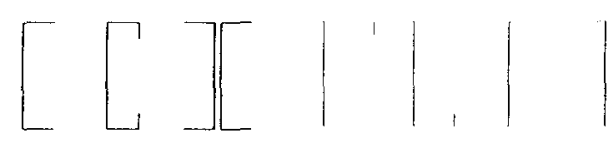

FIGURA 5.6 - Tipos de seções transversais de terças.

Caso se tenha vãos que superem os $7 \mathrm{~m}$, é conveniente que se empreguem terças em forma de treliça. Alguns tipos usuais de treliças em chapa dobrada estão representados na figura 5.7 . 

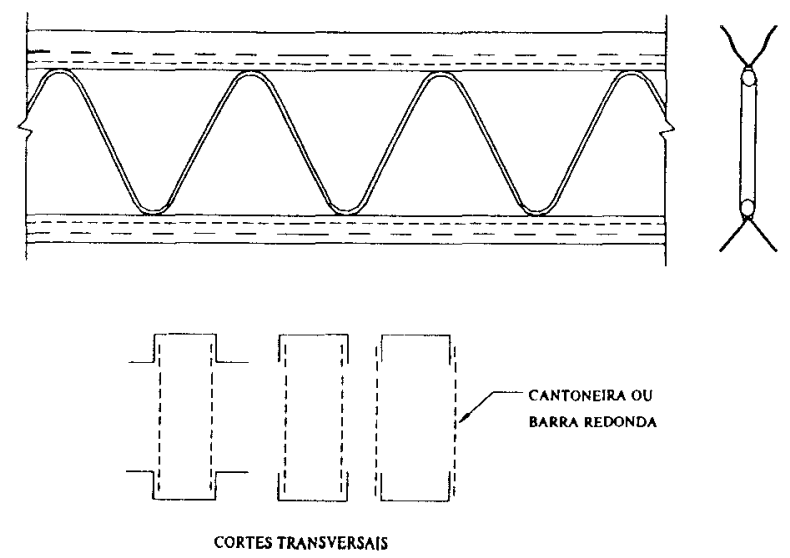

FIGURA 5.7 - Tipos de treliças.

Visando simplificar a ligação da terça com a tesoura, e também das terças com a telha, as abas das terças devem ser montadas com a mesma inclinação da cobertura. São vários os tipos de ligações que podem ser realizados entre estes elementos. É prática usual ligar estes elementos por meio de parafusos o que proporciona a vantagem de se poder desmontar a estrutura se necessário. A figura 5.8 ilustra alguns exemplos das ligações mais usadas.

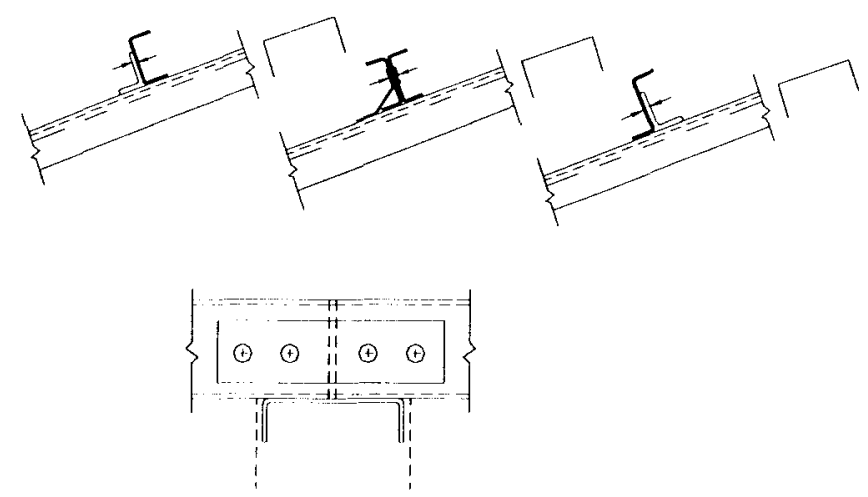

FIGURA 5.8 - Detalhe em ligações parafusadas.

O capítulo 6 descreve os procedimentos de cálculo para terças, apresentando os principais aspectos a serem considerados e no anexo I estão os resultados dos momentos admissíveis calculados.

A importância das terças como elemento estrutural pode ser observada pelo consumo de aço que as mesmas representam para edificações industriais leves, onde atingem um percentual de 40 a $60 \%$ do peso total da estrutura. 
Costumam ser dimensionadas sem grandes refinamentos e pouca atenção é dada aos seus deslocamentos, estado limite de utilização, sendo que este último é crítico para várias situações.

\subsection{2 - TRELIÇAS DE COBERTURA}

Treliças são elementos estruturais compostos por banzos e diagonais e/ou montantes.

As treliças devem ser projetadas de modo que as forças atuem nos nós, para evitar os momentos fletores nas barras. Os banzos devem ser projetados contínuos, evitando as emendas e com trechos retos entre os nós. As barras que forem solicitadas a compressão devem ser projetadas com o menor comprimento possível, procurando evitar o problema de flambagem.

As treliças, quando triangulares ou trapezoidais, recebem popularmente a denominação de tesouras.

As tesouras podem ter diversas formas, em função do tipo de telha utilizada, inclinação do telhado, etc, e alguns exemplos de tesouras e treliças estão representadas na figura 5.9 .

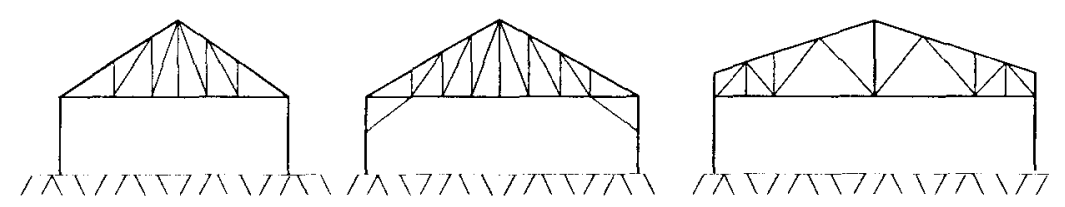

(a)

(b)

(c)

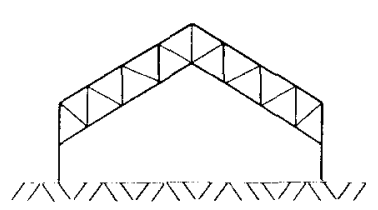

(d)

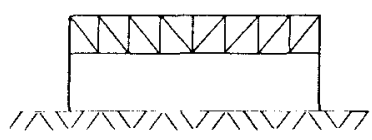

(e)

FIGURA 5.9 - Exemplos de tesouras.

A tesoura mais simples é a triangular, figura $5.9 \mathrm{a}$, sendo frequentemente utilizada para pequenos vãos. Para se ter uma maior rigidez para as ações laterais de vento, pode-se colocar uma mão-francesa partindo da coluna até o primeiro montante, figura $5.9 \mathrm{~b}$, ou pode-se adotar uma outra solução como a tesoura 
trapezoidal, figura 5.9c, que possibilita engastá-la às colunas, proporcionando uma maior rigidez para qualquer tipo de carregamento. Tesouras com inclinações elevadas, figura $5.9 \mathrm{~d}$, são comumente utilizadas em silos para material a granel, onde a inclinação é função do ângulo de atrito do material. Uma opção para pequenas inclinações de $0^{\circ}$ a $5^{\circ}$, é a treliça de banzos paralelos, figura $5.9 \mathrm{e}$, empregada principalmente em vigas mestras de sheds.

Os principais tipos de perfis em chapa dobrada empregados nas tesouras são as duplas cantoneiras de abas iguais e desiguais, os perfis " $U$ " e os perfis cartolas, como apresenta a figura 5.10 .

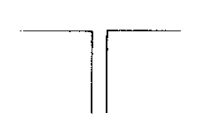

(a)

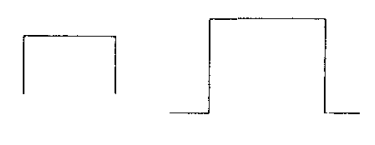

(b)

(c)

FIGURA 5.10 - Tipos de seções transversais empregadas nas tesouras.

Normalmente empregam-se para os banzos, tanto inferior quanto superior, duplas cantoneiras com abas iguais e perfil tipo "U", permitindo-se assim um apoio melhor às terças e facilitando o posicionamento de chapas que ligam as barras que formam os contraventamentos.

Para as diagonais e montantes empregam-se normalmente as seções tipo cantoneiras e perfil "U". Existe uma série de maneiras de se dispor estas seções, duas delas estão apresentadas na figura 5.11.
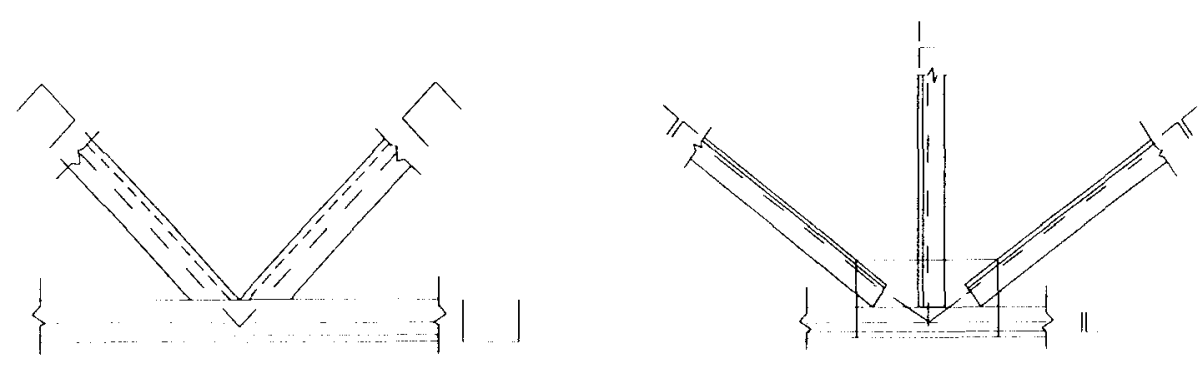

FIGURA 5.11 - Detalhes de ligações das diagonais com os banzos.

As treliças de cobertura são elementos estruturais que têm por finalidade receber a ação permanente da cobertura através das terças, bem como as ações acidentais, e vinculadas às colunas, dando origem à estrutura portante principal 
denominada de pórtico. Na figura 5.12 estão apresentados exemplos de apoios engastados de treliças em colunas e na figura 5.13 estão indicados apoios rotulados.

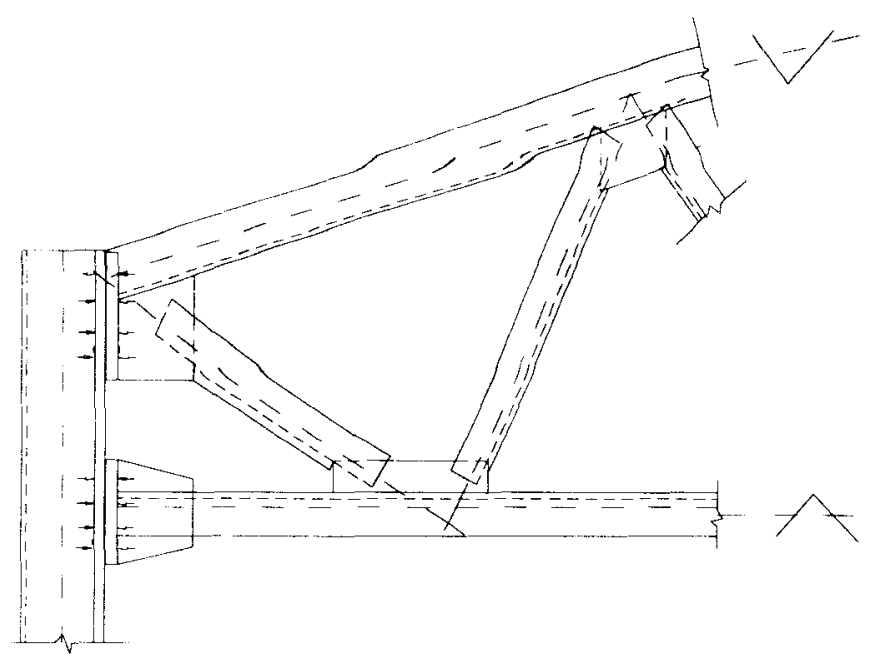

FIGURA 5.12 - Detalhe de apoio engastado de treliças com colunas.

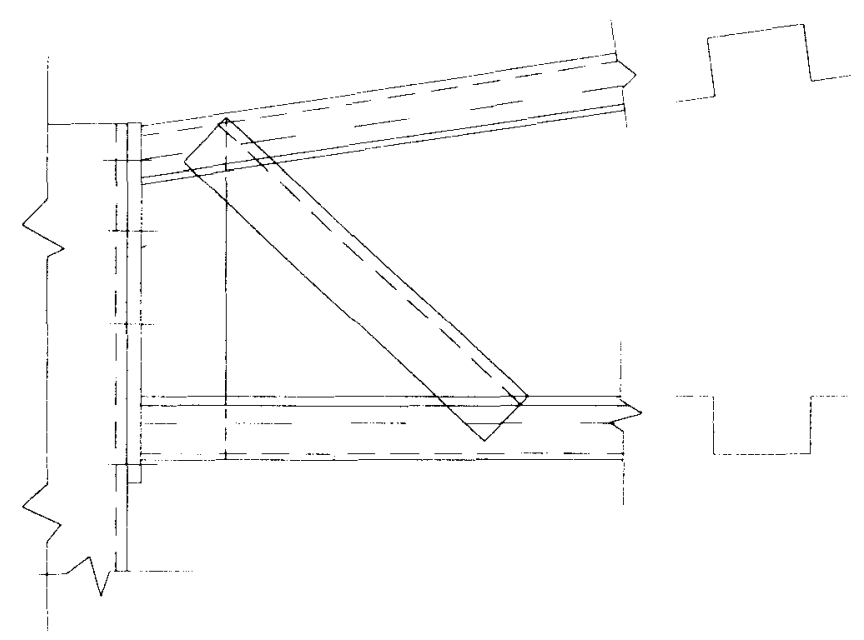

FIGURA 5.13 - Detalhe de apoio de treliças soldadas.

A vantagem das coberturas treliçadas em relação às coberturas com vigas de alma cheia é que podem ser empregadas para grandes vãos, reduzindo o peso próprio da estrutura. 


\subsection{3 - COLUNAS}

As colunas são elementos estruturais verticais ou levemente inclinados solicitados por ações axiais de compressão e por momentos fletores.

As forças axiais de compressão provém dos efeitos das cargas verticais transmitidas pelas coberturas, do peso próprio da estrutura e da treliça e das ações acidentais atuantes na cobertura, como por exemplo a ação do vento. Além disso ficará sujeita à flexão devida à ação do vento atuando sobre o fechamento lateral.

Para as colunas, dá-se preferência para o emprego do perfil de alma cheia se este atender às solicitaç̃̃es de cálculo e às condições de estabilidade. Os serviços de fabricação ficam limitados ao corte e à furação ou, adicionalmente, à solda nos elementos da ligação. Entretanto, para solicitações maiores, exigindo uma maior rigidez, empregam-se colunas treliçadas, o que é a solução normalmente utilizada para estruturas com perfis conformados a frio.

A combinação realizada com perfis dobrados, que podem ser de seção aberta ou fechada, irá atender à utilização como colunas.

Os perfis de seção fechada, denominados de perfis caixão, que são obtidos da união de dois perfis "U" enrijecidos ou não, possuem uma grande resistência à torção e um bom aspecto estético. O seu emprego pode deixar de ser viável devido ao peso próprio superior a solução de treliçamento. A figura 5.14 apresenta tipos de seções transversais utilizados em colunas.

As colunas de barras compostas por vários perfis, ligados de trecho em trecho por travejamento em treliças ou chapas, são caracterizadas por grande resistência advindas da inércia proporcionada pelo afastamento das membruras.

Para grandes comprimentos de flambagem, o seu uso é frequente, sendo o treliçamento usualmente constituído apenas por diagonais formadas por cantoneiras, geralmente de abas iguais, conforme ilustra a figura 5.15.

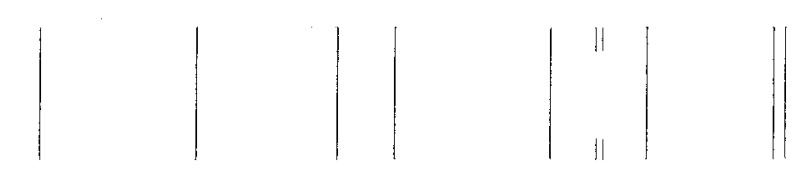

FIGURA 5.14 - Seções transversais de colunas. 

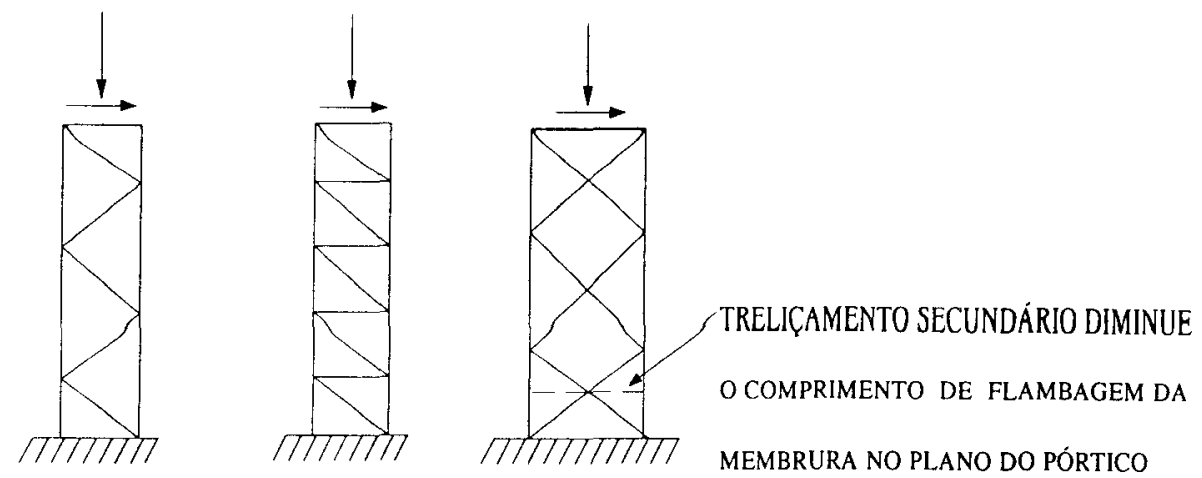

(SE NECESSÁRIO)

FIGURA 5.15 - Colunas treliçadas.

Se a distância entre os nós do treliçamento for grande, pode ser necessário o uso de peças horizontais para diminuir o comprimento de flambagem dos perfis no plano da coluna, permitindo assim obter um dimensionamento mais econômico.

Podem ser necessárias emendas nas colunas, por consequência de algumas limitações como o sistema de transporte a ser utilizado até a obra. As emendas mais utilizadas nas montagens são feitas por parafusos. Estas emendas são mais recomendadas que a solda de campo.

As soldas feitas no campo, por serem mais simples e tornarem mais simples a fabricação das peças, são mais empregadas, porém as dificuldades da inspeção e controle de qualidade existem.

As emendas parafusadas podem ser feitas com talas ou com chapas de topo. As soldadas podem ser feitas pela ligação direta de um perfil ao outro ou usando-se chapas-cobrejuntas.

As bases das colunas são responsáveis para transmitir os esforços normais de compressão, os momentos e as forças horizontais às fundações. As colunas em chapa dobrada são ligadas às fundações através de bases rotuladas ou engastadas, de acordo com a função estática que devem desempenhar. Exemplos de base de coluna rotulada e engastada estão apresentados a seguir na figura 5.16. 

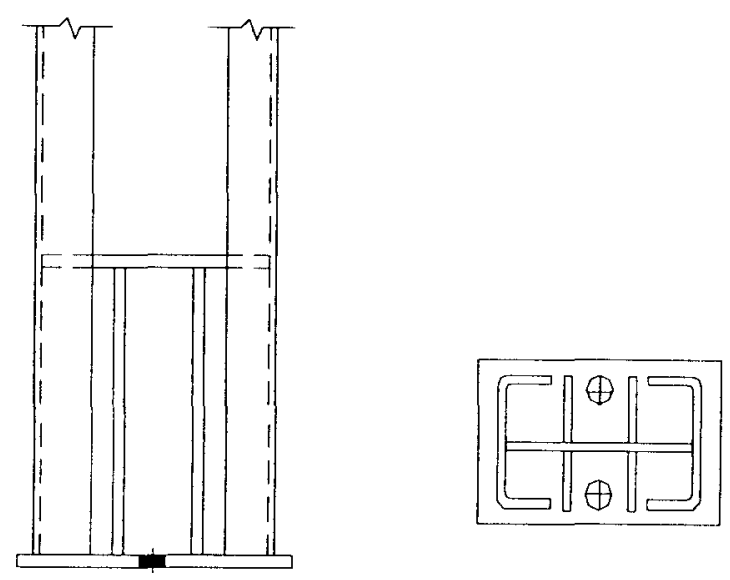

(a) Base rotulada
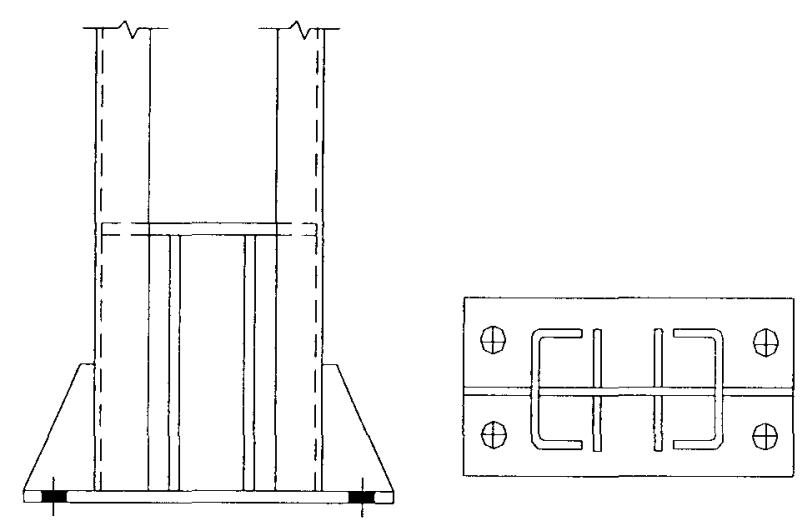

(b) Base engastada

FIGURA 5.16 - Bases de colunas.

\subsection{4 - CONTRAVENTAMENTOS}

Com a finalidade de garantir a estabilidade lateral dos elementos estruturais, limitando-se assim os comprimentos de flambagem locais e globais são feitos contraventamentos, proporcionando à estrutura uma maior rigidez fora do plano da estrutura principal e garantindo um comportamento espacial.

Existem uma série de maneiras de se dispor os contraventamentos, desde que as barras sejam racionalmente localizadas, de modo a contraventar os nós em um determinado plano, garantindo assim a estabilidade neste plano. A figura 5.17 apresenta um exemplo comum de sistemas de contraventamentos usados nos edifícios industriais. 


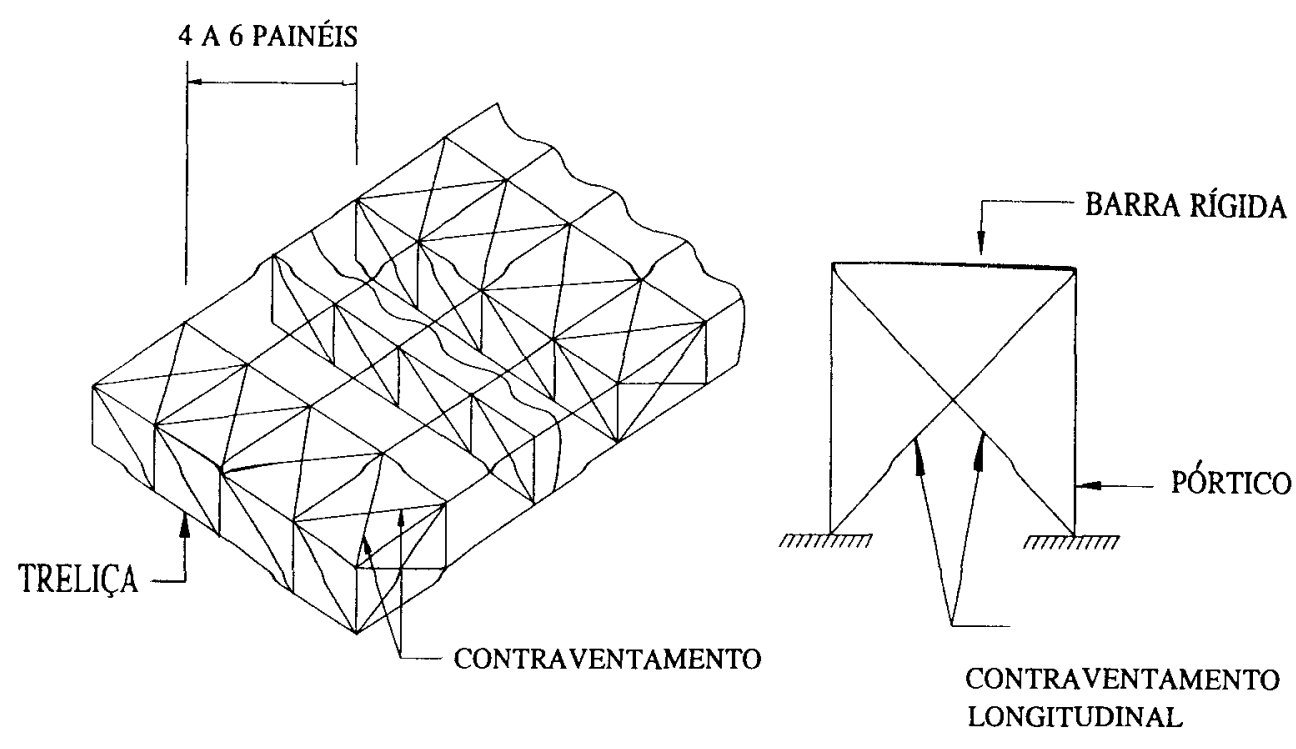

FIGURA 5.17 - Sistemas de contraventamentos.

Deve-se verificar a necessidade do contraventamento garantindo a estabilidade no plano da terça, dos pórticos transversais, dos pórticos longitudinais e em alguns casos do plano do banzo inferior dos pórticos transversais, principalmente quando formados por treliças.

Os contraventamentos, que se encontram no plano do banzo superior e do banzo inferior das tesouras, devem ser dimensionados em função da ação do elemento que contraventa (normalmente 2 a $6 \%$ da força existente na barra a contraventar).

Estes valores da força atuante no contraventamento é somente para o caso em que não existam ações externas aplicadas sobre o mesmo.

Os contraventamentos das colunas, compostos por barras dispostas em "X" associadas a uma "barra rígida", normalmente a viga de testeira, devem ser dimensionados em função das ações normais provenientes do fechamento frontal (quando for o caso) ou por porcentagens na ordem de 4 a $6 \%$ dos esforços existentes nos elementos a contraventar.

Os contraventamentos estão sujeitos, basicamente, aos esforços de tração e/ou compressão. As principais seções em perfis constituídos de chapa dobrada utilizadas nos contraventamentos são as cantoneiras e barras redondas.

Visando facilitar o uso dos perfis dobrados a frio apresenta-se, na tabela 5.1, os principais perfis empregados, com seção simples ou composta e onde são mais adequados. Na tabela 5.2 são apresentados os perfis de seção múltipla. 
TABELA 5.1 - Perfis de seção simples ou composta

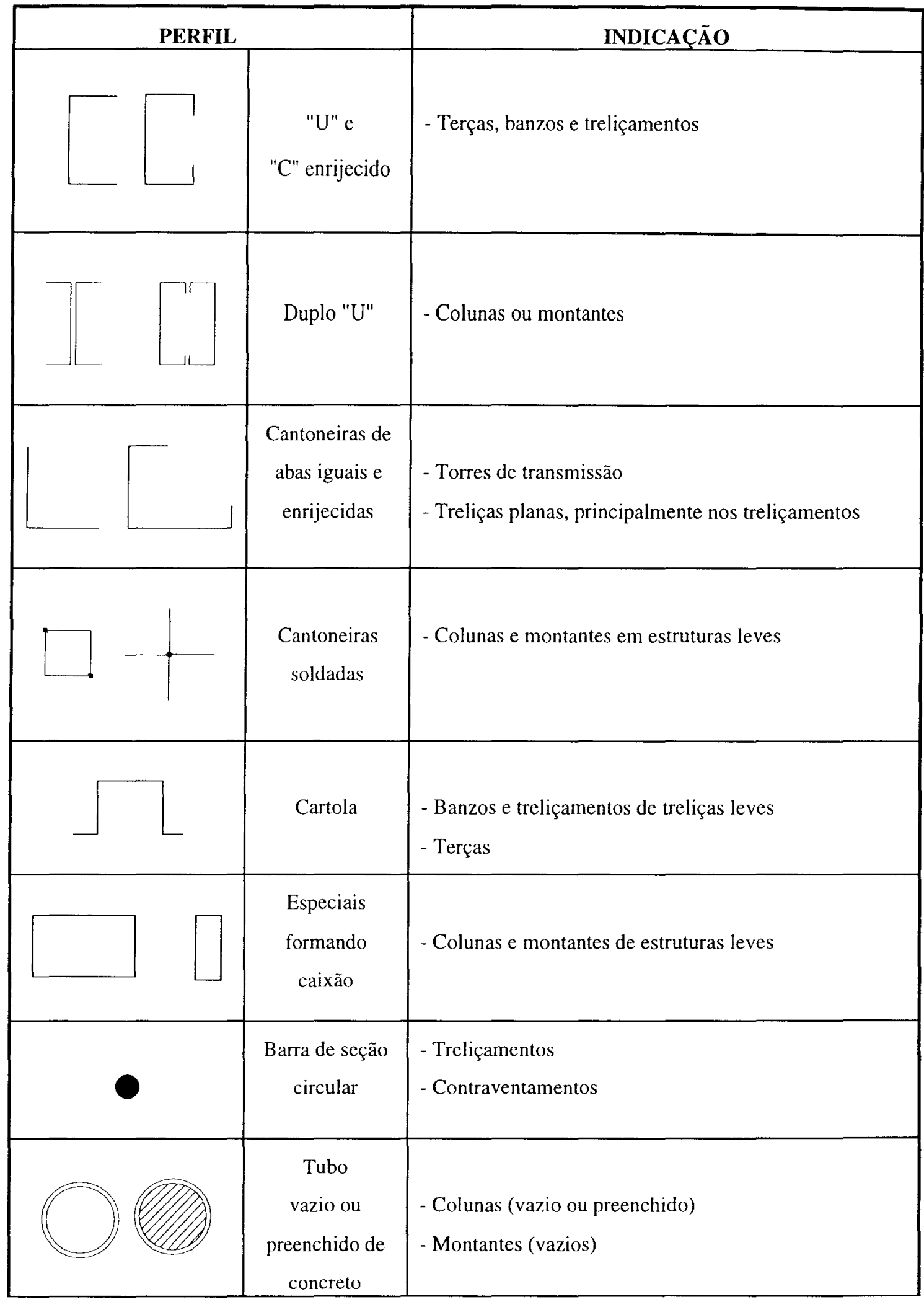


TABELA 5.2 - Perfis de seção múltipla

\begin{tabular}{|c|c|c|c|}
\hline \multicolumn{3}{|c|}{ PERFIL } & INDICAÇÃO \\
\hline & & $\begin{array}{c}\text { Duas cantoneiras } \\
\text { de abas iguais }\end{array}$ & - Banzos e treliçamentos \\
\hline & & $\begin{array}{l}\text { Dois C, com } \\
\text { travejamento }\end{array}$ & $\begin{array}{l}\text { - Colunas } \\
\text { - Treliçamentos }\end{array}$ \\
\hline EDPPA & EA & $\begin{array}{l}\text { Dois C, com } \\
\text { travejamento e } \\
\text { enchimento de } \\
\text { concreto }\end{array}$ & - Colunas \\
\hline & & $\begin{array}{c}\text { Quatro } \\
\text { cantoneiras de } \\
\text { abas iguais e } \\
\text { cantoneiras de } \\
60^{\circ} \text { travejadas }\end{array}$ & $\begin{array}{l}\text { - Colunas } \\
\text { - Treliças de cobertura }\end{array}$ \\
\hline
\end{tabular}




\section{CAPÍTULO 6}

\section{SISTEMÁTICA DE CÁLCULO PARA ANÁLISE DE TERÇAS}

\section{1 - INTRODUÇÃO}

A finalidade deste capítulo é apresentar a sistemática de cálculo utilizada para o pré-dimensionamento das terças apresentadas no anexo deste trabalho. Empregaram-se os critérios de projeto da norma AISI (1980) considerando-se para o cálculo o método das tensões admissíveis.

Obtiveram-se valores dos momentos admissiveis correspondentes a: flambagem local da mesa (FLM), flambagem local da alma (FLA) e flambagem lateral com torção (FLT). O cálculo dos momentos admissíveis foram efetuados considerando vãos com comprimento $\mathrm{L}=4,5$ e $6 \mathrm{~m}$, uma e duas linhas de correntes (figura 6.1), espessura $t=1,90,2,66,3,04,3.50,4,05$ e 4,80mm, o tipo de aço A570/A, A470/E, SAC 51 e SAC 50 para os perfis "U" não enrijecidos e perfis "U" enrijecidos.

Através de planilhas de cálculo, foi possível ilustrar os valores obtidos dos momentos em formas de tabelas e gráficos. O "momento fletor admissível" de cada perfil é o "menor" valor obtido entre os valores de FLM, FLA e FLT.
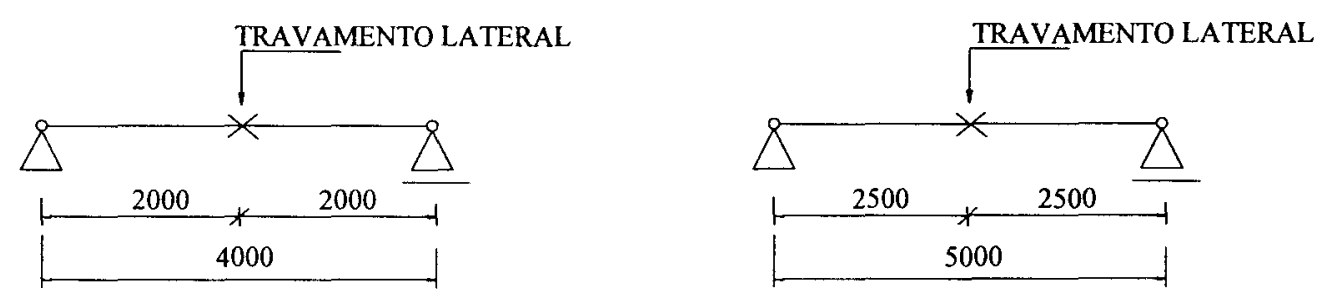

FIGURA 6.1 - Comprimentos "L" das terças 

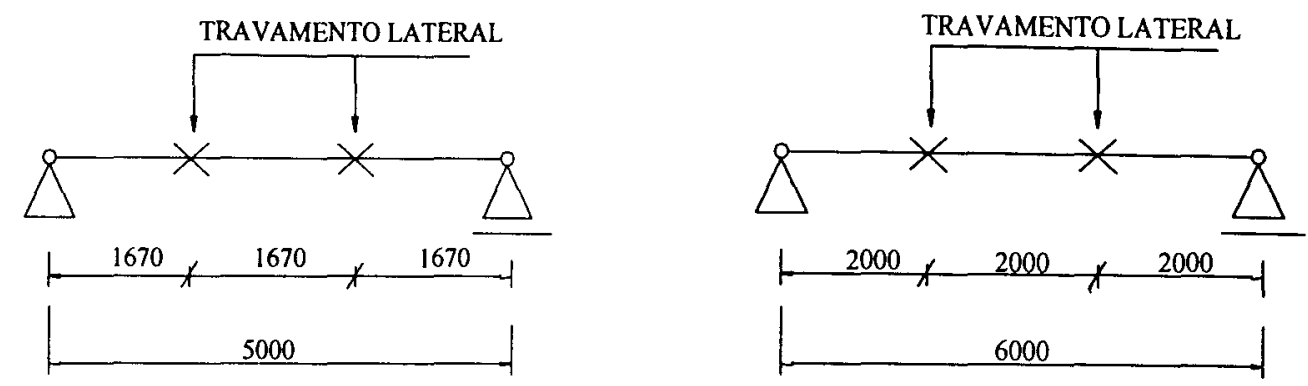

FIGURA 6.1 - Continuação

\section{2 - MÉTODO UTILIZADO PARA O PRÉ-DIMENSIONAMENTO}

\subsection{1 - RELAÇÕES BÁSICAS}

Considerou-se para o pré-dimensionamento dos perfis os critérios de projeto da norma AISI (1980), obedecendo os limites prescritos pela mesma, utilizando o método das tensões admissíveis, sendo a mesma notação usada por SÁLES \& MALITE (1993). O procedimento de cálculo para os perfis foi feito da seguinte maneira:

PERFIL "U" $(75 \times 40 \times 1,90): 2,22 \mathrm{~kg} / \mathrm{m}$

raio de dobra $=$ espessura $=1,90 \mathrm{~mm} \quad \mathrm{~L}=5 \mathrm{~m}$

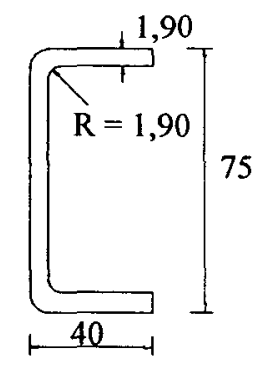

$$
\begin{aligned}
& A=2,83 \mathrm{~cm} 2 \\
& \mathrm{IX}=25,16 \mathrm{~cm} 4 \\
& \mathrm{Iy}=4,57 \mathrm{~cm} 4 \\
& \mathrm{Iyc}=\mathrm{Iy} / 2 \\
& \mathrm{Wx}=6,71 \mathrm{~cm} 3
\end{aligned}
$$

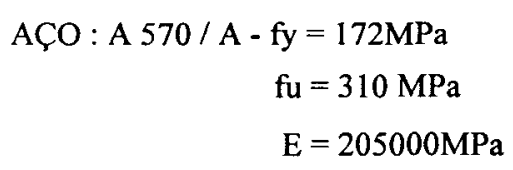

SEÇÃO TRANSVERSAL

a) Flambagem local da mesa - FLM (mesa comprimida não enrijecida)

$$
\left(\frac{b}{t}\right) \leq \frac{166}{\sqrt{f_{y}}} \rightarrow\left(\frac{b}{t}\right)=\frac{40-2 \times 190}{1,90^{\prime}}=19,05 \quad \Rightarrow \quad 19,05>12,70
$$


Está compreendido entre: $\quad 166 / \sqrt{f_{y}}<(w / t) \leq 25$, portanto a equação de " $\mathrm{f}_{\mathrm{c}}$ " será:

$$
\begin{aligned}
& f_{c}=0,60 f_{y}-\frac{\left(b / t-166 / \sqrt{f_{y}}\right)\left(0,087 f_{y}-12,80\right)}{3,625\left(1-6,64 / \sqrt{f_{y}}\right)} \\
& f_{c}=9,95 \mathrm{KN} / \mathrm{cm}^{2} \\
& \rightarrow M_{a d m}=W_{x} f_{c} \rightarrow M_{a d m}=64,08 \mathrm{KN} . \mathrm{cm}
\end{aligned}
$$

b) Flambagem local da alma - FLA (viga com mesa comprimida não enrijecida)

$$
\begin{gathered}
\frac{b}{t}=\frac{75-2 \times 1,90}{1,90}=37,47 \\
f_{b w}=\left[1,26-0,00019\left(\frac{h}{t}\right) \sqrt{f_{y}}\right] 0,60 f_{y} \leq 0,60 f_{y} \\
f_{b w}=12,04 \mathrm{KN} / \mathrm{cm}^{2}>0,60 f_{y} \\
\text { - área da mesa } \rightarrow A_{f}=3,62 \times 0,19=0,688 \mathrm{~cm}^{2} \\
\text { - área efetiva da mesa } \rightarrow A_{f}^{\prime}=\left(f_{c} / f\right) A_{f}=0,637 \mathrm{~cm}^{2}
\end{gathered}
$$

- posição do centro de gravidade da seção efetiva:

$$
\bar{y}=\frac{0051 \times 3,655}{\dot{2}, 83-0,051}=0,068
$$

- momento de inércia de seção efetiva:

$$
I_{x}^{\prime}=25,2+2,83(0,068)^{2}-0,051(3,655+0,068)^{2}=24,46 \mathrm{~cm}^{4}
$$

- módulo de resistência à flexão com relação a fibra comprimida da seção efetiva:

$$
W_{x}^{\prime}=\frac{24,46}{3,365+0,068}=6,57 \mathrm{~cm}^{3}
$$


$-\operatorname{adotar} 0,60 \mathrm{f}_{\mathrm{y}} \rightarrow \begin{aligned} & M_{\text {adm }}=6,57 \times 10,32 \times(75 / 71,2) \\ & M_{a d m}=71,42 \mathrm{kNcm}\end{aligned}$

c) Flambagem lateral com torção - FLT

Admitindo-se duas linhas de corrente ao longo do vão, o comprimento não travado (L) será $L / 3\left(L_{b}=1,67\right)$. Assume-se o coeficiente de flexão $C_{b}$ igual a 1 .

$$
\begin{gathered}
\lambda_{b}^{2}=\frac{L^{2} W_{x}}{d I_{y c}}=10.9190,36 \pi^{2} E C_{b} / f_{y}<\lambda_{b}^{2}<1,8 \pi^{2} E C_{b} / f_{y} \\
4.235<10.919<21.174 \\
f_{b}=\frac{2}{3} f_{y}-\frac{f_{y}^{2}}{5,4 \pi^{2} E C_{b}} \lambda_{b}^{2} \quad \Rightarrow \quad f_{b}=8,56 \mathrm{KN} / \mathrm{cm}^{2} \\
\rightarrow M_{a d m}=W_{x} f_{b} \quad \rightarrow \quad M_{a d u}=57,43 \mathrm{KN} . \mathrm{cm}
\end{gathered}
$$

Portanto, o momento fletor admissivel do perfil é o menor valor entre FLM, FLA e FLT. Neste caso será:

$$
\begin{array}{r}
M_{a d m}=57,43 \mathrm{KN} . \mathrm{cm}(\text { flambagem lateral com torção) } \\
\text { TABELA } 1 U(75 \times 40 \times 1,90)
\end{array}
$$

Este mesmo critério de cálculo foi adotado para o pré-dimensionamento dos outros perfis. Para cada perfil considerado, obtiveram-se os valores dos momentos críticos que estão apresentados no anexo I em forma de tabelas e gráficos para fácil entendimento e aplicação.

Em caráter ilustrativo, a seguir é apresentado um exemplo que consiste no cálculo de uma terça mediante a aplicação das tabelas fornecidas.

\section{3 - EXEMPLO ILUSTRATIVO PARA ANÁLISE DE TERÇA EMPREGANDO AS TABELAS}

Devido à inclinação do telhado, as terças são solicitadas à flexão oblíqua para as solicitações na direção das ações gravitacionais, como o peso próprio ou 
sobrecarga*. Para a ação do vento, são solicitadas à flexão simples, pois sua resultante é sempre perpendicular à superfície onde ela atua.

Será adotado o perfil "U" enrijecido, a inclinação do telhado de $15^{\circ}$ e o espaçamento entre terças de $2 m$.

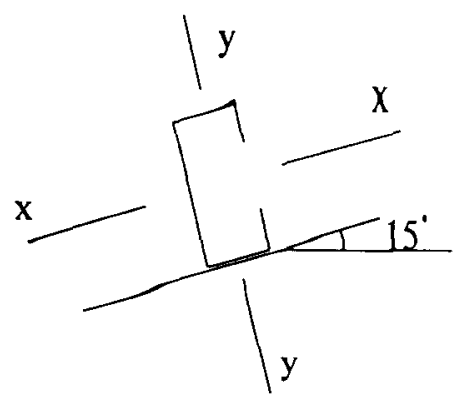

$a-$ Ações atuantes

i) permanentes

$$
\begin{array}{ll}
\text { peso próprio } & \rightarrow 0,05 \mathrm{kN} / \mathrm{m} \\
\text { telha } & \rightarrow 0,05 \mathrm{kN} / \mathrm{m}^{2} \times 2,0 \mathrm{~m}=0,10 \mathrm{kN} / \mathrm{m} \\
\text { total } & \rightarrow 0,15 \mathrm{kN} / \mathrm{m}
\end{array}
$$

ii) sobrecarga do telhado $\rightarrow q=0,25 \mathrm{kN} / \mathrm{m}^{2} \times 2,0 \mathrm{~m}=0,50 \mathrm{kN} / \mathrm{m}$

iii) ação do vento (NBR 6123)

Admitindo-se um galpão industrial na cidade de São Carlos, $V_{0}=40 \mathrm{~m} / \mathrm{s}$, com dimensões de $25 m$ de comprimento por $20 m$ de largura e $9 m$ de altura.

$$
\begin{aligned}
& V_{0}=40 \mathrm{~m} / \mathrm{s} \\
& \text { velocidade característica } \rightarrow V_{k}=V_{o} \times S_{1} \times S_{2} \times S_{3} \\
& S_{1} \rightarrow \text { fator topográfico } S_{1}=1,0 \\
& S_{2} \rightarrow \text { rugosidade do terreno, dimensões da edificação e altura sobre o } \\
& \quad \text { terreno }
\end{aligned}
$$

\footnotetext{
* Esta sobrecarga é recomendada pela Norma Brasileira NBR-8800, sendo um valor elevado para edificações industriais leves. Cabe ao calculista adotar este valor ou propor, justificando, um valor alternativo.
} 
Rugosidade do terreno $\rightarrow$ categoria $V I$ - área industrial parcialmente desenvolvida

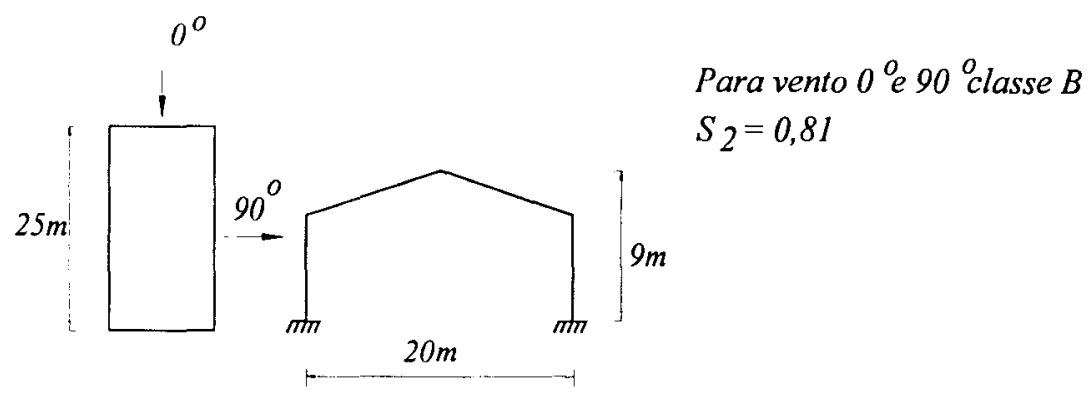

$S_{3} \rightarrow$ fator estatístico considerando-se edificação e instalação industrial com baixo fator de ocupação

$S_{3}=0,95$

$V_{k}=40 \times 1 \times 0,81 \times 0,95$

$V_{k}=30,78 \mathrm{~m} / \mathrm{s}$

Pressão de obstrução $\rightarrow q=0,613 \bigvee_{\mathrm{k}}^{2} \times 10^{-3}=0,58 \mathrm{kN} / \mathrm{m}^{2}$

Como exemplo será adotado $\Delta C_{p}=1$

$\mathrm{q}_{\mathrm{V}}^{\prime}=q_{v^{\times}} \times C_{p \times 2,00} \rightarrow \mathrm{q}_{\mathrm{V}}^{\prime}=-1,16 \mathrm{kN} / \mathrm{m}$

$b$ - situação de carregamento (inclinação do telhado $\cong 11,5^{\circ}$ )

1) permanente + sobrecarga $\rightarrow P=0,15\left(\cos 11,5^{\circ}\right)+0,50\left(\cos 11,5^{\circ}\right)$

$\rightarrow P=0,64 \mathrm{kN} / \mathrm{m}$

2) permanente + vento (sucção) $\rightarrow P=0,15(\cos 11,5)+(-1,16)$

$\rightarrow P=-1,01 \mathrm{kN} / \mathrm{m}$ 
c-Diagramas de momentos solicitantes
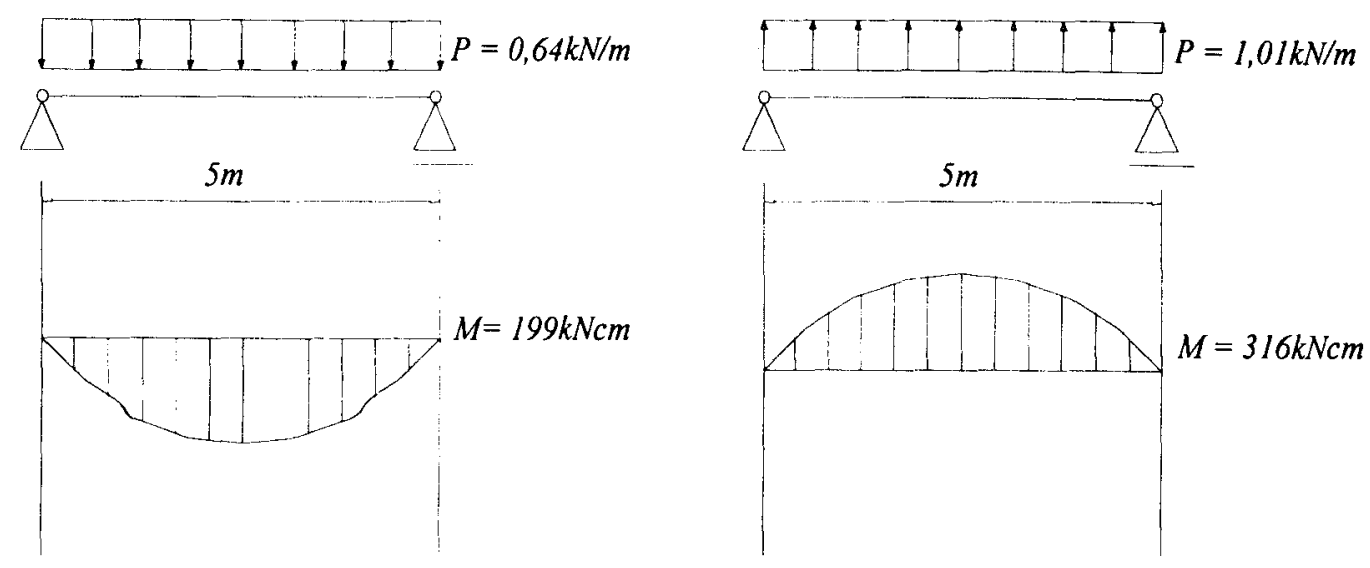

\subsection{1 - ESCOLHA DO PERFIL}

Portanto com o valor do momento solicitante no eixo " $\mathrm{x}$ ", pode-se entrar nas tabelas e escolher o perfil com o momento admissível que melhor se adapta para cada situação.

Para este exemplo, o perfil adotado será o da tabela número 38

U enrijecido $(127 \times 40 \times 25 \times 2,66)$.
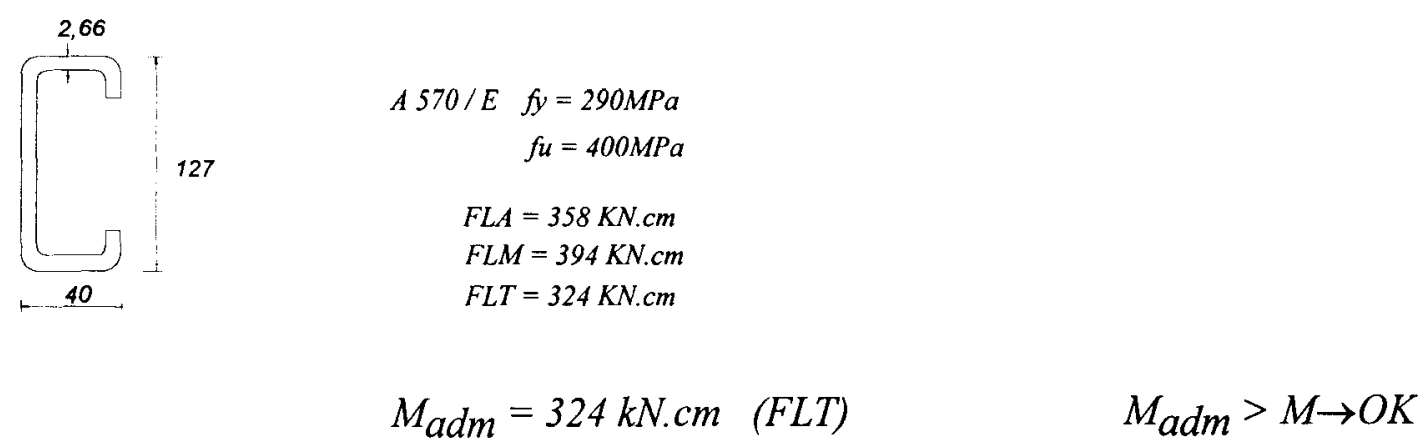

Situação de carregamento $\rightarrow$ Permanente + sobrecarga

$$
\begin{aligned}
& P=0,15(\operatorname{sen} 11,5)+0,50(\operatorname{sen} 11,5) \\
& P=0,13 \mathrm{kN} / \mathrm{m}
\end{aligned}
$$


Diagrama de momento solicitante:

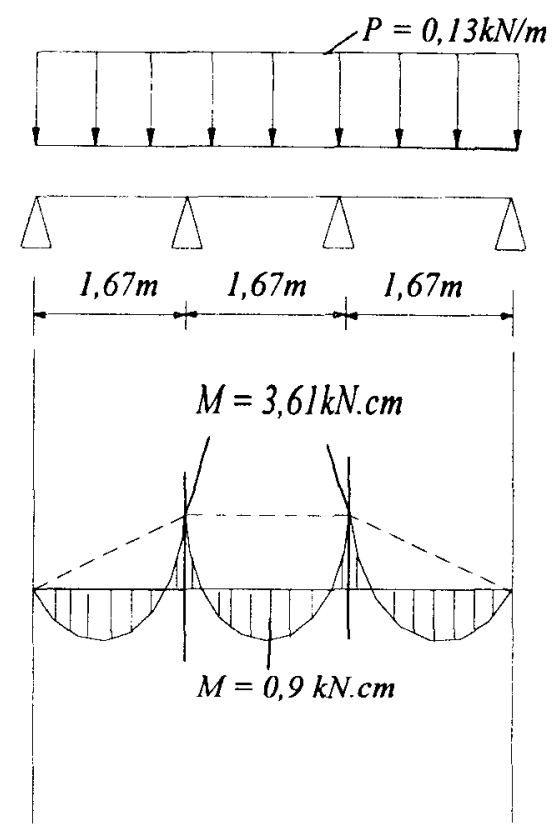

a) Flambagem local da mesa - FLM (mesa comprimida enrijecida

Flambagem local $\rightarrow$ na flexão em torno do eixo de menor inércia " $y$ ", a alma do perfil resulta comprimida junto aos apoios centrais (correntes), devendo-se verificar sua largura efetiva:

$$
\left(\frac{b}{t}\right)=\frac{127-4 \times 2,66}{2,66}=43,7>\left(\frac{b}{t}\right)_{\lim }=\frac{449}{\sqrt{f_{y}}}
$$

- largura efetiva $\rightarrow b_{e f}=\frac{667 \times t}{\sqrt{f}}\left[1-\frac{146}{(b / t) \sqrt{f}}\right]$

onde:

$f \rightarrow$ máxima tensão atuante na seção efetiva.

$$
\begin{aligned}
& f=\frac{M}{W_{e f}} \rightarrow f=\frac{0,9}{5,87}=0,153 \mathrm{kN} / \mathrm{cm}^{2} \\
& b_{e f}=\frac{667 \times t}{\sqrt{f_{y}}}\left[1-\frac{146}{43,74 \sqrt{f_{y}}}\right] \Rightarrow b_{e f}=-243 \mathrm{~cm}
\end{aligned}
$$


$\rightarrow \quad b=b_{e f} \rightarrow$ não converge, portanto, não ocorre flambagem local. Desta forma, não é necessário calcular um novo $\mathrm{W}$.

Calculando a tensão critica de flambagem da chapa:

$$
\begin{aligned}
f_{c r}=\frac{k{ }^{2} E}{12\left(1-v^{2}\right)(b / t)^{2}}=38,74 \mathrm{kN} / \mathrm{cm}^{2} \gg \gg f \\
M_{a d m}=W \times 0,6 f_{y}=5,87 \times 0,6 \times 29 \\
M_{a d m}=102,14 \mathrm{kNcm}
\end{aligned}
$$

b) Flambagem local da alma - FLA (mesa comprimida enrijecida)

$$
\begin{aligned}
& \left(\frac{b}{t}\right)=\frac{40-4 \times 2,66}{2,66}=11,04 \quad b=b_{e f} \\
& f_{b w}=\left[1,21-0,00013\left(\frac{h}{t}\right) \sqrt{f_{y}}\right] 0,6 f_{y} \leq 0,6 f_{y} \Rightarrow f_{b w}=12,3 \mathrm{kN} / \mathrm{cm}^{2}
\end{aligned}
$$

usar 0,6fy $\begin{aligned} M_{a d m} & =0,6 f_{y} \times w \times(d / b) \\ M_{a d m} & =68,09 \mathrm{kNcm}\end{aligned}$

Para as terças em perfis de chapa dobrada, é válida a seguinte equação que faz a interação das solicitações nos dois planos:

$$
\begin{aligned}
& \frac{M_{x}}{M_{a d m}}+\frac{M_{y}}{M_{a d m}} \leq 1,0 \\
& \frac{316}{324}+\frac{0,90}{102}=0,98<1,0(O K)
\end{aligned}
$$

Portanto, verifica-se que o perfil escolhido resiste às solicitações impostas a ele. 


\section{CAPÍTULO 7}

\section{CONSIDERAÇÕES FINAIS E CONCLUSÕES}

Em razão da frequente utilização dos perfis de chapa dobrada como elementos estruturais na construção civil, procurou-se neste trabalho apresentar alguns aspectos teóricos para o dimensionamento e projeto deste elementos.

Apesar do seu grande emprego nos dias atuais, a única norma brasileira para o cálculo dos perfis conformados a frio NB-143 encontra-se obsoleta e em desuso fazendo com que os calculistas desta área utilizem de experiências com outros tipos de perfis metálicos ou empreguem normas estrangeiras mais recentes. Neste trabalho foram utilizadas, por exemplo, as normas AISI (1980) e CSA (1984).

Quanto ao aspecto de dimensionamento, ressaltaram-se a importância e a necessidade de se prevenir os fenômenos da flambagem por flexão, por torção e por flexão e torção simultaneamente.

Estes problemas de flambagem dependem das condições de vinculação e das características geométricas da seção transversal, havendo, deste modo, particularizações para a utilização e solução das equações diferenciais regentes da instabilidade.

O processo de cálculo consiste em determinar a força ou o momento crítico de flambagem da barra. E por serem vigas delgadas faz-se necessário considerar as características setoriais da seção transversal. Estas características podem ser tabeladas facilitando grandemente o cálculo.

Quanto ao aspecto de projeto, discutiu-se sobre algumas disposições dos elementos estruturais. Como o assunto é vasto e complexo, não se teve a pretensão de apresentar um estudo completo, e sim, uma abordagem de alguns aspectos interessantes e essenciais ao desenvolvimento de um modelo construtivo no caso de uma edificação composta de perfis conformados a frio. 
Considerando a grande importância dos perfis de chapa dobrada como elementos estruturais para as terças, desenvolveu-se uma análise dos momentos fletores admissíveis que podem ser aplicados para um pré-dimensionamento destes elementos.

Através dos resultados obtidos, evidencia-se que a flambagem nestes elementos ocorrerá na maioria dos casos por flexão e torção, resultados estes já esperados. Como já mencionado, os valores finais estão apresentados em forma de tabelas e gráficos onde podem ser consultados e possibilitando sua fácil aplicação. Com estes valores espera-se facilitar e auxiliar o cálculo e o pré-dimensionamento das terças.

Para comprovar esta afirmação, no sexto capítulo foi desenvolvido um exemplo de aplicação que ilustra a utilização destas tabelas.

Conclui-se que presente trabalho apresenta um procedimento para o cálculo dos elementos conformados a frio, de uma forma mais atualizada com as normas estrangeiras e também uma contribuição para o cálculo do pré-dimensionamento das terças.

Os estudos dos elementos conformados a frio são apresentados na literatura de forma restrita, com poucos trabalhos desenvolvidos. Este tema é de grande interesse e há, ainda, diversos assuntos a serem pesquisados.

Pode-se sugerir, por exemplo, trabalhos no sentido de desenvolver outras tabelas e programas para o dimensionamento de perfis estruturais, permitindo uma maior sistematização do cálculo para todos os componentes estruturais.

Por meio deste trabalho, procurou-se apresentar os fundamentos teóricos que estão embutidos em um procedimento normativo ou de cálculo, com perfis de chapa dobrada que, espera-se, possam ser úteis a estudantes, profissionais e pesquisadores do assunto. 
TABELA 1

VALORES ADMISSIVEIS DOS MOMENTOS PARA FLM, FLA e FLT em $\mathrm{kN} . \mathrm{cm}$

\begin{tabular}{|c|c|c|c|c|c|c|c|c|c|c|c|c|}
\hline & \multicolumn{12}{|c|}{ TIPOS DE ACO } \\
\hline & \multicolumn{3}{|l|}{ A 5707A } & \multicolumn{3}{|l|}{ A570TE } & \multicolumn{3}{|l|}{ SAC 41} & \multicolumn{3}{|l|}{ SAC 50 } \\
\hline \multirow{2}{*}{$\begin{array}{l}L b=167 \\
\text { esp }=1.9\end{array}$} & \multicolumn{3}{|c|}{$F Y=172 \mathrm{MPa} F u=310 \mathrm{MPa}$} & \multicolumn{3}{|c|}{$F y=290 \mathrm{MPa} F u=400 \mathrm{MPa}$} & \multicolumn{3}{|c|}{$F y=245 \mathrm{MPa} F u=400 \mathrm{MPa}$} & \multicolumn{3}{|c|}{$F_{Y}=373 \mathrm{MPa} F u=500 \mathrm{MPa}$} \\
\hline & FLM & FLA & FLT & FLM & FLA & FLT & $\overline{\text { FLM }}$ & FLA & FLT & FLM & FLA & FLT \\
\hline$U(75 \times 40)$ & 64 & 71 & 57 & 86 & 106 & 73 & 77 & 92 & 69 & 100 & 129 & 75 \\
\hline$U(100 \times 40)$ & 94 & 103 & 84 & 126 & 156 & 107 & 113 & 135 & 101 & 146 & 191 & 109 \\
\hline$U(127 \times 40)$ & 131 & 142 & 115 & 176 & 217 & 146 & 157 & 188 & 139 & 204 & 268 & 148 \\
\hline $\mid v(150 \times 40)$ & 165 & 179 & 144 & 222 & 276 & 180 & 199 & 238 & 173 & 257 & 341 & 182 \\
\hline$U(200 \times 40)$ & 252 & 272 & 214 & 338 & 424 & 258 & 303 & 365 & 241 & 392 & 528 & 258 \\
\hline$U(250 \times 40)$ & 353 & 380 & 290 & 474 & 599 & 336 & 425 & 515 & 333 & 550 & 750 & 336 \\
\hline
\end{tabular}

A $570 / A$

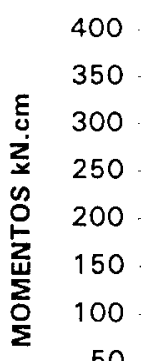

50

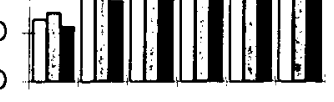

PERFIS

OFLM $\triangle F L A \square F L$
A $570 / E$

SAC 41

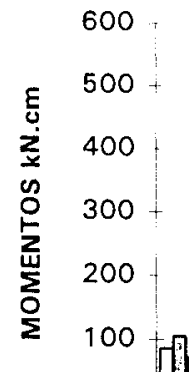

0 国

$\begin{array}{llllll}1 & 2 & 3 & 4 & 5 & 6\end{array}$

PERFIS

DFLM ๑FLA $\approx F L T$
SAC 50 
TABELA 2

Valores admissiveis dos momentos para FLM, FLA e FLT em KN.cm

\begin{tabular}{|c|c|c|c|c|c|c|c|c|c|c|c|c|}
\hline & \multicolumn{12}{|c|}{ TIPUS DE Aप़U } \\
\hline & \multirow{2}{*}{\multicolumn{3}{|c|}{$\begin{array}{l}\mathrm{A} 570 / \mathrm{A} \\
\mathrm{Fy}=172 \mathrm{MPa} F u=310 \mathrm{MPa}\end{array}$}} & \multicolumn{3}{|l|}{ A570/E } & \multicolumn{3}{|l|}{ SAC 41 } & \multicolumn{3}{|l|}{ SAC 50} \\
\hline \multirow{2}{*}{$\begin{array}{l}\mathrm{Lb}=167 \\
\mathrm{esp}=2,66\end{array}$} & & & & $F_{Y}=290 \mathrm{MPa}$ & $=400 \mathrm{MPa}$ & & $F y=245 \mathrm{MPa}$ & $=400 \mathrm{MP}$ & & $F y=373 \mathrm{MPa}$ & $=500 \mathrm{MPg}$ & \\
\hline & FLM & FLA & FLT & FLM & FLA & FLT & FLM & FLA & FLT & FLM & FLA & FLT \\
\hline$U(75 \times 40)$ & 92 & 103 & 76 & 141 & 164 & 99 & 123 & 141 & 93 & 172 & 204 & 101 \\
\hline$U(100 \times 40)$ & 136 & 148 & 113 & 209 & 238 & 145 & 183 & 204 & 137 & 254 & 297 & 147 \\
\hline$U(127 \times 40)$ & 190 & 203 & 156 & 293 & 328 & 198 & 255 & 281 & 188 & 356 & 412 & 200 \\
\hline$U(150 \times 40)$ & 242 & 256 & 196 & 372 & 414 & 245 & 324 & 355 & 235 & 452 & 521 & 247 \\
\hline$U(200 \times 40)$ & 370 & 386 & 291 & 569 & 630 & 351 & 497 & 538 & 342 & 692 & 794 & 351 \\
\hline $\mid U(250 \times 40)$ & 521 & 540 & 397 & 801 & 884 & 457 & 699 & 754 & 453 & 974 & 1117 & 457 \\
\hline
\end{tabular}

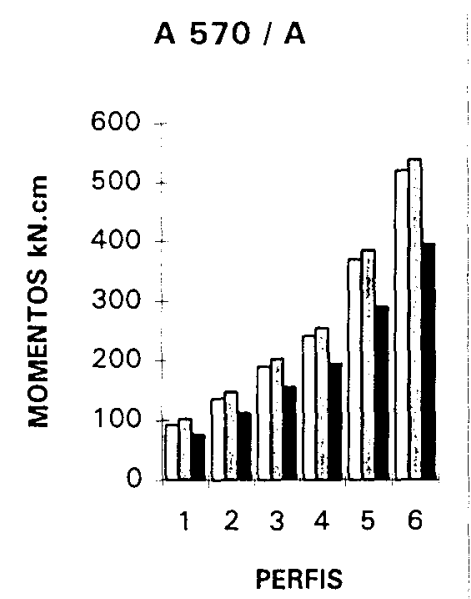

A $570 / E$

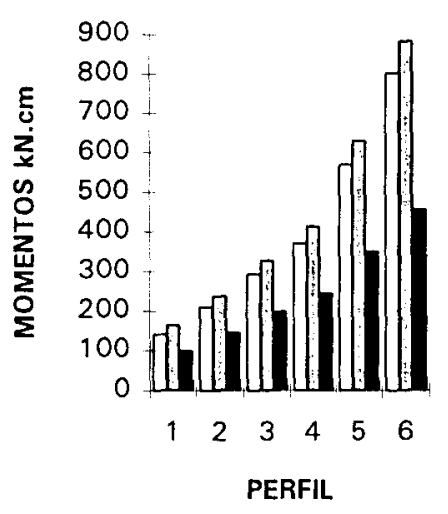

DFLM EFLA $\square F L T$

$\square F L M$ OFLA FLT
SAC 41

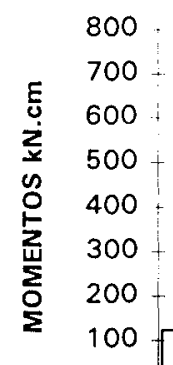

100 .

$\begin{array}{llllll}1 & 2 & 3 & 4 & 5 & 6\end{array}$

PERFIS

$\square F L M \quad G L A \backsim F L T$ 
TABELA 3

VALORES ADMISSÍVEIS DOS MOMENTOS PARA FLM, FLA e FLT em kN.cm

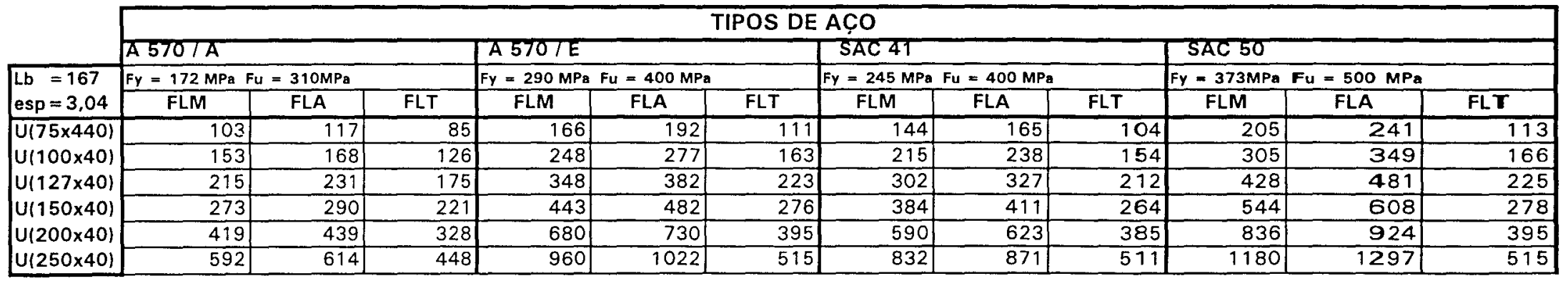

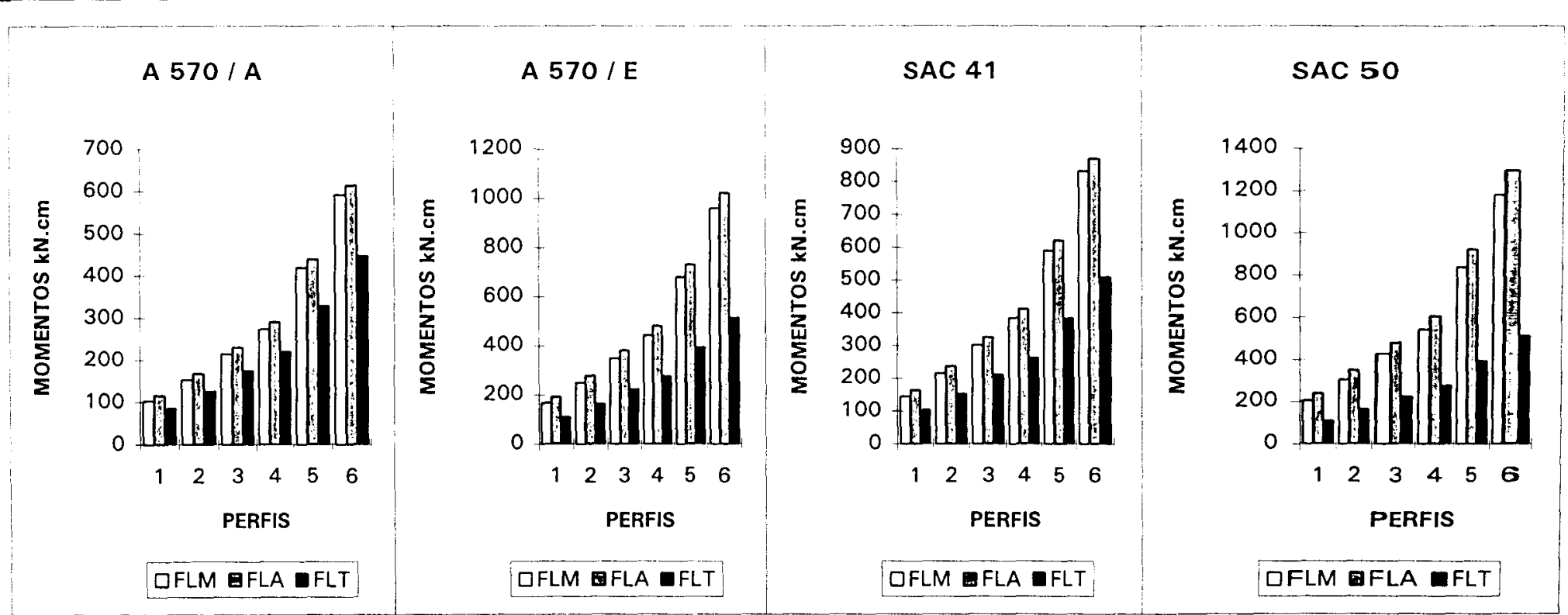


TABELA 4

VALORES ADMISSÍVEIS DOS MOMENTOS PARA FLM, FLA \& FLT em kN.cm

\begin{tabular}{|c|c|c|c|c|c|c|c|c|c|c|c|c|}
\hline & \multicolumn{12}{|c|}{ TIPOS DE AÇO } \\
\hline & A570TA & & & A5701E & & & SAC 4T & & & SAC 50 & & \\
\hline \multirow{2}{*}{$\begin{array}{l}\text { Lb }=167 \\
\text { esp }=3.8\end{array}$} & \multicolumn{3}{|c|}{$F y=172 \mathrm{MPa} F \mathrm{Fu}=310 \mathrm{MPa}$} & \multicolumn{3}{|c|}{$F_{y}=290 \mathrm{MPa} \quad F_{u}=400 \mathrm{MPa}$} & \multicolumn{3}{|c|}{$F y=245 \mathrm{MPa} F u=400 \mathrm{MPa}$} & \multicolumn{3}{|c|}{$F y=373 \mathrm{MPa} F u=500 \mathrm{MPa}$} \\
\hline & FLM & FLA & $\mathrm{FLT}$ & FLM & FLA & FLT & FLM & FLA & $\mathrm{FLT}$ & FLM & FLA & $\mathrm{FLT}$ \\
\hline U(75x40) & 122 & 142 & 102 & 205 & 240 & 133 & 173 & 203 & 125 & 264 & 309 & 136 \\
\hline$U(100 \times 40)$ & 183 & 206 & 152 & 308 & 347 & 196 & 260 & 293 & 185 & 397 & 446 & 20 \\
\hline$U(127 \times 40)$ & 259 & 283 & 212 & 436 & 478 & 269 & 368 & 404 & 256 & 561 & 615 & 273 \\
\hline$U(150 \times 40)$ & 330 & 357 & 267 & 557 & 602 & 334 & 471 & 509 & 320 & 717 & 774 & 337 \\
\hline$U(200 \times 40)$ & 511 & 541 & 399 & 861 & 913 & 479 & 728 & 771 & 467 & 1108 & 1174 & 479 \\
\hline$U(250 \times 40)$ & 724 & 758 & 545 & 1221 & 1278 & 625 & 1031 & 1080 & 620 & 1570 & 1644 & 625 \\
\hline
\end{tabular}

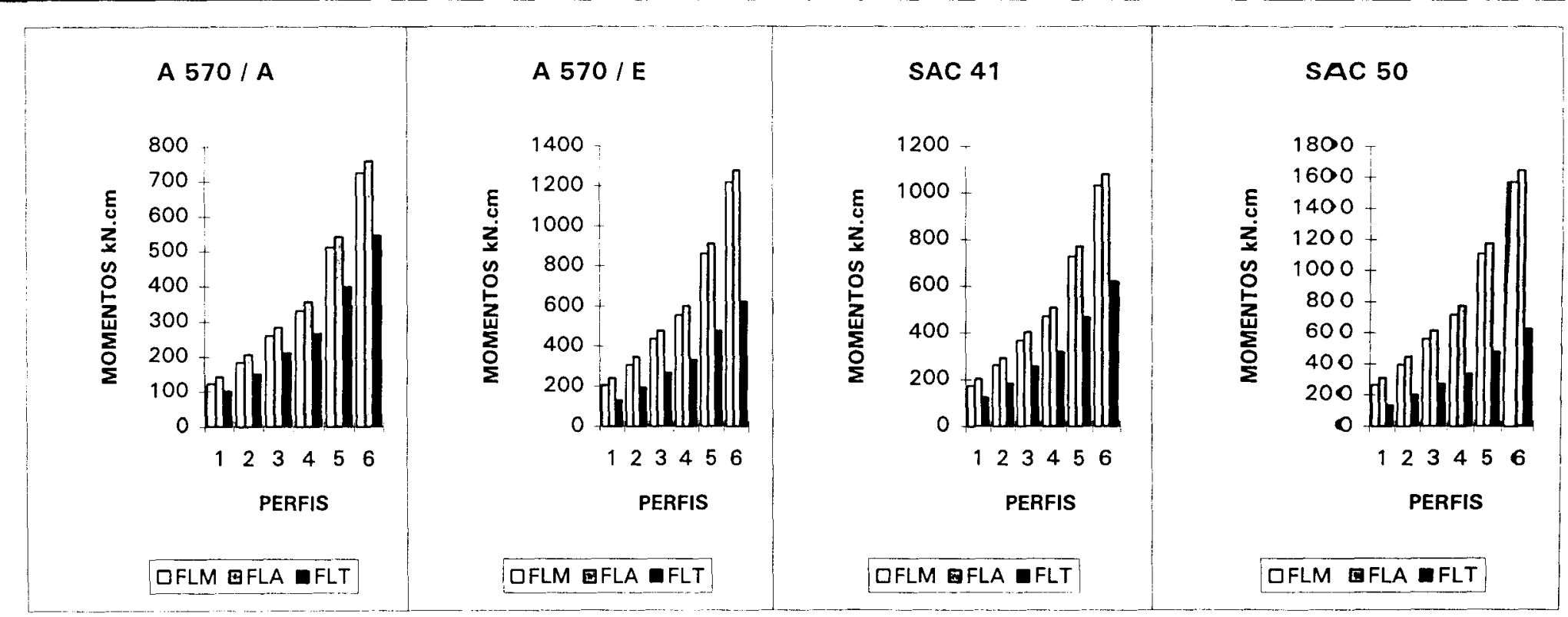


TABELA 5

VALORES ADMISSIVEIS DOS MOMENTOS PARA FLM, FLA E FLT Em KN.cm

\begin{tabular}{|c|c|c|c|c|c|c|c|c|c|c|c|c|}
\hline \multicolumn{13}{|c|}{ TIPOS DE AC̣O } \\
\hline & \multicolumn{3}{|l|}{ A 5701A } & \multicolumn{3}{|l|}{ A5707E } & \multicolumn{3}{|l|}{ SAC 4T } & \multicolumn{3}{|l|}{ SAC 50} \\
\hline \multirow{2}{*}{$\begin{array}{l}L b=167 \\
\text { esp }=4,25\end{array}$} & $F y=172 \mathrm{MPaF}$ & $=310 \mathrm{MPa}$ & & $F y=290 \mathrm{MPa}$ & $=400 \mathrm{MP}$ & & $\mathrm{Fy}=245 \mathrm{MPa}$ & $=400 \mathrm{MP}$ & & $F Y=373 \mathrm{MPa}$ & $=500 \mathrm{MPa}$ & \\
\hline & FLM & FLA & $\mathrm{FLT}$ & FLM & FLA & FLT & FLM & FLA & FLT & FLM & FLA & $\mathrm{FLT}$ \\
\hline$\overline{U(75 \times 40)}$ & 131 & 157 & 110 & 222 & 265 & 145 & 187 & 224 & 136 & 285 & 341 & 149 \\
\hline$U(100 \times 40)$ & 199 & 227 & 165 & 336 & 383 & 215 & 284 & 324 & 202 & 432 & 493 & 220 \\
\hline$U(127 \times 40)$ & 283 & 313 & 232 & 477 & 528 & 295 & 403 & 446 & 280 & 613 & 680 & 299 \\
\hline$U(150 \times 40)$ & 362 & 395 & 293 & 611 & 666 & 367 & 516 & 563 & 351 & 786 & 857 & 370 \\
\hline$U(200 \times 40)$ & 562 & 600 & 439 & 948 & 1012 & 526 & 801 & 855 & 513 & 1219 & 1301 & 526 \\
\hline$U(250 \times 40)$ & 799 & 842 & 601 & 1347 & 1419 & 686 & 1138 & 1199 & 682 & 1733 & 1825 & 686 \\
\hline
\end{tabular}

A $570 / A$

A $570 / E$

SAC 41

SAC 50

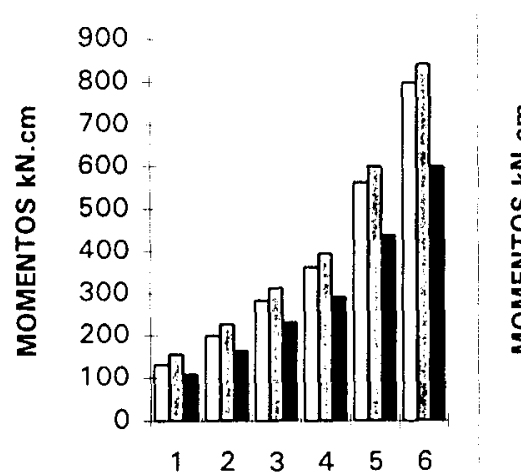

PERFIS

口FLM \&FLA $\square F L T$
1600

1400

i 1000

800

400

200 THWH

$\begin{array}{llllll}1 & 2 & 3 & 4 & 5 & 6\end{array}$

PERFIS

CFLM ÐFLA $\square F L T$

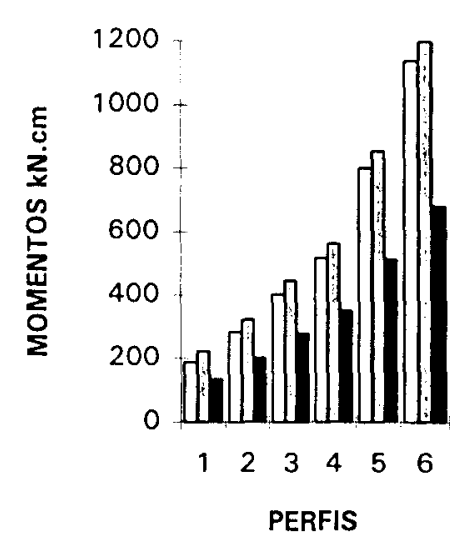

DFLM QFLA $\square$ FLT 
TABELA 6

VALORES ADMISSÍVEIS DOS MOMENTOS PARA FLM, FLA e FLT em kN.cm

\begin{tabular}{|c|c|c|c|c|c|c|c|c|c|c|c|c|}
\hline \multicolumn{13}{|c|}{ TIPOS DE AC̣O } \\
\hline & A5707A & & & A570TE & & & SAC 41 & & & SAC 50 & & \\
\hline \multirow{2}{*}{$\begin{array}{l}\mathrm{Lb}=167 \\
\mathrm{esp}=4.8\end{array}$} & \multicolumn{3}{|c|}{$F_{y}=172 \mathrm{MPa} F u=310 \mathrm{MPa}$} & \multicolumn{3}{|c|}{$F y=290 \mathrm{MPa} F u=400 \mathrm{MPa}$} & \multicolumn{3}{|c|}{$F Y=245 \mathrm{MPa} \quad F u=400 \mathrm{MPa}$} & \multicolumn{3}{|c|}{$F y=373 \mathrm{MPa} F u=500 \mathrm{MPa}$} \\
\hline & FLM & FLA & FLT & FLM & FLA & FLT & FLM & FLA & FLT & FLM & FLA & FLT \\
\hline$U(75 \times 40)$ & 142 & 174 & 120 & 240 & 294 & 158 & 202 & 248 & 148 & 308 & 378 & 164 \\
\hline$U(100 \times 40)$ & 217 & 252 & 181 & 366 & 425 & 236 & 309 & 359 & 222 & 471 & 547 & 242 \\
\hline$U(127 \times 40)$ & 310 & 349 & 255 & 523 & 588 & 326 & 442 & 497 & 309 & 673 & 756 & 330 \\
\hline$U(150 \times 40)$ & 399 & 440 & 323 & 673 & 743 & 405 & 568 & 627 & 387 & 865 & 955 & 408 \\
\hline$U(200 \times 40)$ & 623 & 670 & 486 & 1050 & 1130 & 581 & 887 & 955 & 568 & 1350 & 1453 & 581 \\
\hline$U(250 \times 40)$ & 888 & 941 & 665 & 1497 & 1587 & 758 & 1264 & 1341 & 754 & 1925 & 2041 & 758 \\
\hline
\end{tabular}

A $570 / \mathrm{A}$

A $570 / E$

SAC 41

SAC 50

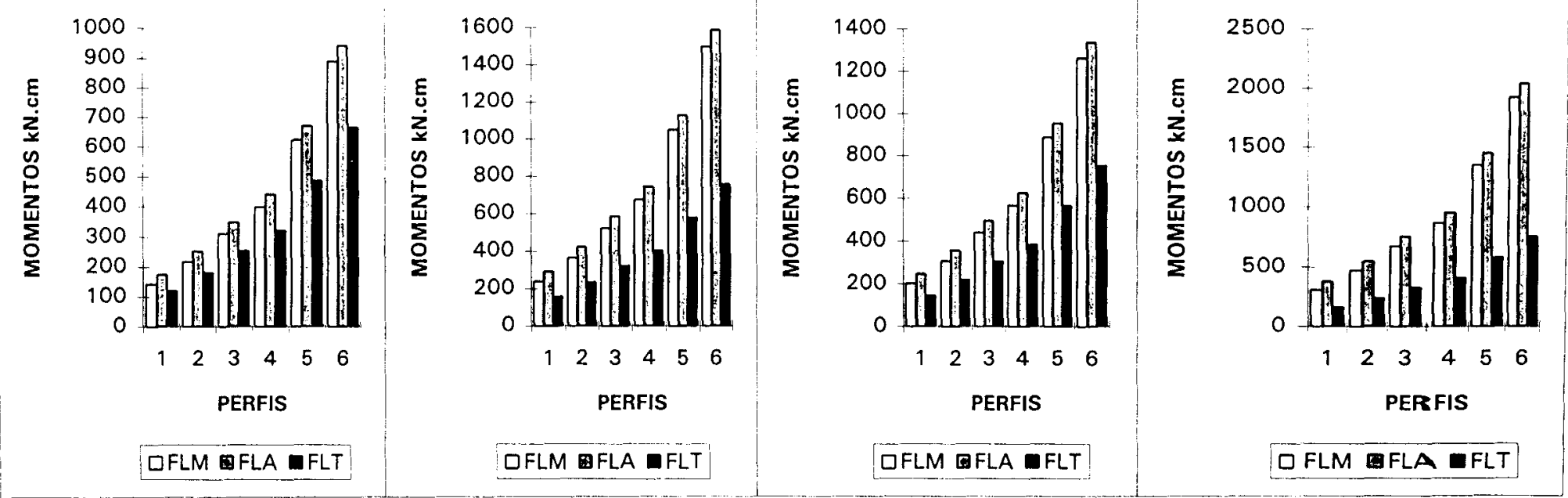


TABELA 7

VALORES ADMISSIVEIS DOS MOMENTOS PARA FLM, FLA E FLT em kN.cm

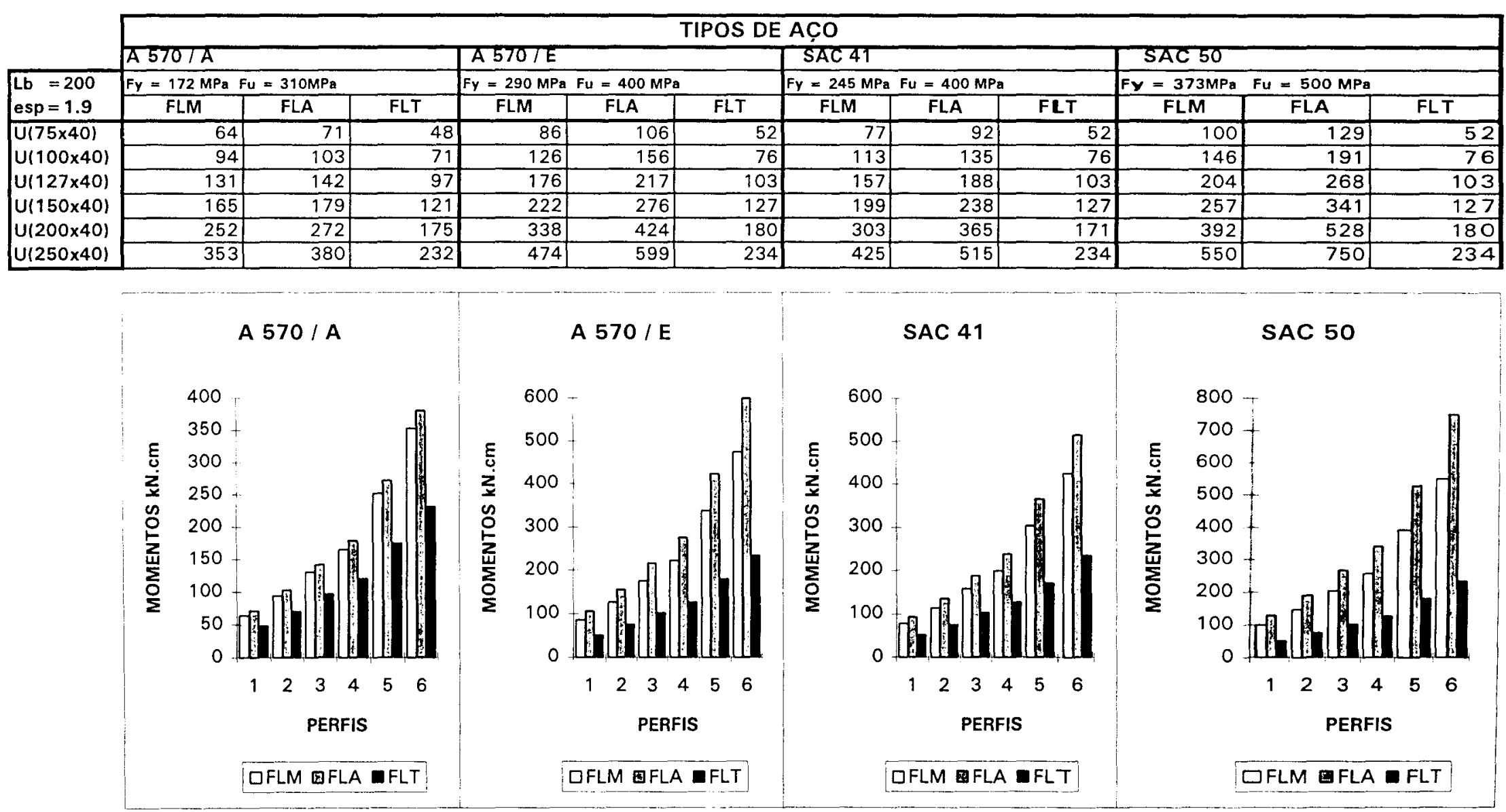


TABELA 8

VALORES ADMISSIVEEIS DOS MOMENTOS PARA FLM, FLA e FLT em kN.cm

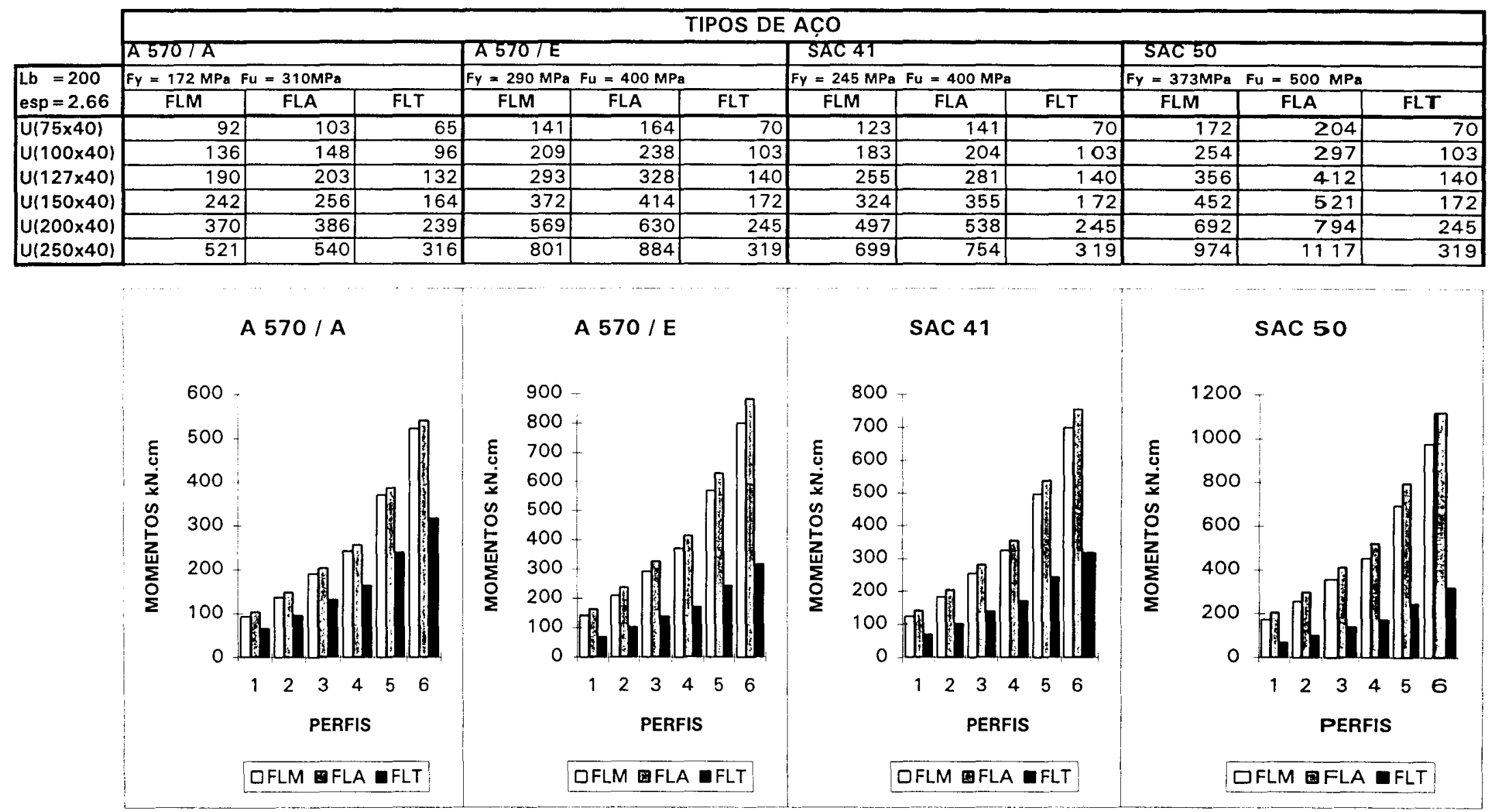


TABELA 9

VALORES ADMISSIVEIS DOS MOMENTOS PARA FLM, FLA e FLT em kN.cm

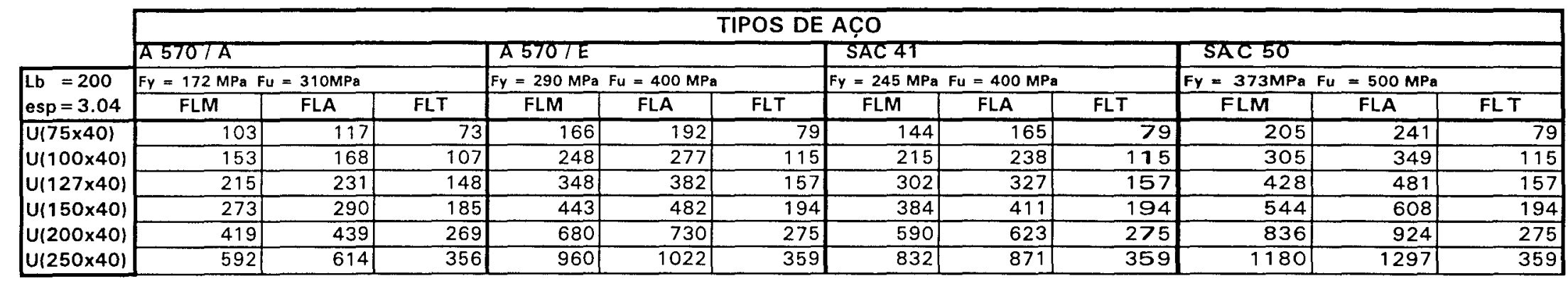

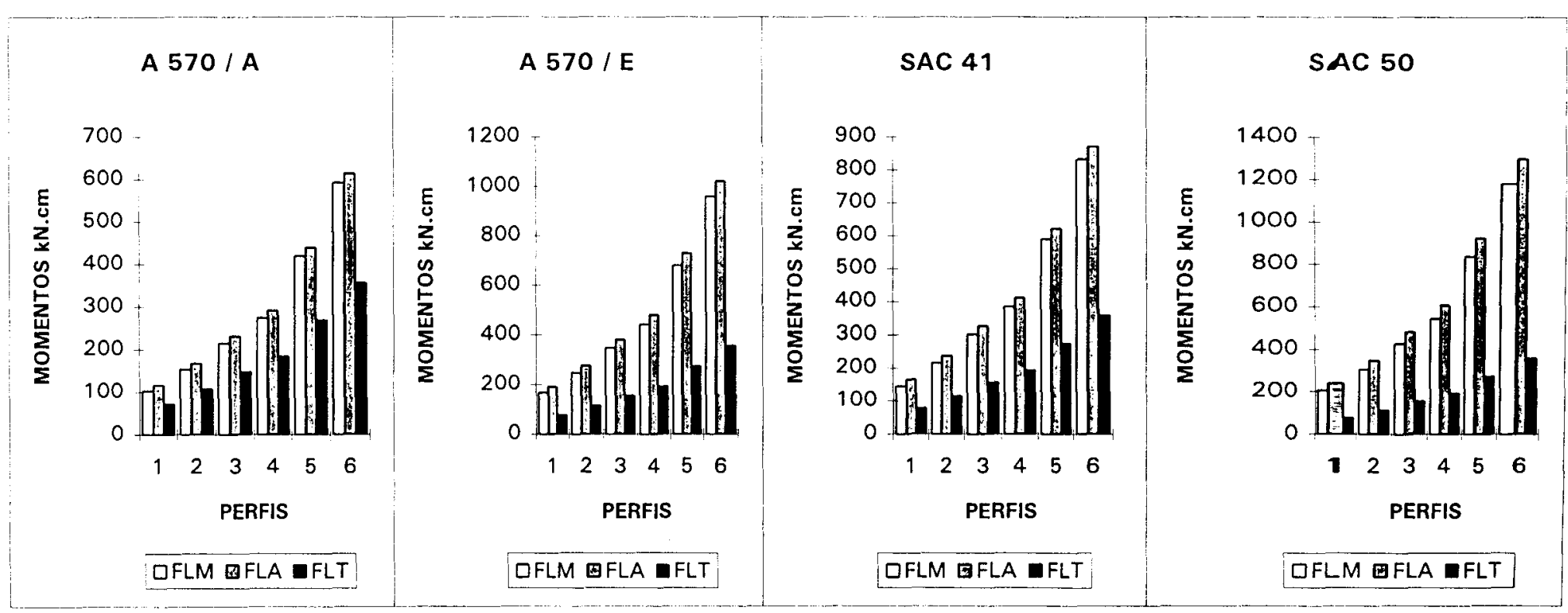


TABELA 10

VALORES ADMISSIVEIS DOS MOMENTOS PARA FLM, FLA e FLT em KN.cm

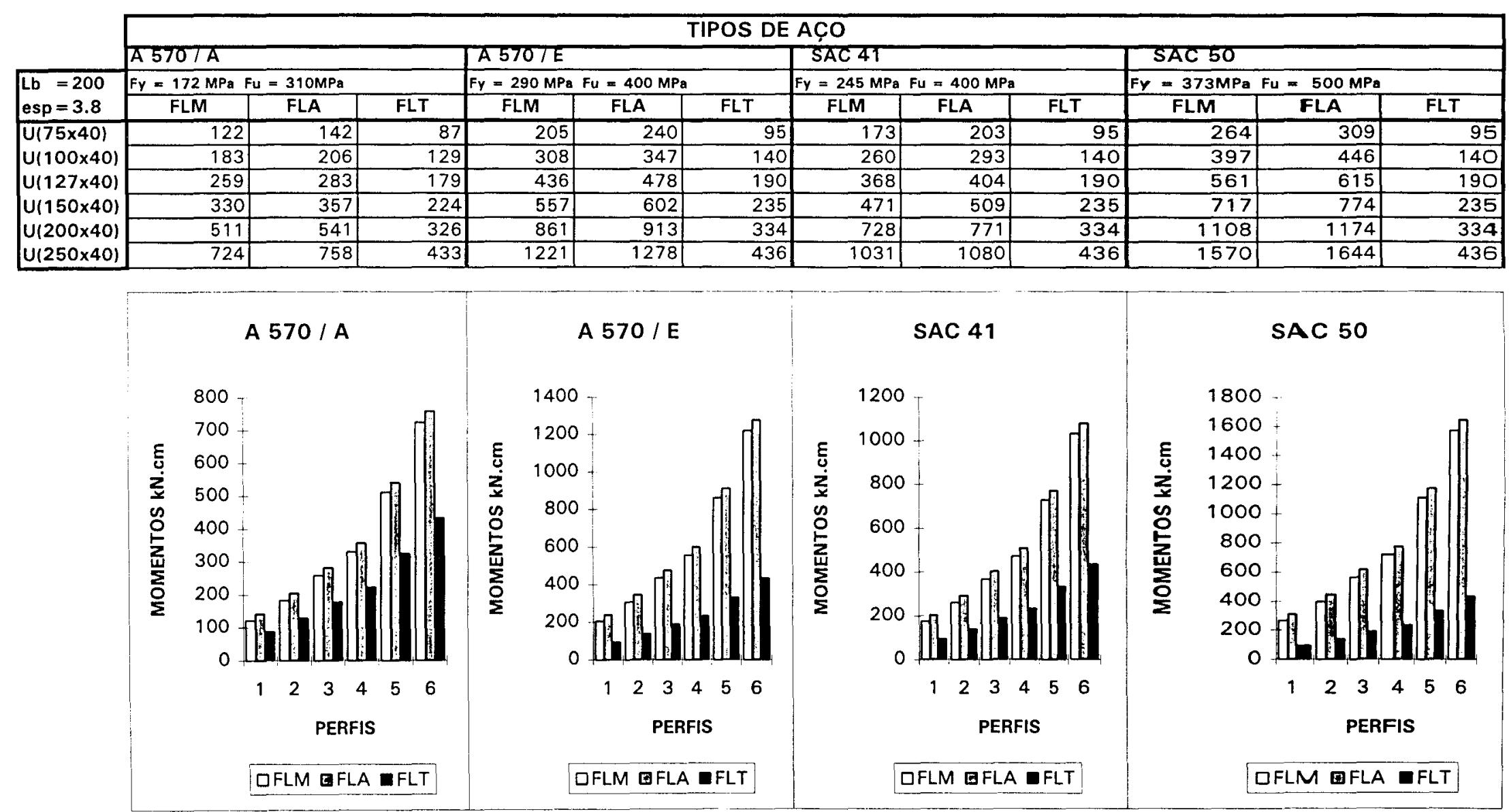


TABELA 11

VALORES ADMISSIVEIS DOS MOMENTOS PARA FLM, FLA e FLT em kN.cm

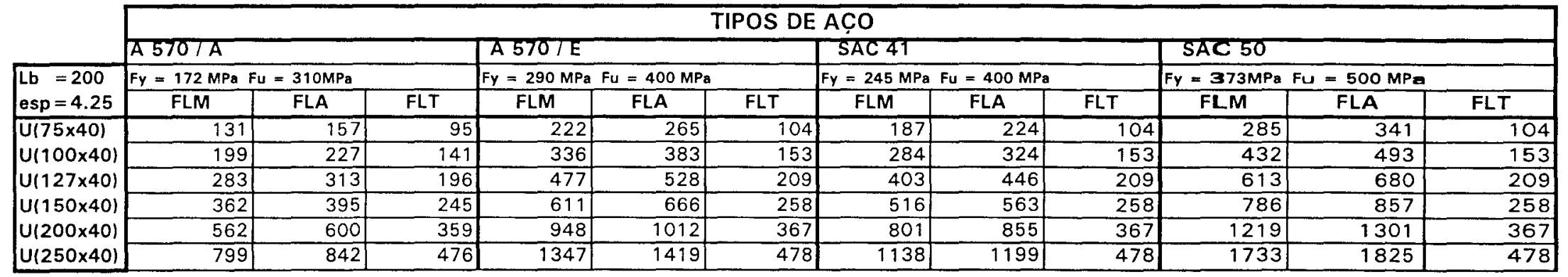

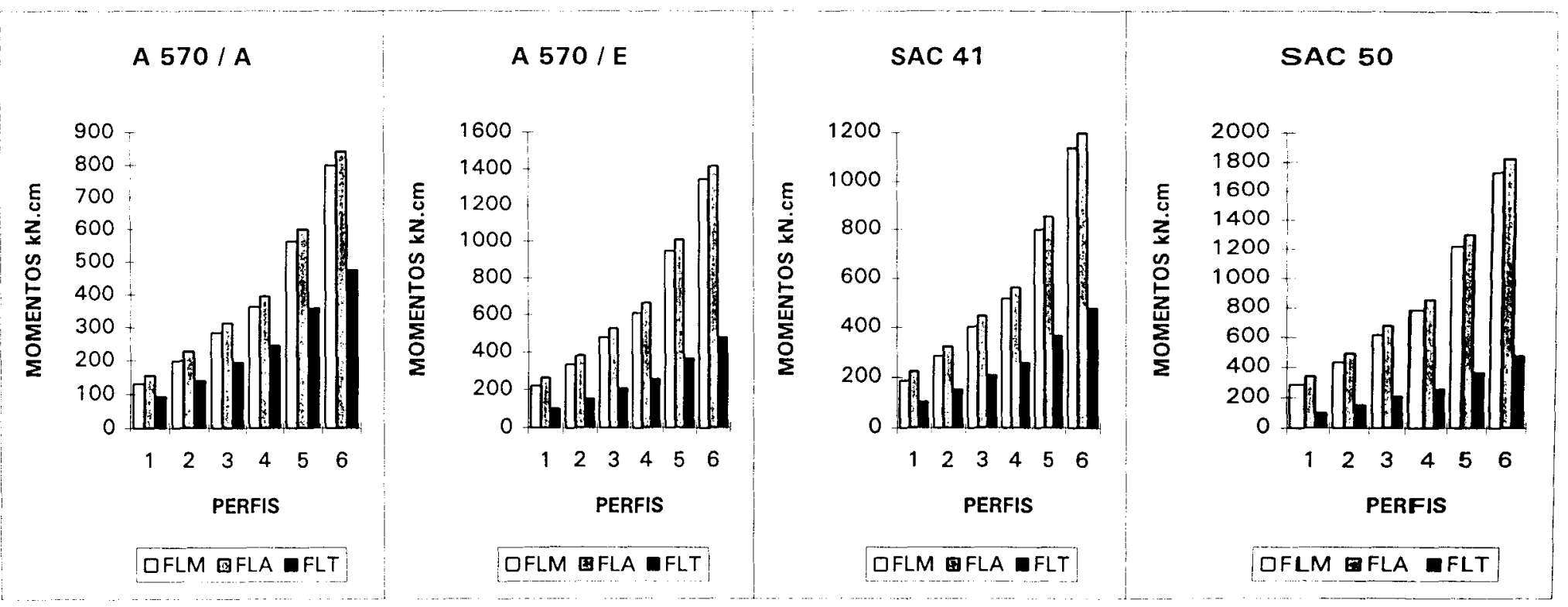


TABELA 12

VALORES ADMISSIVEIS DOS MOMENTOS PARA FLM, FLA \& FLT em $\mathrm{kN} . \mathrm{cm}$

\begin{tabular}{|c|c|c|c|c|c|c|c|c|c|c|c|c|}
\hline & \multicolumn{12}{|c|}{ TIPOS DE AÇO } \\
\hline & \multicolumn{3}{|l|}{ A5707A } & \multicolumn{3}{|l|}{ A5707E } & \multicolumn{3}{|l|}{ SAC 4T } & \multicolumn{3}{|l|}{ SAC 50} \\
\hline \multirow{2}{*}{$\begin{array}{l}\mathrm{Lb}=200 \\
\mathrm{esp}=4.8\end{array}$} & \multicolumn{3}{|c|}{$F_{y}=172 \mathrm{MPa} \quad \mathrm{Fu}=310 \mathrm{MPa}$} & \multicolumn{3}{|c|}{$\mathrm{Fy}=290 \mathrm{MPa} F u=400 \mathrm{MPa}$} & \multicolumn{3}{|c|}{$F y=245 \mathrm{MPa} F u=400 \mathrm{MPa}$} & \multicolumn{3}{|c|}{$F y=373 \mathrm{MPa} F u=500 \mathrm{MPa}$} \\
\hline & FLM & FLA & FLT & FLM & FLA & FLT & FLM & FLA & FLT & FLM & FLA & FLT \\
\hline$U(75 \times 40)$ & 142 & 174 & 103 & 240 & 294 & 114 & 202 & 248 & 114 & 308 & 378 & 114 \\
\hline$U(100 \times 40)$ & 217 & 252 & 155 & 366 & $\overline{425}$ & 169 & 309 & 359 & 169 & 471 & 547 & 169 \\
\hline$U(127 \times 40)$ & 310 & 349 & 216 & 523 & 588 & 230 & 442 & 497 & 230 & 673 & 756 & 230 \\
\hline$U(150 \times 40)$ & 399 & 440 & 271 & 673 & 743 & 284 & 568 & 627 & 284 & 865 & 955 & 284 \\
\hline $\mid U(200 \times 40)$ & 623 & 670 & 397 & 1050 & 1130 & 405 & 887 & 955 & 405 & 1350 & 1453 & 405 \\
\hline$U(250 \times 40)$ & 888 & 941 & 526 & 1497 & 1587 & 528 & 1264 & 1341 & 528 & 1925 & 2041 & 528 \\
\hline
\end{tabular}

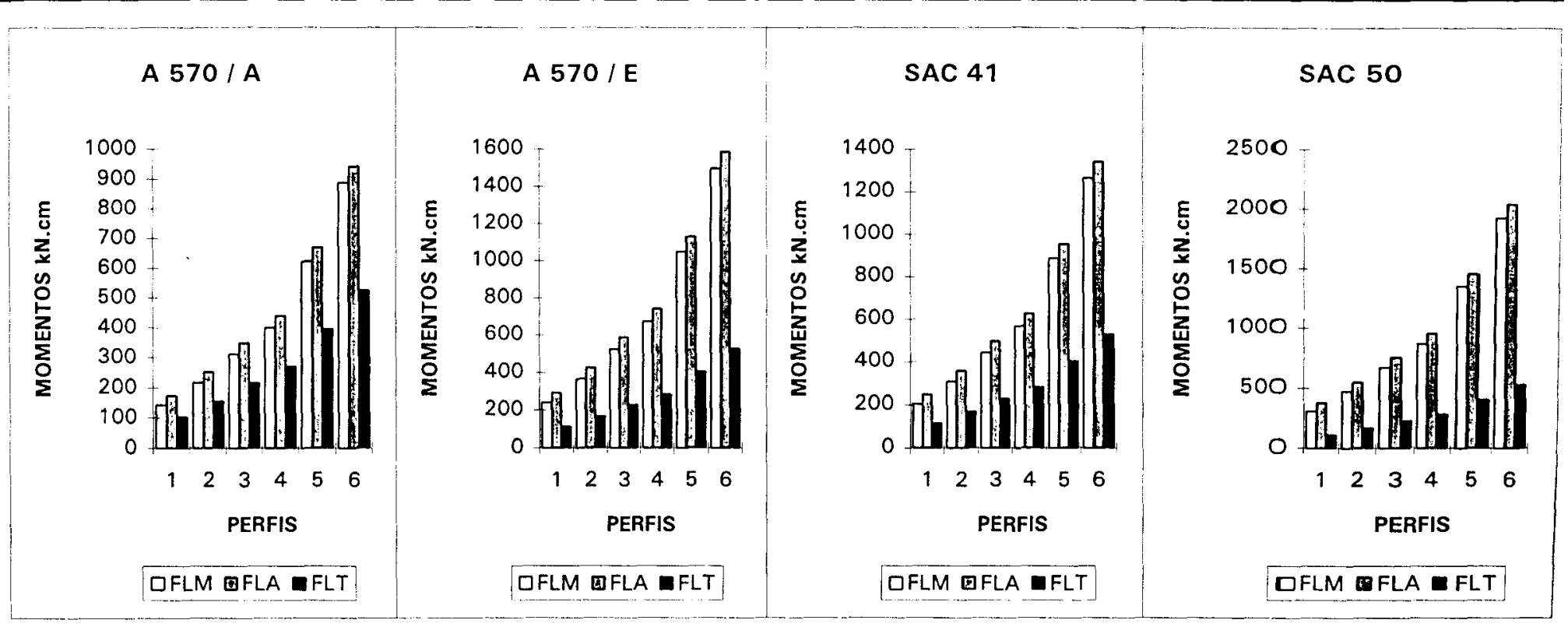


TABELA 13

VALORES ADMISSIVEIS DOS MOMENTOS PARA FLM, FLA e FLT em kN.cm

\begin{tabular}{|c|c|c|c|c|c|c|c|c|c|c|c|c|}
\hline \multicolumn{13}{|c|}{ TIPOS DE AC̣O } \\
\hline & \multicolumn{3}{|l|}{ A 5707A } & \multicolumn{3}{|l|}{ A5707E } & \multicolumn{3}{|l|}{ SAC 4T } & \multicolumn{3}{|l|}{ SAC 50} \\
\hline \multirow{2}{*}{$\begin{array}{l}\mathrm{Lb}=250 \\
\mathrm{esp}=1.9\end{array}$} & $F y=172 \mathrm{MPa} F$ & $310 \mathrm{MPa}$ & & $F y=290 \mathrm{MPa}$ & $=400 \mathrm{MP}$ & & $F_{y}=245 \mathrm{MPa}$ & $1=400 \mathrm{MPa}$ & & $F y=373 \mathrm{MPa}$ & $F u=500 \mathrm{MPa}$ & \\
\hline & FLM & FLA & FLT & FLM & FLA & FLT & FLM & FLA & FLT & FLM & $F$ & $\mathrm{FLT}$ \\
\hline$U(75 \times 40)$ & 64 & 71 & 33 & 86 & 106 & 33 & 77 & 92 & 33 & 100 & 129 & 33 \\
\hline$(U(100 \times 40)$ & 94 & 103 & 49 & 126 & 156 & 49 & 113 & 135 & 49 & 146 & 191 & 49 \\
\hline$U(127 \times 40)$ & 131 & 142 & 66 & 176 & 217 & 66 & 157 & 188 & 66 & 204 & 268 & 66 \\
\hline$U(150 \times 40)$ & 165 & 179 & 81 & 222 & 276 & 81 & 199 & 238 & 81 & 257 & 341 & 81 \\
\hline$U(200 \times 40)$ & 252 & 272 & 115 & 338 & 424 & 115 & 303 & 365 & 109 & 392 & 528 & 115 \\
\hline$U(250 \times 40)$ & 353 & 380 & 150 & 474 & 599 & 150 & 425 & 515 & 150 & 550 & 750 & 150 \\
\hline
\end{tabular}

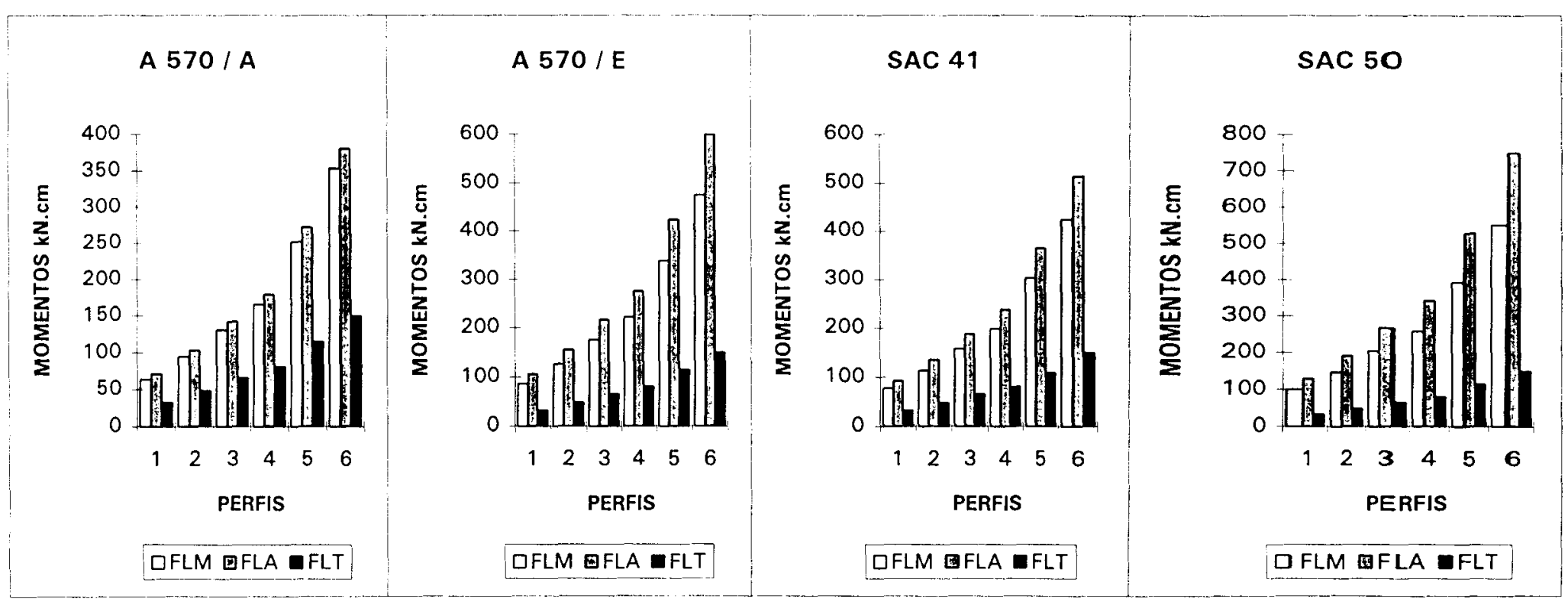


TABELA 14

VALORES ADMISSIVEIS DOS MOMENTOS PARA FLM, FLA E FLT em kN.cm

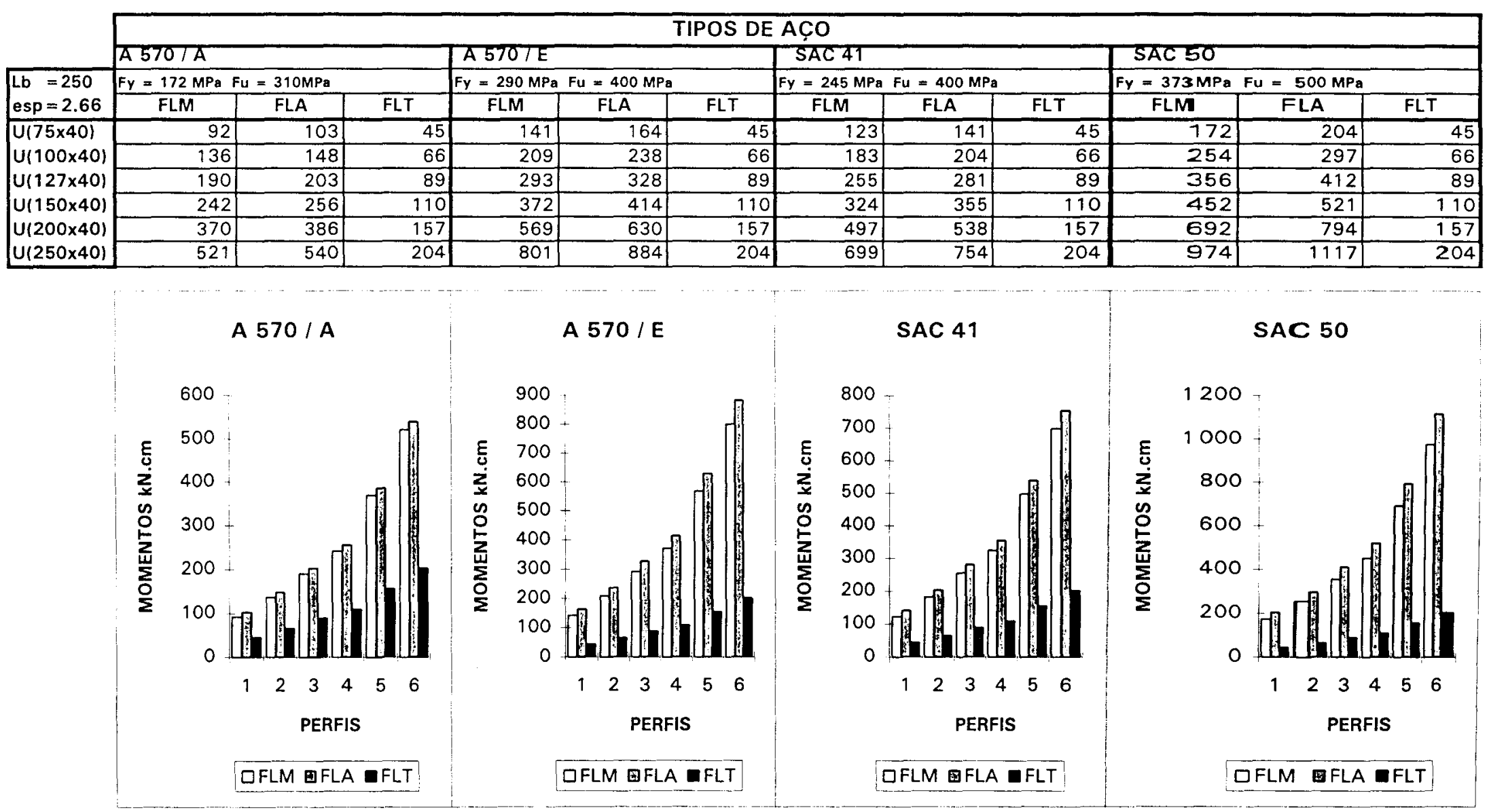


TABELA 15

VALORES ADMISSÍVEIS DOS MOMENTOS PARA FLM, FLA E FLT em kN.cm

\begin{tabular}{|c|c|c|c|c|c|c|c|c|c|c|c|c|}
\hline & \multicolumn{12}{|c|}{ TIPOS DE ACO } \\
\hline & \multirow{2}{*}{\multicolumn{3}{|c|}{ A5707A }} & \multicolumn{3}{|l|}{ A5707E } & \multicolumn{3}{|l|}{ SAC 4T } & \multicolumn{3}{|l|}{ SAC 50} \\
\hline \multirow{2}{*}{$\begin{array}{l}\mathrm{Lb}=250 \\
\text { esp }=3.04\end{array}$} & & & & $\mathrm{Fy}=290 \mathrm{MPa}$ & $=400 \mathrm{MP}$ & & $F y=245 \mathrm{MPa}$ & $=400 \mathrm{MP}$ & & $F y=373 \mathrm{MPa}$ & $\mathrm{Fu}=500 \mathrm{MPa}$ & \\
\hline & FLM & FLA & $\overline{F L T}$ & FLM & FLA & FLT & FLM & FLA & FLT & FLM & FLA & FLT \\
\hline$U(75 \times 40)$ & 103 & 117 & 50 & 166 & 192 & 50 & 144 & 165 & 50 & 205 & 241 & 50 \\
\hline$U(100 \times 40)$ & 153 & 168 & 74 & 248 & 277 & 74 & 215 & 238 & 74 & 305 & 349 & 74 \\
\hline$U(127 \times 40)$ & 215 & 231 & 101 & 348 & 382 & 101 & 302 & 327 & 101 & 428 & 481 & 101 \\
\hline$U(150 \times 40)$ & 273 & 290 & 124 & 443 & 482 & 124 & 384 & 411 & 124 & 544 & 608 & 124 \\
\hline$U(200 \times 40)$ & 419 & 439 & 176 & 680 & 730 & 176 & 590 & 623 & 176 & 836 & 924 & 176 \\
\hline$U(250 \times 40)$ & 592 & 614 & 230 & 960 & 1022 & 230 & 832 & 871 & 230 & 1180 & 1297 & 230 \\
\hline
\end{tabular}

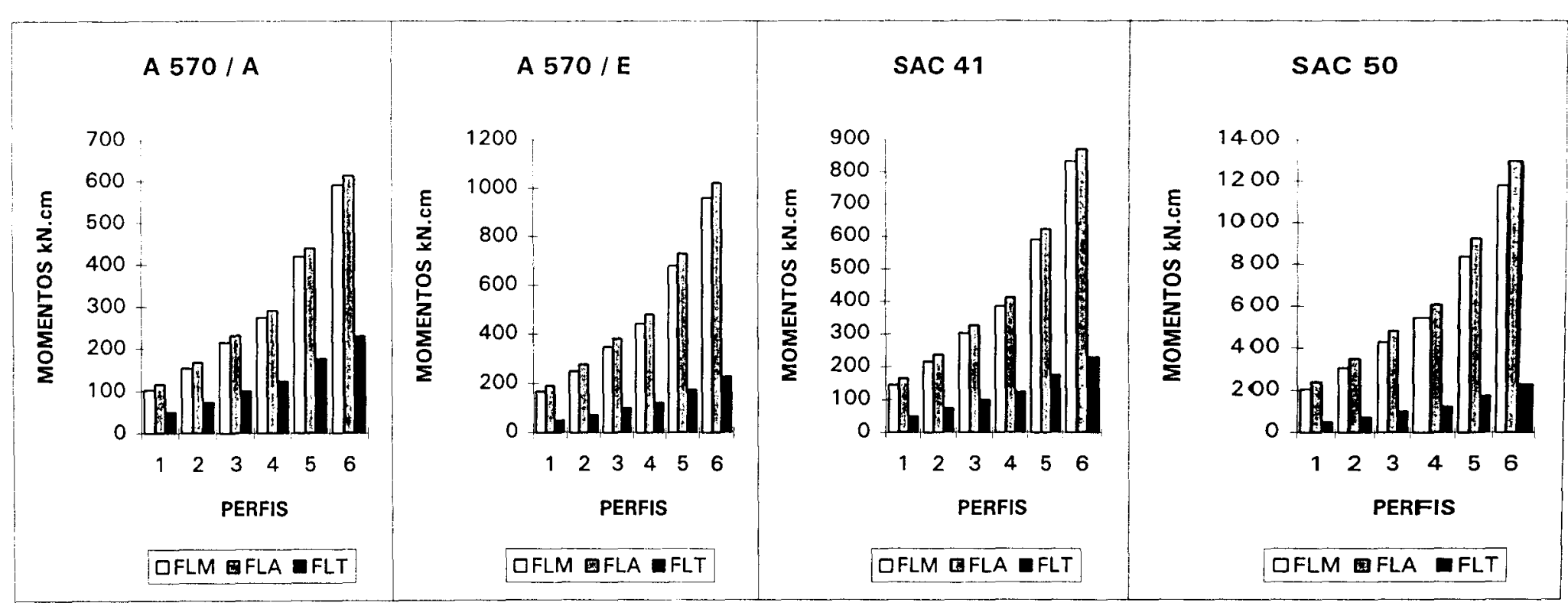


TABELA 16

VALORES ADMISSÍVEIS DOS MOMENTOS PARA FLM, FLA e FLT em kN.cm

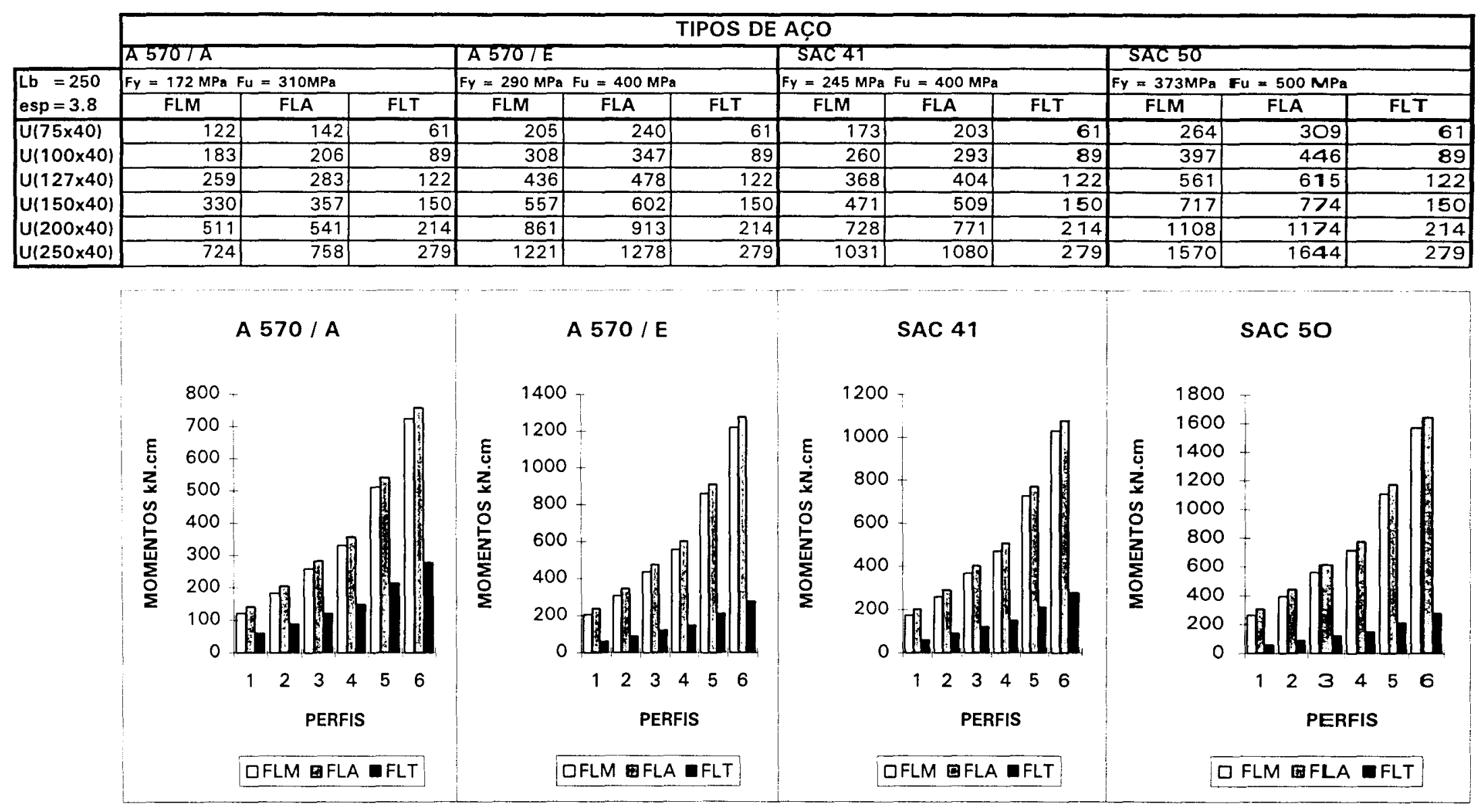


TABELA 17

VALORES ADMISSIVEIS DOS MOMENTOS PARA FLM, FLA \& FLT em kN.cm

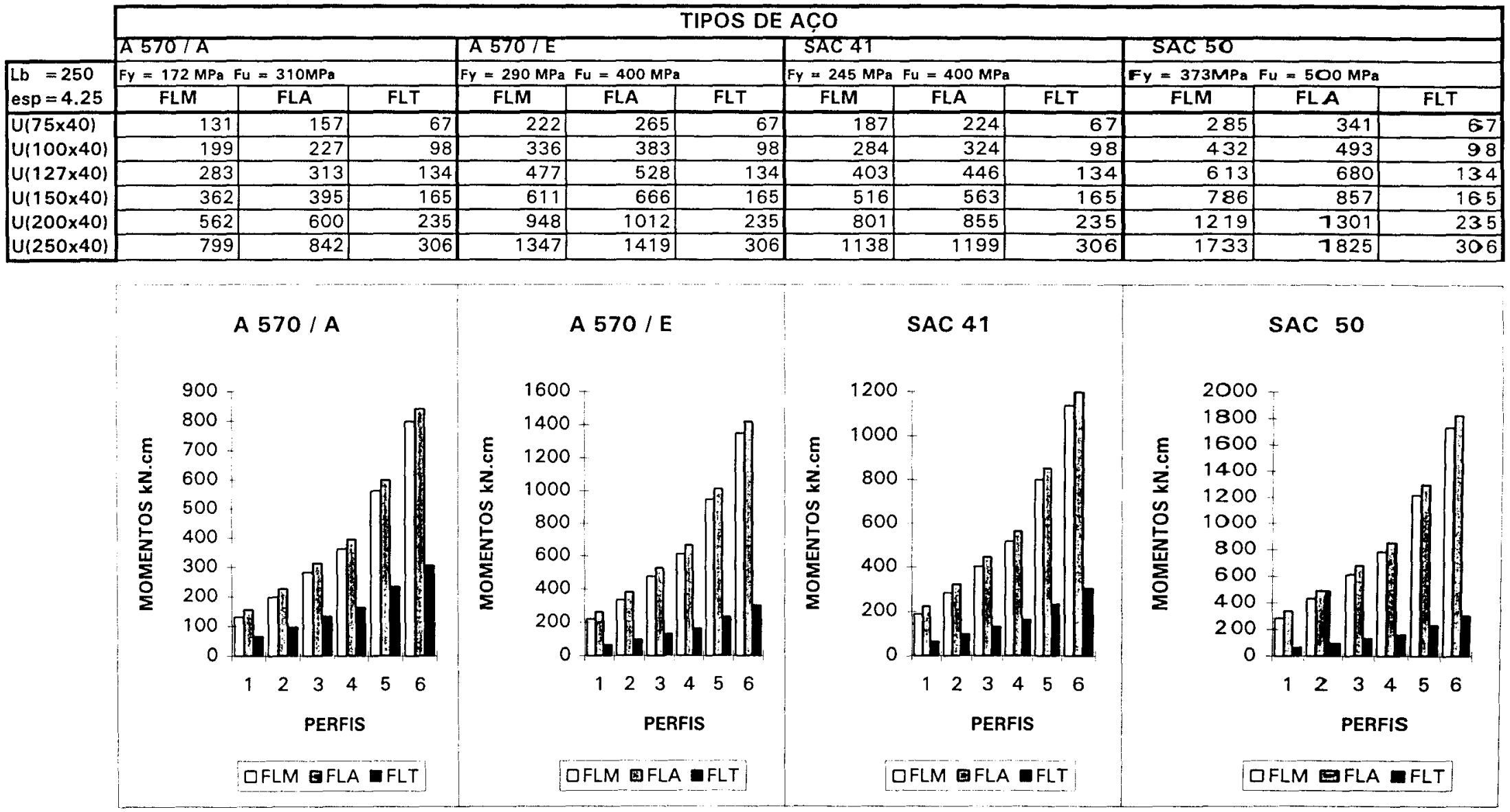


TABELA 18

VALORES ADMISSÍVEIS DOS MOMENTOS PARA FLM, FLA e FLT em kN.cm

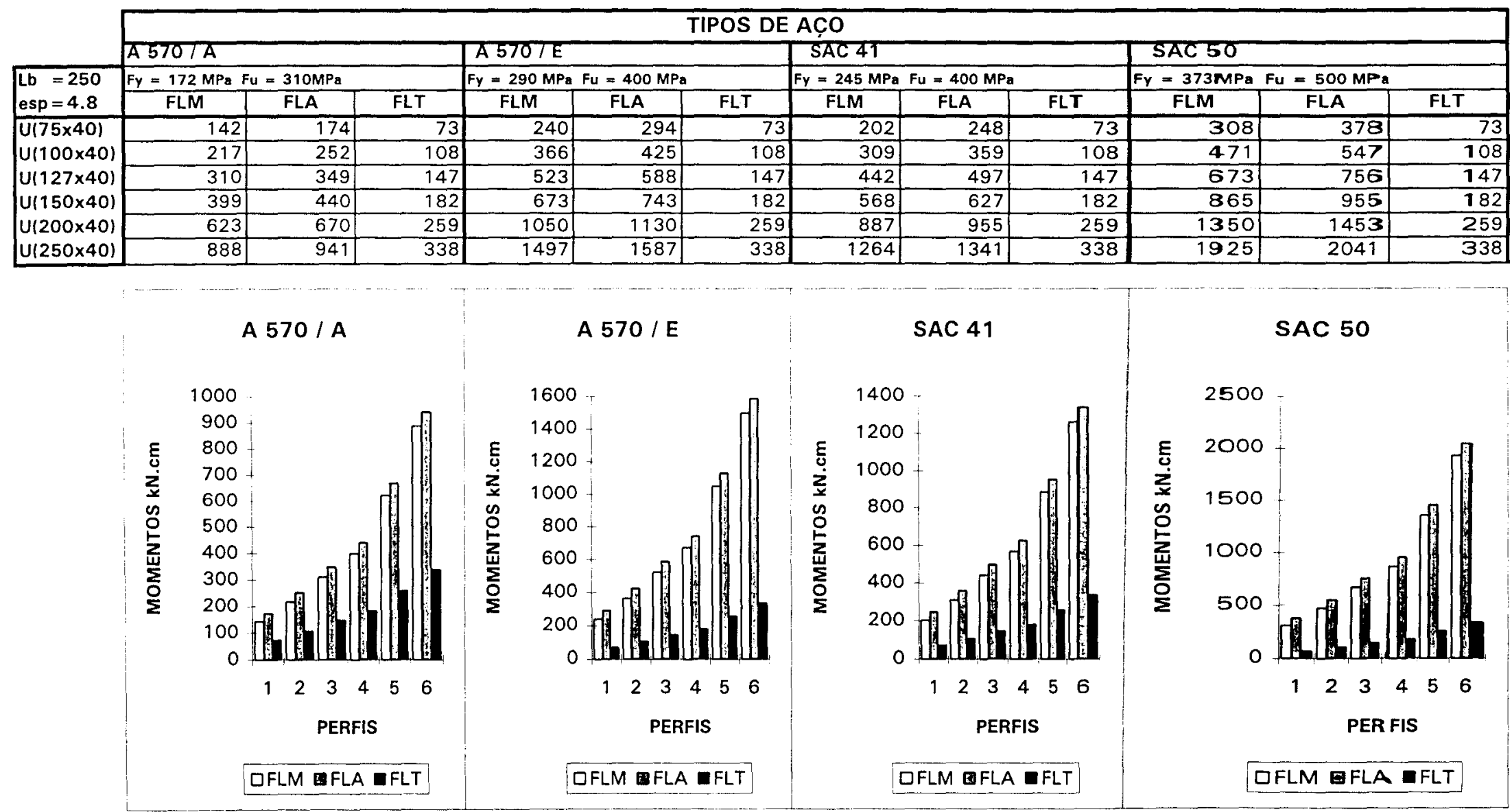


TABELA 19

VALORES ADMISSÍVEIS DOS MOMENTOS PARA FLM, FLA e FLT em kN.cm

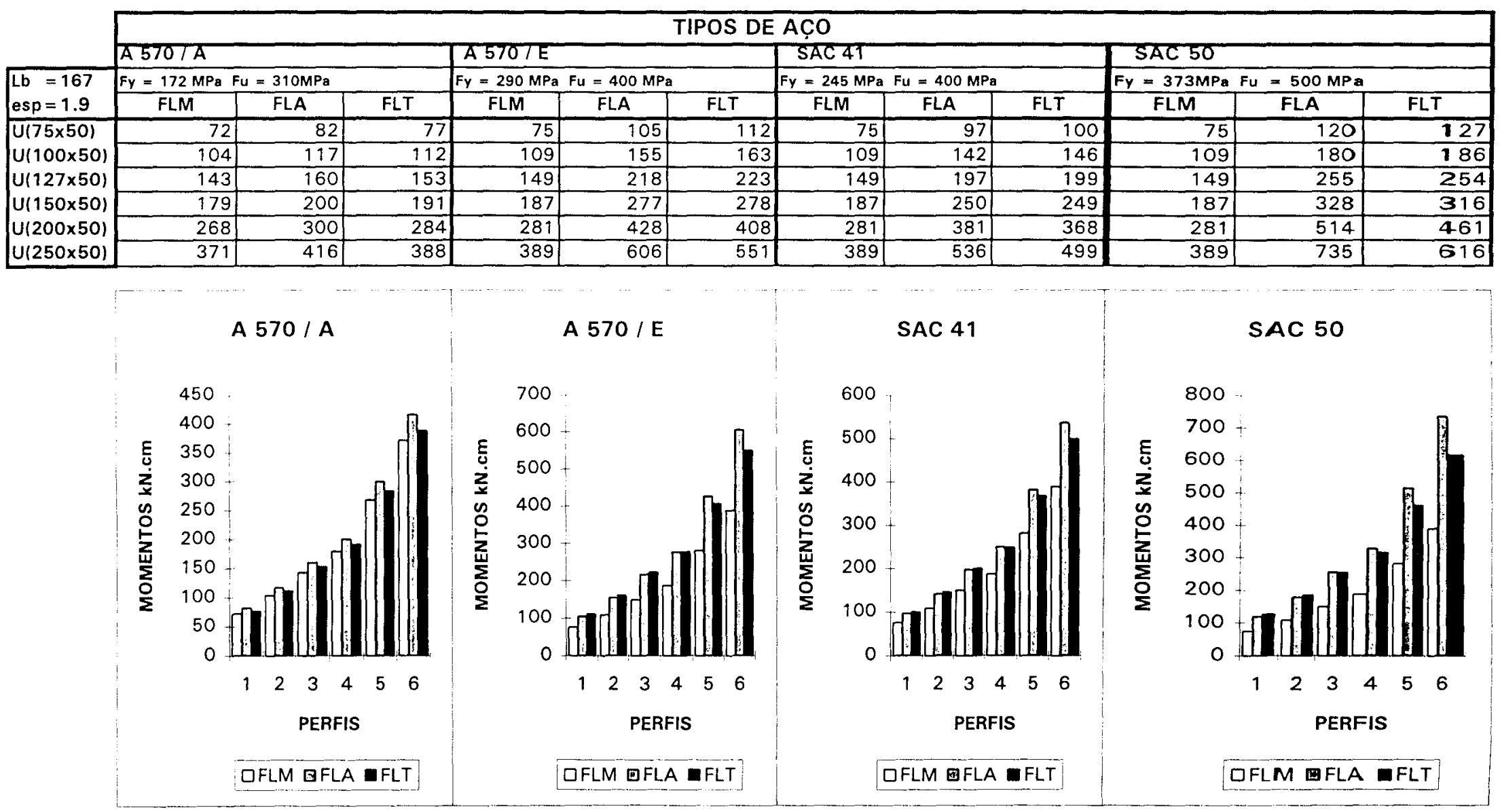


TABELA 20

VALORES ADMISSIVEIS DOS MOMENTOS PARA FLM, FLA e FLT em kN.cm

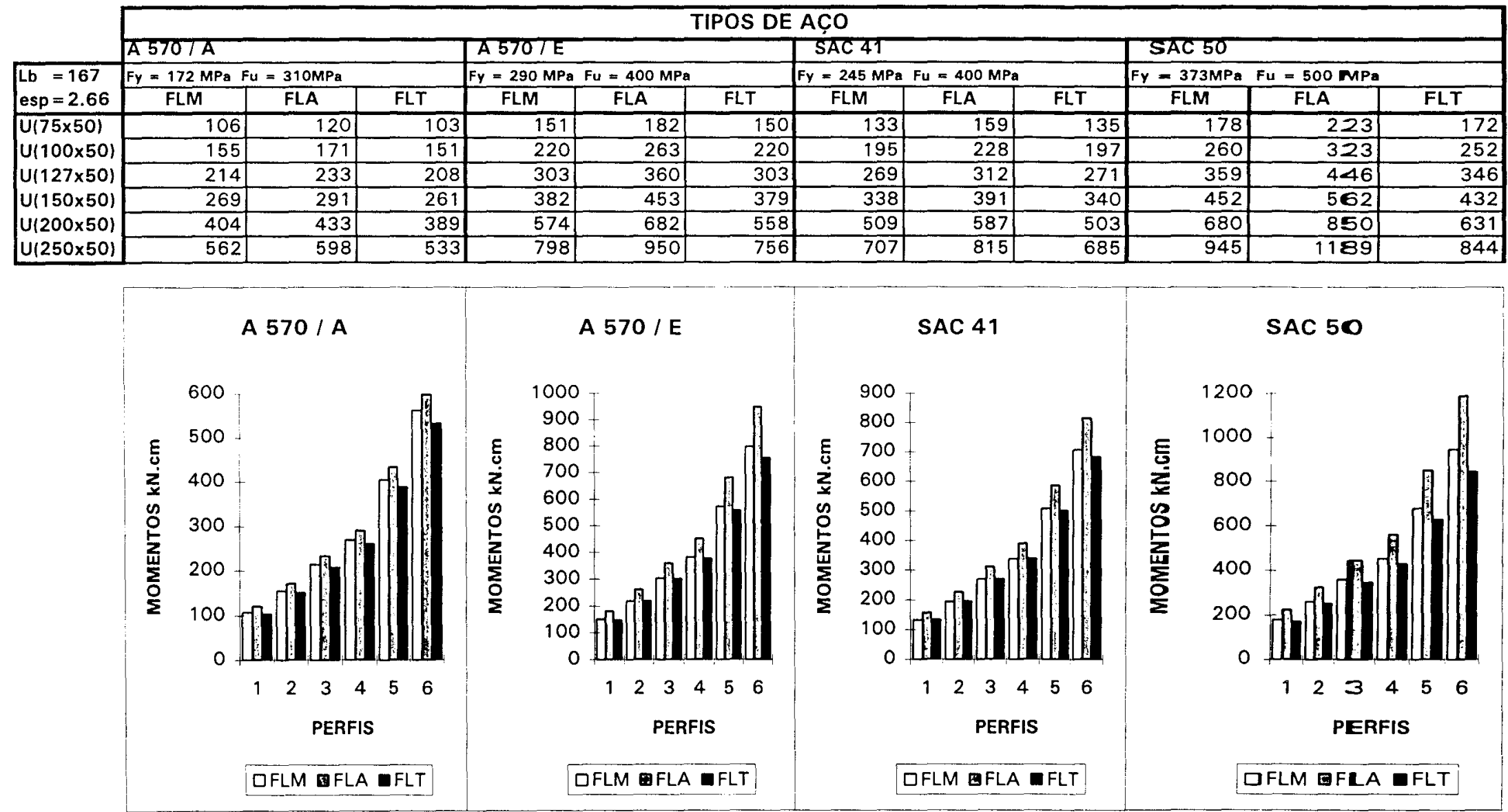


TABELA 21

VALORES ADMISSÍVEIS DOS MOMENTOS PARA FLM, FLA e FLT em kN.cm

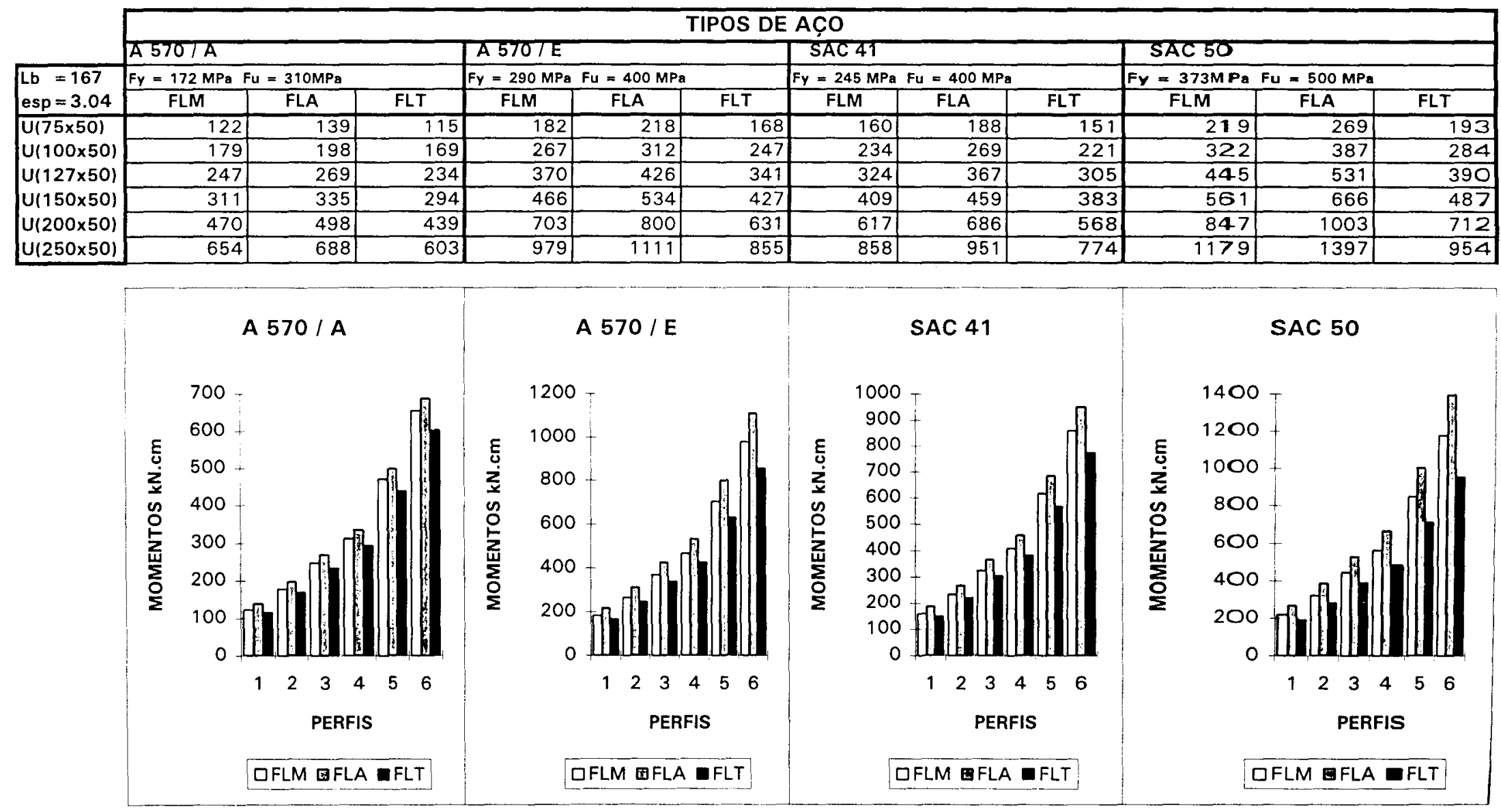


TABELA 22

VALORES ADMISSIVEIS DOS MOMENTOS PARA FLM, FLA \& FLT em kN.cm

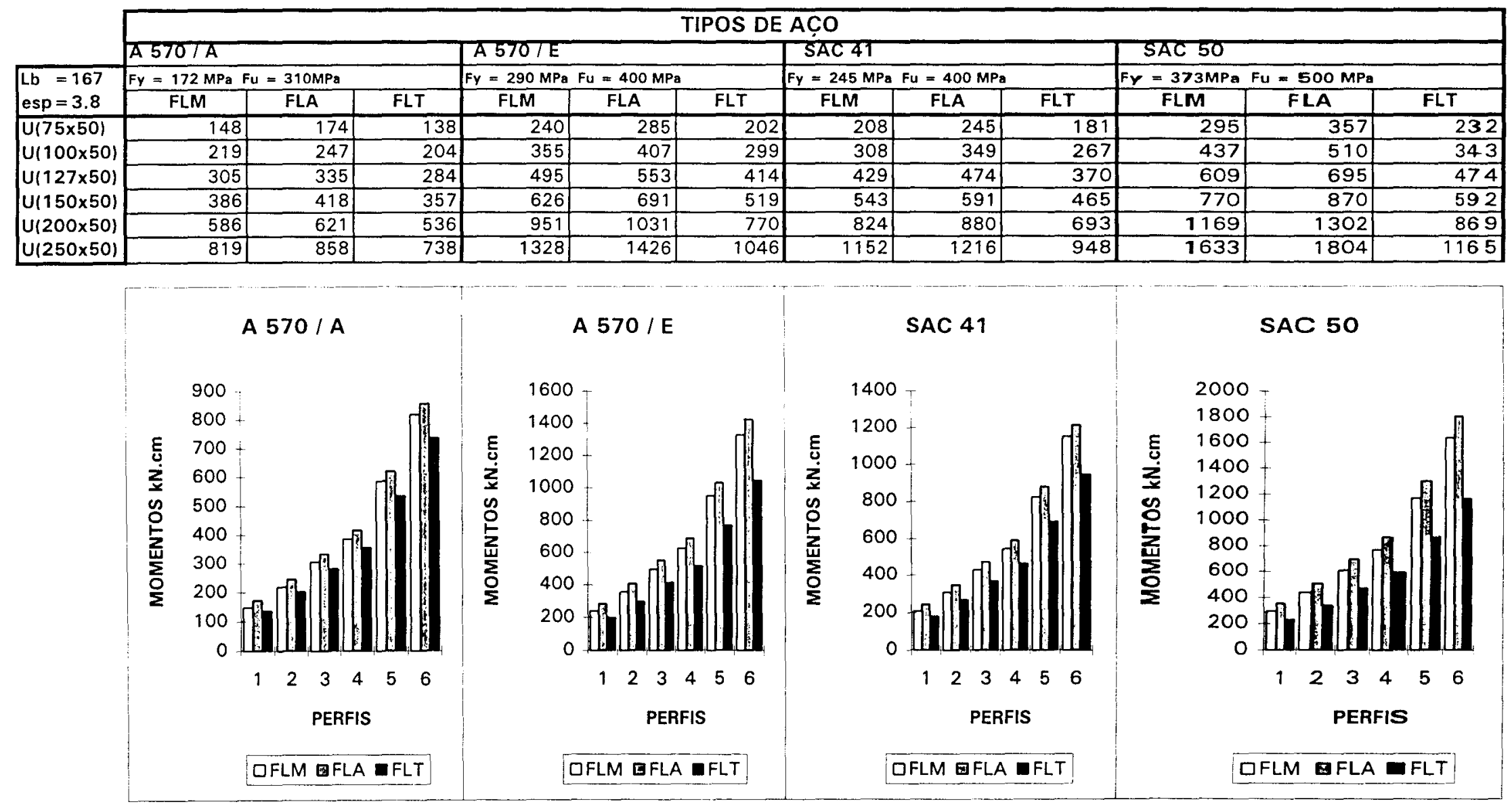


TABELA 23

VALORES ADMISSÍVEIS DOS MOMENTOS PARA FLM, FLA e FLT em kN.cm

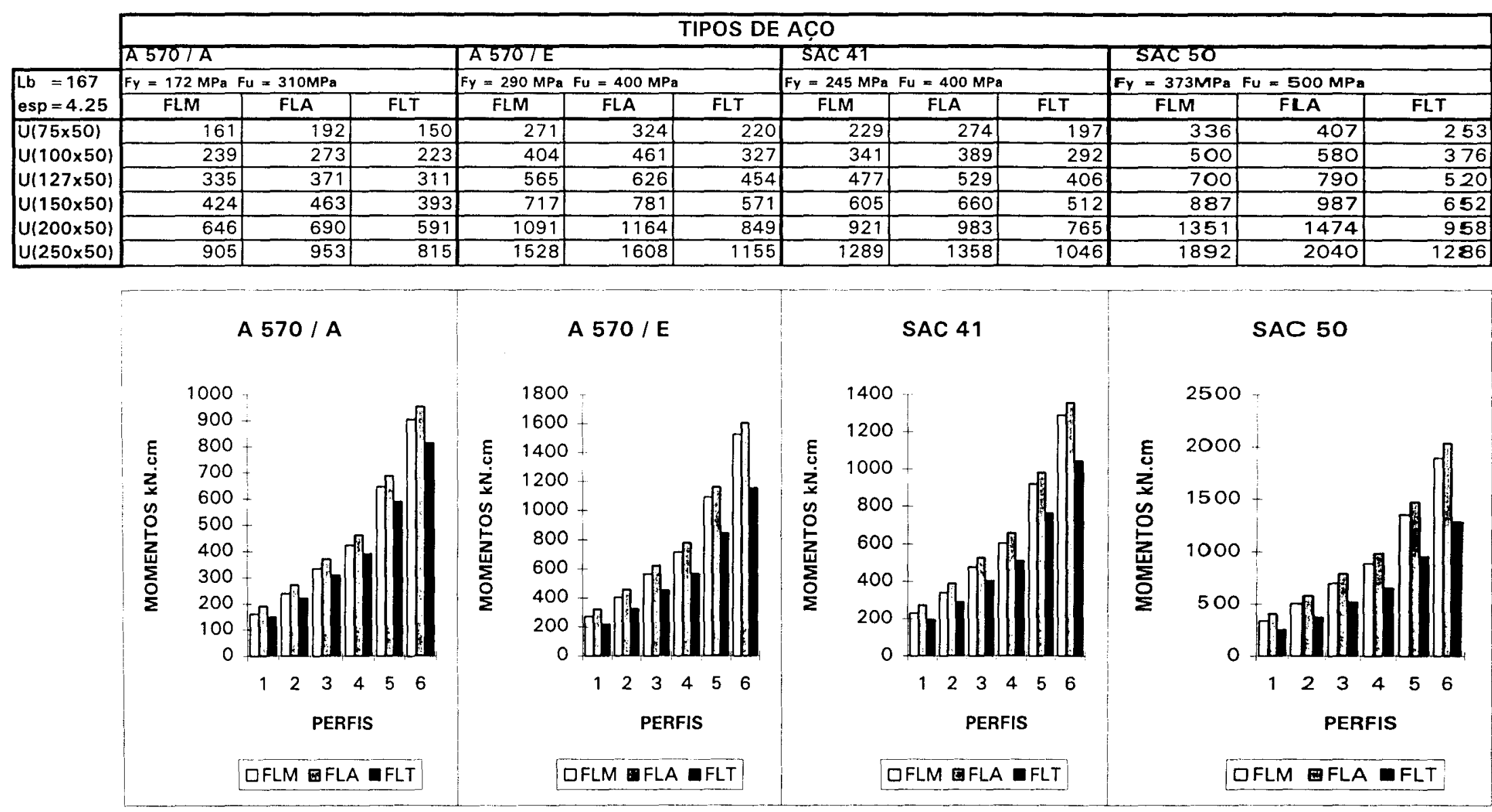


TABELA 24

VALORES ADMISSÍVEIS DOS MOMENTOS PARA FLM, FLA e FLT em kN.cm

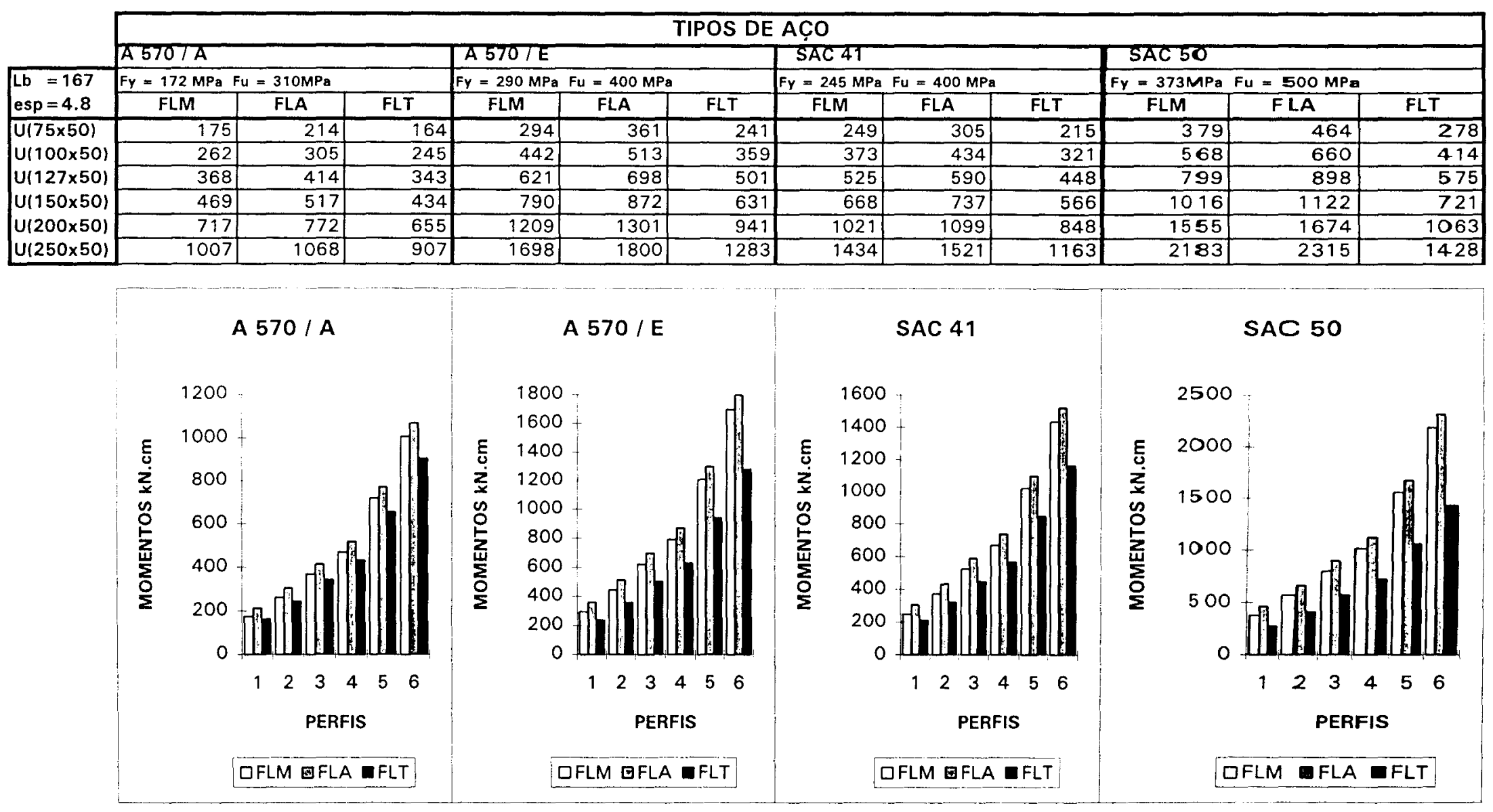


TABELA 25

VALORES ADMISSÍVEIS DOS MOMENTOS PARA FLM, FLA E FLT em kN.cm

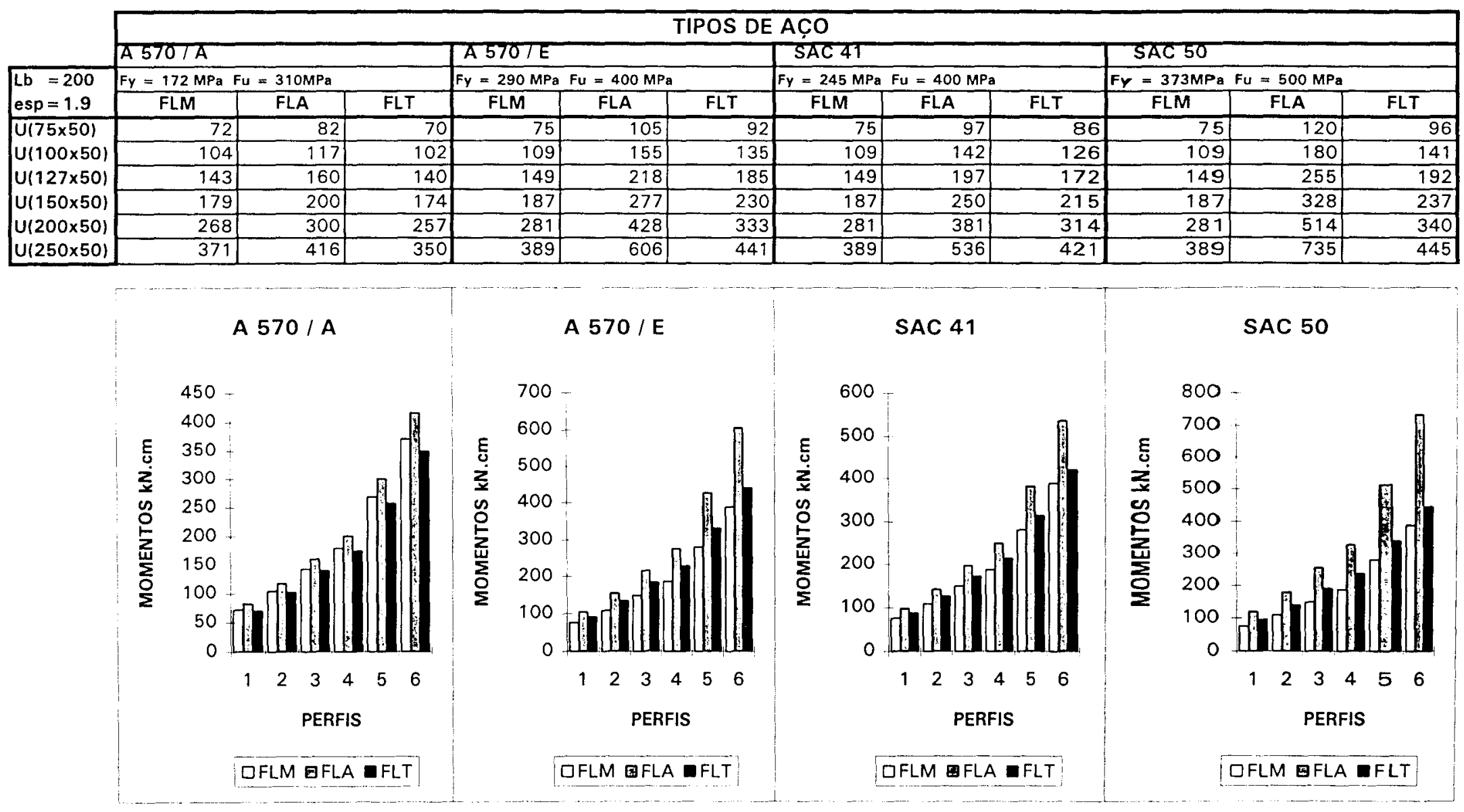


TABELA 26

VALORES ADMISSIVEIS DOS MOMENTOS PARA FLM, FLA e FLT em kN.cm

\begin{tabular}{|c|c|c|c|c|c|c|c|c|c|c|c|c|}
\hline \multicolumn{13}{|c|}{ TIPOS DE AC̣O } \\
\hline & \multirow{2}{*}{\multicolumn{3}{|c|}{$\begin{array}{l}\mathrm{A} 5707 \mathrm{~A} \\
\mathrm{Fy}=172 \mathrm{MPa} \mathrm{Fu}=310 \mathrm{MPa}\end{array}$}} & \multirow{2}{*}{\multicolumn{3}{|c|}{$\begin{array}{l}A 5707 \mathrm{E} \\
\mathrm{Fy}=290 \mathrm{MPa} \quad \mathrm{Fu}=400 \mathrm{MPa}\end{array}$}} & \multicolumn{3}{|l|}{ SAC 4T } & \multicolumn{3}{|l|}{ SAC 50 } \\
\hline \multirow{2}{*}{$\begin{array}{l}\text { Lb }=200 \\
\text { esp }=2.66\end{array}$} & & & & & & & $\mathrm{Fy}=245 \mathrm{MPa}$ & $=400 \mathrm{MPa}$ & & $\mathrm{Fy}=373 \mathrm{MPa}$ & $F u=500 \mathrm{MPa}$ & \\
\hline & FLM & FLA & FLT & FLM & FLA & FLT & FLM & FLA & FLT & FLM & FLA & FLT \\
\hline U(75x50) & 106 & 120 & 94 & 151 & 182 & 125 & 133 & 159 & 117 & 178 & 223 & 130 \\
\hline$U(100 \times 50)$ & 155 & 171 & 138 & 220 & 263 & 183 & 195 & 228 & 171 & 260 & 323 & 192 \\
\hline$U(127 \times 50)$ & 214 & 233 & 190 & 303 & 360 & 252 & 269 & 312 & 235 & 359 & 446 & 262 \\
\hline $\mathrm{U}(150 \times 50)$ & 269 & 291 & 238 & 382 & 453 & 313 & 338 & 391 & 293 & 452 & 562 & 324 \\
\hline$U(200 \times 50)$ & 404 & 433 & 352 & 574 & 682 & 455 & 509 & 587 & 429 & 680 & 850 & 465 \\
\hline$U(250 \times 50)$ & 562 & 598 & 479 & 798 & 950 & 604 & 707 & 815 & 576 & 945 & 1189 & 609 \\
\hline
\end{tabular}

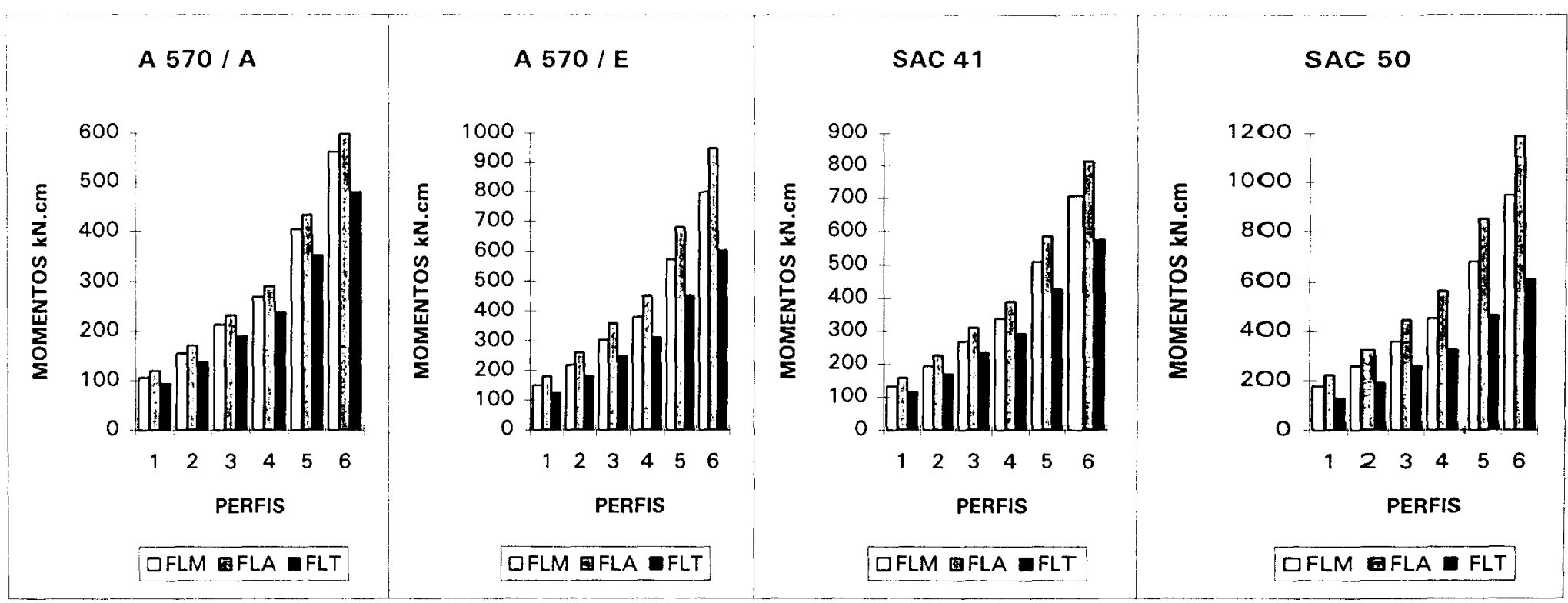


TABELA 27

VALORES ADMISSIVEIS DOS MOMENTOS PARA FLM, FLA e FLT em KN.cm

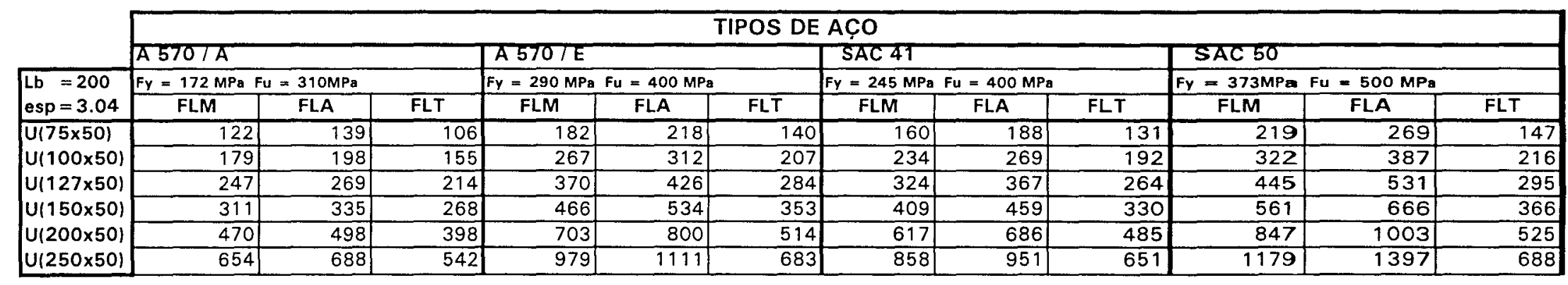

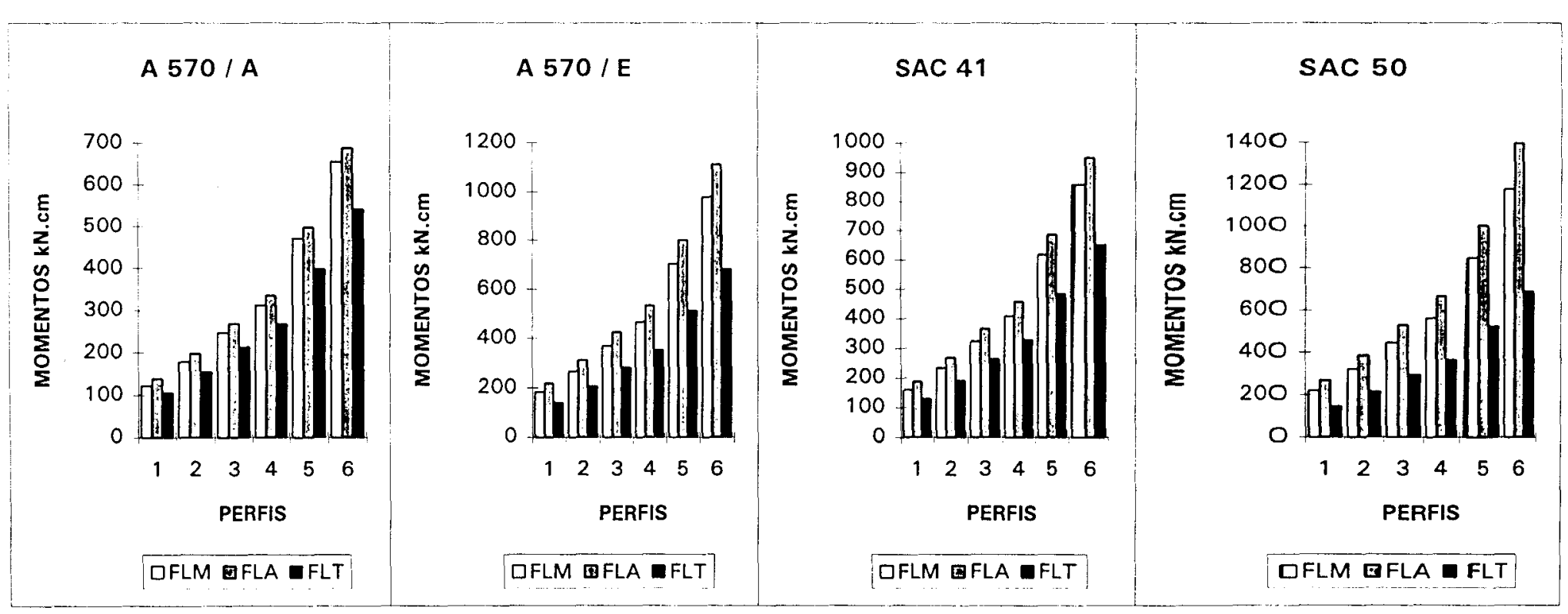


TABELA 28

VALORES ADMISSÍVEIS DOS MOMENTOS PARA FLM, FLA e FLT em kN.cm

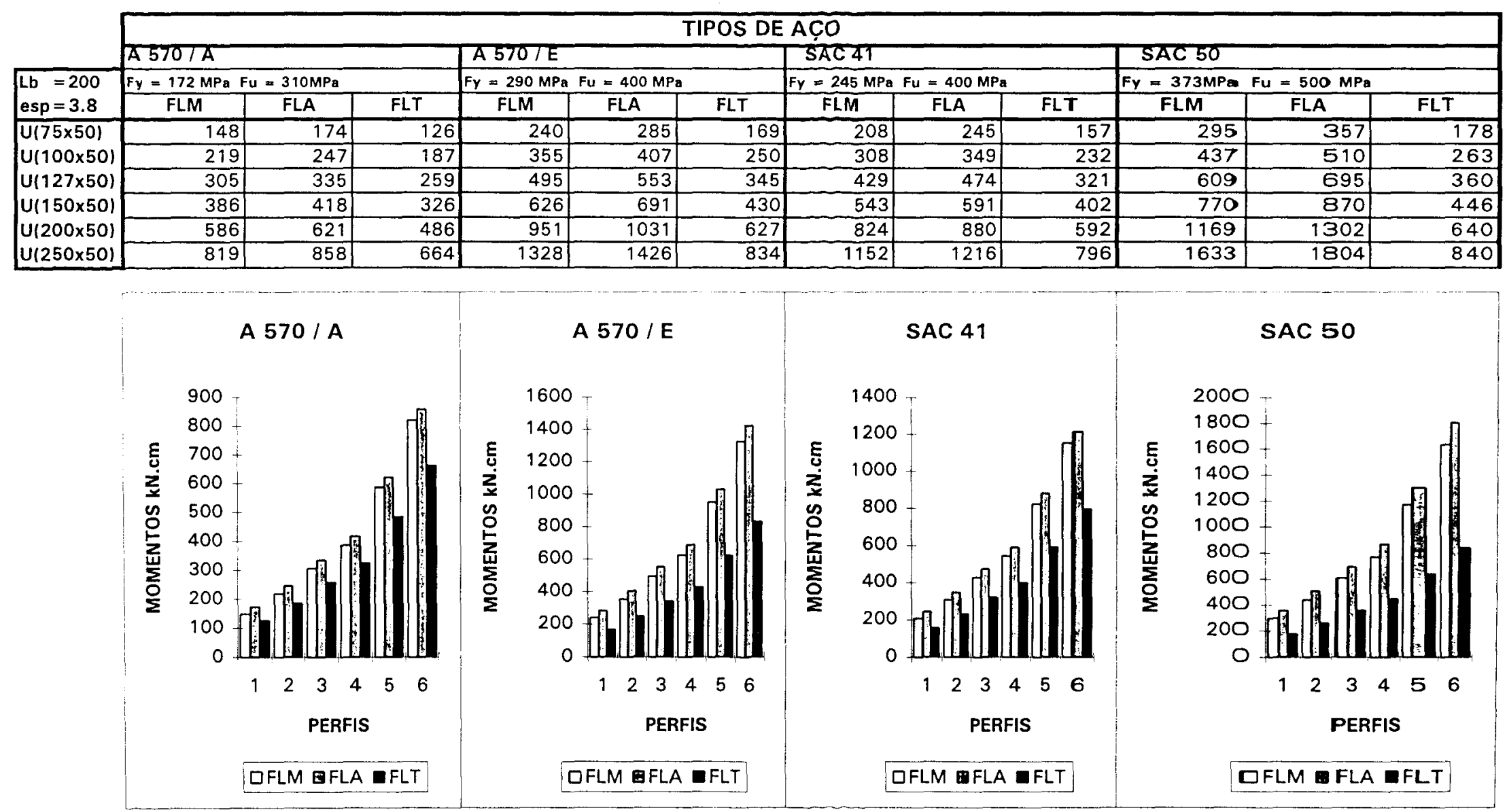


TABELA 29

VALORES ADMISSÍVEIS DOS MOMENTOS PARA FLM, FLA E FLT em kN.cm

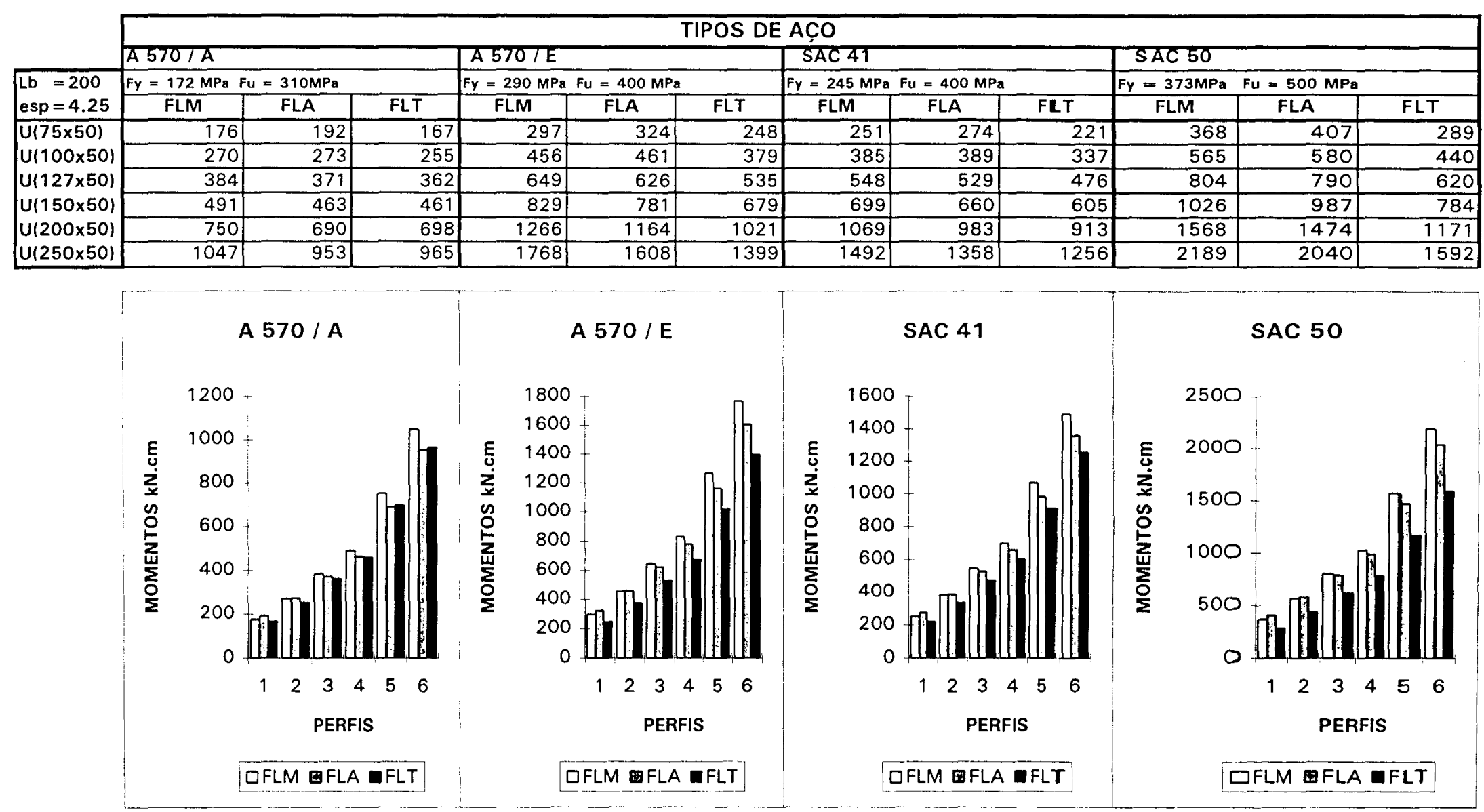


TABELA 30

VALORES ADMISSÍVEIS DOS MOMENTOS PARA FLM, FLA e FLT em kN.cm

\begin{tabular}{|c|c|c|c|c|c|c|c|c|c|c|c|c|}
\hline \multicolumn{13}{|c|}{ TIPOS DE AC̣O } \\
\hline & A 5701A & & & A 5707E & & & SAC 4T & & & SAC 50 & & \\
\hline \multirow{2}{*}{$\begin{array}{l}L b=200 \\
\text { esp }=4.8\end{array}$} & \multicolumn{3}{|c|}{$F y=172 \mathrm{MPa} F \mathrm{Fu}=310 \mathrm{MPa}$} & \multicolumn{3}{|c|}{$F y=290 \mathrm{MPa} F u=400 \mathrm{MPa}$} & \multicolumn{3}{|c|}{$F_{y}=245 \mathrm{MPa} F u=400 \mathrm{MPa}$} & \multicolumn{3}{|c|}{$F_{y}=373 \mathrm{MPa} F u=500 \mathrm{MPa}$} \\
\hline & FLM & FLA & FLT & FLM & FLA & FLT & FLM & FLA & FLT & FLM & FLA & FLT \\
\hline$U(75 \times 50)$ & 175 & 214 & 150 & 294 & 361 & 203 & 249 & 305 & 188 & 379 & 464 & 215 \\
\hline$U(100 \times 50)$ & 262 & 305 & 225 & 442 & 513 & 302 & 373 & 434 & 280 & 568 & 660 & 320 \\
\hline $\mathrm{U}(127 \times 50)$ & 368 & 414 & 314 & 621 & 698 & 419 & 525 & 590 & 389 & 799 & 898 & 439 \\
\hline$U(150 \times 50)$ & 469 & 517 & 396 & 790 & 872 & 524 & 668 & 737 & 489 & 1016 & 1122 & 545 \\
\hline$U(200 \times 50)$ & 717 & 772 & 594 & 1209 & 1301 & 767 & 1021 & 1099 & 723 & 1555 & 1674 & 783 \\
\hline$U(250 \times 50)$ & 1007 & 1068 & 814 & 1698 & 1800 & 1021 & 1434 & 1521 & 976 & 2183 & 2315 & 1028 \\
\hline
\end{tabular}

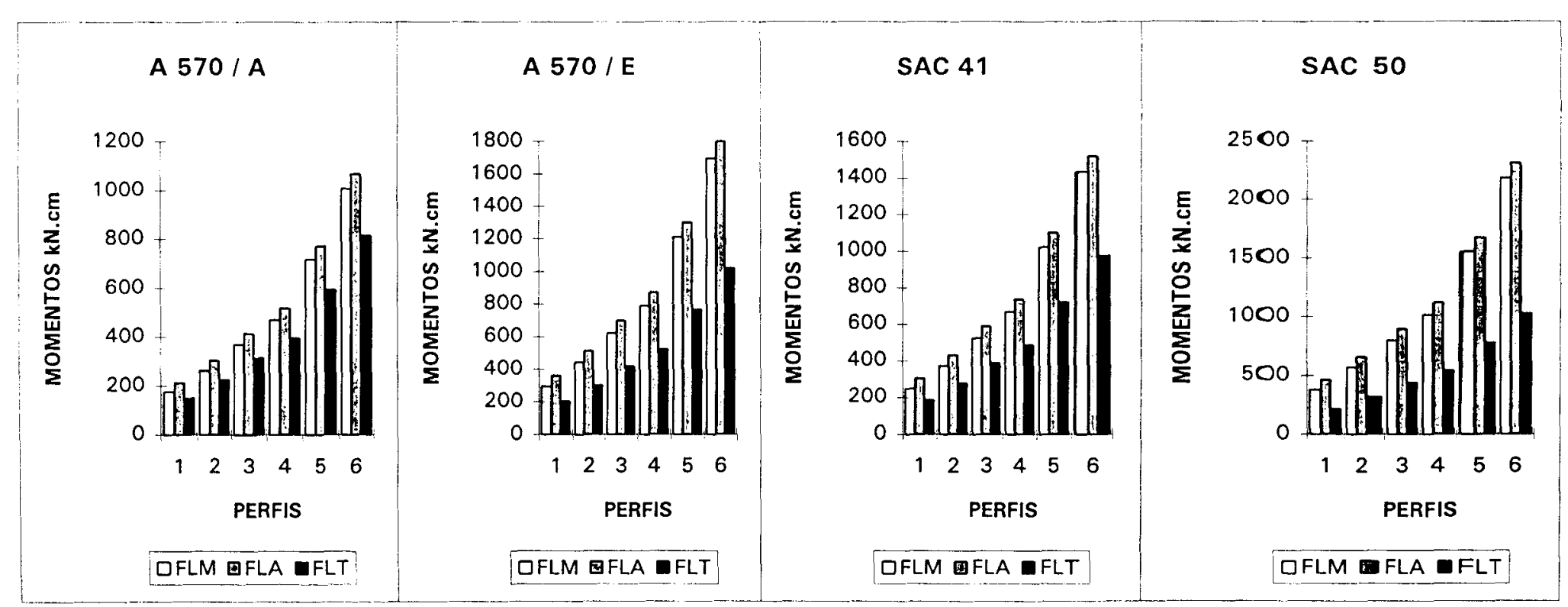


TABELA 31

VALORES ADMISSÍVEIS DOS MOMENTOS PARA FLM, FLA e FLT em kN.cm

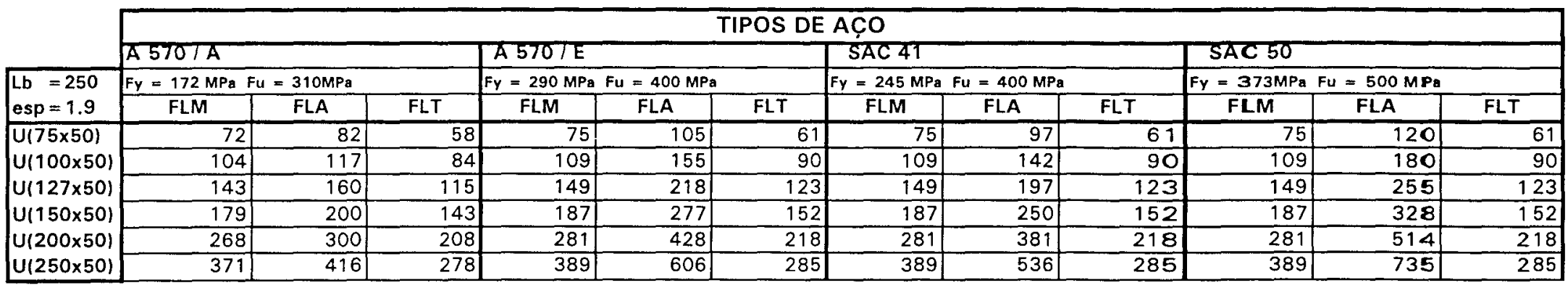

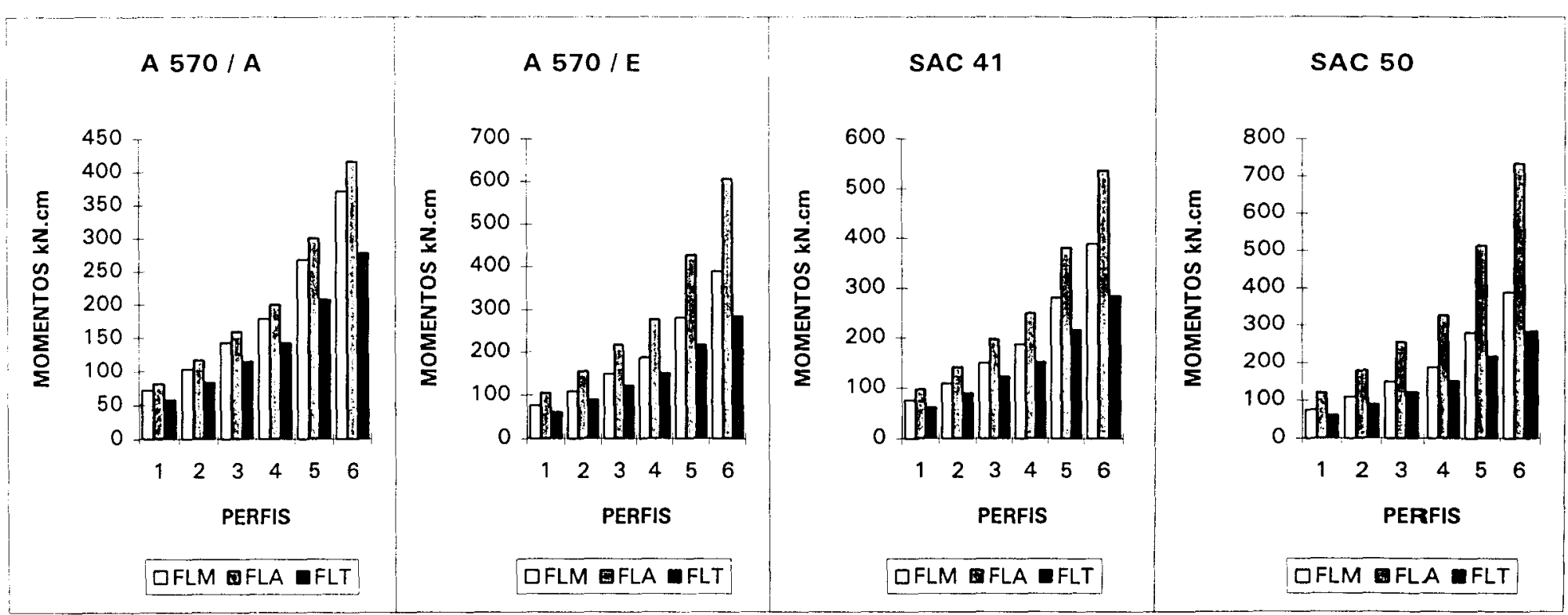


TABELA 32

VALORES ADMISSÍVEIS DOS MOMENTOS PARA FLM, FLA e FLT em kN.cm

\begin{tabular}{|c|c|c|c|c|c|c|c|c|c|c|c|c|}
\hline \multicolumn{13}{|c|}{ TIPOS DE AC̣O } \\
\hline & A570/A & & & \multirow{2}{*}{\multicolumn{3}{|c|}{ A 5707E }} & \multicolumn{3}{|l|}{ SAC 41} & \multicolumn{3}{|l|}{ SAC 50} \\
\hline \multirow{2}{*}{$\begin{array}{l}\text { Lb }=250 \\
\text { esp }=2.66\end{array}$} & \multicolumn{3}{|c|}{$F y=172 \mathrm{MPa} F u=310 \mathrm{MPa}$} & & $y=400 \mathrm{MP}$ & & $F y=245 \mathrm{MPa}$ & $=400 \mathrm{MPd}$ & & $F Y=373 \mathrm{MPa}$ & $=500 \mathrm{MPa}$ & \\
\hline & FLM & FLA & FLT & FLM & FLA & FLT & FLM & FLA & $\mathrm{FLT}$ & FLM & FLA & FLT \\
\hline$U(75 \times 50)$ & 106 & 120 & 78 & 151 & 182 & 83 & 133 & 159 & 83 & 178 & 223 & 83 \\
\hline $\mid v(100 \times 50)$ & 155 & 171 & 114 & 220 & 263 & 123 & 195 & 228 & 123 & 260 & 323 & 123 \\
\hline$U(127 \times 50)$ & 214 & 233 & 157 & 303 & 360 & 168 & 269 & 312 & 168 & 359 & 446 & 168 \\
\hline$U(150 \times 50)$ & 269 & 291 & 195 & 382 & 453 & 208 & 338 & 391 & 208 & 452 & 562 & 208 \\
\hline $\mathrm{U}(200 \times 50)$ & 404 & 433 & 285 & 574 & 682 & 297 & 509 & 587 & 297 & 680 & 850 & 297 \\
\hline$U(250 \times 50)$ & 562 & 598 & 380 & 798 & 950 & 390 & 707 & 815 & 390 & 945 & 1189 & 390 \\
\hline
\end{tabular}

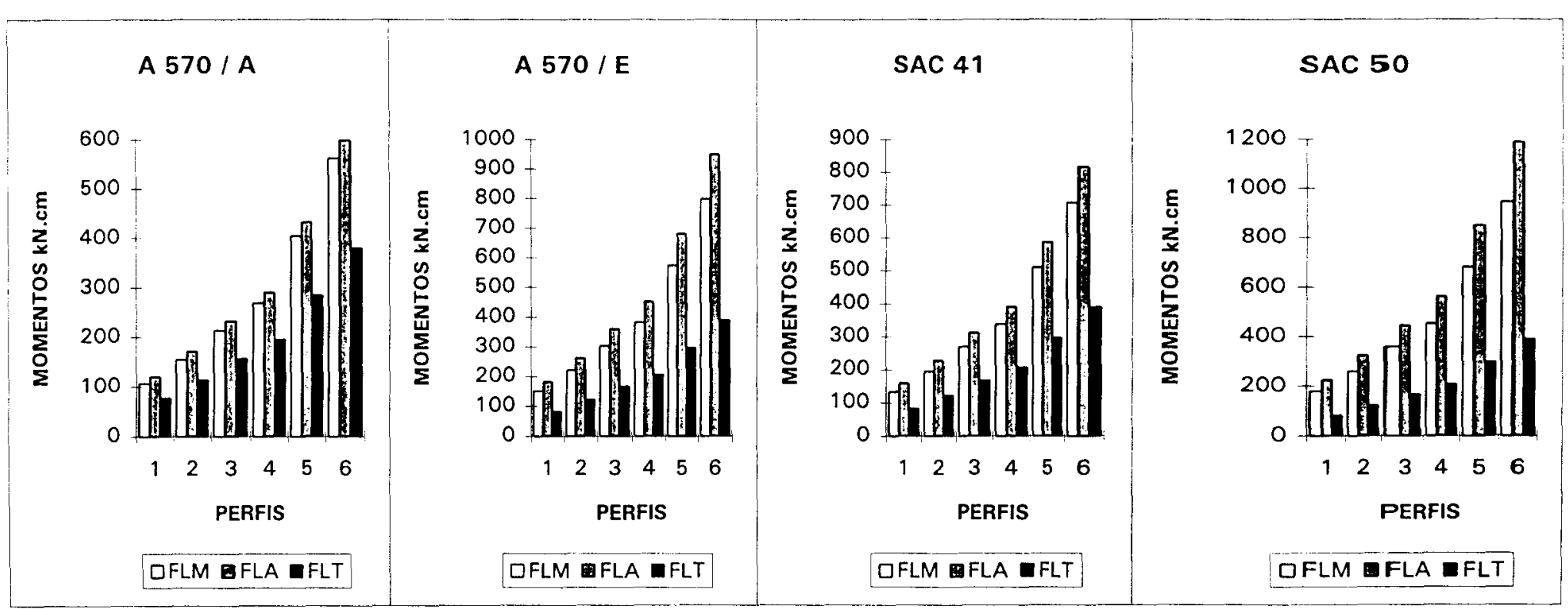


TABELA 33

VALORES ADMISSIVEIS DOS MOMENTOS PARA FLM, FLA E FLT em KN.cm

\begin{tabular}{|c|c|c|c|c|c|c|c|c|c|c|c|c|}
\hline \multicolumn{13}{|c|}{ TIPOS DE AC̣O } \\
\hline & A5701A & & & A 570/E & & & SAC 4T & & & & & \\
\hline \multirow{2}{*}{$\begin{array}{l}\mathrm{Lb}=250 \\
\mathrm{esp}=3.04\end{array}$} & \multicolumn{3}{|c|}{$F y=172 \mathrm{MPa} F u=310 \mathrm{MPa}$} & \multicolumn{3}{|c|}{$F y=290 \mathrm{MPa} F u=400 \mathrm{MPa}$} & \multicolumn{3}{|c|}{$F y=245 \mathrm{MPa} \quad F u=400 \mathrm{MPa}$} & \multicolumn{3}{|c|}{$\mathrm{Fy}=373 \mathrm{MPa} \mathrm{Fu}=500 \mathrm{MPa}$} \\
\hline & FLM & FLA & FLT & FLM & FLA & FLT & FLM & FLA & FLT & FLM & FLA & FLT \\
\hline$U(75 \times 50)$ & 122 & 139 & 87 & 182 & 218 & 94 & 160 & 188 & 94 & 219 & 269 & 94 \\
\hline$U(100 \times 50)$ & 179 & 198 & 128 & 267 & 312 & 138 & 234 & 269 & 138 & 322 & 387 & 138 \\
\hline$U(127 \times 50)$ & 247 & 269 & 176 & 370 & 426 & 189 & 324 & 367 & 189 & 445 & 531 & 189 \\
\hline$U(150 \times 50)$ & 311 & 335 & 220 & 466 & 534 & 234 & 409 & 459 & 234 & 561 & 666 & 234 \\
\hline $\mathrm{U}(200 \times 50)$ & 470 & 498 & 322 & 703 & 800 & 336 & 617 & 686 & 336 & 847 & 1003 & 336 \\
\hline$U(250 \times 50)$ & 654 & 688 & 430 & 979 & 1111 & 440 & 858 & 951 & 440 & 1179 & 1397 & 440 \\
\hline
\end{tabular}

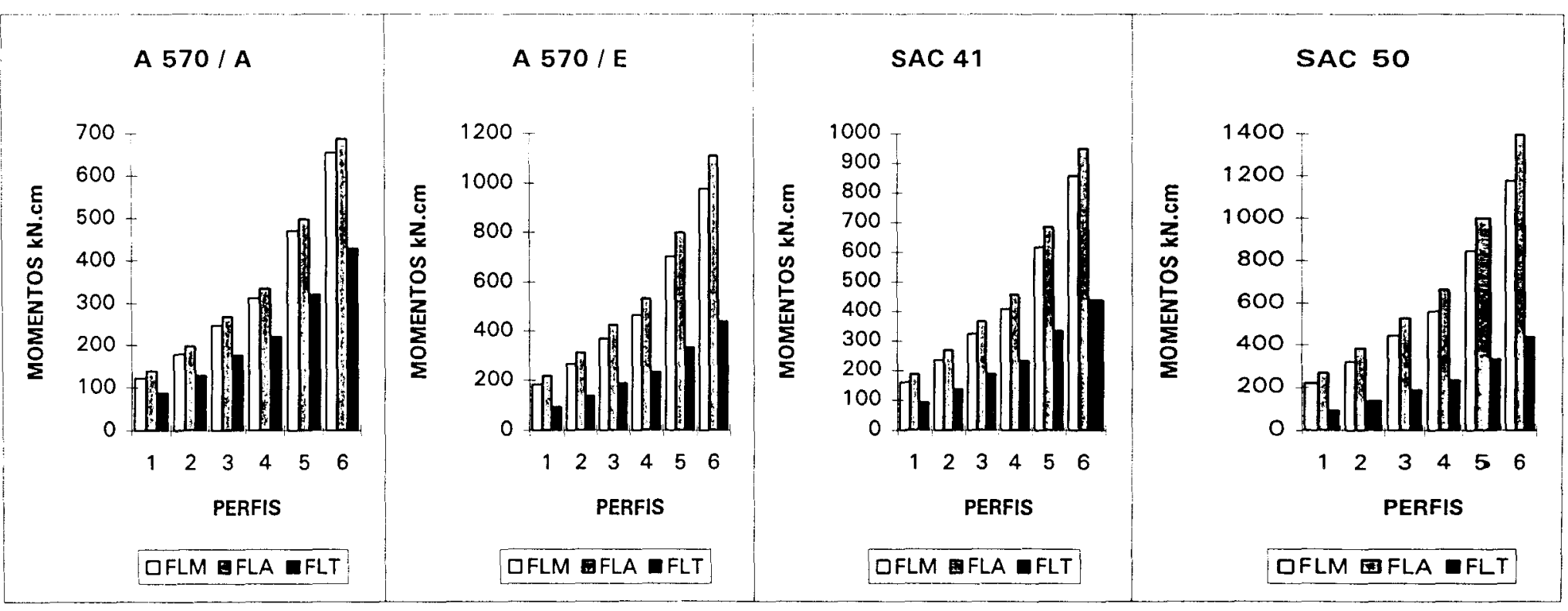


TABELA 34

VALORES ADMISSÍVEIS DOS MOMENTOS PARA FLM, FLA e FLT em kN.cm

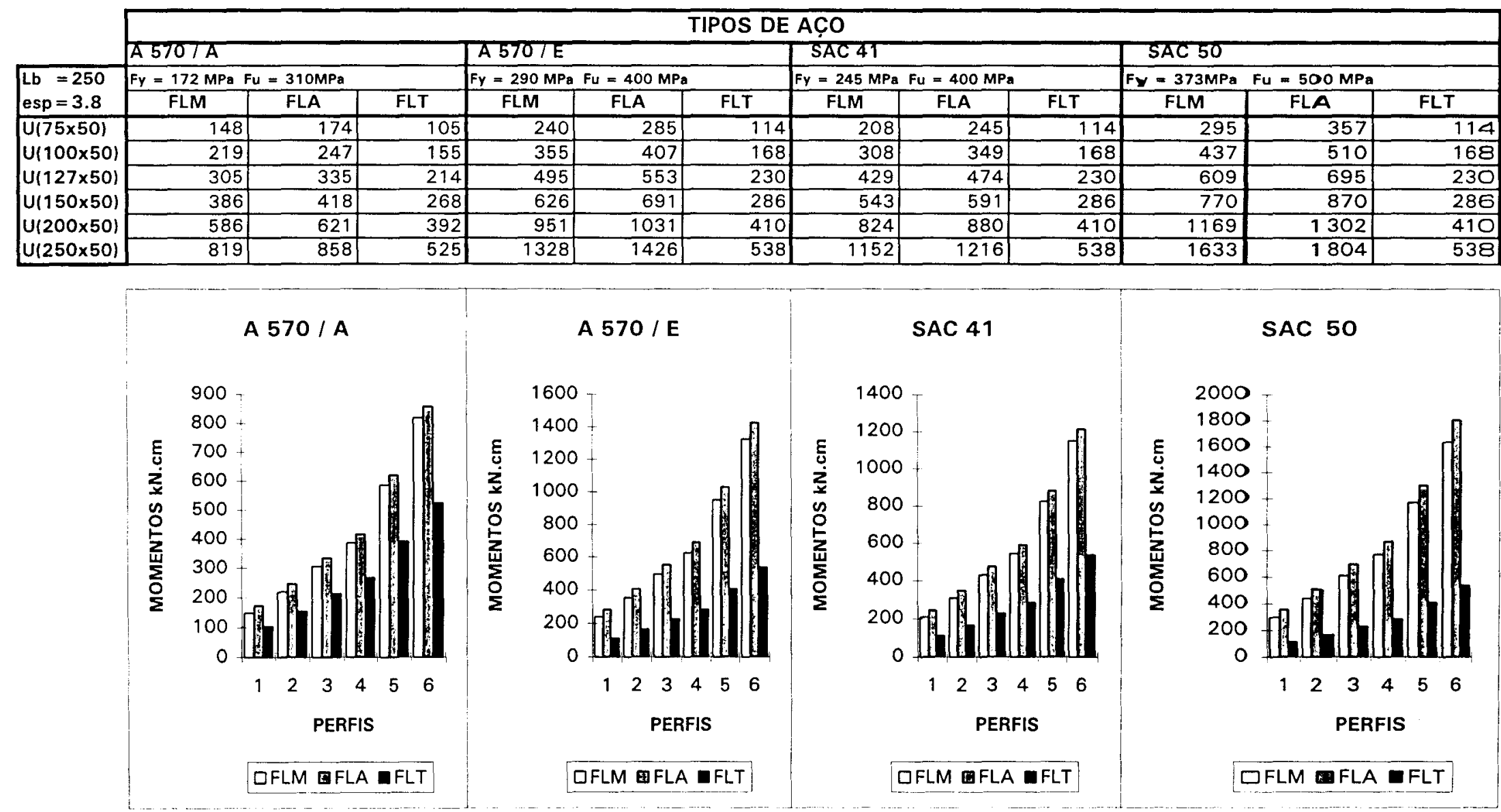


TABELA 35

VALORES ADMISSIVEIS DOS MOMENTOS PARA FLM, FLA e FLT em kN.cm

\begin{tabular}{|c|c|c|c|c|c|c|c|c|c|c|c|c|}
\hline \multicolumn{13}{|c|}{ TIPOS DE AC̣O } \\
\hline & \multicolumn{3}{|l|}{ A5701A } & \multicolumn{3}{|l|}{ A $5707 \mathrm{E}$} & \multicolumn{3}{|l|}{ SAC 41 } & \multicolumn{3}{|l|}{$54 C 50$} \\
\hline \multirow{2}{*}{$\begin{array}{l}L b=250 \\
\text { esp }=4.25\end{array}$} & $\mathrm{Fy}=172 \mathrm{MPa}$ & $=310 \mathrm{MPa}$ & & $F y=290 \mathrm{MPa}$ & $=400 \mathrm{MP}$ & & $\mathrm{Fy}=245 \mathrm{MPa}$ & $=400 \mathrm{MP}$ & & $\mathrm{FY}=373 \mathrm{MPa}$ & $F u=500 \mathrm{MPa}$ & \\
\hline & FLM & FLA & FLT & FLM & FLA & $\overline{F L T}$ & FLM & FLA & FLT & FLM & FLA & $\overline{F L T}$ \\
\hline$U(75 \times 50)$ & 161 & 192 & 115 & 271 & 324 & 125 & 229 & 274 & 125 & 336 & 407 & 125 \\
\hline$U(100 \times 50)$ & 239 & 273 & 170 & 404 & 461 & 185 & 341 & 389 & 185 & 500 & 580 & 185 \\
\hline$U(127 \times 50)$ & 335 & 371 & 236 & 565 & 626 & 254 & 477 & 529 & 254 & 700 & 790 & 254 \\
\hline$U(150 \times 50)$ & 424 & 463 & 295 & 717 & 781 & 315 & 605 & 660 & 315 & 887 & 987 & 315 \\
\hline$U(200 \times 50)$ & 646 & 690 & 433 & 1091 & 1164 & 452 & 921 & 983 & 452 & 1351 & 1474 & 452 \\
\hline$U(250 \times 50)$ & 905 & 953 & 579 & 1528 & 1608 & 593 & 1289 & 1358 & 593 & 1892 & 2040 & 593 \\
\hline
\end{tabular}

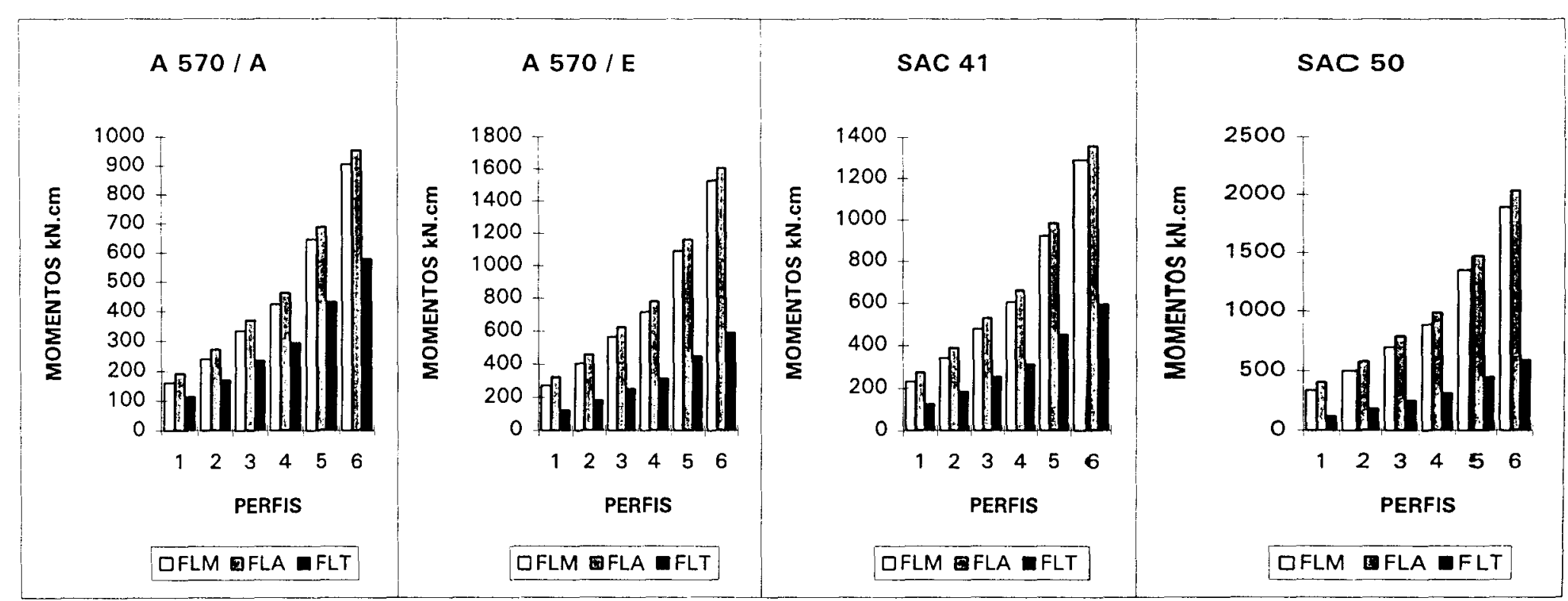


TABELA 36

VALORES ADMISSIVEIS DOS MOMENTOS PARA FLM, FLA e FLT em kN.cm

\begin{tabular}{|c|c|c|c|c|c|c|c|c|c|c|c|c|}
\hline \multicolumn{13}{|c|}{ TIPOS DE AC̣O } \\
\hline & \multicolumn{3}{|l|}{ A 55707A } & \multicolumn{3}{|l|}{ A 5701E } & \multicolumn{3}{|l|}{ SAC 41} & \multicolumn{3}{|l|}{ SAC 50} \\
\hline \multirow{2}{*}{$\begin{array}{l}\mathrm{Lb}=250 \\
\text { esp }=4.8\end{array}$} & $F_{Y}=172 \mathrm{MPaF}$ & $310 \mathrm{MPa}$ & & $F Y=290 \mathrm{MPa}$ & $\mathrm{I}=400 \mathrm{MPa}$ & & $F y=245 \mathrm{MPa}$ & $=400 \mathrm{MPg}$ & & $\mathrm{Fy}=373 \mathrm{MPa}$ & $F u=500 \mathrm{MPa}$ & \\
\hline & FLM & FLA & FLT & FLM & FLA & FLT & FLM & FLA & FLT & FLM & FLA & FLT \\
\hline $\mathrm{U}(75 \times 50)$ & 175 & 214 & 126 & 294 & 361 & 138 & 249 & 305 & 138 & 379 & 464 & 138 \\
\hline$U(100 \times 50)$ & 262 & 305 & 188 & 442 & 513 & 205 & 373 & 434 & 205 & 568 & 660 & 205 \\
\hline$U(127 \times 50)$ & 368 & 414 & 260 & 621 & 698 & 281 & 525 & 590 & 281 & 799 & 898 & 281 \\
\hline$u(150 \times 50)$ & 469 & 517 & 326 & 790 & 872 & 349 & 668 & 737 & 349 & 1016 & 1722 & 349 \\
\hline$U(200 \times 50)$ & 717 & 772 & 480 & 1209 & 1301 & 501 & 1021 & 1099 & 501 & 1555 & 1674 & 501 \\
\hline$U(250 \times 50)$ & 1007 & 1068 & 643 & 1698 & 1800 & 658 & 1434 & 1521 & 658 & 2183 & 2315 & 658 \\
\hline
\end{tabular}

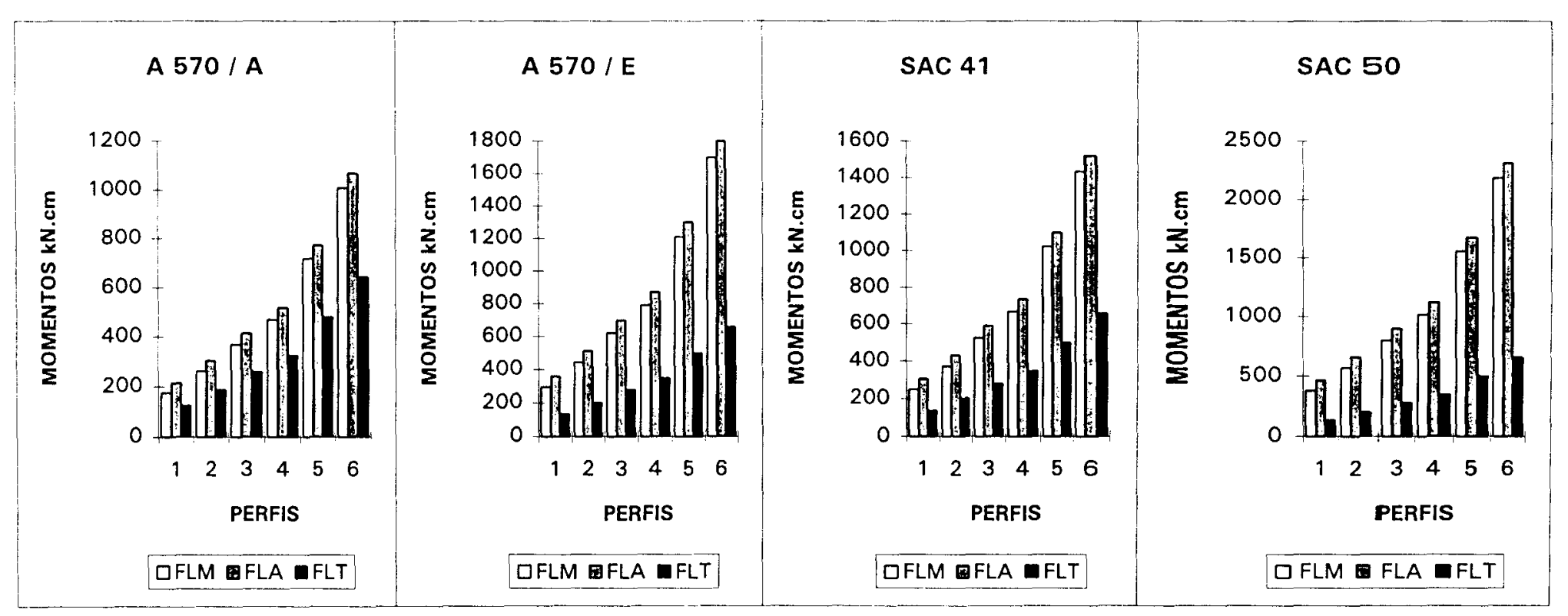


VALORES ADMISSÍVEIS DOS MOMENTOS PARA FLM, FLA e FLT em KN.cm

\begin{tabular}{|c|c|c|c|c|c|c|c|c|c|c|c|c|}
\hline & \multicolumn{12}{|c|}{ TIPOS DE AC̣O } \\
\hline & \multicolumn{3}{|l|}{ A570/A } & \multicolumn{3}{|l|}{ A 570/E } & \multicolumn{3}{|l|}{ SAC 41 } & \multicolumn{3}{|l|}{ SAC 50} \\
\hline \multirow{2}{*}{$\begin{array}{l}L b=167 \\
\text { esp }=1.9\end{array}$} & \multicolumn{3}{|c|}{$F y=172 \mathrm{MPa} F u=310 \mathrm{MPa}$} & \multirow{2}{*}{\multicolumn{3}{|c|}{$F y=290 \mathrm{MPa} F u=400 \mathrm{MPa}$}} & \multicolumn{3}{|c|}{$F_{y}=245 \mathrm{MPa} F u=400 \mathrm{MPa}$} & \multirow{2}{*}{\begin{tabular}{c|}
$F y=373 \mathrm{MPa}$ \\
$F L M$
\end{tabular}} & \multicolumn{2}{|l|}{$\mathrm{Fu}=500 \mathrm{MPa}$} \\
\hline & FLM & FLA & FLT & & & & FLM & FLA & FLT & & FLA & FLT \\
\hline$U(75 \times \times 40 \times 25)$ & 78 & 84 & 80 & 105 & 142 & 118 & 94 & 120 & 105 & 122 & 183 & 137 \\
\hline$U(100 \times 40 \times 25)$ & 116 & 125 & 119 & 156 & 212 & 176 & 140 & 179 & 156 & 181 & 272 & 204 \\
\hline$U(127 \times 50 \times 25)$ & 162 & 175 & 165 & 218 & 296 & 245 & 195 & 250 & 218 & 253 & 380 & 284 \\
\hline$U(150 \times 40 \times 25)$ & 205 & 222 & 209 & 276 & 374 & 309 & 247 & 316 & 275 & 320 & 481 & 357 \\
\hline$U(200 \times 40 \times 25)$ & 311 & 336 & 314 & 417 & 555 & 461 & 374 & 478 & 411 & 484 & 692 & 530 \\
\hline$U(250 \times 40 \times 25)$ & 431 & 461 & 432 & 580 & 726 & 629 & 519 & 629 & 563 & 672 & 895 & 718 \\
\hline
\end{tabular}

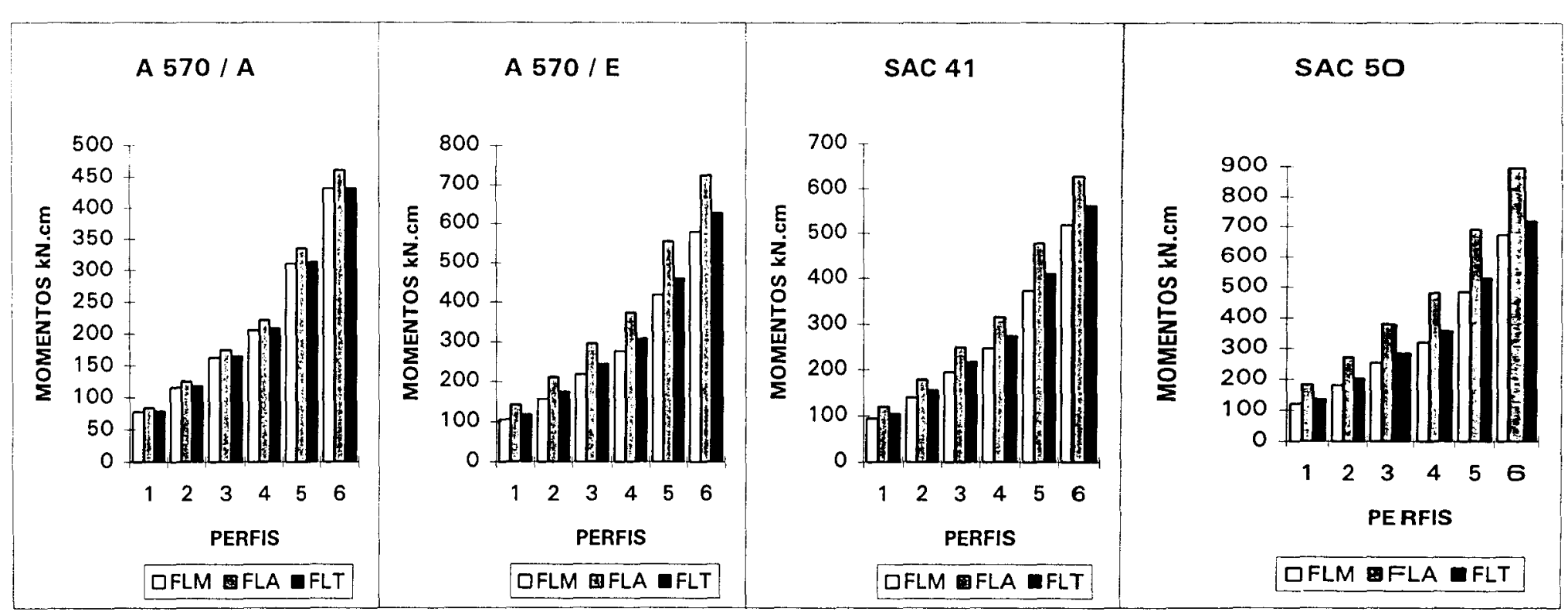


VALORES ADMISSIVEIS DOS MOMENTOS PARA FLM, FLA e FLT em KN.cm

\begin{tabular}{|c|c|c|c|c|c|c|c|c|c|c|c|c|}
\hline \multicolumn{13}{|c|}{ TIPOS DE AC̣O } \\
\hline & \multicolumn{3}{|l|}{ A 570/A } & \multicolumn{3}{|l|}{ A 570/E } & \multicolumn{3}{|l|}{ SAC 41 } & \multicolumn{3}{|l|}{ SAC 50} \\
\hline \multirow{2}{*}{$\begin{array}{l}L b=167 \\
\text { esp }=2.66\end{array}$} & $\mathrm{Fy}=172 \mathrm{MPa}$ & $=310 \mathrm{MPa}$ & & $\mathrm{Fy}=290 \mathrm{MPa}$ & $1=400 \mathrm{MPa}$ & & $\mathrm{Fy}=245 \mathrm{MPa}$ & $=400 \mathrm{MP}$ & & $F y=373 \mathrm{MPa}$ & $\mathrm{Fu}=500 \mathrm{MPa}$ & \\
\hline & FLM & FLA & $\overline{F L T}$ & FLM & FLA & FLT & FLM & FLA & FLT & FLM & FLA & FLT \\
\hline 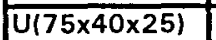 & 109 & 110 & 104 & 168 & 185 & 153 & 147 & 156 & 136 & 204 & 238 & 178 \\
\hline$U(100 \times 40 \times 25)$ & 165 & 166 & 156 & 254 & 279 & 231 & 221 & 236 & 206 & 308 & 359 & 268 \\
\hline$U(127 \times 40 \times 25)$ & 233 & 234 & 220 & 358 & 394 & 324 & 312 & 333 & 289 & 435 & 506 & 375 \\
\hline$U(150 \times 40 \times 25)$ & 296 & 297 & 279 & 455 & 501 & 410 & 397 & 423 & 365 & 553 & 645 & 473 \\
\hline$U(200 \times 40 \times 25)$ & 451 & 453 & 421 & 694 & 764 & 614 & 606 & 645 & 550 & 844 & 983 & 704 \\
\hline$U(250 \times 40 \times 25) \mid$ & 630 & 633 & 582 & 969 & 1066 & 840 & 845 & 901 & 755 & 1178 & 1343 & 954 \\
\hline
\end{tabular}

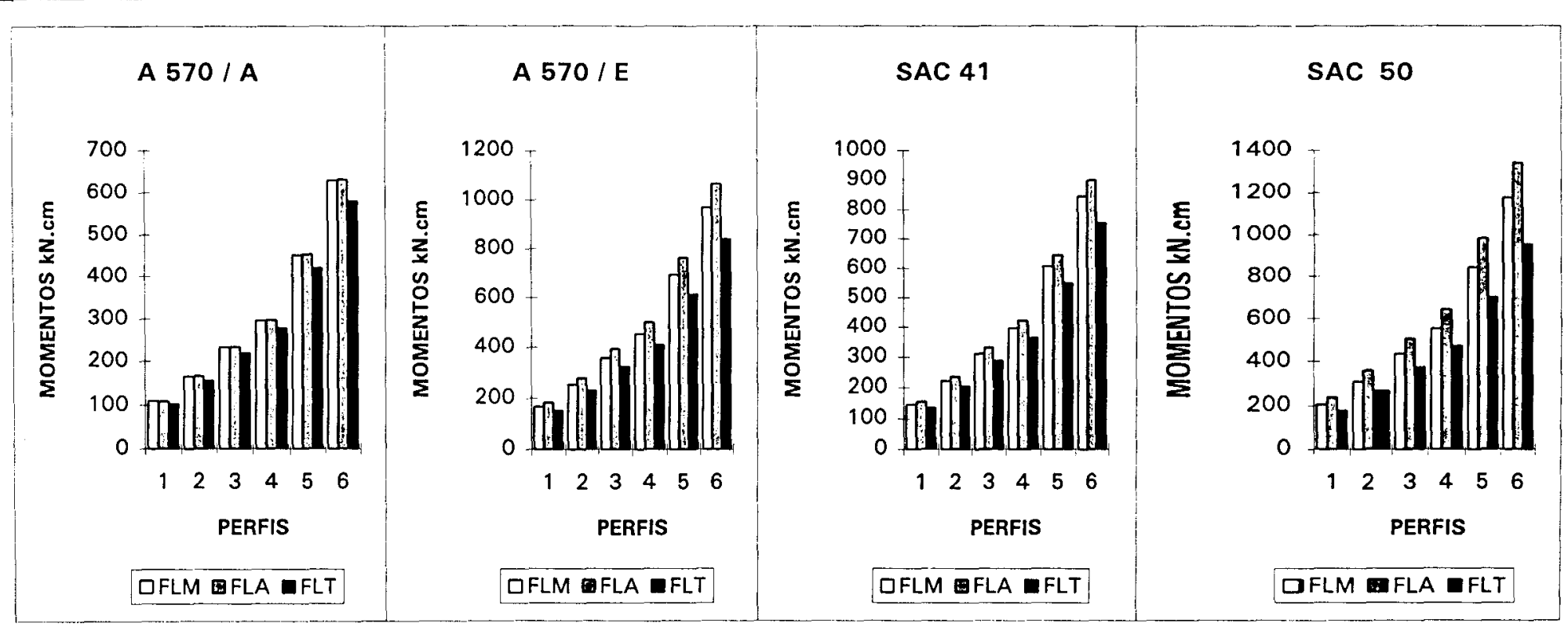


VALORES ADMISSIVEIS DOS MOMENTOS PARA FLM, FLA e FLT em KN.cm

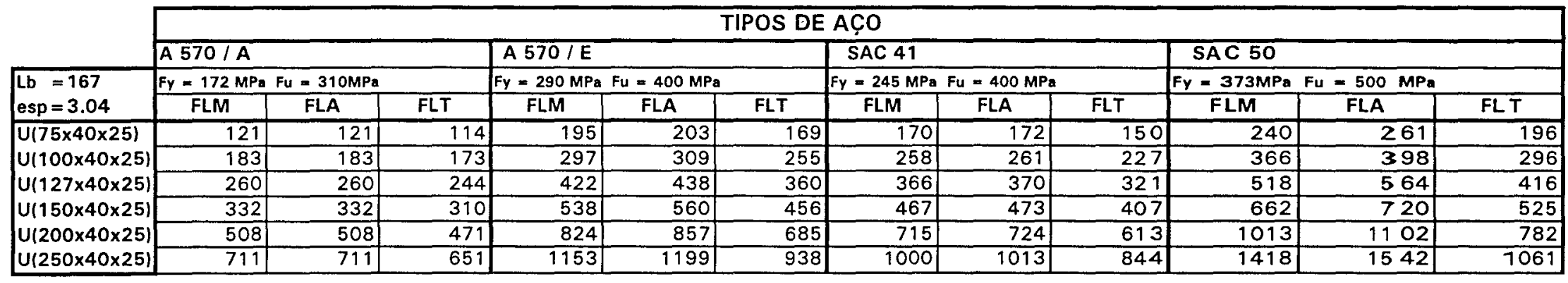

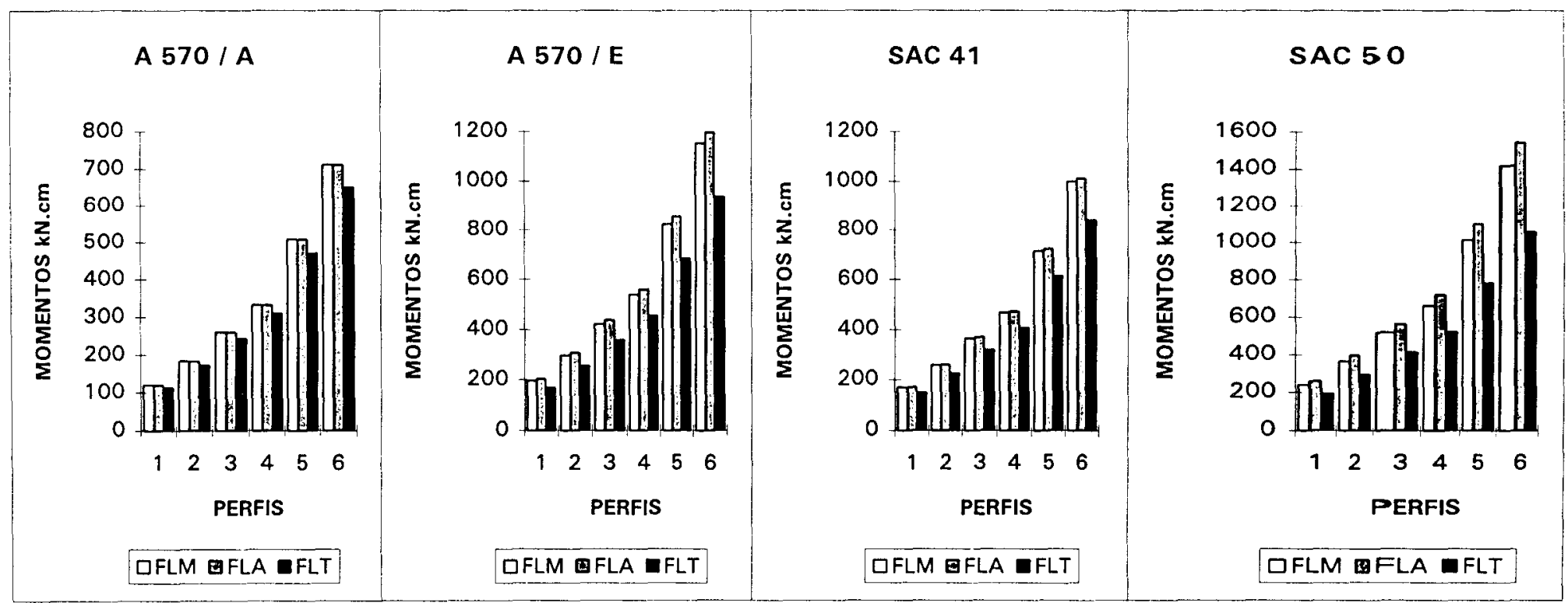


TABELA $40 \quad$ "U" ENRIJECIDO

VALORES ADMISSÍVEIS DOS MOMENTOS PARA FLM, FLA e FLT em KN.cm

\begin{tabular}{|c|c|c|c|c|c|c|c|c|c|c|c|c|}
\hline & \multicolumn{12}{|c|}{ TIPOS DE AC̣O } \\
\hline & \multicolumn{3}{|l|}{ A570/A } & \multicolumn{3}{|l|}{ A $570 / E$} & \multicolumn{3}{|l|}{ SAC 41 } & \multicolumn{3}{|l|}{ SAC 50} \\
\hline \multirow{2}{*}{$\begin{array}{l}L b=167 \\
\text { esp }=3.80\end{array}$} & \multicolumn{3}{|c|}{$F_{Y}=172 \mathrm{MPa} F U=310 \mathrm{MPa}$} & \multicolumn{3}{|c|}{$F y=290 \mathrm{MPa} F u=400 \mathrm{MPa}$} & \multicolumn{3}{|c|}{$F y=245 \mathrm{MPa} F u=400 \mathrm{MPa}$} & \multicolumn{3}{|c|}{$\mathrm{Fy}=373 \mathrm{MPa} F \mathrm{Fu}=500 \mathrm{MPa}$} \\
\hline & FLM & FLA & FLT & FLM & FLA & FLT & FLM & FLA & FLT & FLM & FLA & FLT \\
\hline$U(75 \times 40 \times 25)$ & 138 & 138 & 131 & 234 & 234 & 194 & 197 & 197 & 173 & 300 & 300 & 226 \\
\hline$|U(100 \times 40 \times 25)|$ & 215 & 215 & 202 & 362 & 362 & 298 & 306 & 306 & 265 & 465 & 465 & 345 \\
\hline$|U(127 \times 40 \times 25)|$ & 308 & 308 & 288 & 519 & 519 & 423 & 438 & 438 & 377 & 667 & 667 & 487 \\
\hline$U(150 \times 40 \times 25)$ & 395 & 395 & 368 & 666 & $6 \overline{66}$ & 538 & 563 & 563 & 481 & 857 & 857 & 617 \\
\hline $\mathrm{U}(200 \times 40 \times 25)$ & 611 & 611 & 562 & 1029 & 1029 & 812 & 870 & 870 & 730 & 1324 & 1324 & 923 \\
\hline $\mathrm{U}(250 \times 40 \times 25)$ & 859 & 859 & 781 & 1449 & 1449 & 1115 & 1224 & 1224 & 1007 & 1864 & 1864 & 1251 \\
\hline
\end{tabular}

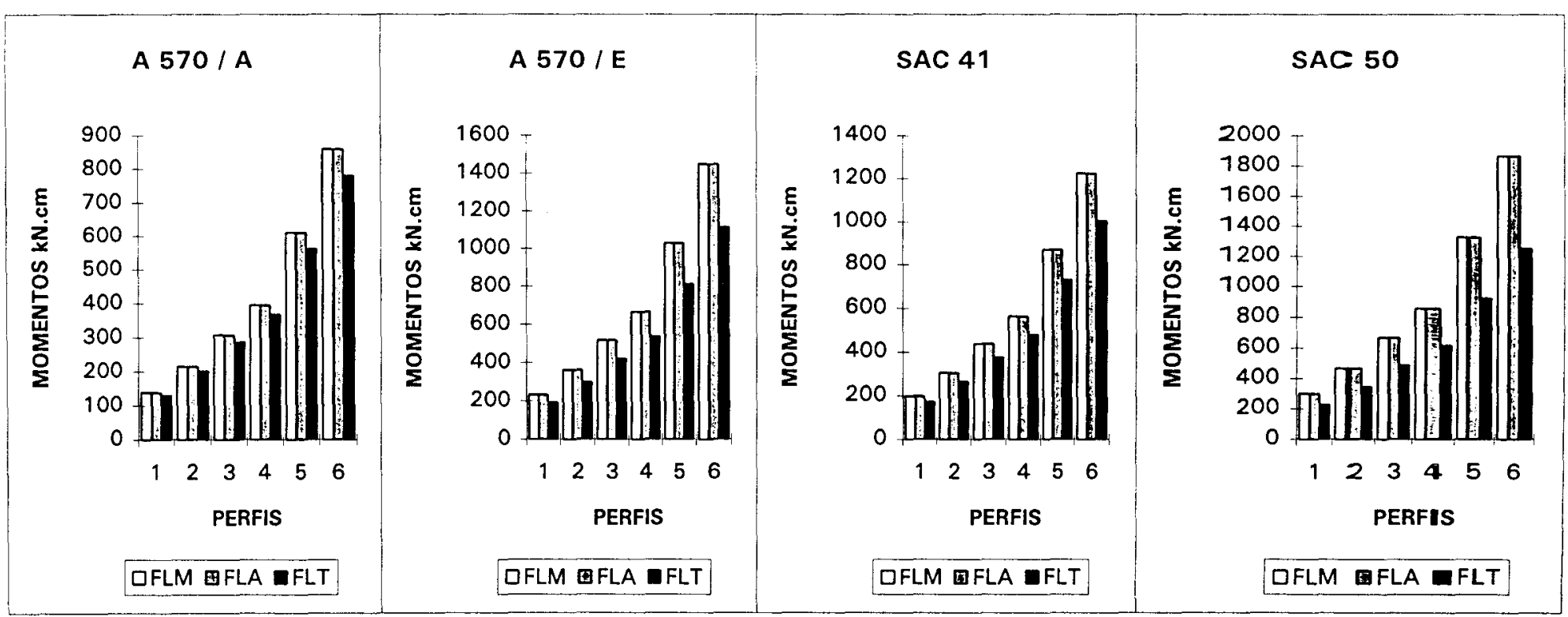


VALORES ADMISSIVEIS DOS MOMENTOS PARA FLM, FLA \& FLT em KN.cm

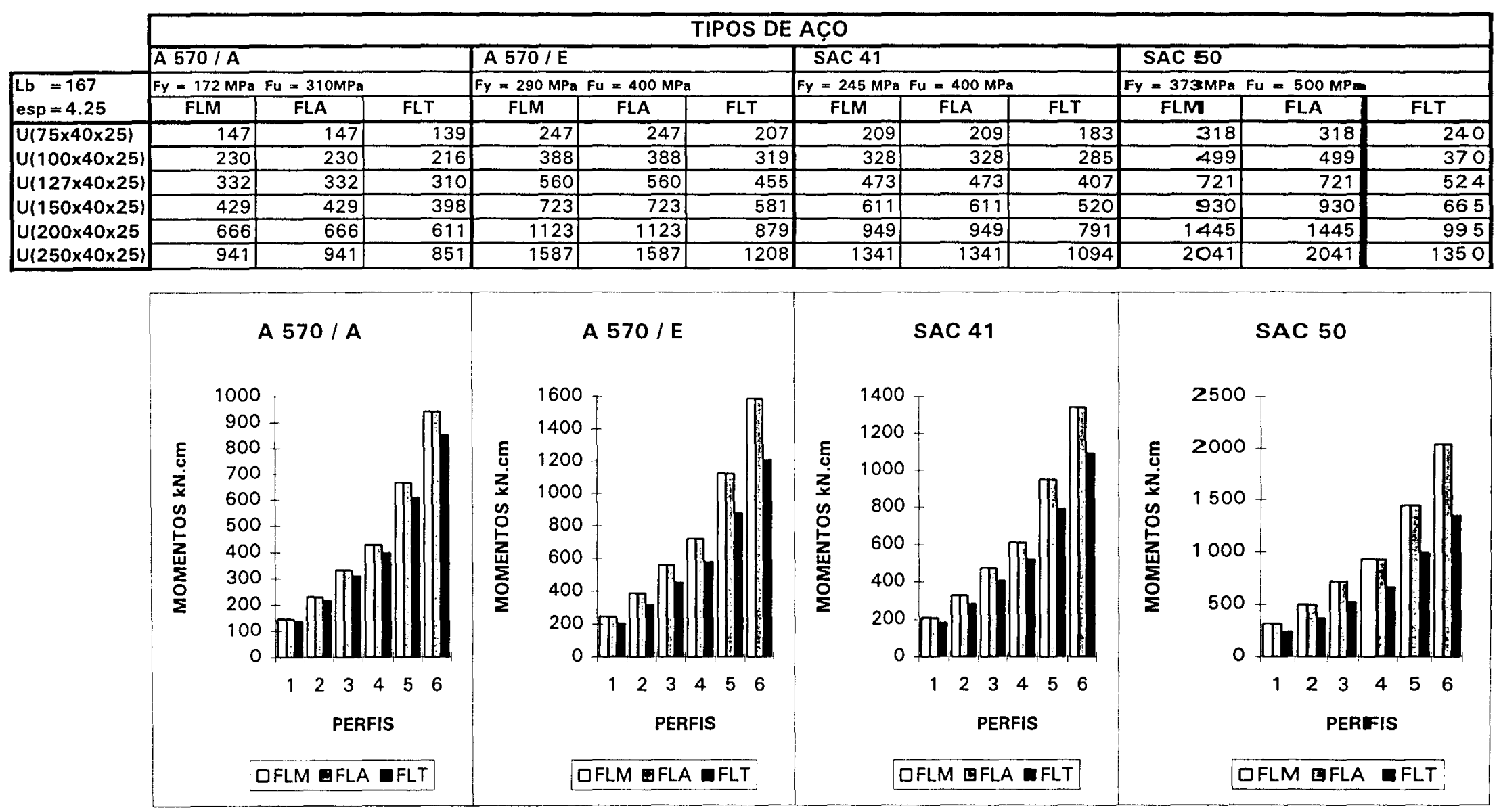


VALORES ADMISSÍVEIS DOS MOMENTOS PARA FLM, FLA E FLT em KN.cm

\begin{tabular}{|c|c|c|c|c|c|c|c|c|c|c|c|c|}
\hline & & & & & & POS DE & AÇO & & & & & \\
\hline & $\widehat{A 570 / A}$ & & & A570/E & & & SAC 41 & & & SAC 50 & & \\
\hline$L b=167$ & $F y=172 \mathrm{MPa}$ & $=310 \mathrm{MPa}$ & & $F Y=290 \mathrm{MPa}$ & $=400 \mathrm{MPt}$ & & $\mathrm{FY}=245 \mathrm{MPa}$ & $=400 \mathrm{MPa}$ & & $\mathrm{Fy}=373 \mathrm{MPa}$ & $=500 \mathrm{MPa}$ & \\
\hline esp $=4.25$ & FLM & FLA & FLT & FLM & FLA & FLT & FLM & FLA & FLT & FLM & FLA & FLT \\
\hline$U(75 \times 40 \times 25)$ & 155 & 155 & $\overline{124}$ & 261 & 261 & 155 & 220 & 220 & 148 & 335 & 335 & 156 \\
\hline$U(100 \times 40 \times 25)$ & 246 & 246 & 193 & 415 & 415 & 233 & 351 & 351 & 227 & 534 & 534 & 233 \\
\hline$|U(127 \times 40 \times 25)|$ & 359 & 359 & 276 & 606 & 606 & 323 & 512 & 512 & 318 & 779 & 779 & 323 \\
\hline$U(150 \times 40 \times 25)$ & 466 & 466 & 351 & 785 & 785 & 403 & 664 & 664 & 400 & 1010 & 1010 & 403 \\
\hline$U(200 \times 40 \times 25)$ & 729 & 729 & 531 & 1230 & 1230 & 587 & 1039 & 1039 & 587 & 1582 & 1582 & 587 \\
\hline$U(250 \times 40 \times 25)$ & 1035 & 1035 & 726 & 1746 & 1746 & 779 & 1475 & 1475 & 779 & 2245 & 2245 & 779 \\
\hline
\end{tabular}

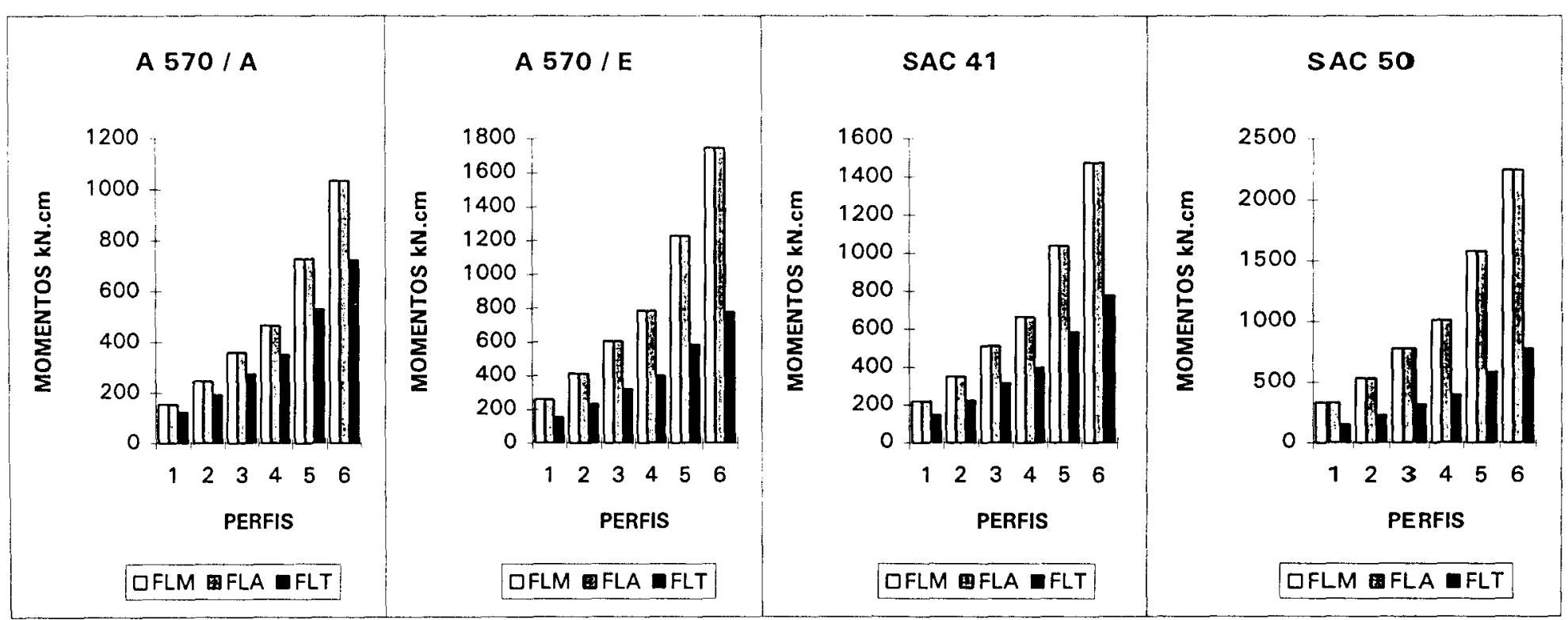


VALORES ADMISSÍVEIS DOS MOMENTOS PARA FLM, FLA \& FLT em KN.cm

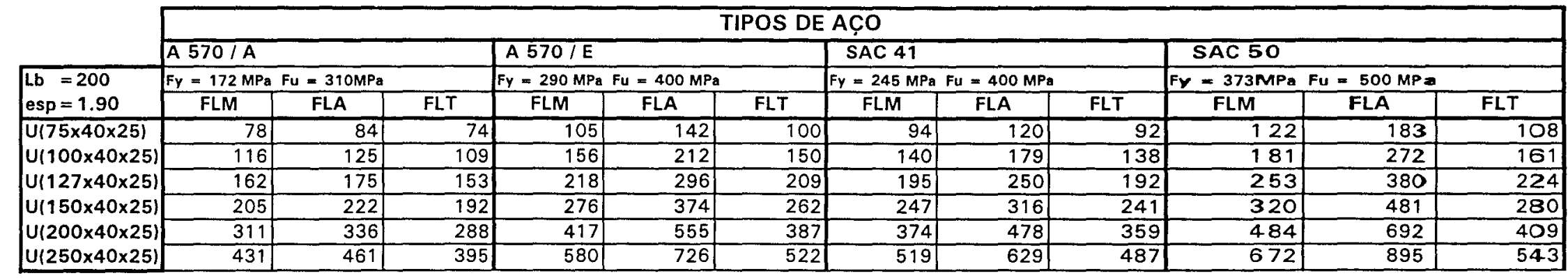

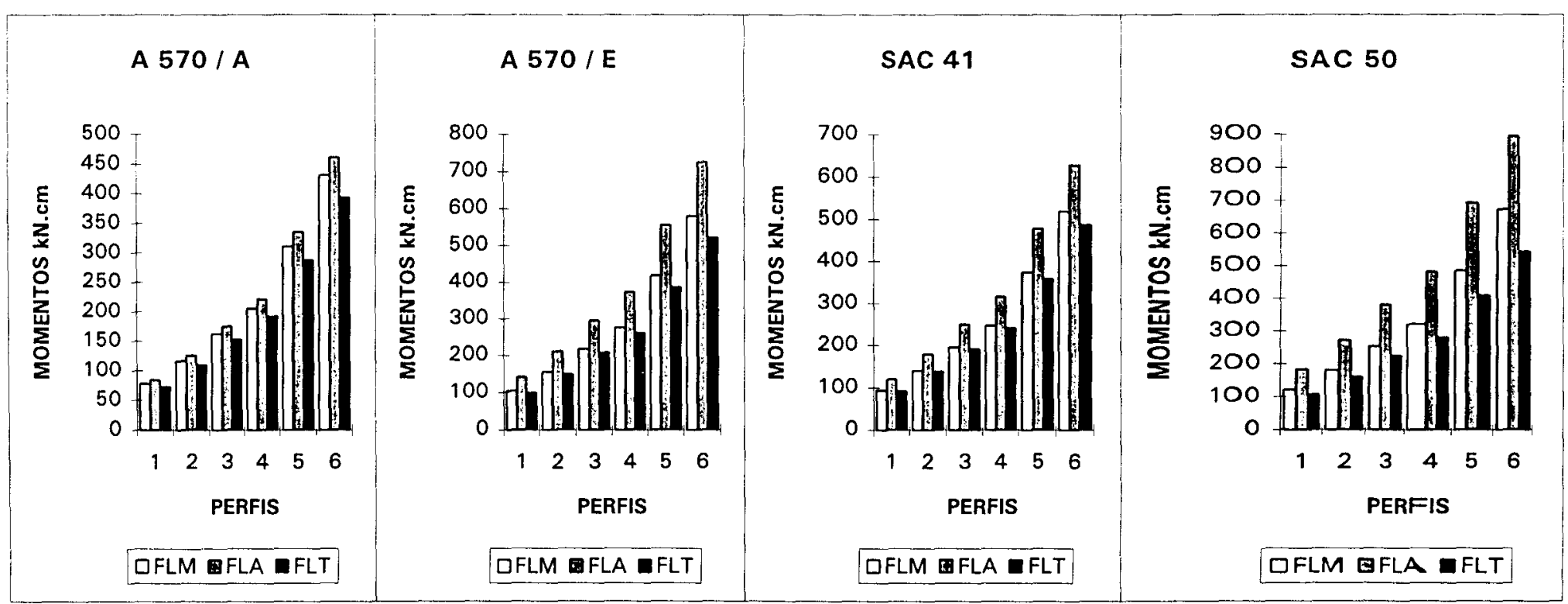


TABELA $44 \quad$ "U" ENRIJECIDO

VALORES ADMISSÍVEIS DOS MOMENTOS PARA FLM, FLA e FLT em KN.cm

\begin{tabular}{|c|c|c|c|c|c|c|c|c|c|c|c|c|}
\hline \multicolumn{13}{|c|}{ TIPOS DE AC̣O } \\
\hline & \multicolumn{3}{|l|}{ A570/A } & \multicolumn{3}{|l|}{ A570/E } & \multicolumn{3}{|l|}{ SAC 41 } & \multicolumn{3}{|l|}{ SAC 50} \\
\hline $\mathrm{Lb}=200$ & $\mathrm{Fy}=172 \mathrm{MPa}$ & $\mathrm{Fu}=310 \mathrm{MPa}$ & & $\mathrm{Fy}=290 \mathrm{MPa}$ & $=400 \mathrm{MPa}$ & & $F y=245 \mathrm{MPa}$ & $=400 \mathrm{MPa}$ & & $F Y=373 \mathrm{MPa}$ & $F_{u}=500 \mathrm{MPa}$ & \\
\hline$e s p=2.66$ & FLM & FLA & FLT & FLM & FLA & FLT & FLM & FLA & FLT & FLM & FLA & FLT \\
\hline$U(75 \times 40 \times 25)$ & 109 & 110 & 96 & 168 & 185 & 131 & 147 & 156 & 120 & 204 & 238 & 141 \\
\hline$U(100 \times 40 \times 25)$ & 165 & 166 & 144 & 254 & 279 & 197 & 221 & 236 & 181 & 308 & 359 & 211 \\
\hline$U(127 \times 40 \times 25)$ & 233 & 234 & 202 & 358 & 394 & 275 & 312 & 333 & 253 & 435 & 506 & 293 \\
\hline$U(150 \times 40 \times 25)$ & 296 & 297 & 256 & 455 & 501 & 346 & 397 & 423 & 320 & 553 & 645 & 367 \\
\hline$U(200 \times 40 \times 25)$ & 451 & 453 & 385 & 694 & 764 & 512 & 606 & 645 & 477 & 844 & 983 & 535 \\
\hline$U(250 \times 40 \times 25)$ & 630 & 633 & 529 & 969 & 1066 & 691 & 845 & 901 & 648 & 1178 & 1343 & 710 \\
\hline
\end{tabular}

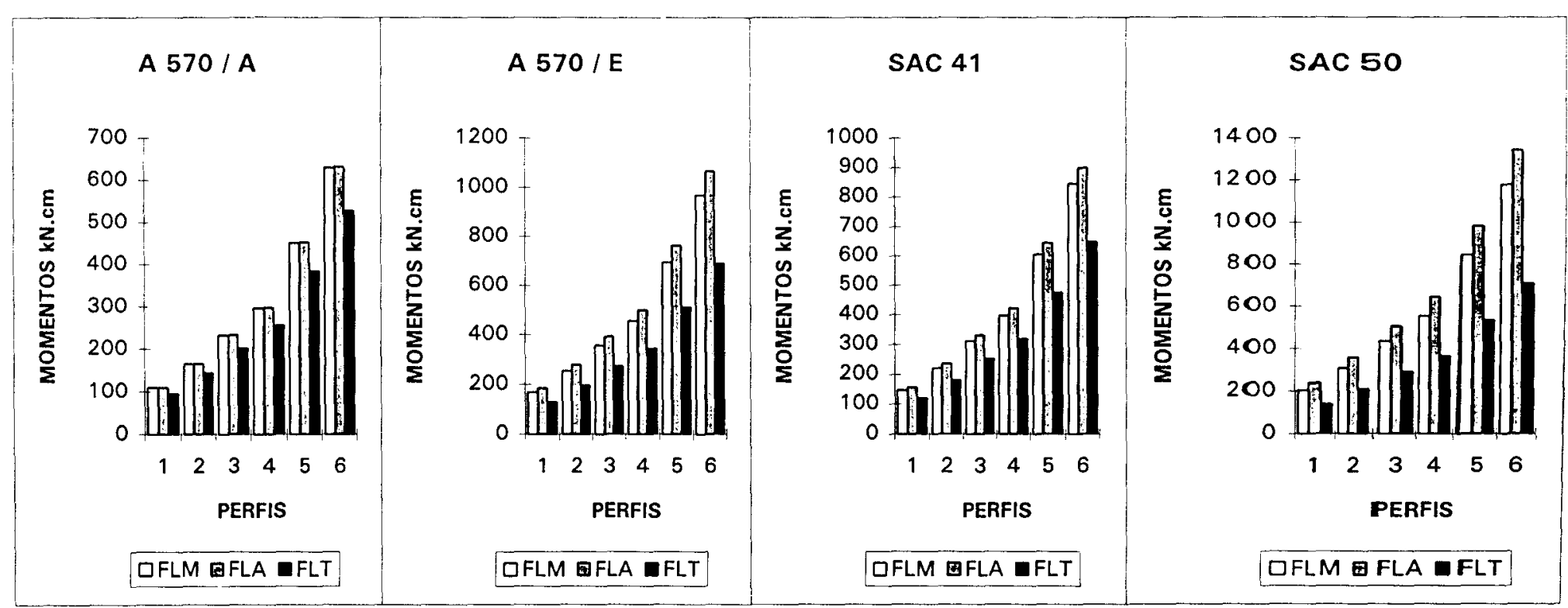


VALORES ADMISSÍVEIS DOS MOMENTOS PARA FLM, FLA E FLT em KN.cm

\begin{tabular}{|c|c|c|c|c|c|c|c|c|c|c|c|c|}
\hline \multirow{4}{*}{$\begin{array}{l}\text { Lb }=200 \\
\text { esp }=3.04\end{array}$} & \multicolumn{11}{|c|}{ TIPOS DE AC̣O } & \multirow[b]{4}{*}{ FLT } \\
\hline & \multirow{2}{*}{\multicolumn{3}{|c|}{$\begin{array}{l}\mathrm{A} 570 / \mathrm{A} \\
\mathrm{Fy}=172 \mathrm{MPa} F \mathrm{Fu}=310 \mathrm{MPa}\end{array}$}} & \multicolumn{3}{|l|}{ A570/E } & \multicolumn{3}{|l|}{ SAC 41} & \multicolumn{2}{|l|}{ SAC 50 } & \\
\hline & & & & $\mathrm{Fy}=290 \mathrm{MPa}$ & $=400 \mathrm{MPg}$ & & $F y=245 \mathrm{MPa}$ & $=400 \mathrm{MPg}$ & & $F Y=373 \mathrm{MPa}$ & $F_{u}=500 \mathrm{MPa}$ & \\
\hline & FLM & FLA & FLT & FLM & FLA & FLT & FLM & FLA & FLT & FLM & $F L A$ & \\
\hline 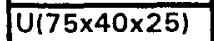 & 121 & 121 & 105 & 195 & 203 & 144 & 170 & 172 & 132 & 240 & 261 & 155 \\
\hline$U(100 \times 40 \times 25)$ & 183 & 183 & 159 & 297 & 309 & 217 & 258 & 261 & 200 & 366 & 398 & 233 \\
\hline $\mid U(127 \times 40 \times 25)$ & 260 & 260 & 225 & 422 & 438 & 304 & 366 & 370 & 281 & 518 & 564 & 324 \\
\hline$v(150 \times 40 \times 25)$ & 332 & 332 & 285 & 538 & 560 & 383 & 467 & 473 & 355 & 662 & 720 & 406 \\
\hline$|U(200 \times 40 \times 25)|$ & 508 & 508 & 430 & 824 & 857 & 569 & 715 & 724 & 531 & 1013 & 1102 & 591 \\
\hline$|\mathrm{u}(250 \times 40 \times 25)|$ & 711 & 711 & 591 & 1153 & 1199 & 766 & 1000 & 1013 & 721 & 1418 & 1542 & 784 \\
\hline
\end{tabular}

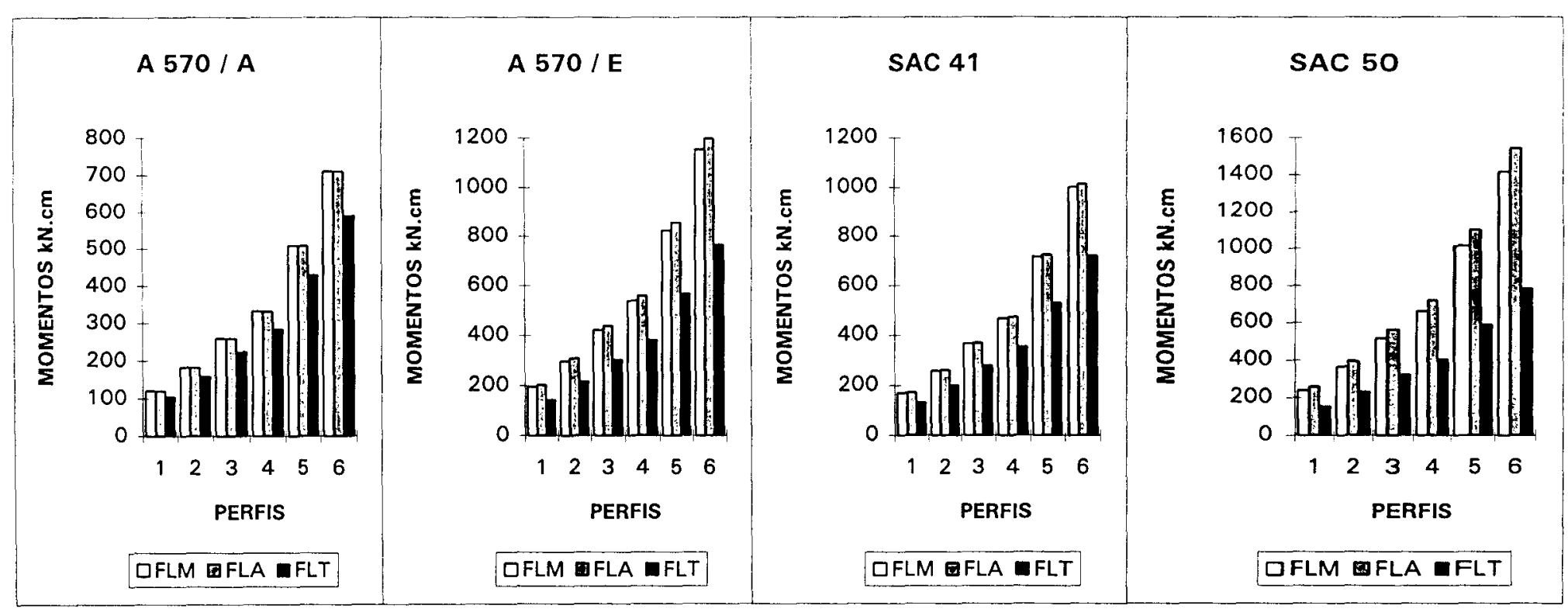


VALORES ADMISSIVEIS DOS MOMENTOS PARA FLM, FLA E FLT em KN.cm

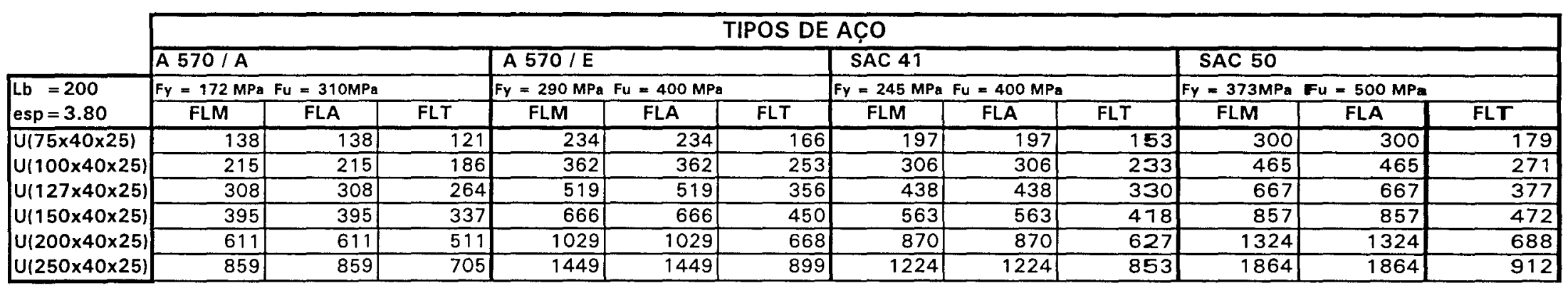

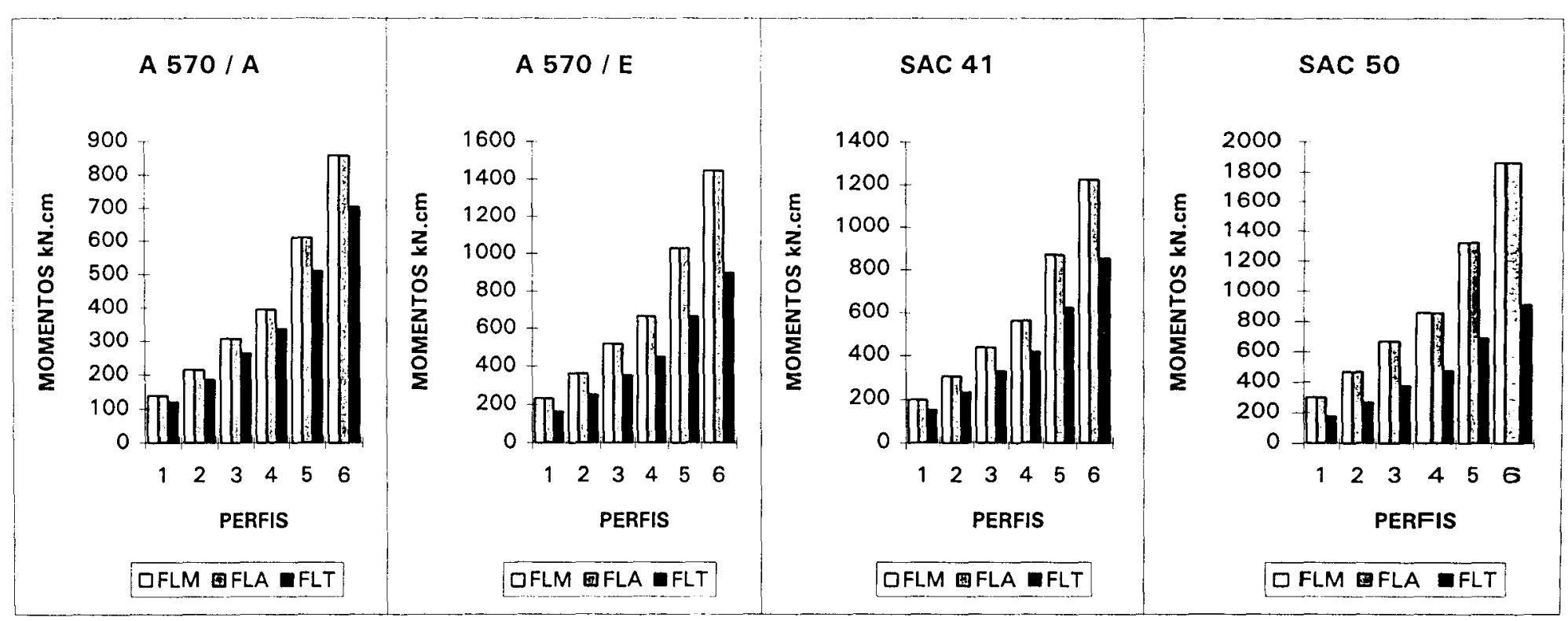


VALORES ADMISSÍVEIS DOS MOMENTOS PARA FLM, FLA \& FLT em KN.cm

\begin{tabular}{|c|c|c|c|c|c|c|c|c|c|c|c|c|}
\hline & \multicolumn{12}{|c|}{ TIPOS DE AC̣O } \\
\hline & \multicolumn{3}{|l|}{$A 570 / A$} & \multicolumn{3}{|l|}{ A 570/E } & \multicolumn{3}{|l|}{ SAC 41 } & \multicolumn{3}{|l|}{ SAC 50 } \\
\hline \multirow{2}{*}{$\begin{array}{l}\mathrm{Lb}=200 \\
\mathrm{esp}=4.25\end{array}$} & $F y=172 \mathrm{MPa}$ & $u=310 \mathrm{MPa}$ & & $F y=290 \mathrm{MPa}$ & $=400 \mathrm{MPa}$ & & $F y=245 \mathrm{MPa}$ & $=400 \mathrm{MPa}$ & & $F y=373 \mathrm{MPa}$ & $500 \mathrm{MPa}$ & \\
\hline & FLM & FLA & FLT & FLM & FLA & FLT & FLM & FLA & FLT & FLM & FLA & FLT \\
\hline$U(75 \times 40 \times 25)$ & 147 & 147 & 129 & 247 & 247 & 177 & 209 & 209 & 162 & 318 & 318 & 191 \\
\hline$|u(100 \times 40 \times 25)|$ & 230 & 230 & 199 & 388 & 388 & 271 & 328 & 328 & 250 & 499 & 499 & 290 \\
\hline$|U(127 \times 40 \times 25)|$ & 332 & 332 & 285 & 560 & 560 & 383 & 473 & 473 & 355 & 721 & 721 & $\overline{404}$ \\
\hline $\mid U(150 \times 40 \times 25)$ & 429 & 429 & 364 & 723 & 723 & 484 & 611 & 611 & 451 & 930 & 930 & 505 \\
\hline$U(200 \times 40 \times 25)$ & 666 & 666 & 554 & 1123 & 1123 & 719 & 949 & 949 & 677 & 1445 & 1445 & 736 \\
\hline$U(250 \times 40 \times 25)$ & 941 & 941 & 766 & 1587 & 1587 & 967 & 1341 & 1341 & 922 & 2041 & 2041 & $\overline{976}$ \\
\hline
\end{tabular}

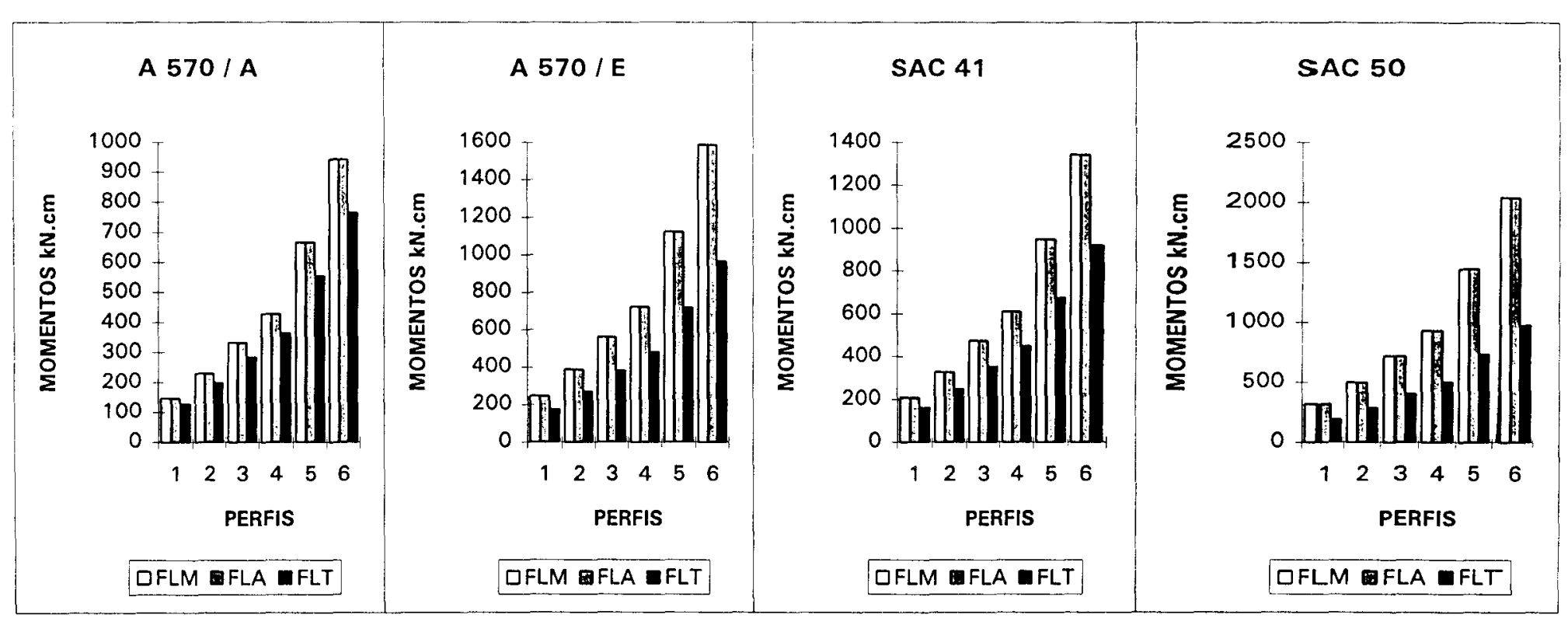


VALORES ADMISSÍVEIS DOS MOMENTOS PARA FLM, FLA \& FLT em KN.cm

\begin{tabular}{|c|c|c|c|c|c|c|c|c|c|c|c|c|}
\hline \multicolumn{13}{|c|}{ TIPOS DE AC̣O } \\
\hline & \multirow{2}{*}{\multicolumn{3}{|c|}{$F_{y}=172 \mathrm{MPa} F u=310 \mathrm{MPa}_{\mathrm{a}}$}} & \multirow{2}{*}{\multicolumn{3}{|c|}{$\begin{array}{l}\text { A } 570 / \mathrm{E} \\
\mathrm{Fy}=290 \mathrm{MPa} \mathrm{Fu}=400 \mathrm{MPa}\end{array}$}} & \multirow{2}{*}{\multicolumn{3}{|c|}{$\begin{array}{l}\text { SAC } 41 \\
F y=245 \mathrm{MPa} F u=400 \mathrm{MPa}\end{array}$}} & \multicolumn{3}{|l|}{ SAC 50} \\
\hline \multirow{2}{*}{$\begin{array}{l}\mathrm{Lb}=200 \\
\mathrm{esp}=4.8\end{array}$} & & & & & & & & & & $F y=373 \mathrm{MPa}$ & $F u=500 \mathrm{MPa}$ & \\
\hline & FLM & FLA & FLT & FLM & FLA & FLT & FLM & FLA & FLT & FLM & FLA & FLT \\
\hline$U(75 \times 40 \times 25)$ & 155 & 155 & 104 & 261 & 261 & 108 & 220 & 220 & 108 & 335 & 335 & 108 \\
\hline$U(100 \times 40 \times 25)$ & 246 & 246 & 158 & 415 & 415 & 162 & 351 & 351 & 162 & 534 & 534 & 162 \\
\hline$|U(127 \times 40 \times 25)|$ & 359 & 359 & 222 & 606 & 606 & 225 & 512 & 512 & 225 & 779 & 779 & 225 \\
\hline $\mid v(150 \times 40 \times 25)$ & 466 & 466 & 279 & 785 & 785 & 281 & 664 & 664 & 281 & 1010 & 1010 & 281 \\
\hline$|U(200 \times 40 \times 25)|$ & 729 & 729 & 409 & 1230 & 1230 & 409 & 1039 & 1039 & 409 & 1582 & 1582 & 409 \\
\hline$|U(250 \times 40 \times 25)|$ & 1035 & 1035 & 543 & 1746 & 1746 & 543 & 1475 & 1475 & 543 & 2245 & 2245 & 543 \\
\hline
\end{tabular}

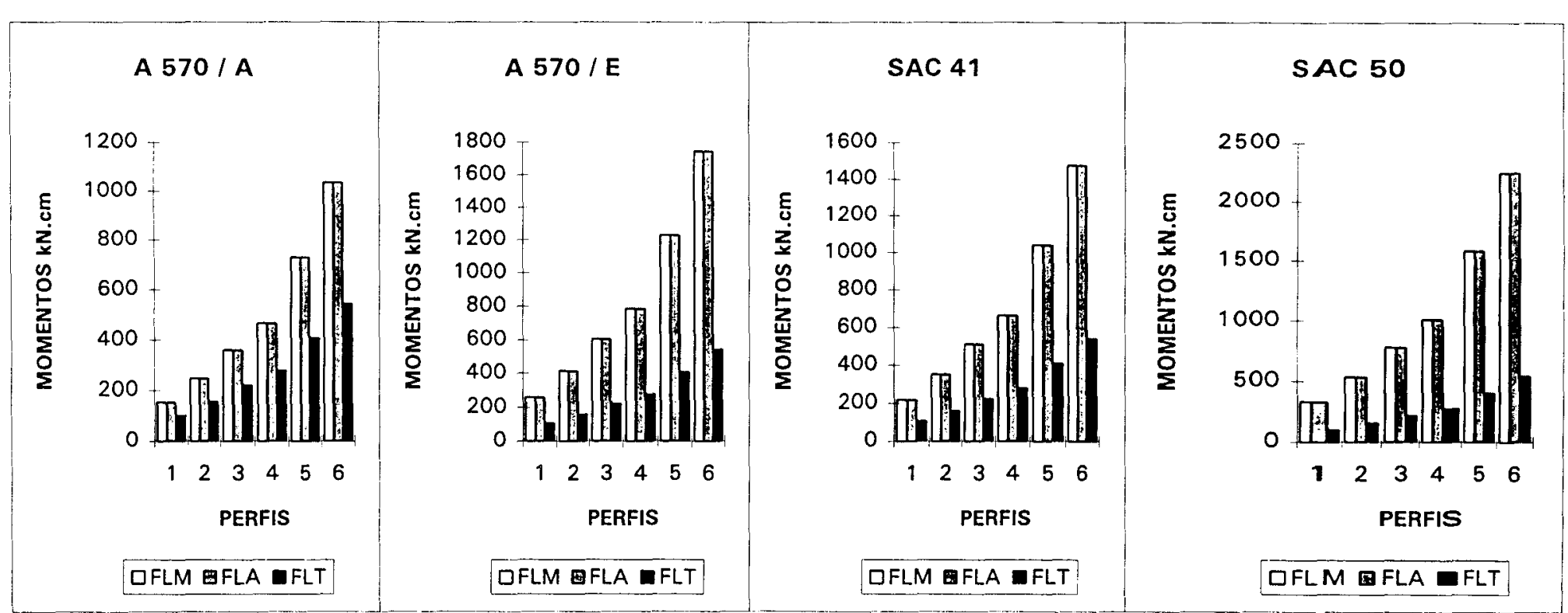


VALORES ADMISSÍVEIS DOS MOMENTOS PARA FLM, FLA e FLT em KN.cm

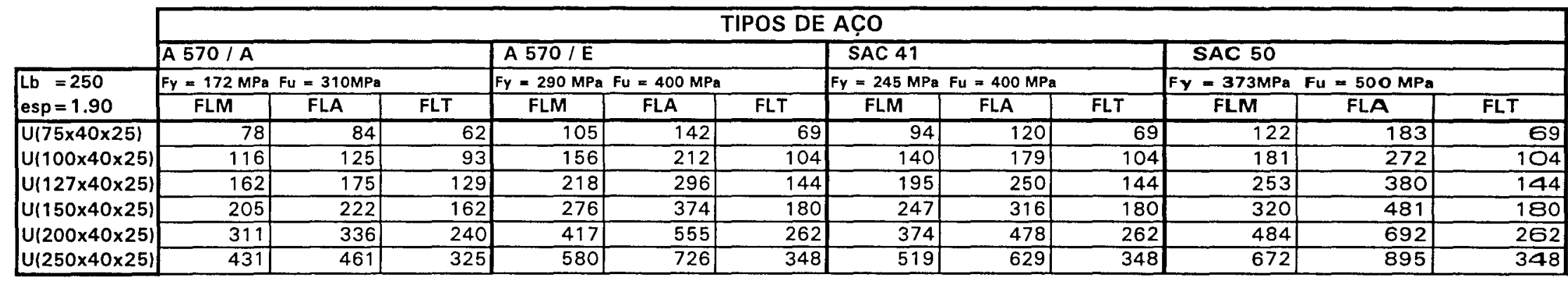

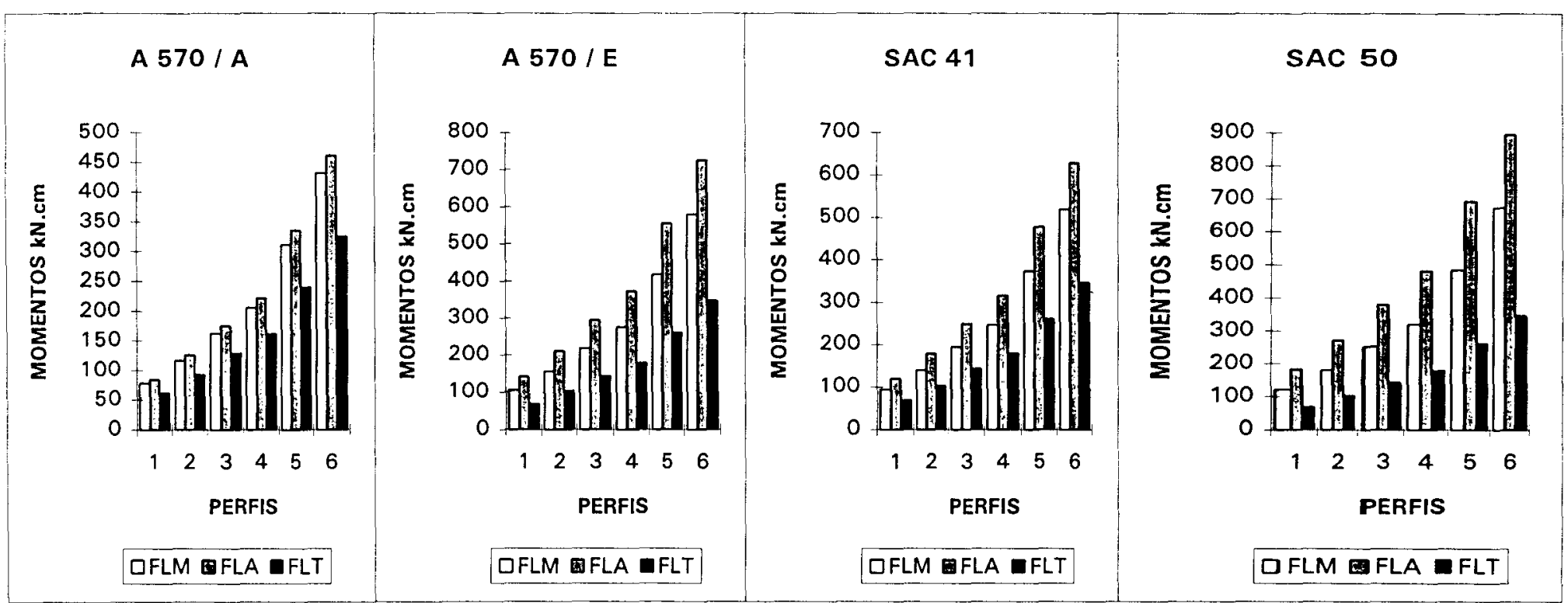


VALORES ADMISSIVEIS DOS MOMENTOS PARA FLM, FLA e FLT em KN.cm

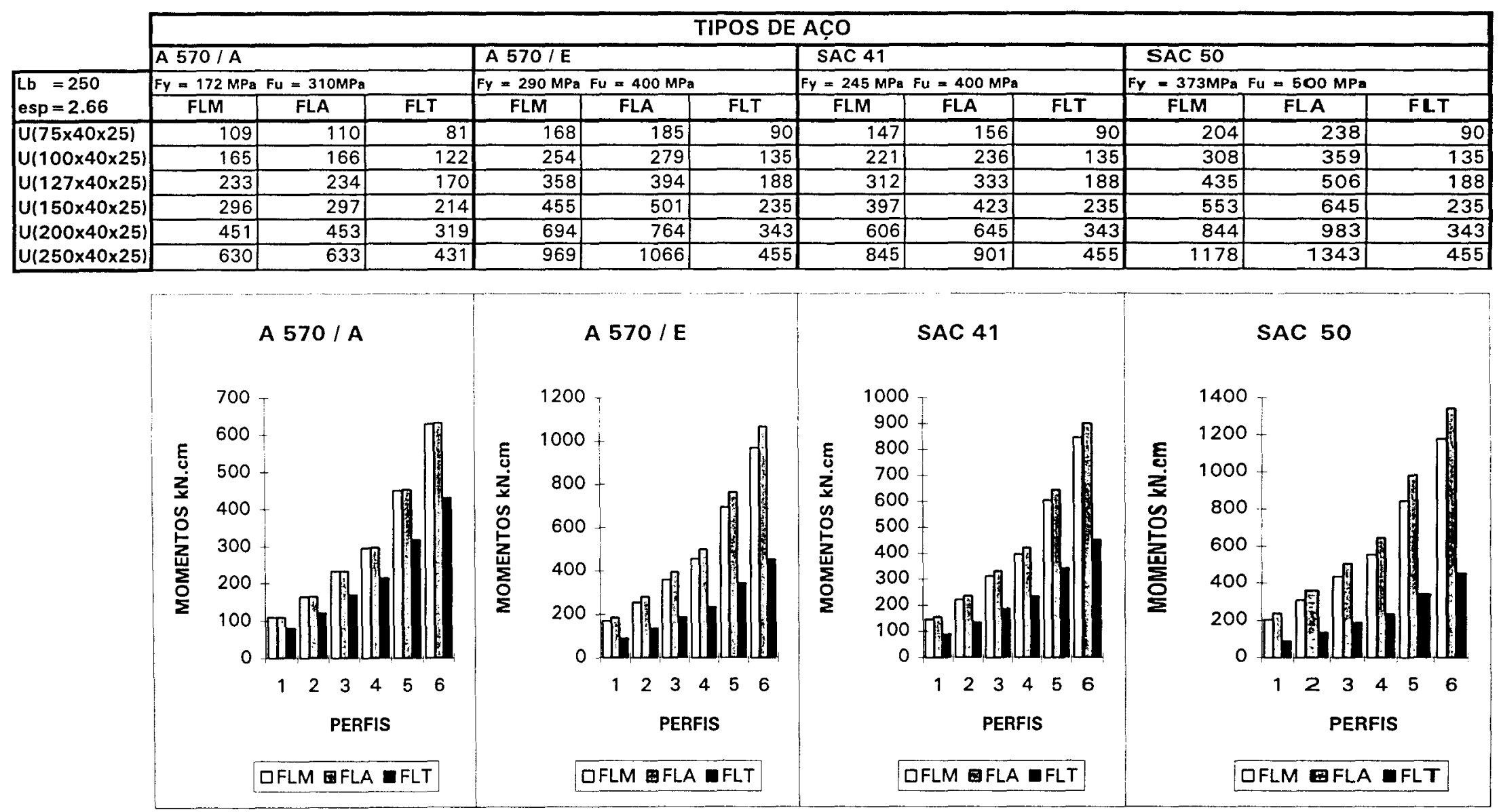


VALORES ADMISSIVEIS DOS MOMENTOS PARA FLM, FLA E FLT em KN.cm

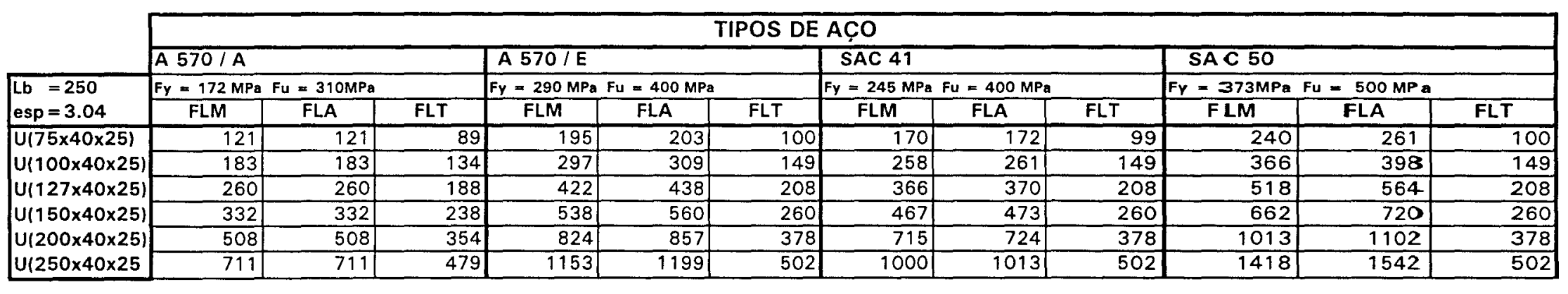

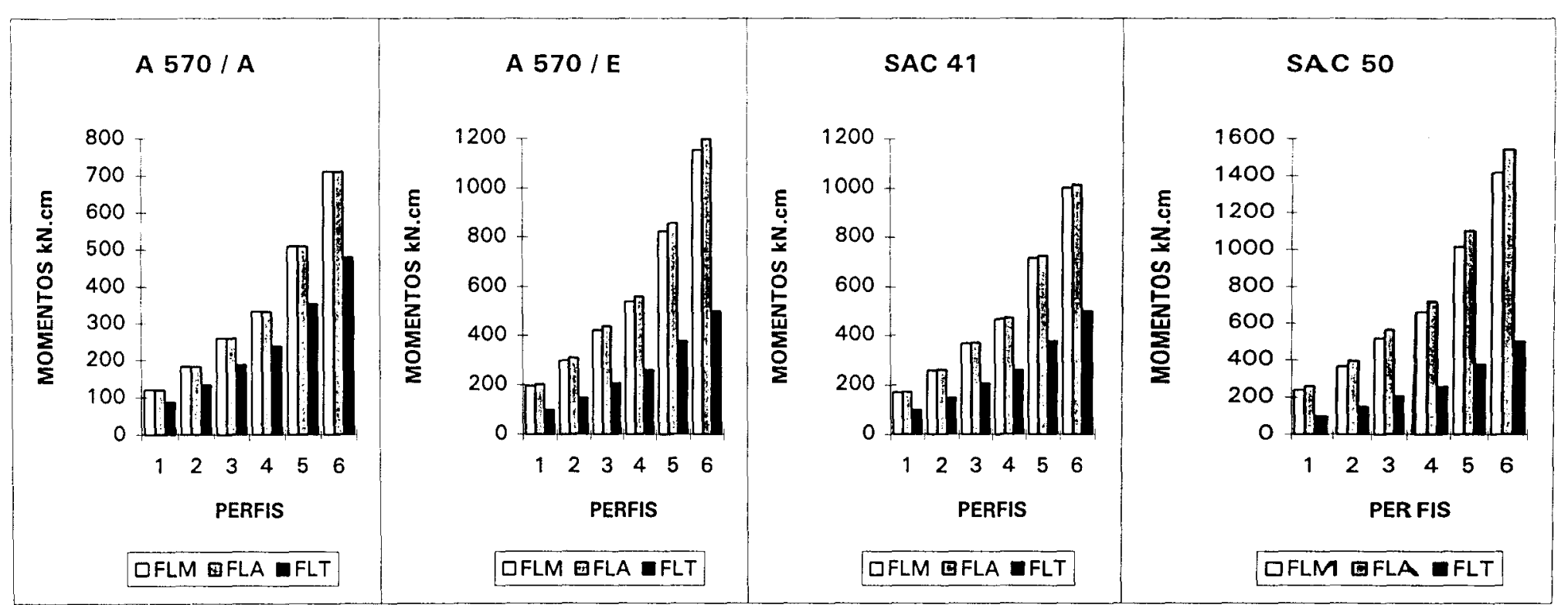


VALORES ADMISSIVEIS DOS MOMENTOS PARA FLM, FLA e FLT em KN.cm

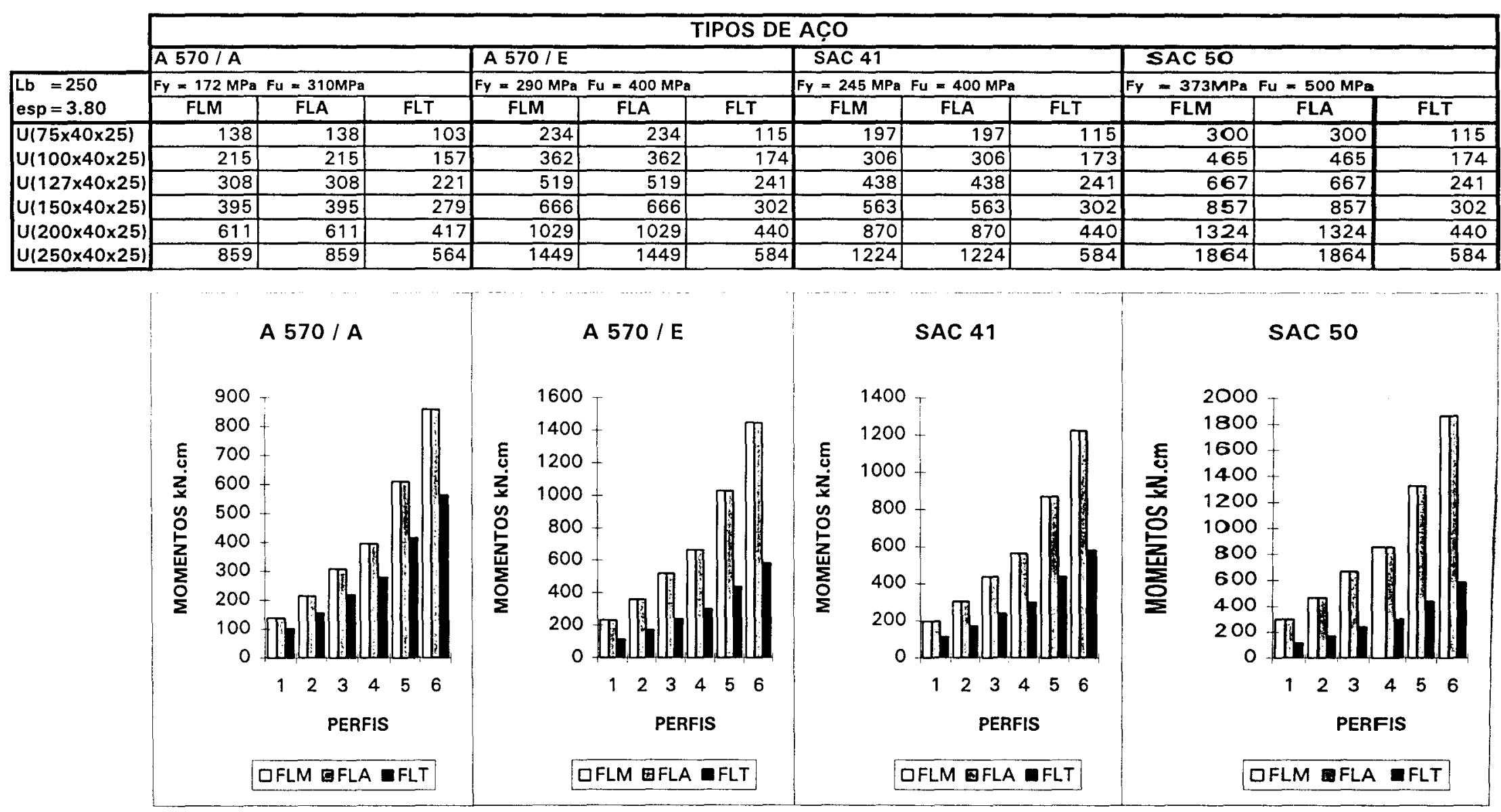


VALORES ADMISSIVEIS DOS MOMENTOS PARA FLM, FLA E FLT em KN.cm

\begin{tabular}{|c|c|c|c|c|c|c|c|c|c|c|c|c|}
\hline & \multicolumn{12}{|c|}{ TIPOS DE AC̣O } \\
\hline & \multicolumn{3}{|l|}{ A 570/A } & \multicolumn{3}{|l|}{ A $570 / E$} & \multicolumn{3}{|l|}{ SAC 41} & \multicolumn{3}{|l|}{ SAC 50} \\
\hline $\mathrm{Lb}=250$ & $F y=172 \mathrm{MPa}$ & $=310 \mathrm{MPa}$ & & $F_{y}=290 \mathrm{MPa}$ & $=400 \mathrm{MP}$ & & $\mathrm{Fy}=245 \mathrm{MPa}$ & $=400 \mathrm{MPg}$ & & $F Y=373 \mathrm{MPE}$ & $F u=500 \mathrm{MPa}$ & \\
\hline esp $=4.25$ & FLM & FLA & FLT & FLM & FLA & FLT & FLM & FLA & FLT & FLM & FLA & FLT \\
\hline$U(75 \times 40 \times 25)$ & 147 & 147 & 109 & 247 & 247 & 123 & 209 & 209 & 123 & 318 & 318 & 123 \\
\hline$|U(100 \times 40 \times 25)|$ & 230 & 230 & 168 & 388 & 388 & 186 & 328 & 328 & 186 & 499 & 499 & 186 \\
\hline$U(127 \times 40 \times 25)$ & 332 & 332 & 237 & 560 & 560 & 258 & 473 & 473 & 258 & 721 & 721 & 258 \\
\hline$U(150 \times 40 \times 25)$ & 429 & 429 & 301 & 723 & 723 & 323 & 611 & 611 & 323 & 930 & 930 & 323 \\
\hline$|\mathrm{U}(200 \times 40 \times 25)|$ & 666 & 666 & 450 & 1123 & 1123 & 471 & 949 & 949 & 471 & 1445 & 1445 & 471 \\
\hline$U(250 \times 40 \times 25)]$ & 941 & 941 & 608 & 1587 & 1587 & 625 & 1341 & 1341 & 625 & 2041 & 2041 & 625 \\
\hline
\end{tabular}

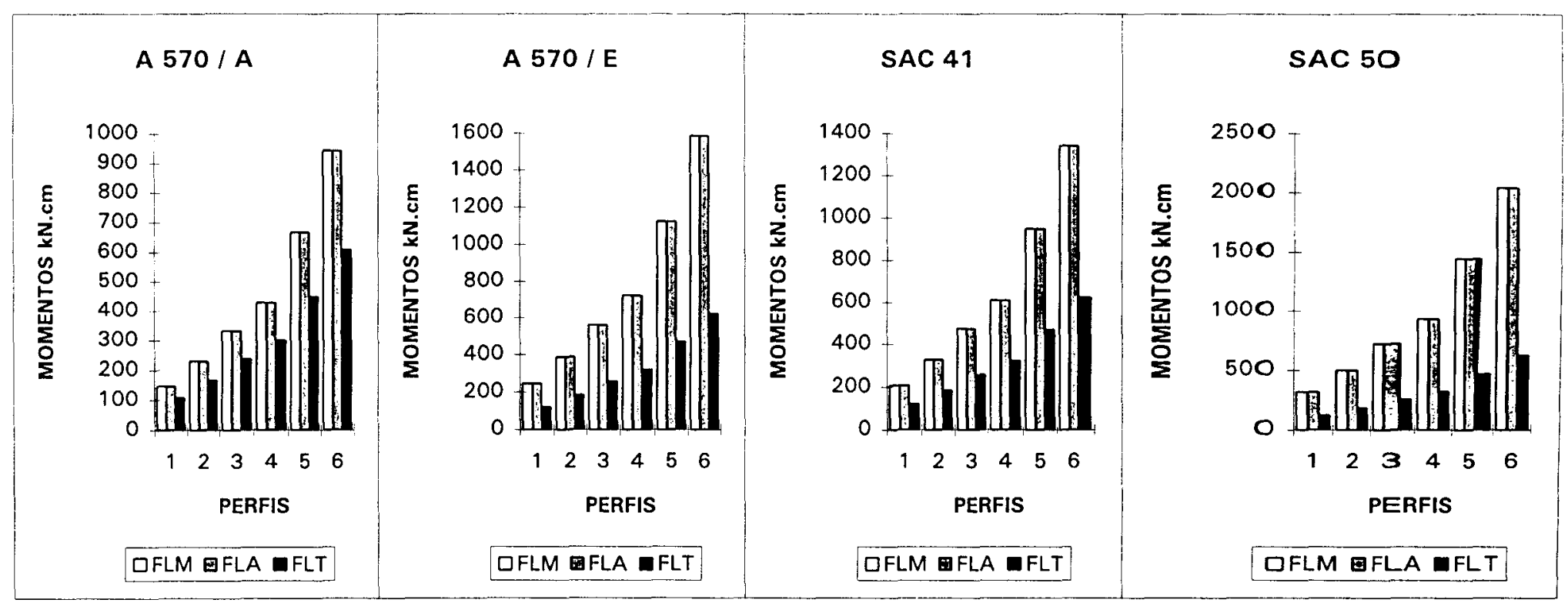


TABELA $54 \quad$ "U" ENRIJECIDO

VALORES ADMISSÍVEIS DOS MOMENTOS PARA FLM, FLA \& FLT em KN.cm

\begin{tabular}{|c|c|c|c|c|c|c|c|c|c|c|c|c|}
\hline & \multicolumn{12}{|c|}{ TIPOS DE AC̣O } \\
\hline & \multirow{2}{*}{\multicolumn{3}{|c|}{$\begin{array}{l}\mathrm{A} \\
\mathrm{Fy}=172 \mathrm{MPa} \quad \mathrm{Fu}=310 \mathrm{MPa}\end{array}$}} & \multicolumn{3}{|l|}{ A570/E } & \multicolumn{3}{|l|}{ SAC 41 } & \multicolumn{3}{|l|}{ SAC 50 } \\
\hline \multirow{2}{*}{$\begin{array}{l}\mathrm{Lb}=250 \\
\mathrm{esp}=4.80\end{array}$} & & & & $F y=290 \mathrm{MPa}$ & $=400 \mathrm{MPz}$ & & $F y=245 \mathrm{MPa}$ & $=400 \mathrm{MPg}$ & & $F y=373 \mathrm{MPa}$ & $\mathrm{Fu}=500 \mathrm{MPa}$ & \\
\hline & FLM & FLA & FLT & FLM & FLA & FLT & FLM & FLA & FLT & FLM & FLA & FLT \\
\hline 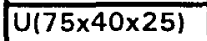 & 155 & 155 & 69 & 261 & 261 & 69 & 220 & 220 & 69 & 335 & 335 & 69 \\
\hline $\mid u(100 \times 40 \times 25)$ & 246 & 246 & 104 & 415 & 415 & 104 & 351 & 351 & 104 & 534 & 534 & 104 \\
\hline$U(127 \times 40 \times 25)$ & 359 & 359 & 144 & 606 & 606 & 144 & 512 & 512 & 144 & 779 & 779 & 144 \\
\hline $\mid U(150 \times 40 \times 25)$ & 466 & 466 & 180 & 785 & 785 & 180 & 664 & 664 & 180 & 1010 & 1010 & 180 \\
\hline $\mathrm{U}(200 \times 40 \times 25)$ & 729 & 729 & 262 & 1230 & 1230 & 262 & 1039 & 1039 & 262 & 1582 & 1582 & 262 \\
\hline$U(250 \times 40 \times 25)$ & 1035 & 1035 & 348 & 1746 & 1746 & 348 & 1475 & 1475 & 348 & 2245 & 2245 & 348 \\
\hline
\end{tabular}

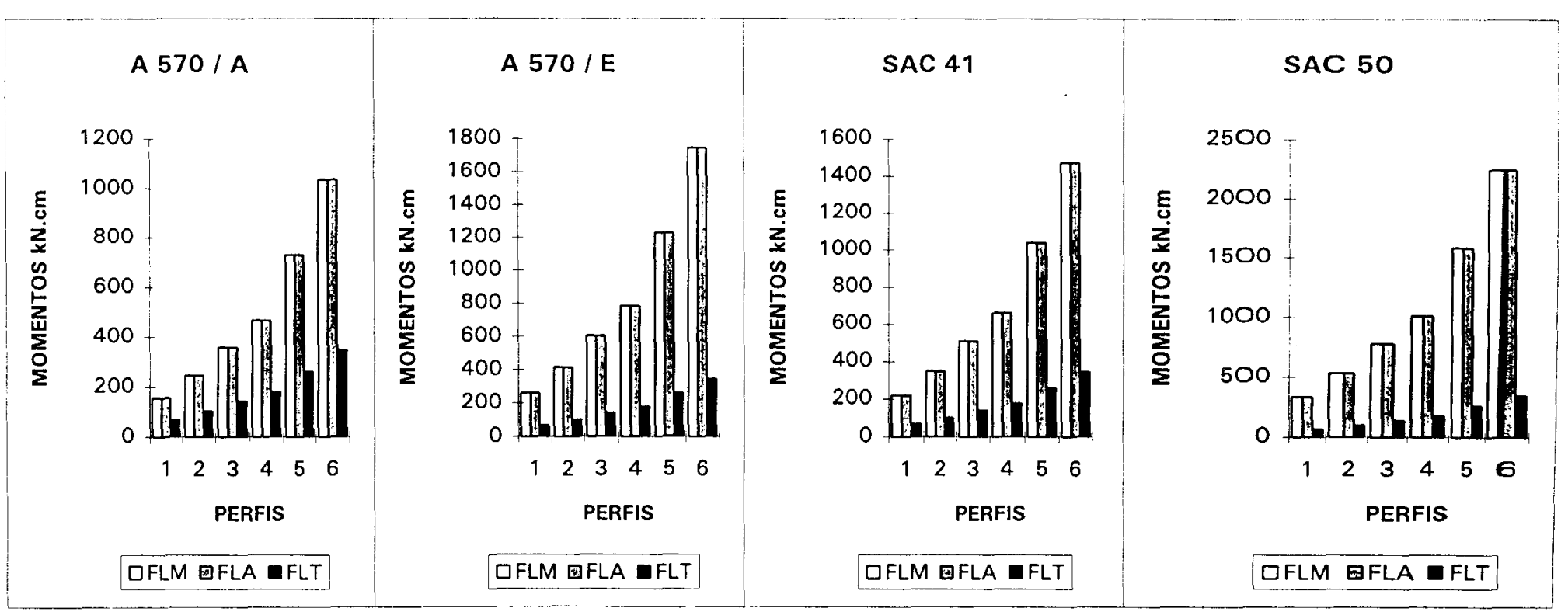


VALORES ADMISSIVEIS DOS MOMENTOS PARA FLM, FLA \& FLT em KN.cm

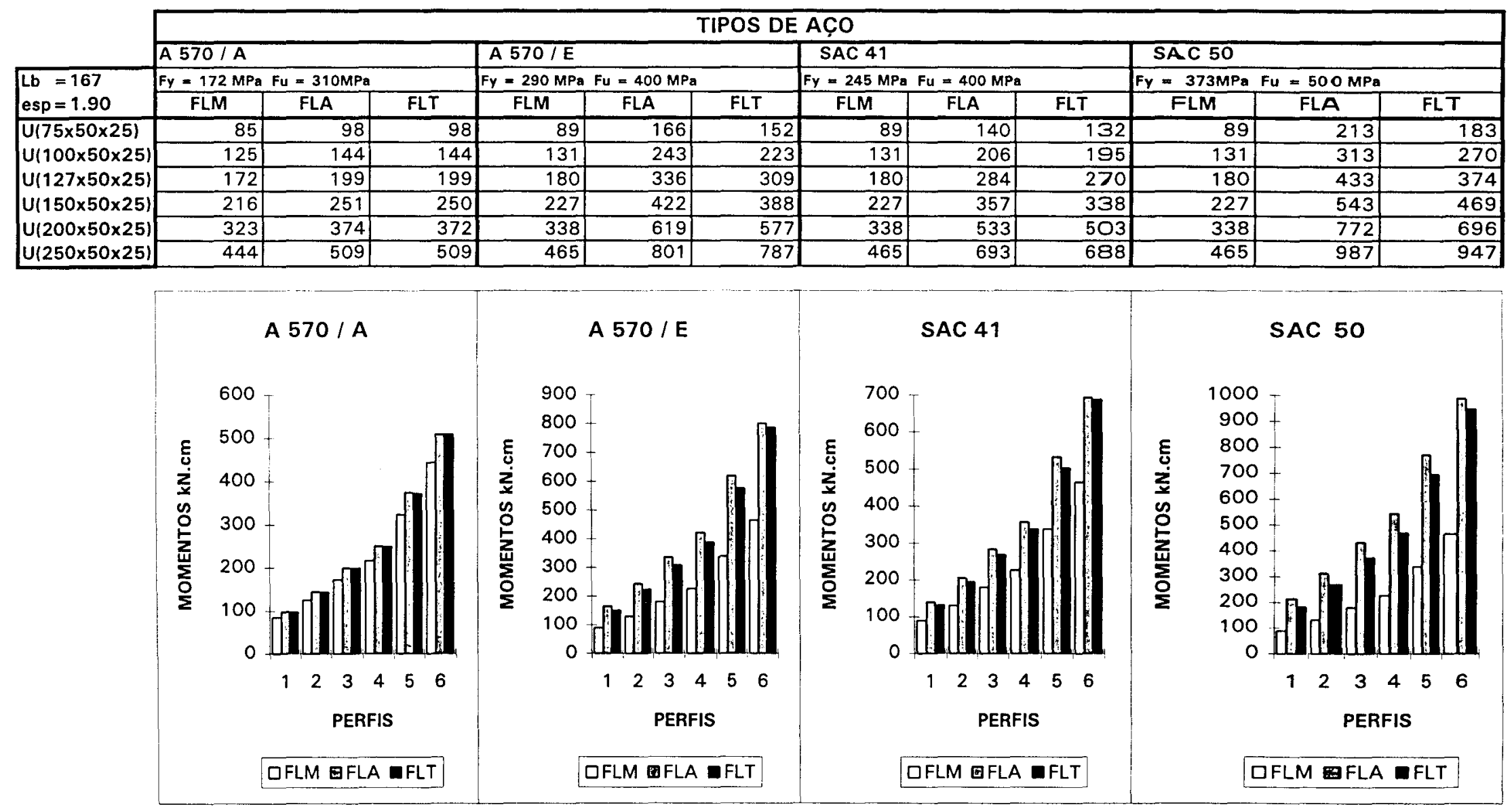


VALORES ADMISSIVEIS DOS MOMENTOS PARA FLM, FLA E FLT em KN.cm

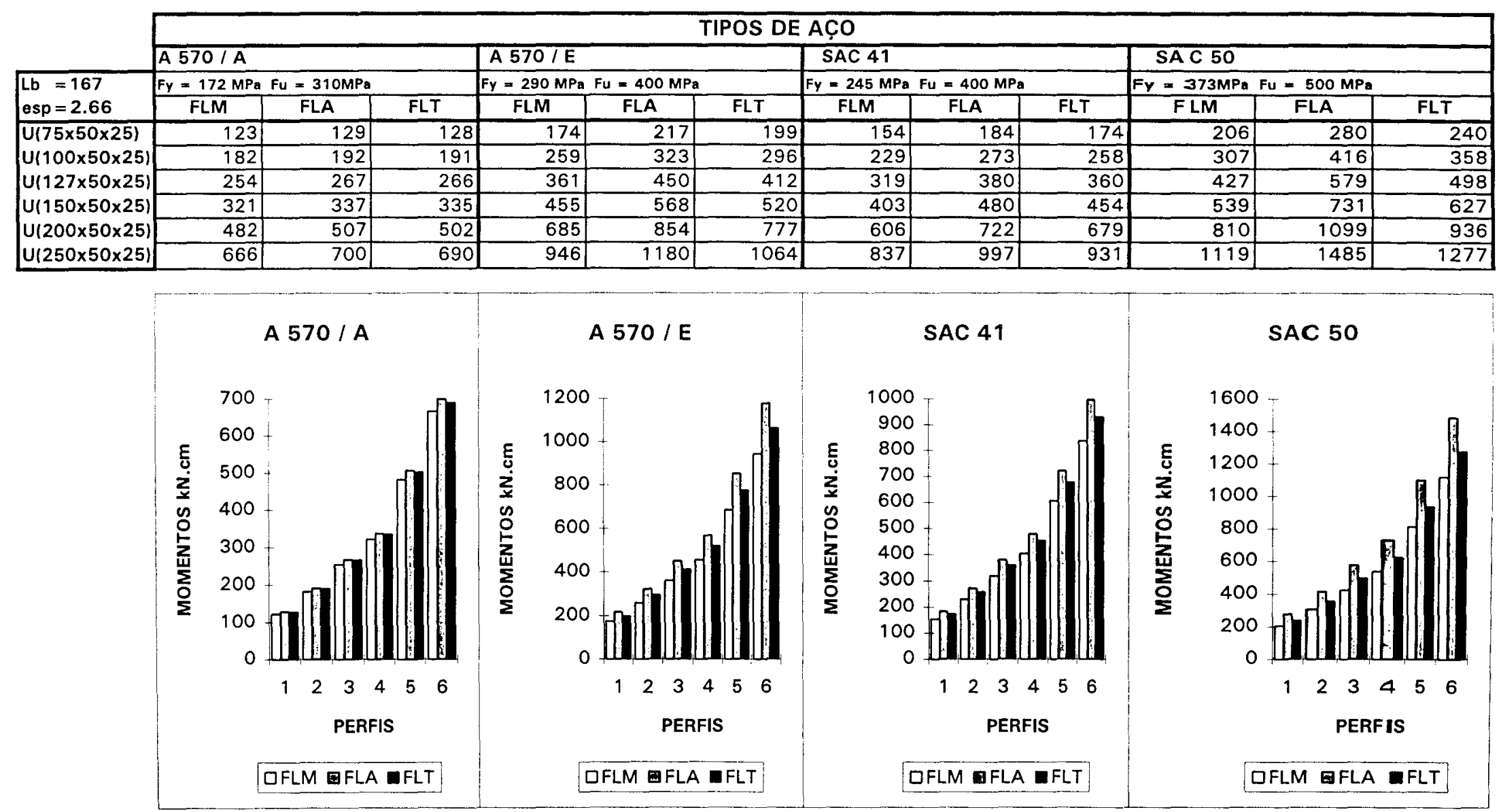


VALORES ADMISSÍVEIS DOS MOMENTOS PARA FLM, FLA \& FLT em KN.cm

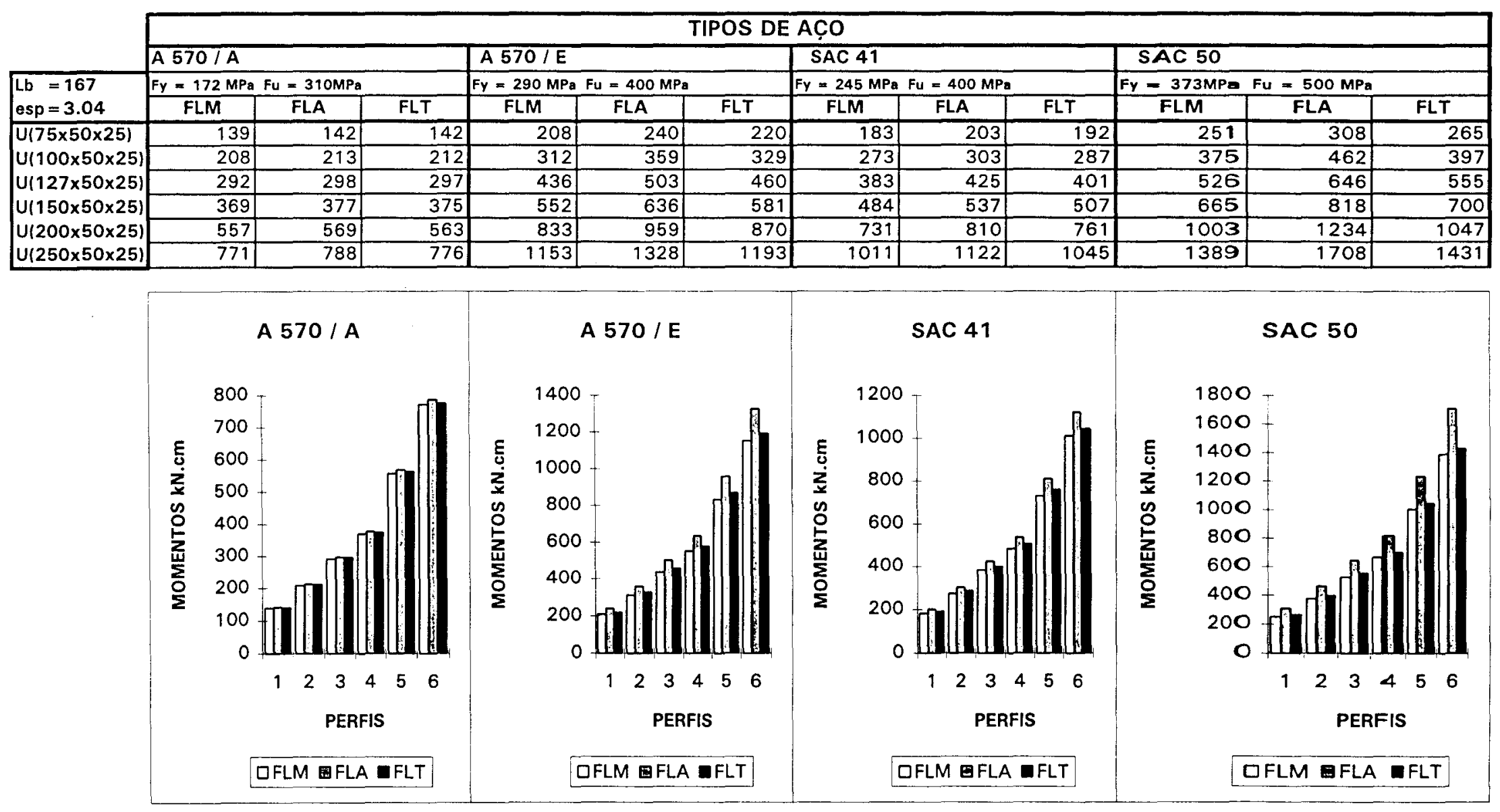


VALORES ADMISSÍVEIS DOS MOMENTOS PARA FLM, FLA e FLT em KN.cm

\begin{tabular}{|c|c|c|c|c|c|c|c|c|c|c|c|c|}
\hline & \multicolumn{12}{|c|}{ TIPOS DE AC̣O } \\
\hline & & & & \multirow{2}{*}{\multicolumn{3}{|c|}{\begin{tabular}{|l}
$\mathrm{A} 570 / \mathrm{E}$ \\
$\mathrm{Fy}=290 \mathrm{MPa} \mathrm{Fu}=400 \mathrm{MPa}$ \\
\end{tabular}}} & \multirow{2}{*}{\multicolumn{3}{|c|}{$\begin{array}{l}\text { SAC } 41 \\
F y=245 \mathrm{MPa} F u=400 \mathrm{MPa}\end{array}$}} & \multicolumn{3}{|l|}{ SAC 50} \\
\hline \multirow{2}{*}{$\begin{array}{l}\mathrm{Lb}=167 \\
\text { esp }=3.80\end{array}$} & \multicolumn{3}{|c|}{$F y=172 \mathrm{MPa} F u=310 \mathrm{MPa}$} & & & & & & & $F y=373 \mathrm{MPa}$ & $\mathrm{Fu}=500 \mathrm{MPa}$ & \\
\hline & FLM & FLA & FLT & FLM & FLA & $\mathrm{FLT}$ & FLM & FLA & FLT & FLM & FLA & FLT \\
\hline$U(75 \times 50 \times 25)$ & 165 & 165 & 164 & 268 & 278 & 255 & 232 & 235 & 223 & 329 & 358 & 309 \\
\hline$U(100 \times 50 \times 25)$ & 251 & 251 & 250 & 407 & 423 & 387 & 353 & 357 & 338 & 500 & 544 & 468 \\
\hline$U(127 \times 50 \times 25)$ & 354 & 354 & 352 & 575 & 598 & 546 & 499 & 505 & 477 & 707 & 769 & 658 \\
\hline$U(150 \times 50 \times 25)$ & 451 & 451 & 447 & 731 & 761 & 692 & 634 & 643 & 605 & 899 & 978 & 834 \\
\hline$|u(200 \times 50 \times 25)|$ & 686 & 686 & 677 & 1112 & 1157 & 1043 & 965 & 977 & 913 & 1367 & 1488 & 1253 \\
\hline$U(250 \times 50 \times 25)$ & 954 & 954 & 937 & 1547 & 1609 & 1436 & 1342 & 1359 & 1259 & 1902 & 2070 & 1718 \\
\hline
\end{tabular}

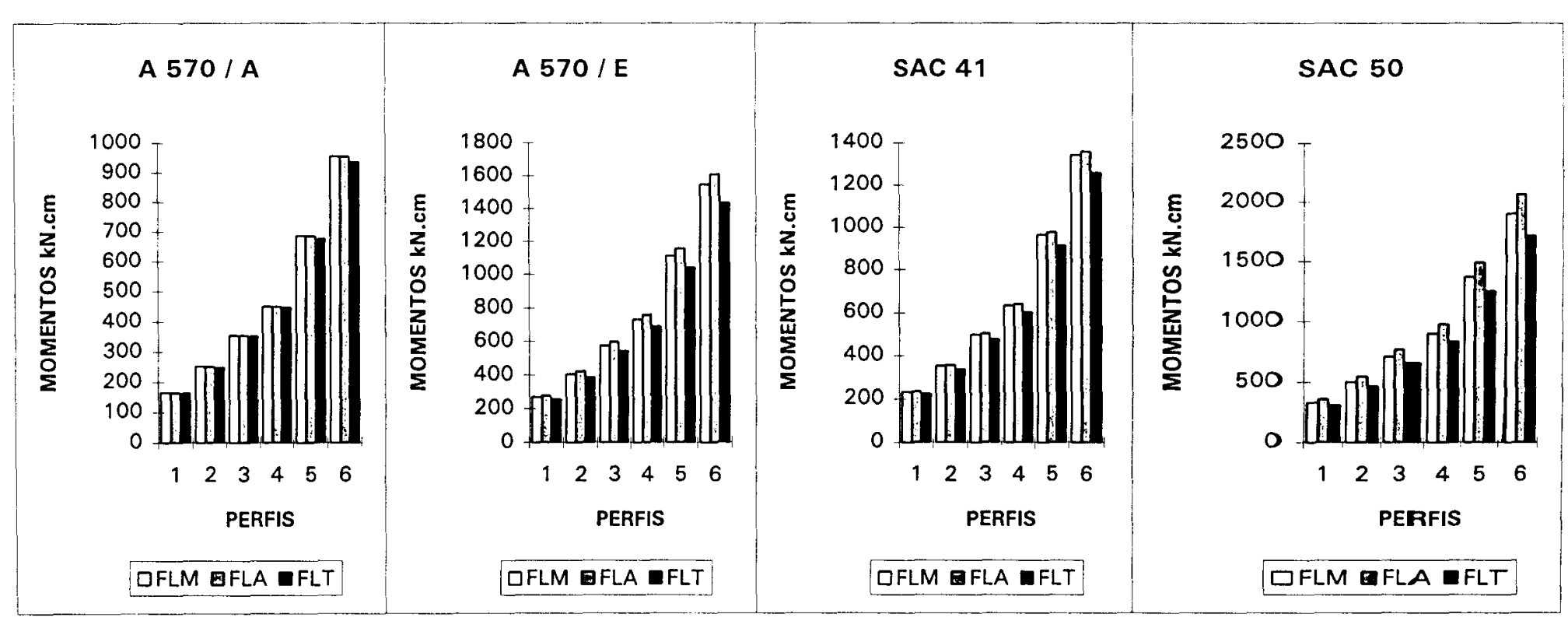


VALORES ADMISSÍVEIS DOS MOMENTOS PARA FLM, FLA E FLT em KN.cm

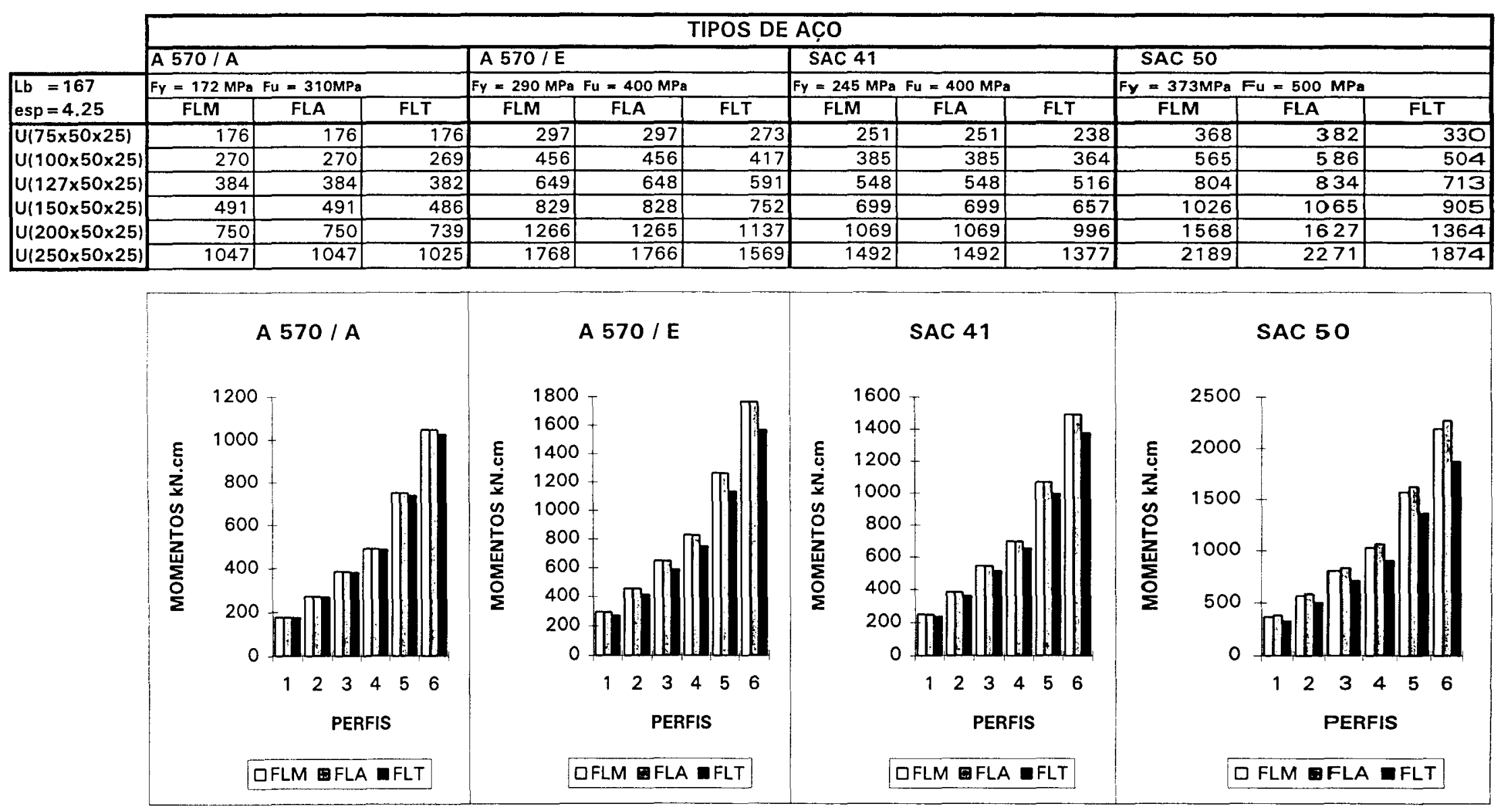


VALORES ADMISSIVEIS DOS MOMENTOS PARA FLM, FLA \& FLT em KN.cm

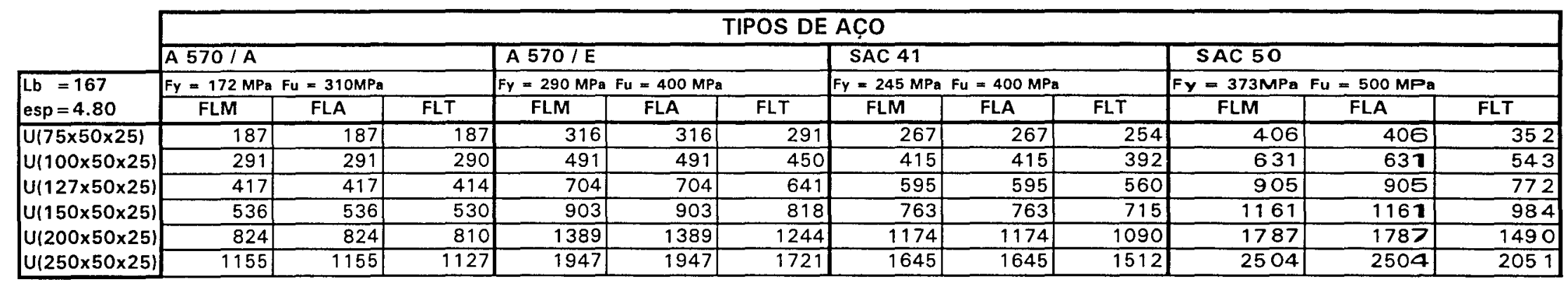

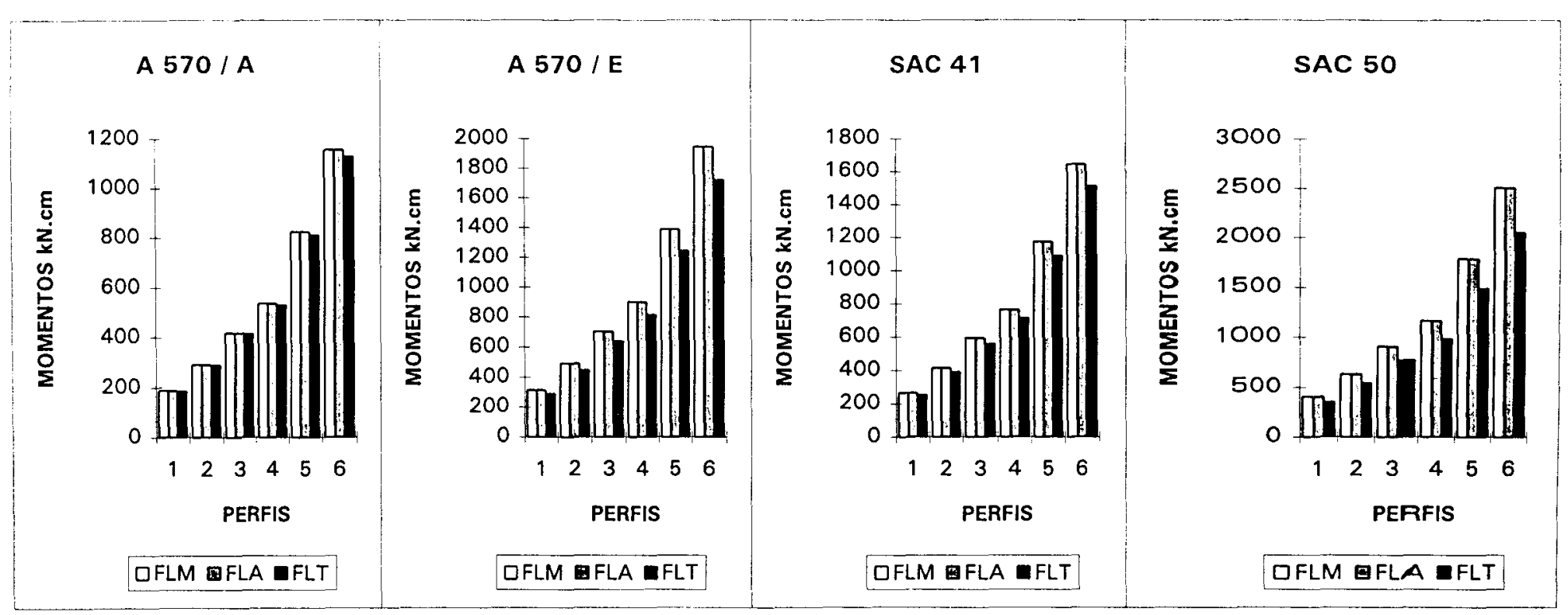


VALORES ADMISSIVEIS DOS MOMENTOS PARA FLM, FLA E FLT em KN.cm

\begin{tabular}{|c|c|c|c|c|c|c|c|c|c|c|c|c|}
\hline \multicolumn{13}{|c|}{ TIPOS DE ACCO } \\
\hline & \multirow{2}{*}{\multicolumn{3}{|c|}{$\begin{array}{l}\mathrm{A} 570 / \mathrm{A} \\
\mathrm{Fy}=172 \mathrm{MPa} F u=310 \mathrm{MPa}\end{array}$}} & \multicolumn{3}{|l|}{ A570/E } & \multicolumn{3}{|l|}{ SAC 41 } & \multicolumn{3}{|l|}{ SAC 50 } \\
\hline \multirow{2}{*}{$\begin{array}{l}\mathrm{Lb}=200 \\
\mathrm{esp}=1.90\end{array}$} & & & & $F y=290 \mathrm{MPa}$ & $=400 \mathrm{MP}$ & & $\mathrm{Fy}=245 \mathrm{MPa}$ & $=400 \mathrm{MP}$ & & $F y=373 \mathrm{MPa}$ & $F_{U}=500 \mathrm{MPa}$ & \\
\hline & FLM & FLA & FLT & FLM & FLA & FLT & FLM & FLA & FLT & FLM & FLA & FLT \\
\hline$U(75 \times 50 \times 25)$ & 85 & 98 & 93 & 89 & 166 & 138 & \begin{tabular}{l|l}
89 \\
\end{tabular} & 140 & 122 & 89 & 213 & 160 \\
\hline$U(100 \times 50 \times 25)$ & 125 & 144 & 137 & 131 & 243 & 203 & 131 & 206 & 180 & 131 & 313 & 236 \\
\hline$u(127 \times 50 \times 25)$ & 172 & 199 & 189 & 180 & 336 & 281 & 180 & 284 & 250 & 180 & 433 & 327 \\
\hline$u(150 \times 50 \times 25)$ & 216 & 251 & 237 & 227 & 422 & 352 & 227 & 357 & 313 & 227 & 543 & 410 \\
\hline $\mathrm{U}(200 \times 50 \times 25)$ & 323 & 374 & 353 & 338 & 619 & 523 & 338 & 533 & 465 & 338 & 772 & 607 \\
\hline$U(250 \times 50 \times 25)$ & 444 & 509 & 483 & 465 & 801 & 711 & 465 & 693 & 633 & 465 & 987 & 821 \\
\hline
\end{tabular}
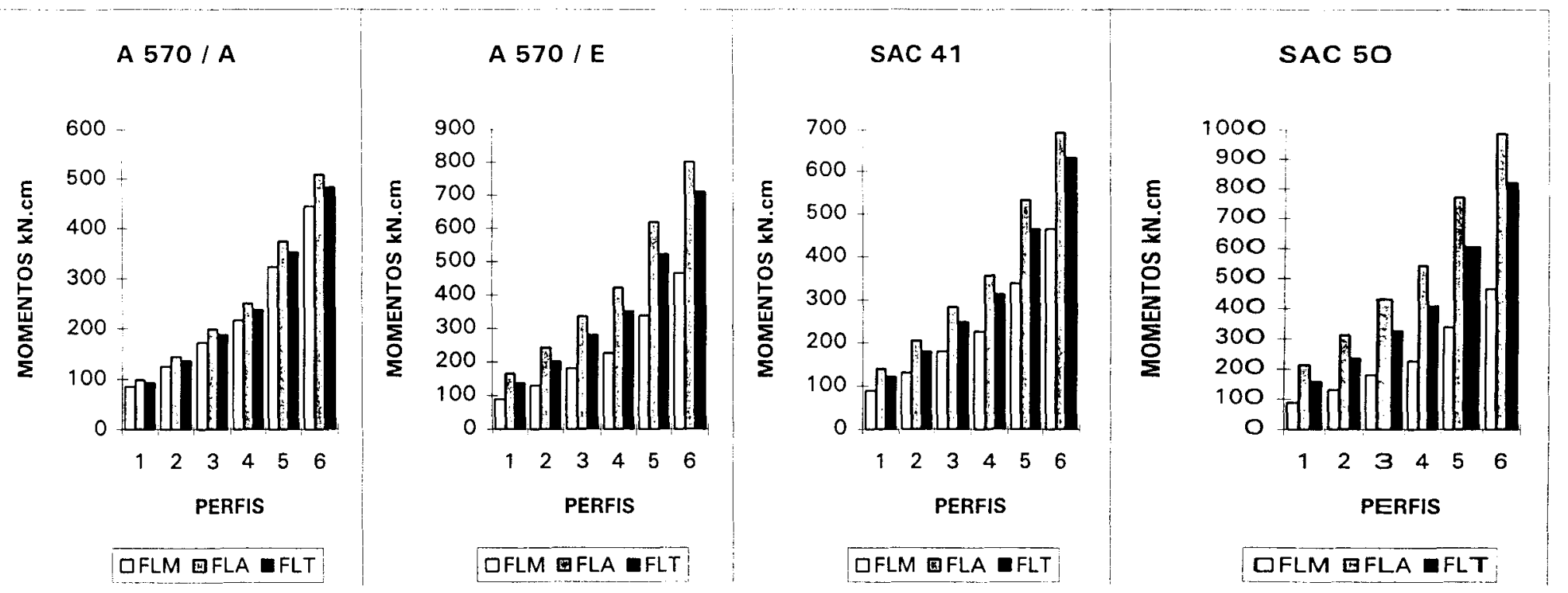
VALORES ADMISSÍVEIS DOS MOMENTOS PARA FLM, FLA \& FLT em KN.cm

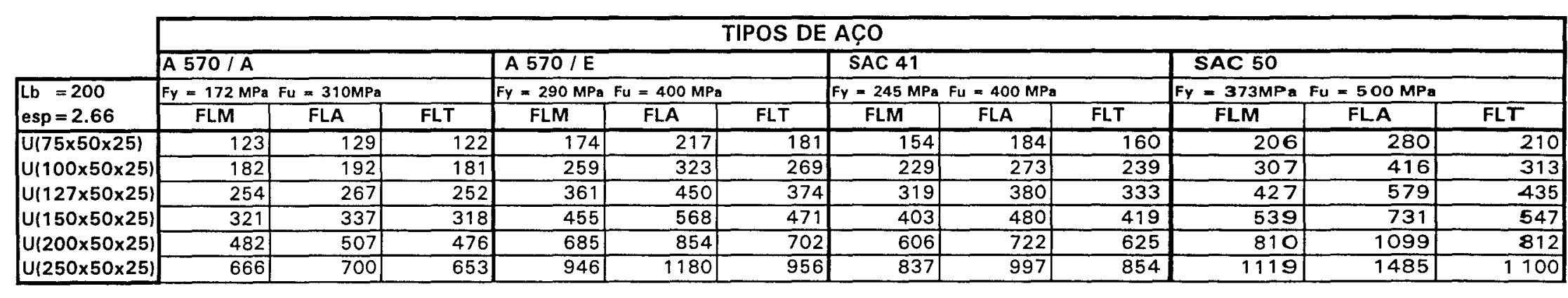

\begin{tabular}{|c|c|c|c|c|c|}
\hline & A $570 / A$ & A $570 / E$ & SAC 41 & & SAC 50 \\
\hline 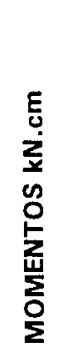 & $\begin{array}{l}700 \\
600+ \\
500 \\
400- \\
300- \\
200- \\
100\end{array}$ & 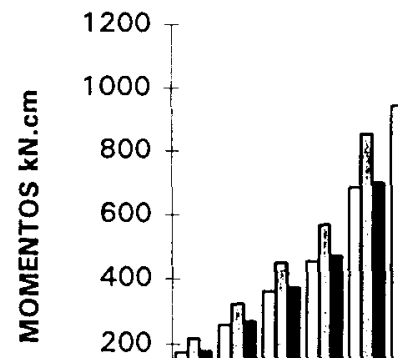 & 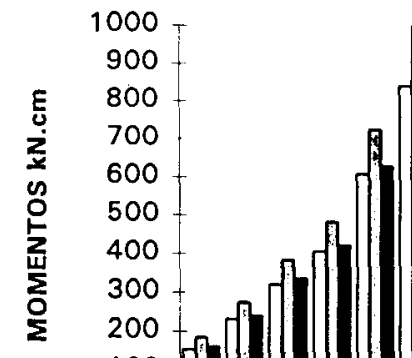 & 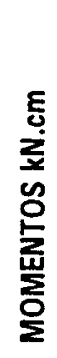 & $\begin{array}{c}1600 \\
1400+ \\
1200- \\
1000- \\
800- \\
600- \\
400-\end{array}$ \\
\hline & 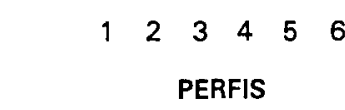 & 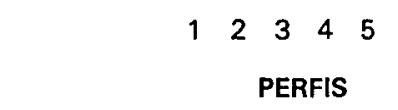 & $\begin{array}{lllll}1 & 2 & 3 & 4 & 5\end{array}$ & & 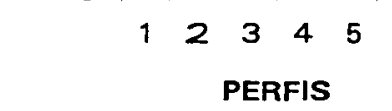 \\
\hline & 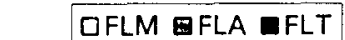 & 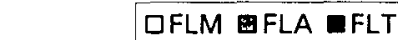 & DFLM \&FLA $\square F L T$ & & $\square F L M$ ๒LA $\square \overline{F L T}$ \\
\hline
\end{tabular}


VALORES ADMISSIVEIS DOS MOMENTOS PARA FLM, FLA \& FLT em KN.cm

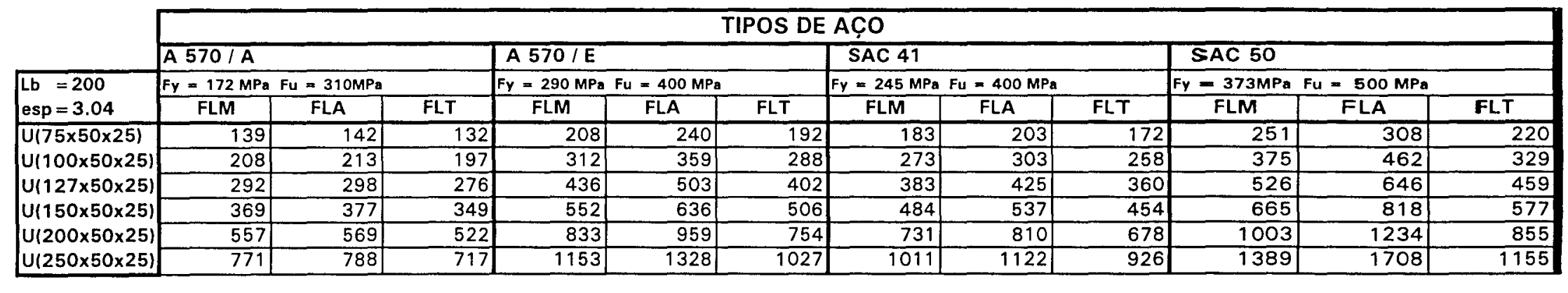

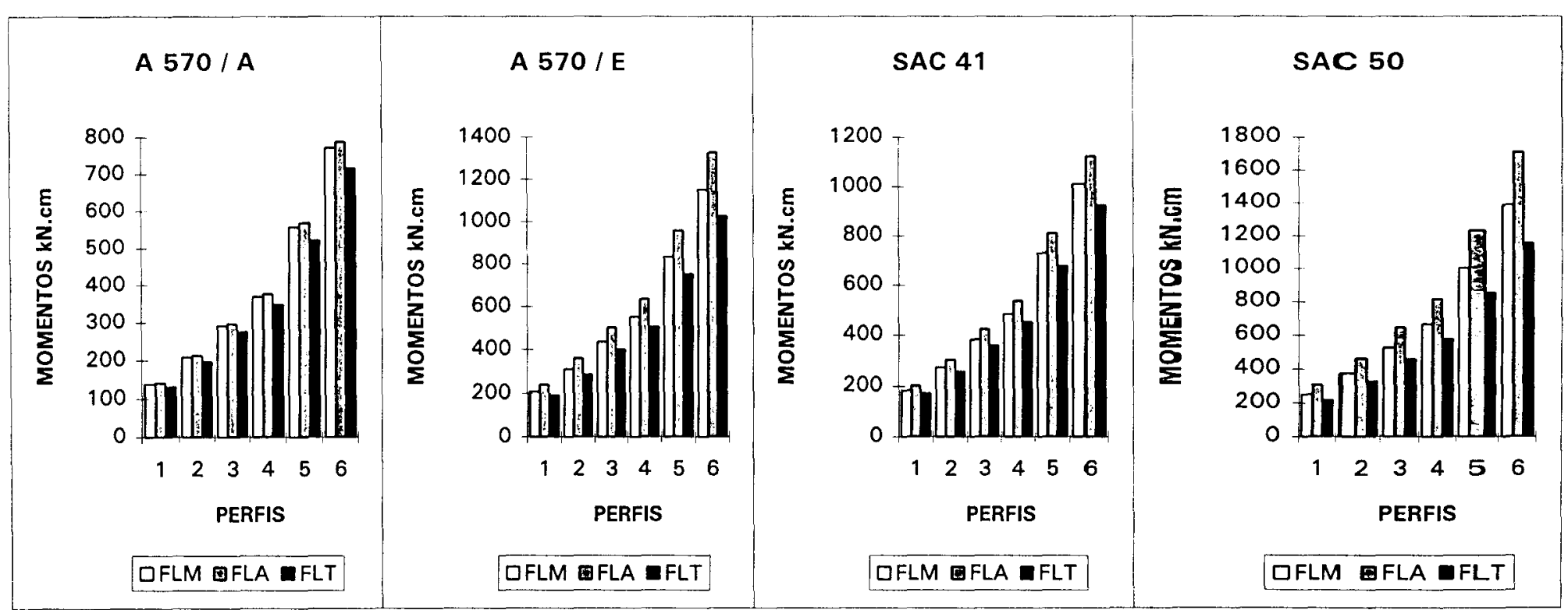


VALORES ADMISSÍVEIS DOS MOMENTOS PARA FLM, FLA e FLT em KN.cm

\begin{tabular}{|c|c|c|c|c|c|c|c|c|c|c|c|c|}
\hline \multirow{4}{*}{$\begin{array}{l}\mathrm{Lb}=200 \\
\text { esp }=3.80\end{array}$} & \multicolumn{12}{|c|}{ TIPOS DE AÇO } \\
\hline & \multicolumn{3}{|l|}{ A570/A } & \multicolumn{3}{|l|}{ A 570/E } & \multicolumn{3}{|l|}{ SAC 41 } & \multicolumn{3}{|l|}{ SAC 50} \\
\hline & $F_{Y}=172 \mathrm{MPa}$ & $=310 \mathrm{MPa}$ & & $F y=290 \mathrm{MPa}$ & $=400 \mathrm{MPt}$ & & $\mathrm{Fy}=245 \mathrm{MPa}$ & $=400 \mathrm{MPa}$ & & $F Y=373 \mathrm{MPa}$ & $F u=500 \mathrm{MPa}$ & \\
\hline & FLM & FLA & FLT & FLM & FLA & FLT & FLM & FLA & FLT & FLM & FLA & FLT \\
\hline$U(75 \times 50 \times 25)$ & \begin{tabular}{|c|}
165 \\
\end{tabular} & 165 & 156 & 268 & 278 & 232 & 232 & 235 & 206 & 329 & 358 & 270 \\
\hline$U(100 \times 50 \times 25)$ & 251 & 251 & 237 & 407 & 423 & 352 & 353 & 357 & 313 & 500 & 544 & 409 \\
\hline$U(127 \times 50 \times 25)$ & 354 & 354 & 334 & \begin{tabular}{l|l}
575 \\
\end{tabular} & 598 & 494 & 499 & 505 & 440 & 707 & 769 & 573 \\
\hline$U(150 \times 50 \times 25)$ & 451 & 451 & 424 & 731 & 761 & 626 & 634 & 643 & 557 & 899 & 978 & 724 \\
\hline$|U(200 \times 50 \times 25)|$ & 686 & 686 & 640 & 1112 & 1157 & 938 & \begin{tabular}{ll|}
965 \\
\end{tabular} & 977 & 838 & 1367 & 1488 & 1079 \\
\hline$U(250 \times 50 \times 25)$ & 954 & 954 & 883 & 1547 & 1609 & 1283 & 1342 & 1359 & 1150 & 1902 & 2070 & 1465 \\
\hline
\end{tabular}

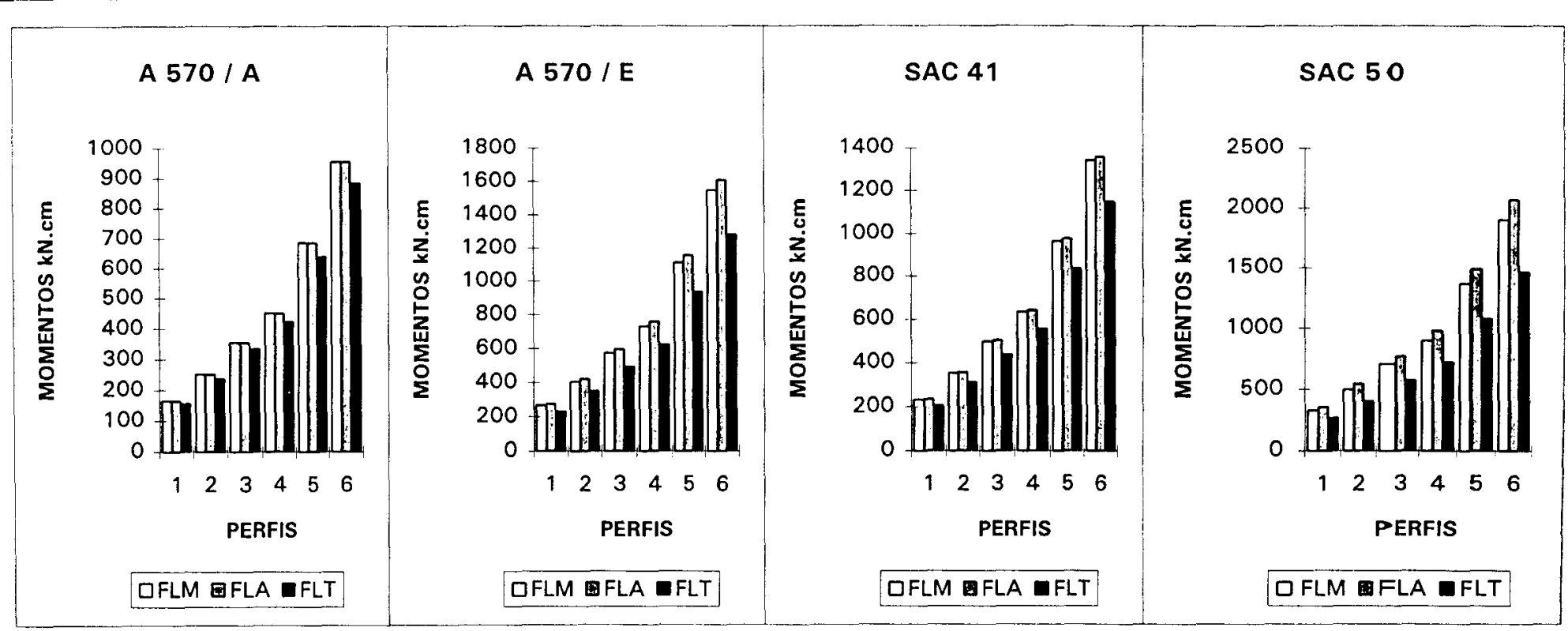




\section{TABELA $65 \quad$ "U" ENRIJECIDO}

VALORES ADMISSIVEIS DOS MOMENTOS PARA FLM, FLA \& FLT em KN.cm

\begin{tabular}{|c|c|c|c|c|c|c|c|c|c|c|c|c|}
\hline & \multicolumn{12}{|c|}{ TIPOS DE AÇO } \\
\hline & \multicolumn{3}{|l|}{ A 570/A } & \multicolumn{3}{|l|}{ A 570/E } & \multicolumn{3}{|l|}{ SAC 41 } & \multicolumn{3}{|l|}{ SAC 50} \\
\hline \multirow{2}{*}{$\begin{array}{l}L b=200 \\
\text { esp }=4.25\end{array}$} & \multicolumn{3}{|c|}{$F y=172 \mathrm{MPa} F u=310 \mathrm{MPa}$} & \multicolumn{3}{|c|}{$\mathrm{Fy}=290 \mathrm{MPa} F u=400 \mathrm{MPa}$} & \multirow{2}{*}{\multicolumn{3}{|c|}{\begin{tabular}{|c|c|}
$F y=245 \mathrm{MPB} F u=400 \mathrm{MPa}$ \\
$F L M$ & $F L A$
\end{tabular}}} & \multicolumn{3}{|c|}{$F Y=373 \mathrm{MPa} \quad F u=500 \mathrm{MPa}$} \\
\hline & FLM & FLA & $\overline{F L T}$ & FLM & \begin{tabular}{l|l|} 
FLA \\
\end{tabular} & FLT & & FLA & & FLM & FLA & FLT \\
\hline 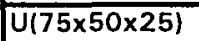 & 176 & 176 & 167 & 297 & 297 & 248 & 251 & 251 & 221 & 368 & 382 & 289 \\
\hline$U(100 \times 50 \times 25)$ & 270 & 270 & 255 & 456 & 456 & 379 & 385 & 385 & 337 & 565 & 586 & 440 \\
\hline$U(127 \times 50 \times 25)$ & 384 & 384 & 362 & 649 & 648 & 535 & 548 & 548 & 476 & 804 & 834 & 620 \\
\hline $\mathrm{U}(150 \times 50 \times 25)$ & 491 & 491 & 461 & 829 & 828 & 679 & 699 & 699 & 605 & 1026 & 1065 & 784 \\
\hline$U(200 \times 50 \times 25)$ & 750 & 750 & 698 & 1266 & 1265 & 1021 & 1069 & 1069 & 913 & 1568 & 1627 & 1171 \\
\hline$U(250 \times 50 \times 25)$ & 1047 & 1047 & 965 & 1768 & 1766 & 1399 & 1492 & 1492 & 1256 & 2189 & 2271 & 1592 \\
\hline
\end{tabular}

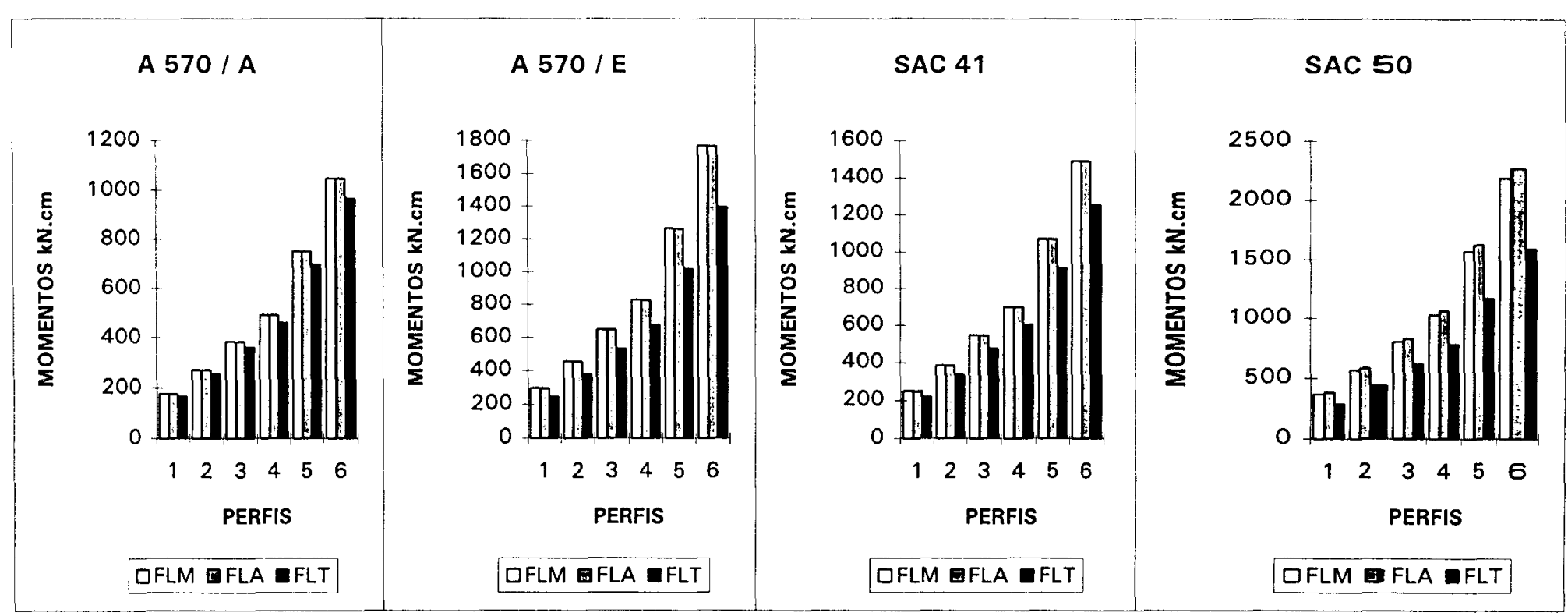


VALORES ADMISSÍVEIS DOS MOMENTOS PARA FLM, FLA e FLT em KN.cm

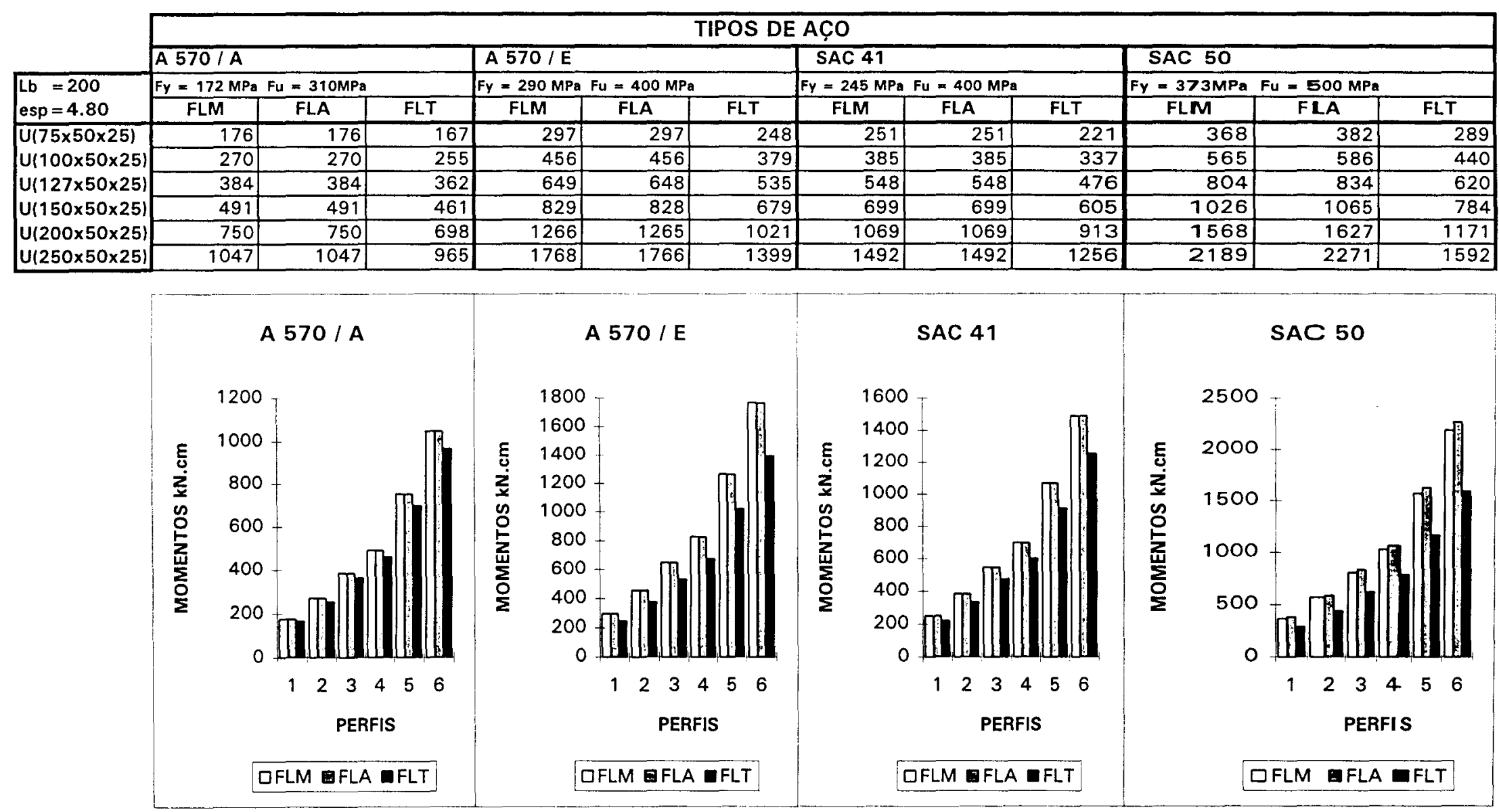


VALORES ADMISSIVEIS DOS MOMENTOS PARA FLM, FLA \& FLT em KN.cm

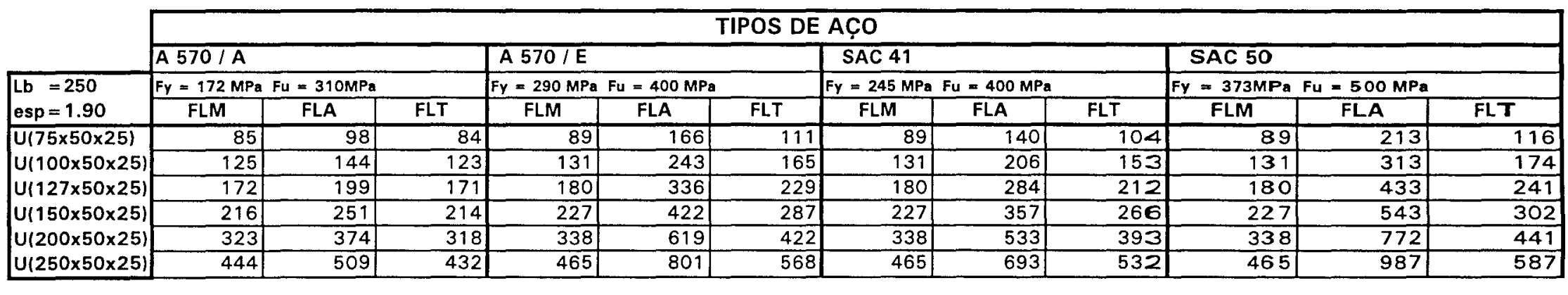

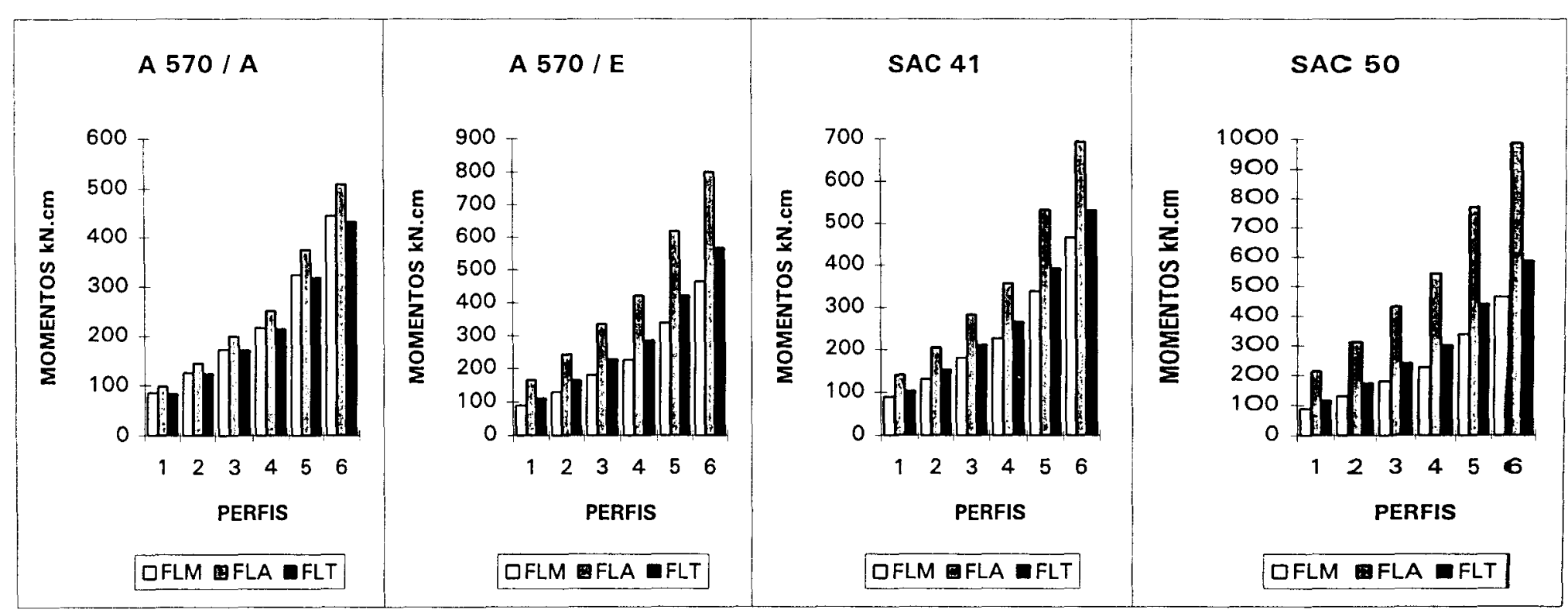


VALORES ADMISSÍVEIS DOS MOMENTOS PARA FLM, FLA e FLT em KN.cm

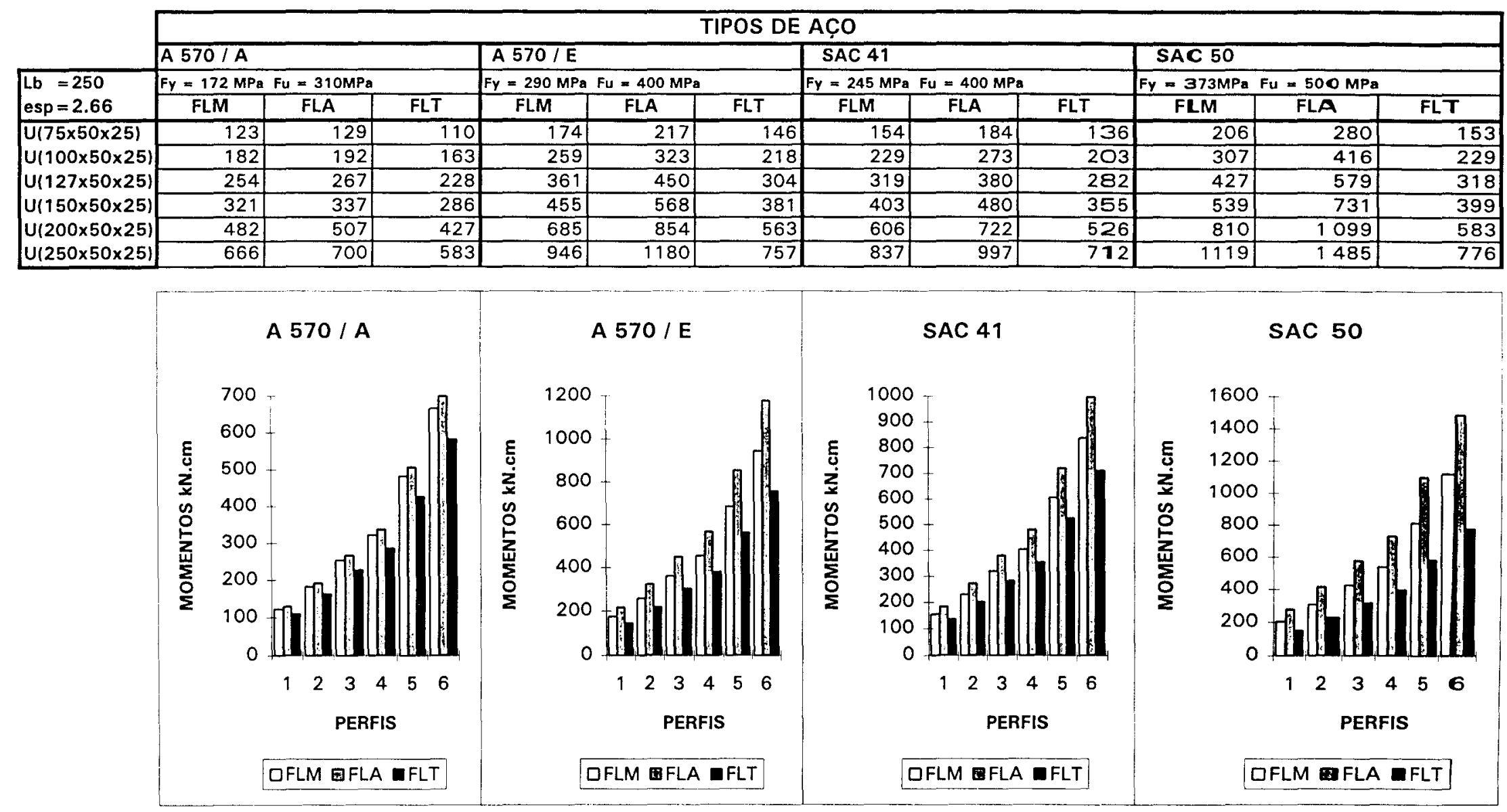


VALORES ADMISSÍVEIS DOS MOMENTOS PARA FLM, FLA \& FLT em KN.cm

\begin{tabular}{|c|c|c|c|c|c|c|c|c|c|c|c|c|}
\hline & \multicolumn{12}{|c|}{ TIPOS DE AC̣O } \\
\hline & \multirow{2}{*}{\multicolumn{3}{|c|}{$\begin{array}{l}\text { A } 570 / \mathrm{A} \\
\mathrm{Fy}=172 \mathrm{MPa} \text { Fu }=310 \mathrm{MPa}\end{array}$}} & \multirow{2}{*}{\multicolumn{3}{|c|}{\begin{tabular}{|l|}
$\mathrm{A} 570 / \mathrm{E}$ \\
$\mathrm{Fy}=290 \mathrm{MPa} \mathrm{Fu}=400 \mathrm{MPa}$ \\
\end{tabular}}} & \multicolumn{3}{|l|}{ SAC 41 } & \multicolumn{3}{|l|}{ SAC 50} \\
\hline \multirow{2}{*}{$\begin{array}{l}\text { Lb }=250 \\
\text { esp }=3.04\end{array}$} & & & & & & & $\mathrm{Fy}=245 \mathrm{MPa}$ & $=400 \mathrm{MPa}$ & & $F y=373 \mathrm{MPa}$ & $F u=500 \mathrm{MPa}$ & \\
\hline & FLM & FLA & FLT & FLM & FLA & FLT & FLM & FLA & FLT & FLM & FLA & FLT \\
\hline$U(75 \times 50 \times 25)$ & 139 & 142 & 121 & 208 & 240 & 162 & 183 & 203 & 150 & 251 & 308 & 169 \\
\hline$U(100 \times 50 \times 25)$ & 208 & 213 & 181 & 312 & 359 & 242 & 273 & 303 & 225 & 375 & 462 & 254 \\
\hline$U(127 \times 50 \times 25)$ & 292 & 298 & 254 & 436 & 503 & 338 & 383 & 425 & 314 & 526 & 646 & 353 \\
\hline$u(150 \times 50 \times 25)$ & 369 & 377 & 320 & 552 & 636 & 424 & 484 & 537 & 396 & 665 & 818 & 442 \\
\hline$U(200 \times 50 \times 25)$ & 557 & 569 & 478 & 833 & 959 & 627 & 731 & 810 & 587 & 1003 & 1234 & 647 \\
\hline$|\mathrm{U}(250 \times 50 \times 25)|$ & 771 & 788 & 653 & 1153 & 1328 & 843 & 1011 & 1122 & 795 & 1389 & 1708 & 861 \\
\hline
\end{tabular}

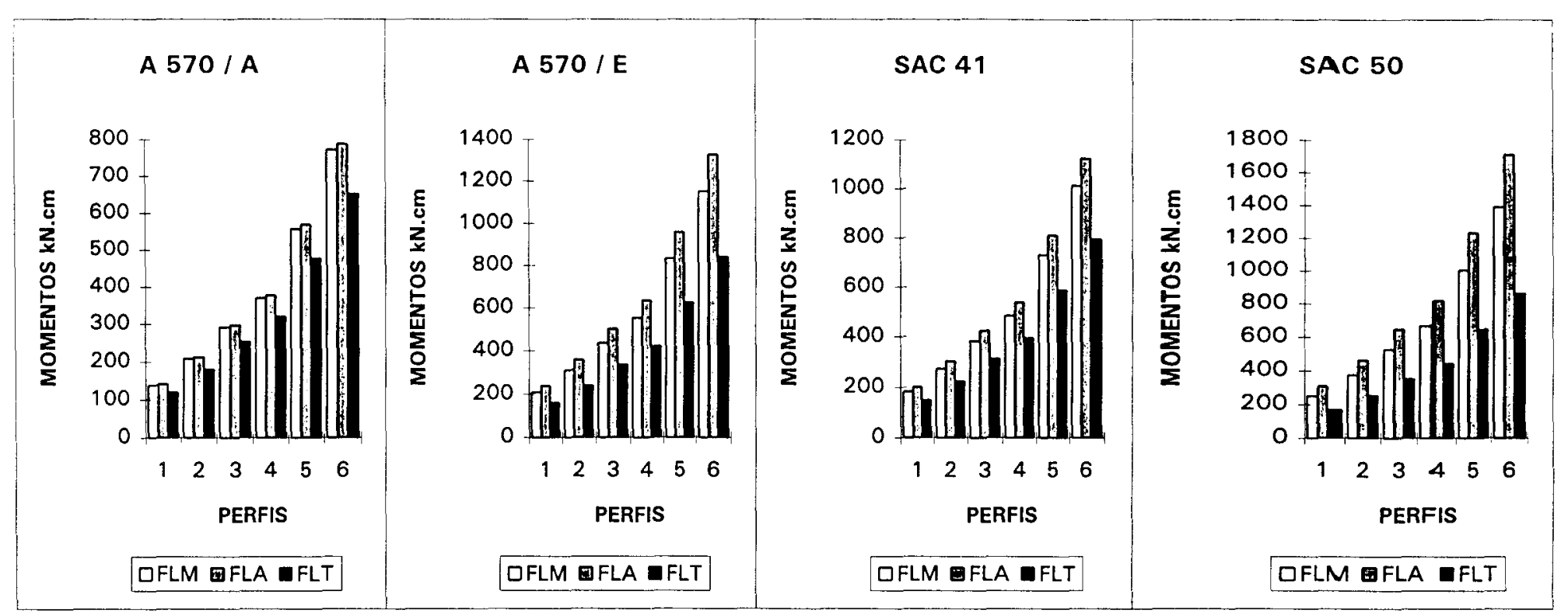


VALORES ADMISSÍVEIS DOS MOMENTOS PARA FLM. FLA e FLT em KN.cm

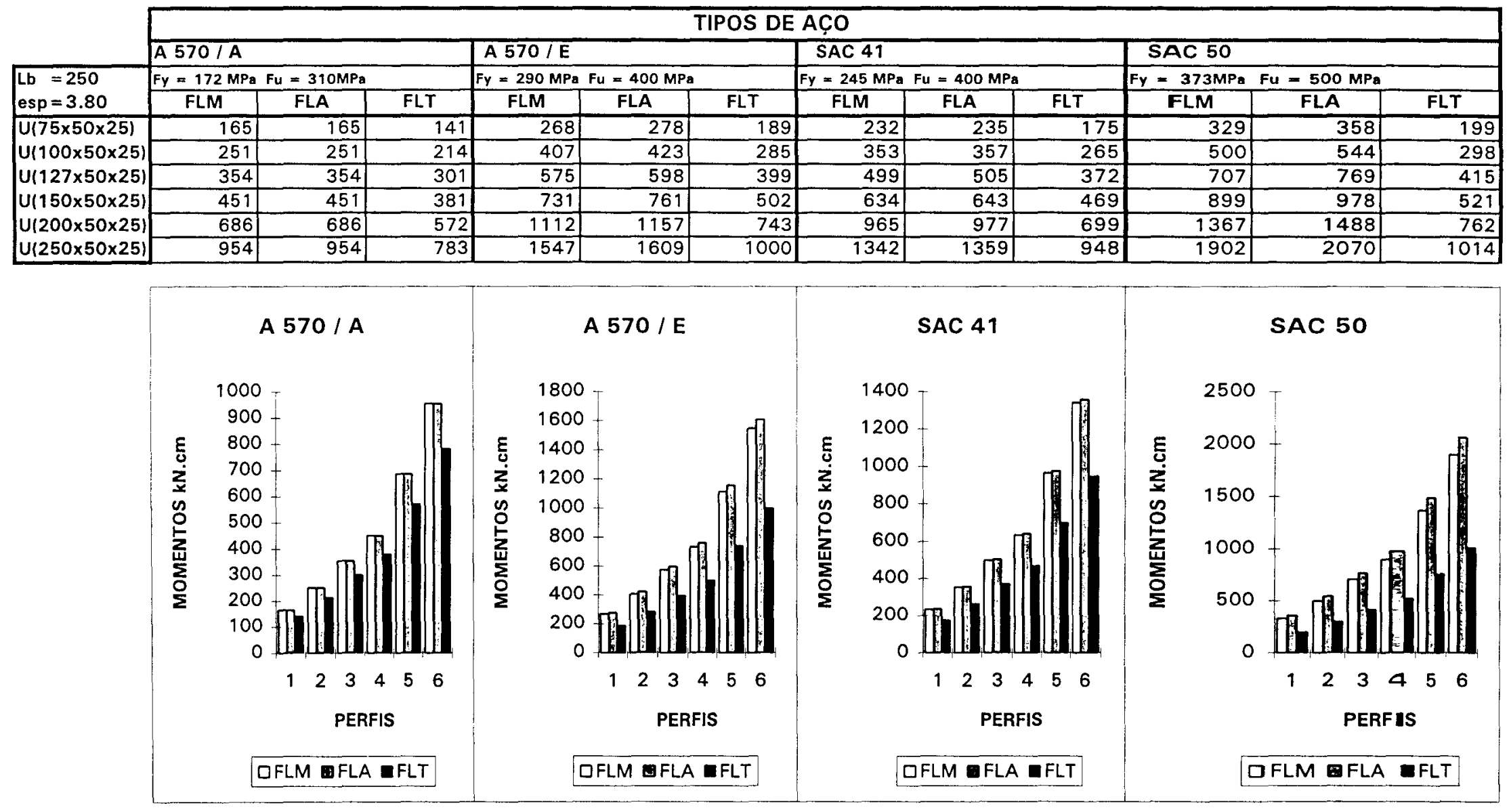


VALORES ADMISSIVEIS DOS MOMENTOS PARA FLM, FLA E FLT em KN.cm

\begin{tabular}{|c|c|c|c|c|c|c|c|c|c|c|c|c|}
\hline & \multicolumn{12}{|c|}{ TIPOS DE AC̣O } \\
\hline & \multirow{2}{*}{\multicolumn{3}{|c|}{$\begin{array}{l}\mathrm{A} 570 / \mathrm{A} \\
\mathrm{Fy}=172 \mathrm{MPa} \mathrm{Fu}=310 \mathrm{MPa}\end{array}$}} & \multicolumn{3}{|l|}{ A $570 / E$} & \multicolumn{3}{|l|}{ SAC 41 } & \multicolumn{3}{|l|}{ SAC 50} \\
\hline \multirow{2}{*}{$\begin{array}{l}\mathrm{Lb}=250 \\
\mathrm{esp}=4.25\end{array}$} & & & & $\mathrm{Fy}=290 \mathrm{MPa}$ & $=400 \mathrm{MPg}$ & & $F y=245 \mathrm{MPa}$ & $=400 \mathrm{MP}$ & & $F y=373 \mathrm{MPa}$ & $=500 \mathrm{MPa}$ & \\
\hline & FLM & FLA & FLT & $\overline{\text { FLM }}$ & FLA & FLT & FLM & FLA & FLT & FLM & FLA & $\overline{F L T}$ \\
\hline$U(75 \times 50 \times 25)$ & 176 & 176 & 151 & 297 & 297 & 203 & 251 & 251 & 188 & 368 & 382 & 214 \\
\hline$U(100 \times 50 \times 25)$ & 270 & 270 & 230 & 456 & 456 & 307 & 385 & 385 & 285 & 565 & 586 & 321 \\
\hline$U(127 \times 50 \times 25)$ & 384 & 384 & 325 & 649 & 648 & 431 & 548 & 548 & 402 & 804 & 834 & 448 \\
\hline $\mid U(150 \times 50 \times 25)$ & 491 & 491 & 413 & 829 & 828 & 543 & 699 & 699 & 508 & 1026 & 1065 & 561 \\
\hline $\mid U(200 \times 50 \times 25)$ & 750 & 750 & 622 & 1266 & 1265 & 804 & 1069 & 1069 & 758 & 1568 & 1627 & 822 \\
\hline$u(250 \times 50 \times 25)$ & 1047 & 1047 & 854 & 1768 & 1766 & 1082 & 1492 & 1492 & 1030 & 2189 & 2271 & 1094 \\
\hline
\end{tabular}
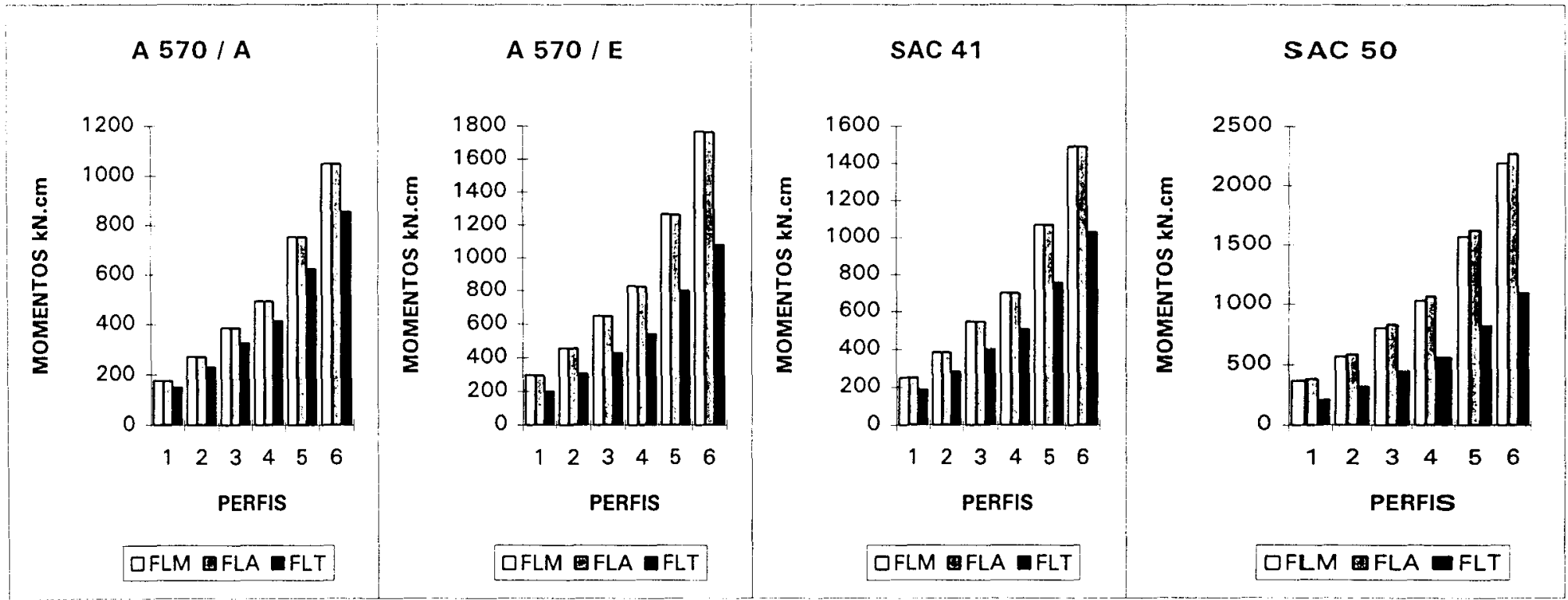
VALORES ADMISSÍVEIS DOS MOMENTOS PARA FLM, FLA E FLT em KN.cm

\begin{tabular}{|c|c|c|c|c|c|c|c|c|c|c|c|c|}
\hline & \multicolumn{12}{|c|}{ TIPOS DE AC̣O } \\
\hline & \multicolumn{3}{|l|}{ A 570/A } & \multicolumn{3}{|l|}{ A570/E } & \multicolumn{3}{|l|}{ SAC 41} & \multicolumn{3}{|l|}{ SAC 50} \\
\hline \multirow{2}{*}{$\begin{array}{l}\mathrm{Lb}=250 \\
\mathrm{esp}=4.80\end{array}$} & \multicolumn{3}{|c|}{$F y=172 \mathrm{MPa} F u=310 \mathrm{MPa}$} & \multicolumn{3}{|c|}{$F y=290 \mathrm{MPa} F u=400 \mathrm{MPa}$} & \multicolumn{3}{|c|}{$F y=245 \mathrm{MPa} F u=400 \mathrm{MPa}$} & \multicolumn{3}{|c|}{$F y=373 \mathrm{MPa} F U=500 \mathrm{MPa}$} \\
\hline & FLM & FLA & FLT & FLM & FLA & FLT & FLM & FLA & FLT & FLM & FLA & FLY \\
\hline $\mathrm{U}(75 \times 50 \times 25)$ & 187 & 187 & 161 & 316 & 316 & 217 & 267 & 267 & 201 & 406 & 406 & 230 \\
\hline$u(100 \times 50 \times 25)$ & 291 & 291 & 248 & 491 & 491 & 331 & 415 & 415 & 308 & 631 & 631 & 346 \\
\hline $\mathrm{U}(127 \times 50 \times 25)$ & 417 & 417 & 352 & 704 & 704 & 466 & 595 & 595 & 435 & 905 & 905 & 483 \\
\hline$U(150 \times 50 \times 25)$ & 536 & 536 & 449 & 903 & 903 & 588 & 763 & 763 & 551 & 1161 & 1161 & 606 \\
\hline $\mid U(200 \times 50 \times 25)$ & 824 & 824 & 679 & 1389 & 1389 & 872 & 1174 & 1174 & 825 & 1787 & 1787 & 887 \\
\hline $\mathrm{U}(250 \times 50 \times 25)$ & 1155 & 1155 & 934 & 1947 & 1947 & 1172 & 1645 & 1645 & 1120 & 2504 & 2504 & 1181 \\
\hline
\end{tabular}

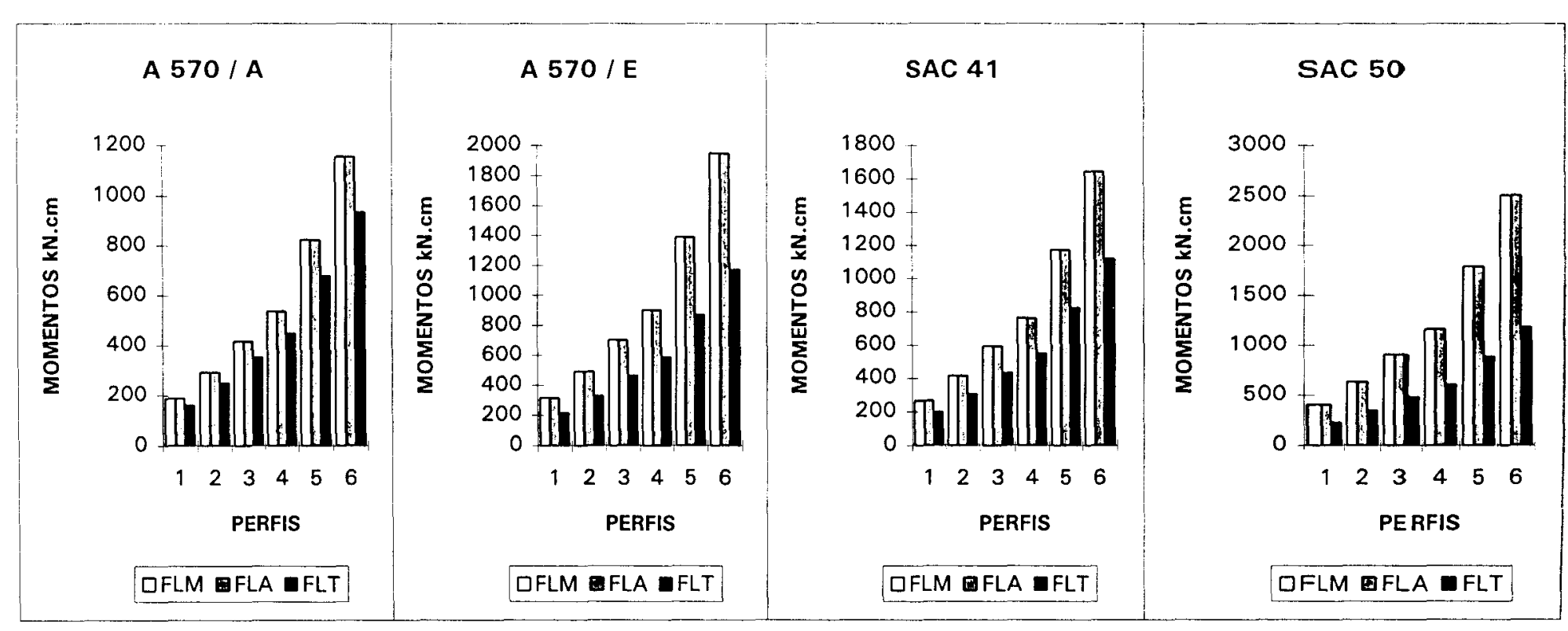




\section{REFERÊNCIAS BIBLIOGRÁFICAS}

AMERICAN IRON AND STEEL INSTITUTE (1986). Cold formed steel design manual. Washington, AISI.

AMERICAN IRON AND STEEL INSTITUTE. (1991). LRFD - Cold formed steel design manual. Washington, AISI.

ANDERSON, J. M.; TRAHAIR, N. S. (1972). Stability of monosymmetric beams and cantilevers. Journal of the Strutural Division, ASCE, v.98 n.ST1, p.269286, Jan.

ASSOCIAÇÃO BRASILEIRA DE NORMAS TÉCNICAS (1983). NBR 8681 Ações e segurança nas estruturas . Rio de Janeiro.

ASSOCIAÇÃO BRASILEIRA DE NORMAS TÉCNICAS. (1967). NB 143 Cálculo de estruturas de aço constituídas por perfis leves. Rio de Janeiro.

ASSOCIAÇÃO BRASILEIRA DE NORMAS TÉCNICAS (1986). NBR 8800 Projeto e execução de estruturas de aço de edifícios. Rio de Janeiro.

BASLER, K. (1961). Strength of plate girders in shear. Journal of the Structural Division, ASCE, v.87, n.ST7, p.151-180, Oct.

BELLEI, I. H. (1994). Edifícios industriais em aço, projeto e cálculo. São Paulo, Pini.

BLEICH, F. (1952). Buckling strength of metal structures. New York,McGrawHill. 
CANADIAN STANDARDS ASSOCIATION (1984). CAN3-S136-M84 - Cold formed steel structural members, Toronto.

CHAJES, A.; BRITVEC, S. J.; WINTER, G. (1963). Effects of cold-straining on structural sheet steels. Journal of the Structural Division, ASCE, v.89, n.ST2, p.1-32, Apr.

CLARK, J. W.; HILL, H. N. (1960). Lateral buckling of beams. Journal of the Structural Division, ASCE, v.86, n.ST7, p.175-196, July

CULVER, C. G. (1965). Exact solution of the biaxial bending equations. Journal of the Structural Division, ASCE, v.92, n.ST2, p.63-83, Apr.

DESMOND, T. P.; PEKOZ, T.; WINTER, G. (1981a). Edge stiffeners for thinwalled members. Journal of the Structural Division, ASCE, v.107, n.2, p.329353, Feb.

DESMOND, T. P.; PEKOZ, T.; WINTER, G. (1981b). Intermediate stiffeners for thin-walled members. Journal of the Structural Division, ASCE, v.107, n.ST4, p.627-649, Apr.

GALAMBOS, T. V. (1963). Inelastic lateral buckling of beams. Journal of the Structural Division, ASCE, v.89, n.ST5, p.217-242, Oct.

GALAMBOS, T. V. (1988). Guide to stability design criteria for metal structures. 4.ed. New York, Wiley-Interscience.

HAUSSLER, R. W. (1964). Strength of elastically stabilized beams. Journal of the Structural Division, ASCE, v.90, n.ST3, p.219-163, June.

HILL, H. N. (1954). Lateral buckling of channels and $\mathrm{z}$ beams. Transactions, ASCE, v.119, p.829-841.

HSIAO, L.; YU, W. W.; GALAMBOS, T. V. (1990). AISI LRFD method for coldformed steel structural members. Journal of the Structural Engineering, ASCE, v.116, n.2, p.500-517, Feb. 
JAVARONI, C. E. (1993). Perfis de aço conformados a frio por dobramento de chapa fina: fundamentos teóricos para o dimensionamento de barras. São Carlos. lv. Dissertação (Mestrado) - EESC, USP.

KALYANARAMAN, V.; PEKOZ, T.; WINTER, G. (1977a) Overal column stability after local buckling. In: INTERNATIONAL COLLOQUIUM ON STABILITY OF STRUCTURES UNDER STATIC AND DYNAMIC LOADS, Washington, 1977. Proceedings. New York, ASCE. p.757-771.

KALYANARAMAN, V; PEKOZ, T; WINTER, G. (1977b). Unstiffened compression elements. Journal of the Structural Division, ASCE, v.103, n.8, p.1833-1848, Sept.

KARREN, K. W. (1967). Corner properties of cold-formed steel shapes. Journal of the Structural Division, ASCE, v.93, n.ST1, p.401-432, Feb.

KARREN, K. W. ; WINTER, G. (1967). Effects of cold-forming on light-gage steel members. Journal of the Structural Division, ASCE, v.93, n.ST1, p.433-469, Feb.

KARREN, K. W. ; WINTER, G.; GOHIL, M. M. (1974). Strain hardening and aging in cold-formed steel. Journal of the Structural Division, ASCE, v.101, nST1, p.187-200, Mar.

KETTER, R. L. (1961). Further studies of the strength of beam-columns. Journal of the Structural Division, ASCE, v.87, nST6, p.244-266, Aug.

KOROL, R. M.; HUDOBA, J. (1972). Plastic behavior of hallow structural sections. Journal of Structural Engineering, ASCE, v.98, n.5, p.1007-1023, May.

LaBOUBE, R. A. (1991). Uplift capacity of z-purlins. Journal of the Structural Engineering, ASCE, v.117, n.4, p.1159-1166, Apr.

LaBOUBE, R. A. (1992). Estimating uplift capacity of light steel roof system. Journal of Structural Engineering, ASCE, v.118, n.3, p.848-852, Mar. 
LIND, N. C.; SCHROFF, D. K. (1975). Utilization of cold formed steel. Journal of Structural Division, ASCE, v.101, n.ST1, p67-78, Jan.

MOLITERNO, A. (1989). Elementos para projetos em perfis leves de aço. São Paulo, Edgard Blücher.

MULLIGAN, G. P. ; PEKOZ, T. (1984). Locally buckled thin-walled columns. Journal of Structural Engineering, ASCE, v.110, n.11,. p2634-2654, Nov.

MULLIGAN, G. P. ; PEKOZ, T. (1987). Local buckling interaction in cold-formed columns. Journal of Structural Engineering, ASCE, v.113, n.3, p.604-620, Mar.

PARAMI, S. R. ; LIND, N. C. (1974). Limit states basis for cold-formed steel design. Journal of the Structural Division, ASCE, v.102, n.ST3, p.475-486, Mar.

POLYZOIS, D. (1987). Sag rods lateral supports for girts and purling. Journal of the Structural Engeneering, ASCE, v.113, n.7, p.1521-1531, July.

POLYZOIS, D.; BIRKEMOE, P. C. (1985). Z- sections girts under negative loading. Journal of Structural Engineering, ASCE, v.111, n.3, p.528-544, Mar.

RACHID, M. (1975). Instabilidade de barras de seção delgada. São Carlos. Tese (Doutorado) - EESC, USP.

RACHID, M. (1992). Instabilidade das Estruturas. São Carlos, EESC, USP. (Notas de aula).

RACHID, M.; MORI, D. D. (1989). Instabilidade: Conceitos - Aplicação na flambagem por flexão. São Carlos, EESC, USP.

RECK, P. H.; PEKOZ, T.; WINTER, G. (1975). Inelastic strength of cold-formed steel beams. Journal of Structural Division, ASCE, v.101, n.ST11, p.21932203, Nov.

SÁLES, J. J.; MALITE, M. (1993). Estruturas de aço constituídas por perfis de chapa dobrada: dimensionamento de barras. EESC, USP. 
SÁLES, J. J.; MALITE, M. (1993). Sistemas estruturais: ações e segurança. São Carlos, EESC, USP.

SÁleS, J. J.; MALITE, M.; PRELORENTZOU, P. A.; GONÇALVES, R. M. (1994). Construções em aço: projeto. São Carlos, ESSC, USP.

SÁLES, J. J.; MALITE, M.; GONÇALVES, R. M. (1996). Edificio industrial em perfis de chapa dobrada - exemplo de cálculo. São Carlos, ESSC, USP.

SCHULTE, H.; YAGUI, T. (1977). Estruturas de aço, elementos básicos. São Carlos, EESC, USP.

TIMOSHENKO, S. P.; GERE, J. M. (1961). Theory of elastic stability. 2. ed. New York, McGraw-Hill.

VLASOV, V. Z. (1961). Thin-walled elastic beams. 2.ed. Jerusalem, Israel Program for Scientific Translations. (translated from Russian).

WENG, C. C. (1991). Effect of residual stress on cold-formed steel strength. Journal of Structural Engineering, ASCE, v.117, n.6, p.1622-1640, June.

WENG, C. C. ; PEKOZ, T. (1990a). Compression tests of cold formed steel columns. Journal of Structural Engineering, ASCE, v.116, n.5, p.1230-1246, May.

WENG, C. C.; PEKOZ, T. (1990b) Residual stresses in cold formed steel members. Journal of Structural Engineering, ASCE, v.116, n.6, p.1611-1625, June.

WINTER, G. (1959). Cold-formed, light-gage steel construction. Journal of the Structural Division, ASCE, v.85, n.ST9, p.151-173, Nov.

WINTER, G. (1987). Cold-formed steel construction. In: WHITE, R. N.; SALMON, C. G. Building structural design handbook. New York, John Wiley \& Sons. cap.20, p.633-659.

YENER, M. ; PEKOZ, T. (1985a). Partial moment redistribution in cold-formed steel. Journal of Structural Engineering, ASCE, v.111, n.6, p.1187-1203, June. 
YENER, M. ; PEKOZ, T. (1985b). Partial stress redistribution in cold-formed steel. Journal of Structural Engineering, ASCE, v.111, n.6, p.1169-1186, June.

YU, W. W. (1985). Cold-formed steel design. New York, John Wiley \& Sons. 